\title{
OXFORD
}

\section{THE PRACTICE OF INDUSTRIAL POLICY}

\section{GOVERNMENT-BUSINESS COORDINATION IN AFRICA AND EAST ASIA}

\section{Edited by \\ John Page and Finn Tarp}


The Practice of Industrial Policy 
UNU World Institute for Development Economics Research (UNU-WIDER) was established by the United Nations University as its first research and training centre, and started work in Helsinki, Finland, in 1985. The mandate of the Institute is to undertake applied research and policy analysis on structural changes affecting developing and transitional economies, to provide a forum for the advocacy of policies leading to robust, equitable, and environmentally sustainable growth, and to promote capacity strengthening and training in the field of economic and social policy-making. Its work is carried out by staff researchers and visiting scholars in Helsinki and via networks of collaborating scholars and institutions around the world.

United Nations University World Institute for Development Economics Research (UNU-WIDER) Katajanokanlaituri 6B, 00160 Helsinki, Finland www.wider.unu.edu 


\section{The Practice of Industrial Policy}

\section{Government-Business Coordination in Africa and East Asia}

Edited by

John Page and Finn Tarp

A study prepared by the United Nations University World Institute for Development Economics Research (UNU-WIDER)

\section{OXFORD}




\section{OXFORD}

UNIVERSITY PRESS

Great Clarendon Street, Oxford, OX2 6DP, United Kingdom

Oxford University Press is a department of the University of Oxford.

It furthers the University's objective of excellence in research, scholarship, and education by publishing worldwide. Oxford is a registered trade mark of Oxford University Press in the UK and in certain other countries

(c) Korea International Cooperation Agency 2017

(C) Chapters 1 and 14 @ United Nations University World Institute for Development Economics Research (UNU-WIDER)

The moral rights of the authors have been asserted

First Edition published in 2017

Impression: 1

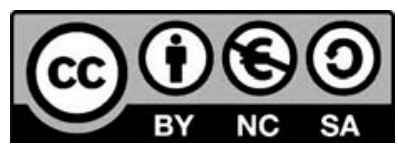

Some rights reserved. This is an open access publication. Except where otherwise noted, this work is distributed under the terms of a Creative Commons Attribution-Non Commercial-Share Alike 3.0 IGO licence (CC BY-NC-SA 3.0 IGO), a copy of which is available at https://creativecommons.org/licenses/by-nc-sa/3.0/igo/.

It is permitted to reuse, share and adapt this work, subject to the following terms:

A Attribution - appropriate credit is given to the original work, the copyright holder and creator, and any changes made to the work are properly indicated.

6 Non-Commercial - the work, or any adaptation of the work, may not be used, distributed or reproduced in any format, by any means, for commercial purposes

(2) Share-Alike - the work, or any adaptation of the work is distributed under the same licence terms as the original, with a URL link provided to the licence.

Enquiries concerning use outside the terms of the Creative Commons licence should be sent to the Rights Department, Oxford University Press, at the above address or to academic.permissions@oup.com.

Published in the United States of America by Oxford University Press 198 Madison Avenue, New York, NY 10016, United States of America

British Library Cataloguing in Publication Data

Data available

Library of Congress Control Number: 2016949486

ISBN 978-0-19-879695-4

Printed in Great Britain by

Clays Ltd, St Ives plc

Links to third party websites are provided by Oxford in good faith and for information only. Oxford disclaims any responsibility for the materials contained in any third party website referenced in this work. 


\section{Foreword}

Academic writing on industrial policy emphasizes the role of consultation and coordination with the private sector, both in designing appropriate public actions and in providing feedback. But, in many cases, a close relationship between business and government can lead to capture and inappropriate policy choices. Managing the tension between close coordination and capture is a central challenge in the practice of industrial policy. The academic literature on implementing industrial policy, however, is remarkably light on practical guidance for policy makers as to how to achieve coordination without capture. There is perhaps no region of the developing world more in need of this guidance than Africa, where twenty years of sustained economic growth have resulted in only modest industrial development and job creation, an issue increasingly emphasized by the continent's leaders themselves.

In 2014 the Korea International Cooperation Agency (KOICA) and the United Nations University World Institute for Development Economics Research (UNU-WIDER) launched a joint research project on 'The Practice of Industrial Policy' to contribute to the topic. This volume, written by national researchers and international experts, presents the results of the joint project.

The book consists of three parts, including framing essays that survey key topics in the practice of industrial policy, case studies from Asia addressing the evolution of business-government coordination, and case studies of efforts to build business-government engagement in Africa. The objective is to assist policy makers develop close coordination between the public and private sector to identify, design, implement, and monitor policies to remove the constraints to industrial development. While simple imitation of institutional frameworks that have been successful in Asia is unlikely to bear fruit in the very different social and political context of Africa, a main purpose of this volume is to 'deconstruct' successful experiences with close coordination and remove them from their political and social context in order to come to grips with the underlying institutional economics of the coordination process. These first principles may then be applied effectively in other institutional and political settings.

I would, on behalf of UNU-WIDER, like to express my deepest gratitude to John Page for taking on the lead role in this project, including co-editing this 
volume. In addition, I wish to express our gratitude to each of the authors for their willingness to participate in the project and for their insightful contributions. Finally, UNU-WIDER gratefully acknowledges the special programme contribution by KOICA for the joint project and the core contributions to its work programme from Denmark, Finland, Sweden, and the United Kingdom.

Finn Tarp

Helsinki, November 2016 


\section{Acknowledgements}

First and foremost, we would like to thank the Korea International Cooperation Agency and its staff for their collaboration in implementing the joint study on 'The Practice of Industrial Policy' as well as UNU-WIDER's core donor group of the governments of Denmark, Finland, Sweden, and the United Kingdom for their support to the Institute's work programme.

We would in addition like to express our sincere gratitude to all of the individual authors: Joseph E. Stiglitz; Justin Yifu Lin and Khuong Minh Vu; Alberto Lemma and Dirk Willem te Velde; Rachel Gisselquist; Eun Mee Kim; Rajah Rasiah; Hinh T. Dinh; Vu-Thanh Tu-Anh; Mulu Gebreeyesus; Haroon Bhorat, Aalia Cassim, and Alan Hirsch; Thomas Farole and Lotta Moberg; Ernest Aryeetey and Nkechi S. Owoo; and John Page.

Last but not least, special thanks go to the UNU-WIDER team, Janis Vehmaan-Kreula for administrative support, Anna-Mari Vesterinen for editorial assistance, and Lorraine Telfer-Taivainen for advice and facilitation of the collaboration with Oxford University Press.

Adam Swallow, Economics and Finance Commissioning Editor at Oxford University Press, provided expert guidance with the publication process, and we are also grateful for the anonymous referee reports that helped sharpen our focus. 



\section{Contents}

List of Figures $\quad$ xi

List of Tables xiii

List of Boxes $\quad \mathrm{XV}$

List of Abbreviations $\quad$ Xvii

Notes on Contributors $\quad$ xxiii

1. Overview and Insights 1

John Page and Finn Tarp

\section{Part I. Coordination and Industrial Policy}

2. Industrial Policy, Learning, and Development Joseph E. Stiglitz

3. Coordination through an Asian Lens Justin Yifu Lin and Khuong Minh Vu

4. State-Business Relations as Drivers of Economic Performance Alberto Lemma and Dirk Willem te Velde

5. State Capability and Prospects for Close Coordination:

Considerations for Industrial Policy in Africa

Rachel M. Gisselquist

\section{Part II. Coordination Mechanisms in Asia}

6. Korea's Evolving Business-Government Relationship

Eun Mee Kim

7. The Industrial Policy Experience of the Electronics Industry in Malaysia

Rajah Rasiah

8. Case Studies of Decentralized Coordination in China

Hinh T. Dinh 
9. The Political Economy of Industrial Development in Viet Nam: Impact of State-Business Relationships on Industrial Performance, 1986-2013

Tu-Anh Vu-Thanh

\section{Part III. Building Coordination in Africa}

10. A Natural Experiment of Industrial Policy: Floriculture and the Metal and Engineering Industries in Ethiopia Mulu Gebreeyesus

11. Policy Coordination and Growth Traps in a Middle-Income Country Setting: The Case of South Africa Haroon Bhorat, Aalia Cassim, and Alan Hirsch

12. Special Economic Zones in Africa: Political Economy Challenges and Solutions

Thomas Farole and Lotta Moberg

13. Ghana's Experiments with Business-Government Coordination Ernest Aryeetey and Nkechi S. Owoo

14. Importing Coordination: Africa's Presidential Investors' Advisory Councils

John Page 


\section{List of Figures}

3.1. Educational attainment: SSA in 2010 vs Asia at the beginning of rapid development

3.2. SSA countries and GDP growth trends

3.3. SSA countries and GDP per capita growth trends

3.4. Catch-up performance, 1990-2010: SSA vs developing Asia

3.5. Employment share of the industry sector in the economy

3.6. Improvement in education and economic growth, 1960-2010: SSA and developing Asia: a global picture

3.7. Human capital development in 2010: SSA vs developing Asia

5.1. Selected WGI, 2014: a comparison of regional averages

7.1. Exports and value-added activities in electrical-electronics industry, Malaysia, 1986-2013

7.2. Contribution of electric-electronics to manufacturing, Malaysia, 1986-2013

7.3. Value chain of ICs, 2014

7.4. Composition of the electrical-electronics industry in electronics value-added activities in per cent, Malaysia, 1989-2013

7.5. Trade, electrical electronics, Malaysia, 2000-13

9.1. Average rate of industrial growth in Viet Nam since Doi Moi (\%)

9.2. Industrial output share by ownership, 1986-2013

9.3. Share of investment and industrial output by ownership

9.4. Newly registered FIEs and DPEs in Viet Nam, 1987-99

11.1. Gross value added and employment growth, by sector, 2001-12 



\section{List of Tables}

4.1. Implementation of budget proposals by the Mauritius JEC to the government

5.1. Fragile states in 2014

5.2. Average 2013 CPIA scores for SSA as compared to other regions

5.3. Comparative capabilities of African states based on 2013 overall CPIA scores

7.1. Technological competency and capability, semiconductor firms, Malaysia, 2014

7.2. Technological competency and capability, semiconductor firms, Malaysia, 2015

10.1. The entry process and export patterns of the Ethiopian flower industry 196

10.2. The structure of Ethiopia's BMEI, 2012-13

10.3. Performance of the BMEI against the target set under GTP

14.1. Number of reforms attributed to PIACs

14.2. Themes of working groups of PIACs, 2009

14.3. Working groups of PIACs, 2012 



\section{List of Boxes}

3.1. The ITRI's role in transforming Taiwan into a high-tech industrial structure

4.1. The OECD PPD Handbook

9.1. The PMRC

9.2. Important reforms initiated by the 1999 Law on Enterprise

10.1. Meles Zenawi's personal promotion of the Ethiopian flower industry 



\section{List of Abbreviations}

\begin{tabular}{ll} 
10-YMA & Ten-Year Moving Average \\
ACEP & Africa Centre for Energy Policy \\
ADLI & Agricultural Development-Led Industrialization \\
AfDB & African Development Bank \\
AGI & Association of Ghana Industries \\
AGOA & African Growth and Opportunity Act \\
AmCham & American Chamber of Commerce \\
AMEICC & AEM-MITI Economic and Industrial Cooperation \\
ANC & African National Conference \\
APITD & Action Plan for Industrial Technology Development \\
ASEAN & Association of Southeast Asian Nations \\
BBBEE & Broad-Based Black Economic Empowerment \\
BEE & Black Economic Empowerment \\
BMEI & Basic Metal and Engineering Industry \\
BNDE & National Development Bank \\
BTA & Bilateral Trade Agreement \\
CDD & Centre for Democracy and Development \\
CFE & Committee on the Future Economy \\
CGEM & General Confederation of Moroccan Enterprises \\
CIBA & Council of Indigenous Business Associations \\
CIEM & Central Institute for Economic Management \\
COMECON & Council for Mutual Economic Assistance \\
COVE & Corporate Village Enterprise \\
CPC & Communist Party of China \\
CPI & Conseil Présidentiel de l'Investissement \\
CPIA & Country Policy and Institutional Assessment \\
CSA & Central Statistics Agency \\
CSC & Committee on Singapore's Competitiveness \\
\hline
\end{tabular}




\begin{tabular}{|c|c|}
\hline CSP & Community, Social, and Public Services \\
\hline DAC & Development Assistance Committee \\
\hline DBE & Development Bank of Ethiopia \\
\hline DEGRP & DFID-ESRC Growth Research Programme \\
\hline DFID-ESRC & $\begin{array}{l}\text { Department for International Development-Economic and Social } \\
\text { Research Council }\end{array}$ \\
\hline DPE & Domestic-Private Enterprise \\
\hline DRC & Democratic Republic of the Congo \\
\hline DTI & Department of Trade and Industry \\
\hline EABMEI & Ethiopian Association of Basic Metal and Engineering Industries \\
\hline EASSY & East African Submarine Cable System \\
\hline ECCSA & Ethiopian Chambers of Commerce and Sector Associations \\
\hline EDB & Economic Development Board \\
\hline EDIF & Export Development and Investment Fund \\
\hline EDRI & Ethiopian Development Research Institute \\
\hline EGAT & Economic Growth and Transformation, LLC \\
\hline EHDA & Ethiopian Horticulture Development Agency \\
\hline EHPEA & Ethiopian Horticulture Producers and Exporters Association \\
\hline EOI & Export-Oriented Industrialization \\
\hline EPA & Economic Planning Agency \\
\hline $\mathrm{EPB}$ & Economic Planning Board \\
\hline EPRDF & Ethiopian People's Revolutionary Democratic Front \\
\hline EPZ & Export-Processing Zone \\
\hline ERC & Economic Review Committee \\
\hline ERCA & Ethiopian Revenue and Customs Authority \\
\hline ESC & Economic Strategies Committee \\
\hline $\mathrm{EU}$ & European Union \\
\hline EuroCham & European Chamber of Commerce \\
\hline FDI & Foreign Direct Investment \\
\hline FIAS & Foreign Investment Advisory Service \\
\hline FIE & Foreign-Invested Enterprise \\
\hline f.o.b. & Free-On-Board \\
\hline FTZ & Free-Trade Zone \\
\hline FYEDP & Five-Year Economic Development Plan \\
\hline GAP & Good Agricultural Practice \\
\hline GDP & gross domestic product \\
\hline
\end{tabular}




\begin{tabular}{|c|c|}
\hline GEA & Ghana Employers' Association \\
\hline GEAR & Growth, Employment and Redistribution \\
\hline GED & Ghanaian Enterprises Decree \\
\hline GIAC & Ghana Investors Advisory Council \\
\hline GIPC & Ghana Investment Promotion Centre \\
\hline GNCC & Ghana National Chamber of Commerce \\
\hline GNCCI & Ghana National Chamber of Commerce and Industry \\
\hline GNI & Gross National Income \\
\hline GNP & Gross National Product \\
\hline GSDPP & Graduate School of Development Policy and Practice \\
\hline GSP & Generalized System of Preferences \\
\hline GTP & Growth and Transformation Plan \\
\hline HAIR & Helicopter Quality, Analytical Skills, Imagination, and Reality \\
\hline $\mathrm{HCI}$ & Heavy and Chemical Industrialization \\
\hline HIPC & Heavily Indebted Poor Countries \\
\hline HPAE & High-Performing Asian Economy \\
\hline HR & Human Resources \\
\hline IC & Integrated Circuit \\
\hline ICT & Information and Communications Technology \\
\hline IDA & International Development Association \\
\hline IDS & Industrial Development Strategy \\
\hline IEA & Institute of Economic Affairs \\
\hline IFC & International Finance Corporation \\
\hline ILO & International Labour Organization \\
\hline IMF & International Monetary Fund \\
\hline IMP1 & First Industrial Master Plan \\
\hline IMP2 & Second Industrial Master Plan \\
\hline IMP3 & Third Industrial Master Plan \\
\hline IPA & Investment Promotion Agency \\
\hline IPPG & Institutions and Pro-Poor Growth Research \\
\hline IPR & Intellectual Property Rights \\
\hline IT & Information Technology \\
\hline ITRI & Industrial Technology Research Institute \\
\hline JBA & Japanese Business Association \\
\hline JEC & Joint Economic Council \\
\hline JIT & Just-In-Time \\
\hline
\end{tabular}




\begin{tabular}{|c|c|}
\hline JPPCC & Joint Public and Private Consultative Committee \\
\hline JSE & Johannesburg Stock Exchange \\
\hline KIST & Korea Institute of Science and Technology \\
\hline KOICA & Korea International Cooperation Agency \\
\hline LFS & Labour Force Survey \\
\hline LICs & Low-Income Countries \\
\hline LMW & Licensed Manufacturing Warehouse \\
\hline LSE & London School of Economics and Political Science \\
\hline M\&L & Medium and Large \\
\hline MASLOC & Microfinance and Small Loans Centre \\
\hline MDAs & Ministries, Departments, and Agencies \\
\hline MEC & Mineral-Energy Complex \\
\hline METEC & Metal and Engineering Corporation \\
\hline METI & Ministry of Economy, Trade and Industry \\
\hline MIDA & Malaysian Industrial Development Authority \\
\hline MIDI & Metal Industry Development Institute \\
\hline MIMOS & Malaysian Institute of Microelectronics Systems \\
\hline MITI & Ministry of Industry and Trade \\
\hline MNC & Multinational Corporation \\
\hline MOEA & Ministry of Economic Affairs \\
\hline MOF & Ministry of Finance \\
\hline MOST & Ministry of Science and Technology \\
\hline MOTI & Ministry of Trade and Industry \\
\hline MPI & Ministry of Planning and Investment \\
\hline MSE & Micro and Small Enterprise \\
\hline MTDC & Malaysian Technology Development Corporation \\
\hline MVA & Manufacturing Value-Added \\
\hline NDRC & National Development and Reform Commission \\
\hline NEDLAC & National Economic Development and Labour Council \\
\hline NEP & New Economic Policy \\
\hline NEPAD & New Partnership for Africa's Development \\
\hline NLC & National Liberation Council \\
\hline NPP & New Patriotic Party \\
\hline NRC & National Redemption Council \\
\hline NSE & New Structural Economics \\
\hline NWC & National Wages Council \\
\hline
\end{tabular}




\begin{tabular}{|c|c|}
\hline ODA & Official Development Assistance \\
\hline ODI & Overseas Development Institute \\
\hline OECD & Organisation for Economic Co-operation and Development \\
\hline OGFZA & Oil \& Gas Free Zone Authority \\
\hline OPEC & Organization of the Petroleum Exporting Countries \\
\hline PASDEP & Plan of Action for Sustainable Development and Eradication of Poverty \\
\hline PEF & Private Enterprise Federation \\
\hline PEMANDU & Performance Management \& Delivery Unit \\
\hline PIAC & Presidential Investors' Advisory Councils \\
\hline PIO & Pioneer Industry Ordinance \\
\hline PIPP & Private Investment Promotion Project \\
\hline PIRT & Presidential Investors' Roundtable \\
\hline PMRC & Prime Minister's Research Commission \\
\hline PNDC & Provisional National Defence Council \\
\hline POSCO & Pohang Iron and Steel Company \\
\hline PPCF & Public-Private Consultative Forum \\
\hline PPD & Public-Private Dialogue \\
\hline PPP & Public-Private Partnership \\
\hline PSAC & Private Sector Advisory Council \\
\hline PSAG & Private Sector Advisory Group \\
\hline PSCC & Private Sector Consultative Committee \\
\hline PSDC & Penang Skills Development Centre \\
\hline PSI & Presidential Special Initiative \\
\hline PSR & Private Sector Roundtable \\
\hline QLFS & Quarterly Labour Force Survey \\
\hline$R \& D$ & Research and Development \\
\hline RDP & Reconstruction and Development Planning \\
\hline RIDP & Regional Industrial Development Plan \\
\hline SAP & Structural Adjustment Programme \\
\hline SBRs & State-Business Relations \\
\hline SEG & State Economic Group \\
\hline SEP & Strategic Economic Plan \\
\hline SEZ & Special Economic Zone \\
\hline SMEs & small and medium-sized enterprises \\
\hline SMMDP & Small and Medium Manufacturing Development Programme \\
\hline SOE & state-owned enterprise \\
\hline
\end{tabular}




$\begin{array}{ll}\text { SRIDP } & \text { Simplified Regional Industrial Development Plan } \\ \text { SSA } & \text { Sub-Saharan Africa } \\ \text { TAC } & \text { Technology Advisory Committee } \\ \text { TFP } & \text { Total Factor Productivity } \\ \text { THC } & \text { Terminal Handling Charge } \\ \text { TNBC } & \text { Tanzania National Business Council } \\ \text { TNPA } & \text { Transnet National Ports Authority } \\ \text { TRIPS } & \text { Trade-Related Aspects of Intellectual Property Rights } \\ \text { TWN } & \text { Third World Network } \\ \text { UN } & \text { United Nations } \\ \text { UNIDO } & \text { United Nations Industrial Development Organization } \\ \text { UNU-WIDER } & \text { United Nations University World Institute for Development Economics } \\ \text { VAR } & \text { Research } \\ \text { VBF } & \text { Vector Auto-Regression } \\ \text { VCCI } & \text { Viet Nam Business Forum } \\ \text { VCP } & \text { Viet Nam's Chamber of Commerce and Industry } \\ \text { VLSI } & \text { Vietnamese Communist Party } \\ \text { WGI } & \text { Very Large-Scale Integration } \\ \text { WTO } & \text { Worldwide Governance Indicators } \\ & \text { World Trade Organization }\end{array}$




\section{Notes on Contributors}

Ernest Aryeetey is Vice Chancellor of University of Ghana and a Professor of Economics. His research work focuses on the economics of development, particularly institutions and their role in development, regional integration, economic reforms, financial systems in support of development, and small enterprise development. He has published widely in the fields of development economics, in particular in the area of informal finance and microfinance in Africa.

Haroon Bhorat is Professor of Economics and Director of the Development Policy Research Unit at the University of Cape Town, in South Africa. He has co-edited four books and has published widely on labour economics, poverty, and income distribution. Haroon holds a National Research Chair, is a Non-Resident Senior Fellow at the Brookings Institution, is a member of the World Bank's Commission on Global Poverty, and a member of the Board of UNU-WIDER. Haroon has advised former Ministers of Finance and two previous South African presidents.

Aalia Cassim is Senior Economist at the National Treasury in South Africa, involved in microeconomic analysis. She has an MSc in Development Economics from the School of Oriental and Asian Studies, University of London. Previously a Senior Researcher at the Development Policy Research Unit, Aalia's interests include industrial policy, youth unemployment, the informal sector, and social welfare. Aalia also worked in the Competition and Regulatory Practice at Genesis Analytics.

Hinh T. Dinh is Senior Fellow at OCP Policy Center in Morocco and President of Economic Growth and Transformation, LLC (EGAT) in the United States. He is former Lead Economist at the World Bank. His research is in development economics, industrialization, and international finance.

Thomas Farole is a Lead Economist at the World Bank, where he works on the intersection between issues of trade, industrial development, and regional development policy. He has published widely on special economic zones and foreign direct investment (FDI), and holds a PhD in economic geography from the London School of Economics and Political Science (LSE).

Mulu Gebreeyesus is a Senior Researcher at the Ethiopian Development Research Institute (EDRI). His current research interest is on industrial policy, trade orientation and firm performance, and small businesses dynamics. He has published widely in the field of development economics and particularly competition and enterprises dynamics (investment, growth, entry-exit, and productivity), the practice and impact 
of industrial policy, and innovation and growth in small businesses in developing countries. He holds a PhD in Economics (2006) from the Department of Economics, University of Gothenburg, Sweden.

Rachel M. Gisselquist, a Political Scientist, is a Research Fellow with UNU-WIDER. She works on the politics of the developing world, with particular attention to ethnic politics and group-based inequality, state fragility, governance, and democratization in sub-Saharan Africa. Her work has been published in various journals and edited volumes, most recently International Peacekeeping, Social Indicators Research, and World Development. She holds a PhD in Political Science from the Massachusetts Institute of Technology and a Master's degree in Public Policy from Harvard University.

Alan Hirsch is Director of the Graduate School of Development Policy and Practice (GSDPP), at the University of Cape Town, in South Africa. Alan was Chief Economist in the Presidency's Policy Unit (2002), representing the presidency at the G20, and cochairing the G20 Development Working Group. He is a board member of the European Centre for Development Policy Management and was also a member of the Organisation for Economic Co-operation and Development (OECD) Secretary-General's Inclusive Growth Advisory Group.

Eun Mee Kim is Dean and Professor in the Graduate School of International Studies at Ewha Womans University in Seoul, South Korea. Her main areas of research include the political economy of development, development cooperation, globalization, and multiculturalism. She has published widely on East Asian development, and, in particular, South Korea's economic development, the business groups (chaebol), and foreign capital, including foreign aid. Her most recent research focuses on South Korea and other emerging donors of development cooperation.

Alberto Lemma is a Research Fellow at the International Economic Development Group at the Overseas Development Institute (ODI) and a member of the group's Private Sector Development Team. His research focuses on private sector development, structural transformation, as well as green growth and development finance Institutions.

Justin Yifu Lin is Professor and Director of Center for New Structural Economics and Honorary Dean of the National School of Development at Peking University. He was Senior Vice President and Chief Economist of the World Bank, 2008-12. He has published widely on agriculture, development, and transition. He is a Corresponding Fellow of the British Academy and a Fellow of the Academy of Sciences for Developing World.

Lotta Moberg is a Macroeconomic Analyst at William Blair \& Co. LLC. She has a PhD in Economics from George Mason University and earned her BA in Economics from Lund University in Sweden. She has worked in Russia for Swedish Foreign Ministry and in Kosovo for the Swedish Defence Forces. She has published articles on special economic zones, tax benefits, tax competition, and municipal bankruptcy.

Nkechi S. Owoo is a Lecturer at the Department of Economics, University of Ghana. She has a specialization in spatial econometrics and her research focuses on microeconomic issues in developing countries, such as demographics, health, gender, and labour economics. 
John Page is Senior Fellow, Global Economy and Development at the Brookings Institution and a Non-Resident Senior Fellow of UNU-WIDER. He is the author of over a hundred published articles on the economics of developing countries and the co-author of the 2009 United Nations Industrial Development Organization (UNIDO) Industrial Development Report: Breaking in and Moving Up: Industrial Challenges for the Bottom Billion and the Middle Income Countries and Made in Africa: Learning to Compete in Industry (2016).

Rajah Rasiah is a Professor of International Development in University of Malaya. He is a recipient of the 2014 Celso Furtado Prize awarded by the World Academy of Sciences in recognition of contribution to concept, theory, measurement, and polices which can stimulate technological upgrading among latecomer economies.

Joseph E. Stiglitz is an American Economist and a Professor at Columbia University. He is also the Co-chair of the High-Level Expert Group on the Measurement of Economic Performance and Social Progress at the OECD, and the Chief Economist of the Roosevelt Institute. A recipient of the Nobel Memorial Prize in Economic Sciences (2001) and the John Bates Clark Medal (1979), he is a former Senior Vice President and Chief Economist of the World Bank and a former member and Chairman of the (US President's) Council of Economic Advisers.

Finn Tarp is Director of UNU-WIDER and Professor of Development Economics at the University of Copenhagen. He has some thirty-eight years of experience in academic and applied development economics research, teaching, and policy analysis. His field experience covers more than twenty years of in-country assignments in thirty-five countries across the developing world, including longer-term assignments in Swaziland, Mozambique, Zimbabwe, and Viet Nam. Finn Tarp has published widely in leading international academic journals alongside a series of books, and he is a member of the World Bank Chief Economist's Council of Eminent Persons.

Dirk Willem te Velde is the Head of the International Economic Development Group and Director of 'Supporting Economic Transformation' at ODI. He is also a Research Leader of the Department for International Development-Economic and Social Research Council (DFID-ESRC) Growth Research Programme. His research interests centre on economic transformation strategies, FDI, trade, growth, and development finance. He has published widely in the field of development economics including state-business relations, FDI, and trade.

Khuong Minh Vu is an Associate Professor at the Lee Kuan Yew School of Public Policy, National University of Singapore. His research and teaching concentrates on economic growth, impacts of information and communications technology (ICT) and globalization, and economic development strategies. He has published widely on these topics with a special focus on Asia.

Tu-Anh Vu-Thanh is the Director of Research at the Fulbright Economics Teaching Program and a Senior Research Fellow at the Harvard Kennedy School's Ash Center for Democratic Governance and Innovation. His main research interests are political economy of development and industrial policy with a focus on the Northeast and Southeast Asia. He has just finished a book co-authored with Dwight H. Perkins on the political economy of industrial policy in Viet Nam. 



\title{
1
}

\section{Overview and Insights}

\author{
John Page and Finn Tarp
}

\subsection{Introduction}

Industrial policy is finally moving away from the fruitless debate on 'picking winners' versus 'levelling the playing field' towards the development policy mainstream. There is increasing recognition that the market imperfections on which theoretical arguments for industrial policies rest are widespread in lowincome countries and that well-designed government policies can contribute to improved economic outcomes. There is also greater understanding that the private sector has a central role to play in formulating and implementing industrial policy. Because much of the information relevant to policy-making is held by firms, some form of structured engagement-often referred to as close or strategic coordination-between the public and private sectors is needed, both to assist in the design of appropriate public actions and to provide effective feedback on their implementation. ${ }^{1}$

There is, however, less agreement on how government-business coordination should be structured, how its objectives should be defined, and how success should be measured. In fact, the academic literature on close coordination provides little guidance on how governments interested in developing a framework for public-private engagement should go about doing it. This is unfortunate, especially for Africa. Nowhere in the developing world is effective industrial policy more needed.

A key role for industrial policy in developing economies is to speed up the process of structural transformation, the movement of labour from lower- to

\footnotetext{
1 See, for example, Hausmann and Rodrik (2006); Rodrik (2007, 2009); Khan and Blankenburg (2009); Cimoli, Dosi, and Stiglitz (2010); Harrison and Rodriguez-Claire (2010); Sutton (2012); Szirmai, Naudé, and Alcorta (2013).
} 
higher-productivity sectors. ${ }^{2}$ In Africa, structural transformation has contributed little to growth and job creation. In fact, until the turn of the 21st century, an increasing share of African workers found themselves in lowproductivity, low-wage employment. Since then, Africa's economic structure has begun to change, but the shift has consisted largely of workers moving from agriculture into services such as trade and distribution. This is movement from very low-productivity to marginally higher-productivity jobs. In sub-Saharan Africa (SSA), services workers are, on average, only about twice as productive as farmers, while output per worker in manufacturing is more than six times that in agriculture. Yet, industry, and especially manufacturing, has stagnated.

In 2014 the Korea International Cooperation Agency (KOICA) and United Nations University World Institute for Development Economics Research (UNU-WIDER) launched a joint research project on 'The Practice of Industrial Policy: Lessons for Africa'. The objective of the project was to help African policy makers develop better coordination between the public and private sectors in order to identify the constraints to faster structural transformation, and to design and implement policies to remove them. This book presents the results of that research. It is structured in three main parts. Part 1 presents four framing chapters that survey key topics in the practice of industrial policy. Part 2 consists of four case studies from Asia addressing the evolution of business-government coordination, while Part 3 contains five case studies of efforts to build business-government engagement in Africa. This introductory chapter provides an overview of common themes and outlines a set of forward-looking ideas for strengthening public-private coordination in Africa. We believe that these ideas must form part of any development agenda for Africa in the years to come.

\subsection{Industrial Policy and Public-Private Coordination}

The dominant view among economists during the past thirty years has been that industrial policy is a bad idea. The underlying argument is based on two lines of reasoning. First, governments do not have the information needed to 'pick winners'. Most economists have regarded the allocation of resources in an economy as too complex and too information intensive a process to be handled effectively by the public sector. ${ }^{3}$ Second, even if governments could solve the information problem, rent-seeking behaviour by private agents would undermine their well-meaning efforts. For this reason, the prevailing argument has been that private actors should be excluded from designing

\footnotetext{
2 See Stiglitz (Chapter 2) and Lin and Vu (Chapter 3) (both this volume).

${ }^{3}$ See Pack and Saggi (2006) for a statement of the mainstream view.
} 
public policies because they will lobby for actions that serve their particular interests (Krueger 1974).

Where market failures are present, the mainstream view has been that policy makers should identify the distortions and then design taxes or subsidies to reduce the gaps between market prices and marginal social costs or values. As Rodrik (2009: 17) notes:

Economists tend to think of policy design as a top-down process ... the principal (government) designs a rule that provides the incentive to the agent (the firms) to act in a socially desirable manner in view of the private information (e.g., costs) that the agent (but not the principal) has. This approach takes the informational asymmetry as given, while keeping the private-sector at arms' length. The bureaucrats simply have to issue the rules and then step aside.

There has been considerable rethinking of this conventional wisdom in the last decade. Information, learning, and geography combine to make a powerful theoretical case for industrial policy (Stiglitz 1996, 2001; Rodrik 2008). There is greater agreement in the profession that markets do not by themselves lead to economic efficiency or a desirable distribution of income, and that market imperfections in low-income countries impede structural transformation. Many markets are incomplete and suffer from coordination failures. Collateral constraints combined with asymmetric information in credit markets can limit investment; and there are potentially large spillovers associated with learning, not just among firms, but also among institutions. ${ }^{4}$ In addition, the new economic geography has drawn attention to a major collective action problem-agglomeration (UNIDO 2009; Howard, Newman, and Tarp 2016).

There are, as well, broader industrial policy objectives at work. In Chapter 2 (this volume) Stiglitz argues that in addition to addressing market failures, industrial policies should attempt to influence the trajectory of growth in favour of greater income equality. Such an objective clearly flies in the face of the traditional 'arm's-length' relationship between the public and private sectors. As he points out, however, the incentives embodied in the price system often favour the interest groups that shape the institutions and regulations governing market transactions. Indeed, as Stiglitz puts it: 'not having an industrial policy-leaving it to the market, structured as it is by special interests-is itself a special-interest agenda' (Chapter 2, this volume).

As the theoretical case for industrial policy has strengthened, new insights have also challenged the traditional top-down model of policy-making. Industrial policy must, in practice, identify and respond to the need for public actions across a very broad front of industries and possible interventions. The growth of global value chains has blurred the boundaries between

\footnotetext{
${ }^{4}$ Stiglitz makes this point in Chapter 2 (this volume).
} 
manufacturing, agro-industry, and tradable services; and these 'productive sector' activities share a number of traits. They rely on export markets for scale, are subject to agglomeration economies, and depend on the knowledge of managers and workers to raise productivity and quality (Newman et al. 2016). Faced with this complexity, public officials cannot know where all of the relevant constraints and distortions are in an economy. ${ }^{5}$ Firms have information crucial to policy design and implementation, making coordination with the private sector essential at two levels: first, to identify and remove constraints to the more rapid growth of the current set of highproductivity industries, and, second, to design and implement strategies to transform the economy.

\subsubsection{Extending a Helping Hand}

Understanding the constraints on firm-level performance requires detailed industry-level information and an ability to come to grips with the environment within which firms operate. Production of a particular good or service often requires a set of specific public inputs (Hausmann, Rodrik, and Sabel 2007). Lemma and te Velde argue in Chapter 4 (this volume) that strategic coordination with the private sector can identify the public actions needed for more rapid enterprise growth. They label this the 'helping hand'. A structured engagement between government and the private sector is used to identify the constraints to the growth of existing high-productivity firms. With the growth of global value chains, the helping hand has become increasingly important in assisting domestic firms to engage with the multinational lead firms that drive them. ${ }^{6}$ An equally important contribution of close coordination to the helping hand is in giving feedback on which interventions work and which do not.

Tu-Anh Vu-Thanh argues in Chapter 9 (this volume) that in post-reform Viet Nam the government actively worked to create a dialogue between the public and private sectors. State actors sought private sector inputs on economic reforms, and at the same time enterprises lobbied for responsive and effective government. Even though there was no formal public-private coordination mechanism, this engagement meant that many domestic and foreign firms actively collaborated with the government to reform policies. In

\footnotetext{
5 See Hausmann, Rodrik, and Sabel (2007), Rodrik (2009), and Harrison and Rodriguez-Claire (2010). This literature shares much in common with an earlier generation of studies of businessgovernment coordination undertaken in the wake of the 'East Asian Miracle' of the 1970s and 1980s (Amsden 1989; Wade 1990; World Bank 1993; Campos and Root 1996).

6 This point is raised by Rasiah in Chapter 7 and by Dinh in Chapter 8 (both this volume). The integration of domestic firms into global value chains is a particularly significant challenge in Africa, where there are few linkages between foreign and domestic firms. See Newman et al. (2016).
} 
Chapter 8 (this volume) Hinh Dinh describes how local authorities in China 'backed winners' through public investments and public-private initiatives to remove constraints to their growth. Once a firm was established and doing well, the local government offered streamlined administrative procedures, support for technological upgrading, and access to market information through networking. Mulu Gebreeyesus shows in Chapter 10 (this volume) how public-private coordination in Ethiopia facilitated the entry of domestic firms into the global cut-flower value chain.

Lemma and te Velde in Chapter 4 (this volume) also survey quantitative and case-study evidence regarding the impact of public-private coordination on firm-level performance. They find that, in Ghana, measures of effective statebusiness relations (SBRs) are positively correlated with higher firm-level total factor productivity (TFP). In Zambia, membership in a business organization increased firm productivity by 37 to 41 per cent, due to business organizations' capacity to lobby for relevant public actions and, to a lesser extent, to their ability to reduce information asymmetries and coordination failures among their members. Firm-level data for fifteen Indian states show that stronger SBRs boost productivity growth in both formal and informal manufacturing firms.

\subsubsection{Shaping Strategic Directions}

In their contributions, Joseph Stiglitz and Justin Lin and Khuong Minh Vu remind us that the process of structural transformation also requires moving in new directions, including, as Stiglitz argues in Chapter 2 (this volume), creating a learning society. Dani Rodrik (2009) refers to this approach as 'industrial policy in the large'. Beyond the helping hand, industrial policy in the large implies thinking of an industry or an activity one would want to see develop, and then putting in place all the public inputs needed for it to succeed (Hausmann, Rodrik, and Sabel 2007). The economic rationale for this type of industrial policy rests on the presence of imperfect markets. In Chapter 2 (this volume) Stiglitz also argues that markets are not well suited on their own to support structural transformations. Imperfections in risk and capital markets mean that individuals, who should move from old to new sectors in lowincome countries, cannot get access to the resources needed to make the shift; yet they have to bear the inevitable risks associated with the transition.

Information externalities and coordination failures further inhibit structural transformation. Because there are high costs to private firms with regard to discovering the next new area in which an economy will be competitive-a process that Hausmann and Rodrik (2003) have famously labelled 'selfdiscovery'-firms will tend to underinvest in new activities, even if they have high social returns. For this reason, implementing industrial policy in 
the large implies giving incentives to compensate first movers in a new sector for the positive information externalities they create by going where no business has gone before. Rent transfers can be in the form of a subsidy, such as trade protection or fiscal transfers, or by the provision of venture capital. ${ }^{7}$

In making industrial policy in the large, governments have used coordination with the private sector to identify promising new activities and build consensus on new strategic directions for the economy. Drawing on their understanding of the experience of a number of East Asian economies, Lin and $\mathrm{Vu}$ argue in Chapter 3 (this volume) that 'an effective economic strategy plays a crucial role in identifying the country's comparative advantage ... and proposing strategic directions and priorities for fostering structural change'. Citing the examples of Singapore and Viet Nam, they argue that a strategy must align the country's economic development efforts across sectors and regions, and strengthen their coherence, consistency, and efficiency. Eun Mee Kim in Chapter 6 (this volume) highlights the central role the Five-Year Economic Development Plans (FYEDPs) and their implementation through the deliberation councils played in the early industrialization drive in South Korea. Rasiah in Chapter 7 (this volume) discusses how the Malaysian Industrial Master Plans shaped business-government relations in the electronics industry.

\subsubsection{Embedded Autonomy}

Any system of incentives designed to help private investors by removing constraints or through a system of incentives, may end up serving as a mechanism to transfer rents to corrupt businessmen or bureaucrats. This is what lies at the heart of some objections to public-private coordination: the fear that the state will be corrupted in the process. While a highly insulated state that holds the private sector at arm's length will lack access to information essential to policy formulation, close public-private relationships without some check on private rent seeking can leave it incapable of transcending individual interests. Managing the tension between coordination and capture is one of the central challenges in implementing industrial policy in practice.

Peter Evans' (1995) influential study of South Korea introduced the term 'embedded autonomy' to describe a way of achieving balance between coordination and capture. The success of the Korean model, he argued, was due to the fact that the public institutions charged with industrial policy design and implementation were both autonomous and embedded in private sector networks. In Chapter 9 (this volume), Tu-Anh Vu-Thanh, gives an example of such embedded autonomy from Viet Nam. The Prime Minister's Research

\footnotetext{
7 Bhorat, Cassim, and Hirsch note in Chapter 11 (this volume) that public venture capital has been an important source of such transfers in the case of South Africa.
} 
Commission (PMRC) and a very small group of highly dedicated technocrats in the Central Institute for Economic Management (CIEM), led by Dr Le Dang Doanh, were the team behind the 1999 Law on Enterprises. At the heart of the PMRC was a core group of a dozen advisors. Most had served as senior experts or researchers in the party-state system, but at the time they held no executive posts in the administration. Since the PMRC members neither held official power nor were in business, they were able to maintain a very high level of autonomy, both in relation to the government and vis-à-vis the enterprise community, while remaining embedded in both.

Lin and $\mathrm{Vu}$ list a number of institutions drawn from the experiences of successful early Asian industrializers, and Kim describes in some detail in Chapter 6 (this volume) the role played by the Economic Planning Board (EPB) as the super ministry in South Korea's early industrialization push. While these institutions were highly structured 'deliberation councils', incorporating public officials and private entrepreneurs, Lemma and te Velde argue in Chapter 4 (this volume) that organizational structures used to achieve embedded autonomy vary significantly, ranging from formal, regular coordination arrangements to informal, ad hoc interactions. In some cases, the formal aspects matter most and the forms are highly visible, as in South Korea. In other cases, such as the reform programme in Viet Nam, informal arrangements, rules, and norms dominate. In sum, while individual country circumstances will define institutional structure, the objective is, in all cases, the same: to set up a framework that (i) engages the public sector in an ongoing conversation with the private sector; and (ii) has the capacity to respond selectively, using a range of policies, to the economic opportunities these conversations identify.

\subsubsection{State Capacity}

A defining characteristic of the East Asian deliberation councils was the high capacity of the bureaucracy charged with managing the process and with implementing decisions. As Lin and Vu note in Chapter 3 (this volume): 'institutional initiatives that establish and support highly competent organizations dedicated to coordinate efforts for industrial diversification and upgrading, efficiency and productivity improvement, and export promotion, are critical to the success of a developing country's industrial policy implementation'. They argue that a number of emerging Asian economies have developed such high-quality implementation mechanisms: Malaysia's Performance Management and Delivery Unit, the Committee on Economic Development Acceleration and Expansion of Indonesia, the National Development and Reform Commission (NDRC) of China, and the National Steering Committee on Information and Communication 
Technology (ICT) of Viet Nam. Each of these serves as a major link between the government and the business community.

One important question is whether embedded autonomy can be achieved in settings where the quality of the public administration is markedly lower than that found in emerging Asia. Rachel Gisselquist introduces a cautionary note in Chapter 5 (this volume) to: 'be careful with attempting industrial policy in fragile settings-and Africa has many fragile settings'. She argues that more attention must be paid to the role of the state in weak institutional settings, and concludes that a relatively high level of coherence within the bureaucracy is needed to achieve embedded autonomy. Tu-Anh Vu-Thanh makes a similar point. Reflecting on the experience of Viet Nam, he argues that business-government coordination requires effective coordination within the state system itself, as well as with the business sector.

Precisely how incoherent does a bureaucracy have to be for it to stand in the way of successful industrial policy? Gisselquist provides no definitive answer. Instead, she notes that there is considerable variation in the coherence of bureaucracies across SSA; she goes on to ask whether efforts to improve business-government collaboration can succeed in circumstances where the bureaucracy is incoherent. She implicitly concludes it is unlikely. The thrust of her warning is that not all countries in Africa will be immediately successful in efforts to implement industrial policy; country context matters. This point is reinforced in the case studies by Farole and Moberg in Chapter 12 and by Page in Chapter 14 (both this volume), in which state capacity-in particular the ability to undertake coordinated policy actions across government-is identified as a major constraint to effective policy implementation.

\subsection{Strategic Coordination in East Asia}

The four chapters in Part 2 deal with a variety of country experiences in implementing strategic coordination between the public and private sectors in East Asia. The country cases span China, Malaysia, South Korea, and Viet Nam. The studies of Malaysia and China focus mainly on interventions designed to remove the obstacles to existing industries. Those of South Korea and Viet Nam are more about 'industrial policy in the large'. They demonstrate that there is no single 'East Asian Model' of industrial policy and public-private coordination. The objectives and instruments of industrial policy and the nature of the coordination process between government and business has varied across countries and over time within the same country. For example, Eun Mee Kim documents in Chapter 6 (this volume) how South Korea has adapted its approach to industrial policy several times over the past forty years in response to growing democratization and a changing power 
dynamic between the state and business. While there is considerable diversity, there are a number of common threads that run through the country cases. Four of these are of particular relevance to understanding businessgovernment coordination in East Asia: commitment, focus, experimentation, and feedback.

\subsubsection{Commitment}

A high level of commitment of senior government officials to the coordination agenda has been characteristic of Asian economies, ranging from Japan to Viet Nam. Senior members of the political and government elite were publicly committed to and accountable for industrial development outcomes. The public officials charged with coordination programmes were sufficiently senior to make the decisions needed for implementation and in most cases reported directly to the highest political authorities. In Japan, a powerful technocratic bureaucracy drove the early industrialization effort, supported by a consistent pro-industry, pro-export policy of successive Liberal Democratic Party governments (Johnson 1982). In the cases of Indonesia, South Korea, Malaysia, and Singapore, the champion was the head of state or government. In Chapter 6 (this volume) Kim argues that in South Korea the ascension to power of President Park Chung Hee resulted in both the creation of a comprehensive developmental state and transformation of the SBR.

In China, party and government officials at all levels ranging from the national to the municipal are actively engaged in the industrial development agenda and they are judged on results achieved. As Dinh notes in Chapter 8 (this volume), provincial governments are likely to be promoted or terminated based on the economic performance of their provinces. In Chapter 12 (this volume), Thomas Farole and Lotta Moberg point out that Viet Nam gave its successful economic zone programme the highest level of political attention. The prime minister championed the scheme, which came directly under his purview, during the early years of its development.

\subsubsection{Focus}

One way in which the flow of information between the public and private sectors was encouraged and the risk of capture was reduced was by focusing on specific constraints to firm performance. Although the practitioners certainly would not have recognized the terminology, they were in effect attempting to address constraints, externalities, or failures of collective action. These types of industrial development problems proved to be best dealt with at the level of specific objectives that could be monitored. The key elements of the process were agreement with the private sector on a specific objective 
and the proposed course of action. A timetable for resolution of the problem was announced and progress in implementation was monitored and reported, often within the context of a deliberation council.

Another way in which focus was achieved was by creating localized enabling environments and extending the improvements across regions and sectors gradually in line with the government's available resources and implementation capacity. In Malaysia and Viet Nam export-oriented industrialization was promoted through the opening of free-trade zones (FTZs) that operated independently from the domestic policy environment. Dinh points out that, in China, various policy approaches have been adopted at the provincial and municipal level depending on the local context and the particular stage of development. Vu-Than argues that the recent decentralization in Viet Nam has caused local governments to become more active in improving the business environment by moving the focus of business-government dialogue closer to the provision of local public inputs.

\subsubsection{Experimentation}

East Asian industrial policy makers have shown a striking willingness to experiment. Ideas were often generated by observation of successful examples from elsewhere. Public actions were identified, developed, and then implemented. The results-measured in terms of specific outcomes-were subsequently carefully observed. When the chosen course of action failed to accomplish the desired outcome, it was usually modified or abandoned. Policies that were deemed successful were frequently replicated in other settings. This almost 'pharmacological'—observe, experiment, implementapproach to policy-making was heavily dependent on a strong two-way flow of information between firms and the government and a high degree of pragmatism on the part of the policy makers concerned.

Kim documents the extent to which South Korea has shifted the focus and instruments of its industrial policies in response to changing circumstances. By the 1980s, private business in general and the chaebol in particular had become too big to be dependent on the state for resources. Recognizing this, Korean policy makers changed from efforts to dominate the private sector, to building a symbiotic relationship with it, and finally to efforts to promote competition among domestic firms. The changes included: shifting industrial targeting from selecting sectors for heavy government subsidies to supporting sunset industries; making industrial policies take backstage to regulatory policies; and abolishing such important institutions as state-owned banks, policy loans, and industrial licensing. In Chapter 8 (this volume), Hinh Dinh shows how China's local industrial policy of 'backing winners' evolved by experimental design and was adapted to local circumstances. 


\subsubsection{Feedback}

Feedback was an essential element of the Asian industrial policy process. Partly this was done, as Kim notes, by measurement of observable outcomes, for example, the rate of growth of jobs, output, or exports. Partly it depended on information gleaned from the private sector. In Chapter 9 (this volume), Tu-Anh Vu-Thanh argues that a top priority of Viet Nam's PMRC in the late 1990s and early 2000s was to observe the economy and society closely through daily interactions with institutions, businesses, and practitioners, as well as through field trips at the local level. Meetings with the business community were held every year to identify obstacles to the operation and development of business, and equally importantly, to build trust. Hinh Dinh notes that in China local governments (prefectures, counties, townships, and villages) are directly connected to industrial clusters. By focusing on individual clusters and communicating frequently with local entrepreneurs, local governments devise policies clearly targeting specific industries. Stiglitz characterizes the combination of experimentation and feedback as institutional learning, writing 'countries that have been successful... have learned how to conduct industrial policies as they have gone along-there has been institutional learning. Industrial policies that work at one stage of development and in one environment do not work in another. ${ }^{8}$

Using feedback was also an important means of building accountability. In Chapter 3 (this volume) Lin and Vu write: 'Putting an economic strategy into a concerted course of action requires not only a strategic vision but also operational skills ... and ... effective management of performance.' Lin and Vu and Kim both point to the formation of South Korea's tripartite Economic and Social Development Commission, involving the public sector, the private sector, and labour unions as a key element in the country's successful globalization drive. Between 1998 and 2011, over 80 per cent of the deliberations made by the Commission were implemented under the oversight of a Committee for Assessment of Implementation set up to guarantee effectiveness. Dinh documents the multiple ways in which the local authorities accountable for industrial development outcomes in China sought feedback from private firms, frequently located in nearby industrial clusters.

\subsection{Coordination Efforts in Africa}

The five African case studies in Part 3 fall into two groups. Three are studies of industrial policy and SBRs in individual countries: Ethiopia, Ghana, and South

${ }^{8}$ Emphasis in original. 
Africa. Two are pan-African studies of specific public-private institutions, special economic zones (SEZ), and the 'deliberation councils' formed in five countries under the sponsorship of the World Bank and the International Monetary Fund (IMF). As in Asia, despite their diversity, the individual studies reveal some common characteristics.

\subsubsection{Uneasy Partners}

Lemma and te Velde suggest that one important outcome of public-private coordination is trust building. The African case studies reveal an uneasy partnership between the state and the business community, often characterized by shifting perceptions, mistrust, and lack of mutual comprehension. In Chapter 13 (this volume) Ernest Aryeetey and Nkechi Owoo describe perhaps the most extreme example of such an uneasy partnership. Under the military and civilian Ghanaian governments headed by President Jerry Rawlings the private sector was excluded from the policy- and decision-making processes. The government refused to engage in a dialogue with long-standing business organizations. It believed that these institutions themselves were part of the culture of corruption that was endemic to the country.

Bhorat, Cassim, and Hirsch note in Chapter 11 (this volume), that one of the first acts of the new South African parliament was to establish the National Economic Development and Labour Council (NEDLAC), a statutory social partnership institution modelled on Singapore. NEDLAC was a 'deliberation council' in all but name. Labour, business, and government were to meet, consider challenges, jointly commission policy research, and agree on policy recommendations. However, cooperation and trust between the three social partners weakened after mid-1996. The 2003 Growth and Development Summit, hosted by President Mbeki, was an attempt to rebuild the social partnership, but the uncertain commitment of the partners to implementation has continued to undermine its effectiveness.

Mulu Gebreeyesus and John Page both point to a bipolar relationship between the state and the private sector in Ethiopia. In 2002, on the government's initiative, a 'Government and Business Community Joint Consultation Forum' was created. The Forum came to an abrupt end in 2005, when lack of government support and political unrest led to its complete abandonment. As the Forum was winding down, however, the government was running highly structured consultations with private investors in priority areas such as cut flowers, leather, and textiles. Meetings with investors in these subsectors were frequent and attended by high government officials, including, many times, the prime minister. Actions were agreed and followed up, often on the spot. 


\subsubsection{Right Hand-Left Hand}

Effective coordination with the private sector and implementation of the public actions derived from the state-business dialogue require effective coordination within government. This is a critical manifestation of the state capacity flagged by Gisselquist in Chapter 5 (this volume). In the African case studies it often appears that the right hand of government is not aware of what the left hand is doing. Bhorat, Cassim, and Hirsch point out in Chapter 11 (this volume) that while industrial policy was on the agenda of the African National Congress both before and during the transition to democracy, several factors undermined its effectiveness, including poor coordination within government. Signs of poor policy coordination emerged in South Africa as early as 1996, when three different and conflicting economic policy frameworks were developed and published by different parts of the government. The Department of Trade and Industry (DTI), which was nominally in charge of industrial policy, faced opposition from the National Treasury on the basis that it was trying to 'pick winners'.

Lack of intra-government coordination is also an important cause of the poor performance of SEZ programmes in Africa. Thomas Farole and Lotta Moberg document in Chapter 12 (this volume) how institutions with vastly different objectives and incentives often failed to work towards a common goal. A lack of alignment in the incentives between people promoting exports and those responsible for fiscal matters, such as the Ministry of Finance (MOF) and the Customs Authority, has contributed to failure of several zone projects. In Tanzania, Nigeria, and Kenya the lack of formal institutional links between investment promotion agencies and those charged with SEZ programmes, such as sitting on each other's boards or forming joint committees, contributes to an operational disconnect. In Chapter 14 (this volume), Page points out that a major cause of lack of impact of the World Bank-IMF Investors' Councils was lack of coordination across ministries in implementing Council decisions.

\subsubsection{Rewards without Referees}

The coordination mechanisms that evolved in Asia to manage the inevitable tension between coordination and capture have been likened to a contest. While the institutional forms varied, they featured three elements essential to all contests: rules, referees, and rewards (World Bank 1993). Kim emphasizes the role that 'carrots and sticks' played during South Korea's early industrialization drive. As the Park administration sought to transform the SBR it used both access to resources and discipline. Dinh documents the role of contests in implementing China's decentralized industrial policies. The African case 
studies suggest that, in many cases, the rewards have been present while the rules and the referees have not.

According to Bhorat, Cassim, and Hirsch (Chapter 11, this volume), an unintended consequence of the structure of the South African economy has been to encourage rent seeking between key players. The corporate sector and trade unions have settled into a stable equilibrium, defined by high rents distributed between organized labour and big business. The strong alliance between the union movement and the ruling party has made it difficult to counter trade union and business interests. Gebreeyesus points out in Chapter 10 (this volume) that even in the case of the Ethiopian flower industry, which is generally regarded as one of the region's outstanding industrial policy successes, the government made thousands of hectares of very cheap land available for floriculture. Not all investors, however, developed the land they acquired from the government, preferring to hold it in anticipation of rising land values. Aryeetey and Owoo (Chapter 13, this volume) point out that Ghana's Local Content Bill, designed to ensure that local companies are active participants in the operations of multinational petroleum companies, gives wide discretionary powers to the Minister of Energy, creating room for subjective contract allocations and potential abuse of power.

\subsection{Improving Close Coordination in Africa}

The case studies in Part 3 indicate that Africa still has some distance to travel in terms of putting in place effective public-private coordination mechanisms. This is so whether governments only want to extend a helping hand to the private sector or have more ambitious plans for industrial policy in the large. While the practice of industrial policy is both complex and country specific, the chapters in this volume provide useful guidance on how to strengthen business-government coordination in Africa. We can identify four key areas for action.

\subsubsection{Leaders Must Lead}

High-level political commitment has been the hallmark of successful strategic coordination. One virtue of having a high-level champion is that it identifies the person who has the job of explaining the policy agenda and who can be held politically responsible for things going right or wrong (Rodrik 2008). When the responsible party is the head of state or government, it raises both the visibility of the coordination process and the level of accountability for its implementation. Gebreeyesus points out that, in Ethiopia, Meles Zenawi, the late prime minister, was personally involved in the successful promotion of 
the flower sector, holding regular meetings with investors and seeking immediate solutions to the business constraints they faced. When the prime minister showed less direct personal interest, as, for example, in the case of basic metals and engineering industries (BMEI), the coordination process was far less effective, even within the same political system and bureaucracy.

Page suggests that President Museveni of Uganda signalled his commitment to the Presidential Investors' Advisory Council (PIAC) by actively participating in meetings and following up on Council decisions. As a result, assessments of the Council in Uganda tend to receive high marks from the private sector. Ghana represents the opposite case. Because President Kufuor could not find time in his schedule to conduct a meeting in more than two years, the Council was abandoned and written off as a failure. Aryeetey and Owoo argue in Chapter 13 (this volume) that this may be symptomatic of a larger problem: there is the perception in Ghana that although the political elites have expressed strong rhetorical support for the private sector, there is not much actual commitment. They suggest that long-term strategic plans which clearly define the SBR would be a more credible mechanism to signal commitment and improve the continuity of policy.

A second reason why high-level leadership is critical to the success of strategic coordination is the need for coherence within government in following up and implementing the decisions reached as a result of public-private problem solving. One of the failings of the Investors' Advisory Councils in Page's view was a lack of follow-up and accountability on the part of the public administration. Where the top leadership was engaged, as in Uganda, government officials were regularly tasked with implementing Council decisions. Where the top leadership showed little engagement, poor implementation was often ascribed to 'lack of capacity in the public administration'. Farole and Moberg (Chapter 12, this volume) note that successful SEZ regimes generally have been linked closely to the head of state or of the government, thereby facilitating coordination across various government ministries and agencies. In Africa, most political leaders have failed to champion SEZs, with the result that lack of coordination within government has seriously impeded their development.

\subsubsection{Go Local}

A defining feature of the public-private coordination mechanisms in such countries as China, South Korea, Viet Nam, and Ethiopia is that they were the result of a national effort to shape institutions and set policy objectives. While the need for national solutions to industrial development problems sounds self-evident, national control of the industrial policy agenda is more often the exception than the rule in Africa. Aid continues to contribute significantly to 
national budgets and donors exercise an outsized level of external influence on public policy. Since about 2000, the World Bank and many bilateral donors have promoted reform of the 'investment climate' as a way to accelerate structural transformation, but these efforts have had little impact on Africa's industrial development (Newman et al. 2016).

This is largely because, as Aryeetey and Owoo point out in Chapter 13 (this volume), the public actions which should form industrial policy have been developed in Washington, instead of being a result of locally driven coordination between government and business. Page contends that the policy agenda for the Investors' Advisory Councils was often set by the World Bank with little or no meaningful consultation. Because the objectives were not owned by the participants, the coordination mechanisms degenerated into 'chat shops'. To make progress, African governments will need to undertake the difficult task of wresting their industrial development agenda away from donor control.

Where local initiatives have occurred in Africa, they have been most successful when business has taken a leading role. Aryeetey and Owoo argue in Chapter 13 (this volume) that the establishment of a number of business associations such as the Association of Ghana Industries (AGI) and the Private Enterprise Federation (PEF) led to increased dialogue and engagement between the state and business community. Gebreeyesus points out that the potential of the Ethiopian flower industry was revealed by the private sector. The flower growers association was self-organized, and its aims were not simply to extract rents from the government. It also actively mobilized its members and other stakeholders to help resolve coordination problems. In contrast, in the Ethiopian metals sector, which consists of highly diversified industries, the initial idea of establishing an industry association came from the government and not from the private sector. The objectives of the association were too broadly defined to make an effective industry action plan, and the association's activities mainly focused on lobbying the government for support.

\subsubsection{Clarify the Rules}

Successful coordination requires that both government and the private sector are clear about objectives and how success will be measured. Gebreeyesus provides an illustration in Chapter 10 (this volume) by comparing the successful industrial policy process in cut flowers with a far less successful attempt to promote the growth and diversification of the BMEI in Ethiopia. In the Ethiopian flower sector, the government institutions responsible for the sector developed mechanisms to monitor the performance of interventions. In contrast, no clear pattern of systematic feedback was developed in the BMEI. This was partly due to the fact that the original metals and engineering programme lacked a clear focus and measurable indicators of success. 
Clarity and transparency are also important tools for fostering accountability. Requests made by firms or business associations for government assistance should in principle be public information. Publication of the activities and decisions of coordinating bodies and periodic accounting of the expenditures made to implement their recommendation can increase public scrutiny. Farole and Moberg make the point in Chapter 12 (this volume) that making feasibility studies of large-scale interventions, such as a new SEZ, open to public review is an important tool for increasing transparency. Ensuring that the government-business dialogue remains open to new entrants can reduce the perception that the process is being monopolized by incumbents, and broader representation can provide a check against conflicts of interest. In Chapter 14 (this volume), Page suggests that one of the design flaws of the World Bank-IMF initiative to establish advisory councils was in excluding small and medium firms. This seriously limited the Councils' legitimacy in the eyes of the local business community.

\subsubsection{Limit the Rewards}

The financial incentives offered under any industrial policy framework need to be commensurate with their social returns. Where governments have often erred in the past-and not just in Africa-is in overestimating the returns to the economy of new industrial activities. Set against that, however, is the risk of doing too little. In Chapter 2 (this volume), Joseph Stiglitz argues that conventional economic wisdom has generally favoured the latter over the former. The helping hand and industrial policy in the large have quite different implications with respect to rewards. In the case of the helping hand, the objective of close coordination is to identify and remove specific constraints to the growth of existing industries. The public actions needed include institutional and regulatory reforms as well as investments in infrastructure and human capital.

There is a significant risk of doing too little to extend the helping hand. Donors and governments in Africa have shown a tendency towards only pursuing regulatory and institutional reforms due to their low fiscal costs, ignoring the physical aspects of the investment climate. The result has been that enterprise surveys consistently find that firms in Africa suffer from major deficiencies of infrastructure and other public inputs (Newman et al. 2016). Coordination with the private sector should be used to identify which public investments in infrastructure or skills receive priority. At the same time, any proposed investments should be subjected to rigorous cost-benefit analysis. While coordination failures are potentially important, solving them need not be costly to the government. The challenge is to get all the investments made in the first place. 
Industrial policy in the large presents a different challenge. It is concerned with the identification and promotion of new activities. This is inherently a more risky endeavour because it is designed to respond to information externalities by subsidizing first movers in new areas of economic activity. The presence of an externality only justifies providing incentives to initial investors and not to those, who learn from the first movers. To limit the scope for misappropriation these incentives must be subject to a performance test. As Kim shows in Chapter 6 (this volume), manufacturing and export volume and growth rate goals were used in the case of South Korea. If firms failed to reach agreed targets, they faced loss of access to public subsidies.

These considerations suggest four rules that should govern the use of incentives in implementing industrial policy:

- Incentives should be limited to new activities where there is evidence that social returns exceed market values.

- There should be clear criteria for success and failure.

- There must be a built-in sunset clause.

- There must be monitoring, benchmarking, and periodic evaluation.

These rules are not beyond the capabilities of many African states. Setting specific targets for jobs, growth, or exports and making them available to the public can increase transparency and public scrutiny. Requiring that an incentive expire unless a review recommends that it be extended places the burden on advocates to show why it remains relevant. A regional peer review process, such as that present in New Partnership for Africa's Development (NEPAD), can be used to strengthen evaluation.

\subsection{Concluding Remarks}

Industrial policy remains a term that regularly generates more heat than light among economists and development practitioners. However, there appears to be a growing consensus that markets can fail both when governments interfere too much and when they engage too little. ${ }^{9}$ Governments have now begun to look for a more balanced strategy to accelerate structural transformation and growth, one that includes active coordination with the private sector. Such a balanced approach is critically needed in Africa, where twenty years of efforts to level the playing field have failed to produce robust structural transformation.

\footnotetext{
9 This is one of the major 'lessons' articulated in World Bank (2005) and by the Commission on Growth and Development (2008).
} 
The institutions that shape government-business relations and foster close coordination are an integral element of industrial policy. Without an effective dialogue with the private sector the government is operating largely in the dark. It will remain ignorant of the constraints faced by existing firms and unable to offer an effective helping hand. It will also lack understanding of new opportunities and the means to build consensus around a long-term development strategy. For the private sector, a constructive engagement with the state offers the chance to help shape public policy and address the most severe constraints to success. For both parties, coordination offers the prospect of greater policy certainty, which is essential to building trust.

The chapters in this book describe successful and unsuccessful attempts to implement industrial policy. They reinforce the truism that there is no single model of success, no 'global best practice' in terms of business-government coordination or industrial policy. At the same time, and in each case studied here, the relationship between the state and business has been a critical element of success or failure in accelerating structural transformation. To this point, the experience of successful coordination between the public and private sectors in Africa has been disappointing. This need not remain the case. With committed leadership, African policy makers can develop the institutions of public-private coordination needed to push the pace of economic progress.

\section{References}

Amsden, A. (1989). Asia's Next Giant: South Korea and Late Industrialization. New York: Oxford University Press.

Campos, J. E., and H. Root (1996). The Key to the Asian Miracle: Making Shared Growth Credible. Washington, DC: Brookings Institution.

Cimoli, M., G. Dosi, and J. Stiglitz (2010). Industrial Policy and Development: Political Economy of Capabilities, Accumulation. Oxford and New York: Oxford University Press.

Commission on Growth and Development (2008). The Growth Report: Strategies of Sustained Growth and Inclusive Development. Washington, DC: World Bank.

Evans, P. (1995). Embedded Autonomy: States and Industrial Transformation. Princeton, NJ: Princeton University Press.

Harrison, A., and A. Rodriguez-Claire (2010). 'Foreign Investment and Industrial Policy for Developing Countries'. In D. Rodrik and M. Rosenzweig (eds), Handbook of Development Economics, vol. 5. The Netherlands: North Holland.

Hausmann, R., and D. Rodrik (2003). 'Economic Development as Self-Discovery'. Journal of Development Economics, 72: 603-33.

Hausmann, R., and D. Rodrik (2006). 'Doomed to Choose: Industrial Policy as Predicament'. Paper prepared for the first Blue Sky seminar organized by the Center for 
International Development, John F. Kennedy School of Government, Harvard University, Cambridge, MA.

Hausmann, R., D. Rodrik, and C. F. Sabel (2007). Reconfiguring Industrial Policy: A Framework with an Application to South Africa. Cambridge, MA: Harvard Kennedy School.

Howard, E., C. Newman, and F. Tarp (2016). 'Measuring Industry Coagglomeration and Identifying the Driving Forces'. Journal of Economic Geography, 15(6): 1055-78.

Johnson, C. (1982). MITI and the Japanese Miracle. Stanford, CA: Stanford University Press.

Khan, M., and S. Blankenburg (2009). 'The Political Economy of Industrial Policy in Asia and Latin America'. In M. Cimoli, G. Dosi, and J. E. Stiglitz (eds), Industrial Policy and Development: The Political Economy of Capabilities Accumulation. Oxford: Oxford University Press.

Krueger, A. O. (1974). 'The Political Economy of the Rent-Seeking Society'. American Economic Review, 64: 291-303.

Newman, C., J. Page, J. Rand, A. Shemeles, M. Soderbom, and F. Tarp (2016). Made in Africa: Learning to Compete in Industry. Washington, DC: Brookings Institution Press.

Pack, H., and S. Saggi (2006). 'Is there a Case for Industrial Policy? A Critical Survey'. World Bank Research Observer, 21(2): 267-97.

Rodrik, D. (2007). 'Industrial Policy for the Twenty-First Century'. In D. Rodrik (ed.), One Economics, Many Recipes: Globalization, Institutions and Economic Growth. Princeton, NJ: Princeton University Press.

Rodrik, D. (2008). 'Normalizing Industrial Policy'. Paper prepared for the Commission on Growth and Development, World Bank, Washington, DC.

Rodrik, D. (2009). 'Industrial Policy: Don't Ask Why, Ask How'. Middle East Development Journal, 1(1): 1-29.

Stiglitz, J. E. (1996). 'Some Lessons from the East Asian Miracle'. World Bank Research Observer, 11(2): 151-77.

Stiglitz, J. E. (2001). 'From Miracle to Crisis to Recovery: Lessons from Four Decades of East Asian Experience'. In J. E. Stiglitz and S. Yusef (eds), Rethinking the East Asian Miracle. Washington, DC: World Bank.

Sutton, J. (2012). Competing in Capabilities. Oxford: Clarendon Press.

Szirmai, A., W. Naudé, and L. Alcorta (2013). Pathways to Industrialization in the 21st Century. Oxford: Oxford University Press.

UNIDO (United Nations Industrial Development Organization) (2009). Industrial Development Report 2009 Breaking In and Moving Up: New Industrial Challenges for the Bottom Billion and the Middle Income Countries. Vienna: UNIDO.

Wade, R. (1990). Governing the Market. Princeton, NJ: Princeton University Press.

World Bank (1993). The East Asian Miracle: Economic Growth and Public Policy. New York: Oxford University Press.

World Bank (2005). Economic Growth in the 1990s: Learning from a Decade of Reform. Washington, DC: World Bank. 


\section{Part I}

Coordination and Industrial Policy 



\section{2}

\section{Industrial Policy, Learning, and Development}

Joseph E. Stiglitz

\subsection{Introduction}

Industrial policy is back in fashion, and rightly so.

There is now an understanding that markets by themselves may not lead to economic efficiency-let alone a desirable distribution of income. The market may not lead to either a good allocation of resources among sectors or the appropriate choice of techniques. Industrial policies, aimed at affecting the economy's sectoral allocation and/or choice of technique, are one of the instruments for addressing these market failures. Appropriately designed government policies can lead to better outcomes. While this is true even for developed countries, it is perhaps particularly true for developing countries, and this is so even if developing countries have less developed governmental institutions. Limitations on the capacity of government should affect the choice of instruments for carrying out industrial policies, but not whether they should undertake industrial policies.

While there is renewed interest in industrial policies, ${ }^{1}$ recent discussions are markedly different from those that characterized an earlier era in our understanding of both the objectives and the instruments of industrial policy. There are broader objectives and more instruments, to echo a more general theme I put forward in criticism of Washington Consensus policies (Stiglitz 1999). For instance, the government plays a central role in shaping the economy, not

\footnotetext{
1 Evidenced, for instance, by the emphasis placed on industrial policies by the previous chief economist of the World Bank, Lin (2012). While I have long had an interest in industrial policies, my more recent engagement began with joint work with Bruce Greenwald (Greenwald and Stiglitz 2006, 2014a, 2014b; Stiglitz and Greenwald 2014a, 2014b). See also Stiglitz and Lin (2014) and Stiglitz, Lin, and Patel (2014).
} 
only through formal industrial policies and in its expenditure and tax policies, but in writing the rules of the game-markets do not exist in a vacuum, and the way that the government structures markets inevitably affects economic structure (Stiglitz 2015). In that sense, every country has an industrial policy but some countries do not know it. And that opens the possibility that the structure of the economy is set, or at least greatly influenced, by special interests. Such an economy is likely to be beset by rent seeking and the resulting pervasive inefficiencies, and the economy will be characterized by lower growth and more inequality than would be the case if the government were more self-consciousness in their direction of the economy.

Financial market deregulation illustrates this: it was actually an agenda pushed by those in the financial sector to increase its size. It was an industrial policy, but one that led to lower growth and more inequality and instability.

A traditional criticism of industrial policies is related to 'political economy', that such policies are likely to be captured by special interests to advance themselves. However, the previous paragraphs highlighted that not having an industrial policy-leaving it to the market, structured as it so often is by special interests-is itself a special-interest agenda. To avoid capture by special interests there must be openness, transparency, and a deeper understanding of the rationale for industrial policies. Some countries have developed institutional arrangements and cultures that have made it more likely that industrial policies will work and less likely that there will be corruption in their implementation.

I need to make four more preliminary remarks:

(1) Industrial policies, as I use the term, are not necessarily aimed at promoting industrialization. The term embraces any policy affecting the sectoral composition of the economy or the choice of technology. Thus, industrial policy in this sense should also be part of corporate governance, anti-trust and competition policy, and monetary policy and bankruptcy frameworks, as well as (more obviously) tax and expenditure policy.

(2) The success of industrial policy is not to be judged by the success or failure of any individual project, but rather has to be evaluated systematically (i.e., on how the performance of the overall economy is affected). At the centre of our analysis is learning and the creation of new institutions, with benefits to those outside the particular project or sectors under scrutiny. That is why Greenwald and I titled our recent book Creating a Learning Society (2014a, $2014 \mathrm{~b}$ ). We were concerned with impacts and learning processes, which even went beyond the economy. We made a case for an 'infant economy' argument for protection, which was distinctly different from an 'infant industry' argument. Our earlier paper (2006) on the subject was titled 'Helping Infant Economies Grow'. In this sense, our work follows on the earlier work of Hirschman (1958) emphasizing the linkages across sectors. In the standard 
vocabulary, there are externalities, and in assessing the success of industrial policy in general and any project in particular, one has to take these into account.

Moreover, good industrial policy incorporates risk taking, and risk taking means that there will be successes and failures. No oil exploration company would judge its performance by pointing out that it drilled some dry wells. What matters is its overall success rate-whether the successes sufficiently offset the failures. Too often, critics of industrial policy point to failures, without weighing against such failures the successes. In the United States, they point to the failure of American solar cell company Solyndra, without noting that studies show the very high average return to public investments in technology, which include, for instance, critical investments in the Internet. Indeed, Mazzucato (2013) goes so far as to claim that in most of the major advances, government has played a central role. Industrial policies (here, meaning technology policies) have worked.

(3) Of course, if there are systematic, repeated failures, that points to a flaw in institutional design, which needs to be corrected. A central theme of this chapter is learning; that is, firms learn only by doing (e.g., the only way to learn to produce steel, and to become better at producing steel is to produce steel). However, the same point is true of institutions: the only way to learn how to do industrial policies is to carry out industrial policies, to learn consciously from one's successes and failures. One of the reasons for the renewed interest in industrial policies is that so many countries have successfully carried out such policies. Countries rightly reason: if other countries, in similar circumstances to us (at the time they carried out such policies) were successful with such policies, why would we not be? East Asia carried out industrial policies when their incomes were far lower than they are today, and where their institutional development was much more limited.

Few economists argue that a country should not have a monetary policy or a central bank simply because in the past its central bank mismanaged. Rather, there is a broad consensus that countries can learn how to conduct monetary policy in ways that promote growth and stability; and that there are institutional arrangements that enhance the likelihood of success.

The same holds for industrial policies, and the analysis here suggest that these policies may be as important for the long-term success of a development strategy as any other.

(4) East Asia's successful industrial policies were based on export-led growth. However, the scope for export-led growth in the future may be more limitedthough there is still scope for African countries to avail themselves of this model. East Asia's success was based not only on exports-after all, Africa has long exported commodities-but on the exports of manufactured goods. I will explain later why there is a difference between exporting commodities and 
exporting manufactured goods: there are economy-wide benefits of learning (including institutional development) associated with the latter that are not typically associated with the former. However, global employment in manufacturing is likely to decrease, as a result of improvements in productivity outstripping increases in demand. China now has a formidable comparative advantage in a wide range of manufacturing goods, but as wages in China rise, its comparative advantage in basic manufacturing, requiring limited skills, is likely to diminish. This will open the opportunity for some other developing countries, at lower stages of development, to enter into manufacturing export-led growth.

This chapter first outlines the general argument for industrial policies, broadening the set of market failures, which should be the objective of such policies. It then focuses more narrowly on learning, which is so essential for development, and how the government can promote it.

\subsection{Towards a Broader Agenda for Industrial Policies}

There are a large number of market failures that impeded development. The underlying principle is simple: in perfectly functioning markets, private returns to any action (any investment) equal social returns. However, the conditions under which this is true are highly restrictive. Government policies can both address the underlying market failures and the consequences.

\subsubsection{Imperfect Risk and Capital Markets}

Any investment in a new industry is risky, yet for reasons that are now well understood, financial markets provide far from adequate insurance against these risks. Industrial policies can help 'socialize' these risks, enabling projects that otherwise would not be undertaken to be implemented. Similarly, entrepreneurial firms need access to capital, but capital markets are notoriously imperfect (Stiglitz and Weiss 1981). Many of the industrial policies of East Asia were directed at correcting this market failure by providing access to funds at commercial or near-commercial rates.

These two limitations are especially relevant to firms (and sectors) where learning is important. Optimal social policy will entail producing beyond the point where the value of the marginal product equals the marginal cost of production; one needs to take into account the value of learning, and the reduction in future costs as a result of increased production today. The implication of learning is that it may be desirable for a firm to produce so much that its current profits are negative. However, if the firm is to do this, it has to find the finance for the loss. With imperfect capital markets, it is likely that it cannot do so. 
Moreover, the value of this learning is highly uncertain-there is uncertainty both about the amount of learning (e.g., the magnitude of reduction in future costs of production) and its value (which depends on future output). Firms cannot insure themselves against these risks, so again, there is likely to be underinvestment in learning.

\subsubsection{Structural Transformation}

An important part of development is structural transformation, moving from an agrarian economy to an industrial economy. Markets do not make such transformations on their own well (Delli Gatti et al. 2012a, 2012b). Those in the declining sector often have low incomes, and the value of their assets (including their human capital) has been diminished by the same forces giving rise to the necessity for structural transformation. The imperfections of risk and capital markets discussed in the previous paragraphs mean that individuals who should move from the old to the new sectors of the economy cannot get access to the resources needed to make the shift, and they have to bear the inevitable risks associated with the transformation.

The result is that the economy can be 'stuck', unable to make a transformation that would be beneficial to most citizens of the country. The shift from an agrarian economy to an industrial economy is particularly difficult, because it is typically associated with urbanization, which requires a large movement of individuals with heavy investment in skills and housing. With more individuals in the old sector(s) than is optimal, incomes will be lower; and the lower incomes will result in lower demands for goods in the non-traded industrial sector.

East Asia managed to break out of the resulting inefficient equilibrium by focusing on exports. The demand for their exports was not limited by the low incomes in their own country. This is one of the reasons that their model of export-led growth was so successful; however, opportunities for manufacturing export-led growth going forward are likely to be more limited. This means that industrial policies will have to be focused on a broader range of industrial policies, including promoting import substitution and the non-traded goods sector.

Import substitution policies got a bad name, especially in Latin America, because the industries that were created often only survived as the result of protection. It was particularly costly when countries protected intermediate goods, because that made goods farther down the production chain less competitive. Countries often paid a high price for this kind of protectionism, and the maintenance of this protection was often associated with corruption. The protected industries generated rents, and, as always, the recipients of such rents were willing to share some of the rents with the politicians who granted the rents to them. 
It is not inevitable that industrial policies promoting import substitution fail in this way. There are institutional safeguards that make it less likely. Even the form of industrial policy affects the extent to which special interests intrude in a distorting way.

\subsubsection{Learning and Imperfect Appropriability}

Market failures associated with learning received insufficient attention in earlier literature, despite their importance. Learning is essential for developmental transformation. However, there are inevitably large spillovers associated with learning-not only technological spillovers, but also institutional spillovers. The development of institutions like financial institutions and an education system that facilitate the functioning of the industrial sector have important spillovers for the rest of the economy. Whenever there are spillovers, private returns differ from social returns. These spillovers manifest themselves in multiple ways in the development process. For instance, firms that take the risk of trying out whether a particular product grows well in the particular environment of the country will not be able to reap the full benefits-if the project is successful, it will be imitated, if it fails, the firm undertaking the experiment bears the losses (Hoff 1997).

Even banks may find it difficult to appropriate the full benefits of their lending to a new entrepreneur. If the entrepreneur is successful, he will be poached away by others; if he fails, the original lender will be forced to bear the losses. This is one of the reasons that new businesses often find it difficult to obtain funds, even if lending to them has strong social benefits (Emran and Stiglitz 2009).

\subsubsection{Macroeconomic Externalities}

Greenwald and Stiglitz (1986) explained why markets with imperfect risk markets and asymmetric information are not in general Pareto efficient. The pervasiveness of market failures means that governments necessarily have to focus their attention on the most important failures.

Among the most important failures are those that affect the macro economy. Firms, on their own, may engage in too much borrowing, especially in foreigndenominated debt. Banks, on their own, may engage in excessive risk taking.

The social cost of instability is enormous, and firms and banks, in their own decision-making, do not fully take into account these social costs (see, e.g., Stiglitz 2013). There are, for instance, long-term hysteresis effects, as informational and organizational capital is destroyed as firms go bankrupt, as educations are interrupted, and as young people, who otherwise would be learning skills on the job, suffer unemployment and see their skills atrophy. 
Thus, industrial policies also need to be designed to reduce the magnitude, structure, and consequences of the liabilities of corporations and banks, in an attempt to reduce the magnitude of economic fluctuations and the frequency of economic crises.

\subsubsection{Inequality}

Inequality should be a concern to any society. Stiglitz $(2012,2015)$, explains why inequality is associated with better economic performance (higher growth and more stability), and theoretical insights, which have been supported by empirical work at the International Monetary Fund (IMF) and the Organisation for Economic Co-operation and Development (OECD) (Berg and Ostry 2011; Berg, Ostry, and Tsangarides 2014; OECD 2015). Markets, by themselves, will pay no attention to their distributional impact. Thus, one of the objectives of industrial policies should be pursuing greater equality. For instance, policies that increase the demand for unskilled labour will reduce inequality. Stiglitz (2015) outlines a broader set of instruments including changes in legal frameworks, which would do so.

\subsubsection{Climate Change}

The objective of industrial policies is to address market failures. Some market failures are more effectively addressed directly; but for a variety of reasons that may prove difficult, in which case industrial policies may be an effective second-best substitute.

Climate change is perhaps the most important market failure facing the global economy. Charging a high enough carbon price would induce individuals and firms to significantly reduce carbon emissions, but with few exceptions, it has proven difficult to induce countries to impose carbon pricing.

Instead, countries have been called upon to make commitments to reduce carbon emissions. One way that developing countries can succeed in reducing carbon emissions is industrial policies that encourage renewable energy, and discourage carbon-intensive industries and technologies.

\subsection{Creating a Learning Society}

In this and Section 2.4, we hone in on industrial policies associated with learning. As we noted, successful and sustained growth requires creating a learning society. This is especially so in the twenty-first century, as we move to a knowledge economy.

The transformation to 'learning societies' that occurred around 1800 for Western economies, and more recently for those in Asia, has had a far greater 
impact on human well-being than improvements in allocative efficiency or resource accumulation (Solow 1957; Stiglitz and Greenwald 2014a, 2014b).

This implies that our focus should be on the impact of policies on technological change, and how it is brought about by learning, as well as research and development (R\&D). In the case of developing countries, the focus should be on the diffusion of knowledge from developed to developing country and the diffusion of knowledge within the country. As the 1998 World Development Report (World Bank 1999) emphasized, what separates developing from developed countries is as much a gap in knowledge as a gap in resources. However, even in developed countries, there are large gaps between the productivity of the best firms and others. ${ }^{2}$

Markets, on their own, are not efficient in promoting innovation and learning (Arrow 1962a, 1962b; Stiglitz 1987; Stiglitz and Greenwald 2014a, 2014b). Because markets on their own will not do a good job in creating a learning society, there need to be systematic interventions by the government. The policies that do this are markedly different from those traditionally advocated by economists, which focus on improving the static efficiency of resource allocation and the accumulation of capital-including policies that constituted the Washington Consensus.

Indeed, from the perspective of creating a learning society, those policies may be counterproductive.

This analysis implies that a central question of growth and development should be: What should governments do to promote growth through learning (technological progress and innovation)?

Creating a learning society entails looking comprehensively at all the factors affecting learning: the education system; what has been called the economy's innovation system, which includes the intellectual property rights (IPR) regime and technology policy; macroeconomic policies, including exchange rate policy; investment policies, and industrial and trade policies. Underlying questions include: How does learning occur? How do we learn to learn? I argue that special attention should be placed on learning by doing, and, by analogy, learning to learn by learning.

We need to look at all policies and institutions through the lens of learning, asking: (a) how they affect capabilities of learning; (b) how they affect incentives to learn (motivate learning); (c) how they facilitate learning and catalyze it, including how they help create mindsets that are conducive to learningmindsets such as those associated with the Enlightenment; and (d) how they impose impediments to learning.

\footnotetext{
2 The existence and persistence of such gaps undermines the concept of an aggregate production function. This has fundamental implications for the way many economists, especially within macroeconomics, approach development.
} 


\subsection{Industrial and Trade Policies}

In this section, we focus on the various instruments that government can use to promote a learning society, suggesting that there are many more 'instruments' for industrial policy than has usually thought to be the case, and explaining how some of the standard policy advice was counterproductive to creating a learning society.

Standard trade theories focus on comparative advantage-on the country's current relative strengths. Korea's comparative advantage in the period after the Korean War was in rice, and it was advised to strip away trade barriers; such policies would have resulted in its focusing on rice. There is a one-time gain from liberalization, from stripping away trade barriers and opening up markets.

Our theories, focusing on learning, provide a different perspective. We focus on the diffusion of technology from developed to less developed countries, on spillovers from one sector to another, and on learning within any sector.

A closer examination of learning (including learning by doing and learning to learn) shows that much of it is what Atkinson and Stiglitz (1969) called localized learning-localized to particular technologies, but not necessarily to particular sectors. Similar technologies can be used across sectors. Many processes, practices, and institutions entail cross-sector learning and have potentially strong positive effects on productivity. Examples include inventory control processes (like just-in-time production), labour management processes, and computerization. Similarly, institutions (such as those providing financial services) that develop to serve one sector may prove useful in others.

Markets will under-invest in (or under-produce in) learning sectors, especially those with large learning spillovers to others, and even more so when there are imperfections in capital markets, or when learning is especially risky (because of the market failures referred to earlier, imperfect insurance and capital markets).

This helps explain the important role of government in promoting innovation and learning (e.g., in the Internet, biotech, or even agriculture in the nineteenth century). And it is especially important when the research projects require large investments (such as the human genome project or the Internet) and in basic research.

For developing countries, Greenwald and I (Greenwald and Stiglitz 2006; Stiglitz and Greenwald 2014a, 2014b) have put forward the 'infant economy' argument for protection. We explain why the industrial sector has greater learning spillovers than the agricultural sector, and therefore why it is desirable to encourage the industrial sector. Central then to growth and development is understanding the structure of learning within an economyincluding within and across sectors. 
The infant economy argument for protection is distinctly different from the infant industry argument. The latter is predicated on imperfections in capital markets. In the infant economy argument, externalities and spillovers, technological and institutional, are crucial.

In a learning economy, we focus on dynamic comparative advantagerecognizing that comparative advantage is endogenous. With learning by doing, a country's comparative advantage is affected by what a country produces.

We have focused on 'learning', but even more important is 'learning to learn'. Industrial and trade policy can enhance an economy's learning capacities. This, of course, introduces complex strategic questions.

\subsubsection{Multiple Instruments}

Traditionally, governments have employed multiple instruments, including subsidies and trade interventions. Trade restrictions have a short-run cost. However, if those 'distortions' lead the economy to produce more of the good with higher learning and learning spillovers, then productivity in future years will be higher. There is a long-run benefit offsetting these short-run costs. Under quite general conditions, it can be shown that it is optimal to impose trade restrictions or to intervene in the market in other ways to promote these sectors.

Unfortunately, the World Trade Organization (WTO) has restricted the set of instruments that developing countries can employ, for example, they may not be able to provide direct subsidies or trade interventions.

Exchange rate policy is an effective, low-cost instrument with some political economy advantages. Because it is broad-based, it is less subject to capture.

Markets will undersupply research, especially basic research. R\&D is even more important in developing countries, for instance, for adapting existing technologies to circumstances of their country, for facilitating the transfer of knowledge (which itself is an important part of the learning process for developing countries), and for leapfrogging. Some countries (such as Brazil) have shown that even in developing countries, industrial policies can promote R\&D, and that even leapfrogging is possible.

\subsubsection{Political Economy}

There is a standard objection to industrial policies based on political economy. The argument holds that with an ideal government, intervention might improve matters, but real-world interventions do not. It is worth observing that such political economy objections are based on political analysis, not 
economic analysis, and the political analysis is often as or more simplistic than the simplistic economic analysis, which we have already criticized.

In fact, almost every successful country has had industrial policies. In the United States in the nineteenth century, the government supported major advances in telecommunications (the telegraph) and agriculture (then the dominant sector of the economy). Of course, the private sector has played a central role in bringing innovation to the market.

Successful countries learned how to manage the political economy problems, through a variety of institutional arrangements, for example, requiring those receiving support to put in funding of their own, peer review systems, sunset clauses, and so on. Broad-based export subsidies and support as in East Asia (including through exchange rate policies and broad-based educational and infrastructure policies) may be a desirable way of promoting the industrial sector, partly because they may be relatively immune from special interest influence.

The infant economy argument in particular has been criticized on the grounds that government cannot pick winners. The point of industrial policies is not to pick winners, but to identify externalities and other market failures. ${ }^{3}$

There is, however, an important lesson to be learned from the failures of industrial policies in the past. The design of industrial policy has to reflect capacities and capabilities of government; governments have to constantly assess how well their industrial policies are working, and whether they are being 'captured' by special interests; and they have to strive constantly to implement industrial policies more effectively.

\subsubsection{Intellectual Property Rights}

When one thinks about creating a learning society, one naturally thinks about IPR. Advocates of IPR often seem to argue that they are at the centre of creating a learning and innovative economy. However, as I (and others) have argued, they are but a small part of a country's innovation system, which includes government-funded research and a country's education system.

There are significant static costs of intellectual property. It impedes the use of information and gives rise to monopoly power. Increasingly, the alleged dynamic benefits have come to be questioned. IPR, especially if poorly designed, can impede innovation and learning. Knowledge is the most important ingredient to production of knowledge, and IPR reduces access to knowledge. Moreover, the patent system intervenes with the open system that

\footnotetext{
3 There are, of course, other objections to industrial policies, which are dealt with more extensively elsewhere, e.g., in Greenwald and Stiglitz (2014a, 2014b).
} 
is essential for the advancement of science. In addition, the patent thicket and patent trolls have provided further impediments to research. The patent system even distorts the pattern of research, encouraging more research directed at extending market power.

These adverse effects are especially significant for developing countries. Successful development entails closing the knowledge gap and necessitating access to knowledge. ${ }^{4}$ It is even more important in areas of health-access to life-saving medicines has implications that go beyond the budget.

\subsection{Economic Diversification: An Application of Policies Aimed at Changing the Structure of Production}

Many regions of the world (notably in Africa and Latin America) are still highly dependent on commodities, making them highly vulnerable to changes in commodity prices. However, a healthy economic structure should not be so dependent on external factors, especially given the high volatility of export markets and prices.

Because the production of these natural resources does not incorporate much skilled labour, it does not incentivize citizens to invest in human capital. Because mining is sufficiently different from other production processes, there are only limited learning spillovers. Commodities production provides a weak basis for creating a learning economy and society.

Many countries failed to implement reforms that might create a more diversified structure of production. Indeed, among the African countries, only a few have made much progress in creating an economy with even limited diversification. Today, one of the main objectives of industrial policies should be to diversify the structure of production.

Approaches that were the rule in the 1980s and 1990s that relied on the market clearly did not work (Noman and Stiglitz 2015). We now have a better theoretical and empirical understanding of these failures. What is required is a portfolio of instruments. Perhaps the most important macro instrument is competitive and stable real exchange rate policies. However, these must be accompanied by industrial policies, public investments, and monetary policies that do not stifle the real sector.

\footnotetext{
4 This explains the call for a 'developmentally oriented' intellectual property regime. The intellectual property regime that is appropriate for a developing country is markedly different from that appropriate for an advanced country. The agreement on Trade-Related Aspects of Intellectual Property Rights (TRIPS) tried to achieve excessive harmonization: the TRIPS regime of WTO is not developmentally oriented. Even so, it is important for developing countries and emerging markets to make full use of the latitude given by TRIPS; most have failed to do so.
} 
Long-term strategies placing technological change and learning at the centre need to ensure macro consistency (full employment and current and capital account balances), which requires a balanced strategy that includes some traditional activities that generate revenues in foreign currency, and others to ensure full employment of the less skilled population.

The state will have to fulfil other roles. Education policies need to ensure that there are no bottlenecks in the supply of well-trained workers. There is need for infrastructure investments, in highways, ports, and airports. Publicprivate partnerships may be able to play some role in providing infrastructure, but we have learned from the past that such partnerships often fail, with the government bearing the losses and the private sector taking the gains. ${ }^{5}$

Even an economy based on natural resources can use those resources as a basis of diversification, as South Africa demonstrated as it moved from earth-moving equipment into automobiles. There are backward, forward, and horizontal linkages that can be exploited (Jourdan 2014). Export taxes and restrictions on natural resources that have not had value-added components may be an important part of the appropriate industrial policies.

Trade in manufactured goods and in services will be important as these formerly natural resource-dependent economies attempt to diversify. The right strategy is, however, more than simply increasing exports and strengthening import competing industries. Strengthening the non-traded sector is necessary, and this, as in the traded-goods sector, requires supply-side measures (e.g., constructing the appropriate infrastructure, providing the appropriate skills through the education system, and ensuring that the financial system is capable of providing finance for small and medium-sized enterprises). But demand-side policies are also necessary: poverty reduction and a larger middle class will increase the size of domestic markets.

\subsection{Industrial Policies: Broader Objectives and More Instruments}

This chapter has set out to argue that we need more expansive industrial policies with broader objectives and more instruments. Industrial policies should be concerned not only with growth, especially through creating a learning society, but also with mitigating inequality and carbon emissions. We have also explained that there is a much wider range of instruments, which is the flip side of the observation made at the beginning of this chapter that all governments, whether they know it or not, are engaged in industrial policy.

\footnotetext{
${ }^{5}$ Part of the problem is an asymmetry in rights and responsibilities: with limited liability, firms can always evade contractual obligations, simply by going into default; and the threat of doing so provides the basis for contract renegotiation. Governments, however, are long-lived, and especially when the country has signed an investment treaty, may be sued for the loss of expected profits.
} 
The rules, institutional and legal frameworks, and policies governing our economy and our society affect the structure of our economy, including the industrial structure and the choice of technology. The choice of one infrastructure over another favours one industry over another; the design of the educational system provides a supply of labour with various skills, which affects the profitability of different industries; and bankruptcy laws may be more favourable to one industry (such as the financial sector) relative to others. If a government decides not to have, or not to enforce, strong competition laws, it favours monopolies and oligopolies, at the expense of the sectors, which use the output of those sectors as inputs.

\subsubsection{Macroeconomics as an Industrial Policy}

Exchange rate policy has traditionally been thought of as a macroeconomic policy but it is also an industrial policy and that is true too of other aspects of macroeconomic policy. Economies that rely on monetary policy for macroeconomic stabilization are, simultaneously, affecting the economies' sectoral allocations, for example, relative to what they would be if the government relied more on fiscal policy. Monetary policy entails varying interest rates in response to economic conditions, putting the burden of adjustment on interest-sensitive sectors. These sectoral effects are ignored in the overly simplistic models typically employed by macro-economists, but they can be of firstorder importance, especially in the developmental process. If, for instance, the interest-sensitive sectors include manufacturing, in which learning potentials are particularly significant, then reliance on interest rates for macroeconomic adjustment can have an adverse developmental effect.

The extent to which governments pursue macro-stability is itself an industrial policy and one that is especially important for creating a learning society. Stability is important to learning, for a number of reasons. Much of our knowledge resides within institutions and within organizations, like firms. Recessions destroy firms and the embedded knowledge that they contain. There is, in effect, negative learning. Moreover, recessions impede learning, as attention is focused on survival. In addition, recessions impede one of the most important aspects of human capital accumulation-on-the-job learning-with long-term consequences for growth and standards of living. Deep downturns lower a country's potential growth rate, not only the level of future income; there are significant hysteresis effects associated with recessions, helping to explain why effects of downturns persist.

This analysis has strong policy implications: there are significant long-term consequences of not having strong counter-cyclical policies. A focus on government debt can be short-sighted and counterproductive, since it can give rise to far more important adverse effects on real wealth accumulation. 


\subsection{Towards a Developmental State}

Few economies have made the transition from a less developed economy to a more advanced economy relying simply on market forces. Successful economies have realized that market failures are pervasive in all economies, and especially in developing countries. Even in developed countries, whenever one talks about innovation, learning, and structural transformation, one is in a world in which there is a presumption that markets are not efficient and that well-designed economic policies, including industrial policies, can improve economic performance. ${ }^{6}$

Successful countries have employed a portfolio of instruments, of interventions, in the market economy. The variety of approaches suggests that there is no one way; but the multiplicity of failures suggests that there are also many ways to fail. The difficulty of achieving a successful developmental transformation suggests that countries should not necessarily seek the optimal set of policies (whatever they might mean or entail), but rather, a politically acceptable strategy, involving a portfolio of instruments, which has a reasonable chance of success. These choices should be based on learning from the success and failures of others. One of the most important lessons to be learned, however, from those countries that have been successful is that they have learned how to conduct industrial policies as they have gone along-there has been institutional learning.

Industrial policies that work at one stage of development and in one environment do not work in another. The mere fact that an industrial policy has been successful may necessitate a change in that policy, because the circumstances of the country have changed. The world today is different than it was at the time when East Asian countries embarked on their transformation. One cannot simply follow what worked well for other countries in the past.

Thus, this chapter has not attempted to set forth a single set of prescriptionsit is not a handbook from which those seeking to pursue industrial policies can look up a set of policies appropriate to their circumstances. Rather, it is a set of principles, which I hope will guide countries as they attempt to forge a set of policies that will lead to a successful developmental transformation.

\footnotetext{
${ }^{6}$ As we have emphasized, credit/revenue constraints are likely to be particularly important, there is likely to be imperfect competition (sometimes because of increasing returns to scale and scope), and risks will be large, but risk markets will be absent. All of these were elements of standard Schumpeterian economics, and should be at the centre of endogenous growth theory and growth policy. Unfortunately, policies are often based on simplistic models, consistent with simplistic ideologies, and used by special interests to advance particular policy agenda. Schumpeter's (1942) own ideas in this area were misguided: even though he recognized that markets would be dominated by a single firm, he thought competition for the market-Schumpeterian competition-would suffice to ensure efficiency. He was wrong, as experience and theory over the subsequent half-century showed (Greenwald and Stiglitz 2014a, 2014b; Stiglitz and Greenwald 2014a, 2014b).
} 


\section{Acknowledgements}

This chapter is based on joint work with Bruce Greenwald. Research and editorial assistance from Debarati Ghosh, Poorya Kabir, and Eamon Kircher-Allen is gratefully acknowledged.

\section{References}

Arrow, K. J. (1962a). 'The Economic Implications of Learning by Doing'. Review of Economic Studies, 29(3): 155-73.

Arrow, K. J. (1962b). 'Economic Welfare and the Allocation of Resources for Invention'. In R. Nelsen (ed.), The Rate and Direction of Inventive Activity: Economic and Social Factors. Princeton, NJ: Princeton University Press and National Bureau of Economic Research (NBER).

Atkinson, A., and J. E. Stiglitz (1969). 'A New View of Technological Change'. Economic Journal, 79(315): 573-8.

Berg, A. G., and J. D. Ostry (2011). Inequality and Unsustainable Growth: Two Sides of the Same Coin?, IMF Staff Discussion Note 11/08. Washington, DC: IMF.

Berg, A. G., J. D. Ostry, and C. Tsangarides (2014). Redistribution, Inequality, and Growth, IMF Staff Discussion Note 14/02. Washington, DC: IMF.

Delli Gatti, D., M. Gallegati, B. Greenwald, A. Russo, and J. E. Stiglitz (2012a). 'Mobility Constraints, Productivity Trends, and Extended Crises'. Journal of Economic Behavior and Organization, 83(3): 375-93.

Delli Gatti, D., M. Gallegati, B. Greenwald, A. Russo, and J. E. Stiglitz (2012b). 'Sectoral Imbalances and Long Run Crises'. In F. Allen, M. Aoki, J.-P. Fitoussi, N. Kiyotaki, R. Gordon, and J. E. Stiglitz (eds), The Global Macro Economy and Finance, IEA Conference vol. 150-III. Houndmills and New York: Palgrave.

Emran, S., and J. E. Stiglitz (2009). 'Financial Liberalization, Financial Restraint, and Entrepreneurial Development'. SSRN. Available at: <http://papers.ssrn.com/sol3/ papers.cfm?abstract_id=1332399> (accessed 30 December 2015).

Greenwald, B., and J. E. Stiglitz (1986). 'Externalities in Economies with Imperfect Information and Incomplete Markets'. Quarterly Journal of Economics, 101(2): 229-64.

Greenwald, B., and J. E. Stiglitz (2006). 'Helping Infant Economies Grow: Foundations of Trade Policies for Developing Countries'. American Economic Review: AEA Papers and Proceedings, 96(2): 141-6.

Greenwald, B., and J. E. Stiglitz (2014a). 'Industrial Policies, the Creation of a Learning Society, and Economic Development'. In J. E. Stiglitz, J. Y. Lin, and E. Patel (eds), The Industrial Policy Revolution, vol. 1: The Role of Government Beyond Ideology. Houndmills and New York: Palgrave Macmillan.

Greenwald, B., and J. E. Stiglitz (2014b). 'Learning and Industrial Policy: Implications for Africa'. In J. E. Stiglitz, J. Y. Lin, and E. Patel (eds), The Industrial Policy Revolution, vol. 2: Africa in the 21st Century. Houndmills and New York: Palgrave Macmillan. 
Hirschman, A. (1958). The Strategy of Economic Development. New Haven, CT: Yale University Press.

Hoff, K. (1997). 'Bayesian Learning in an Infant Industry Model'. Journal of International Economics, 43(3-4): 409-36.

Jourdan, P. (2014). 'Towards a Resource-Based African Industrial Policy'. In J. E. Stiglitz, J. Y. Lin, and E. Patel (eds), The Industrial Policy Revolution, vol. 2: Africa in the 21st Century. Houndmills and New York: Palgrave Macmillan.

Lin, J. Y. (2012). New Structural Economics: A Framework for Rethinking Development and Policy. Washington, DC: World Bank.

Mazzucato, M. (2013). The Entrepreneurial State: Debunking Public vs. Private Sector Myths. London: Anthem Press.

Noman, A., and J. E. Stiglitz (2015). 'Economics and Policy: Some Lessons from Africa's Experience'. In I. C. Monga and J. Y. Lin (eds), The Oxford Handbook of Africa and Economics, vol. 2: Policies and Practices. Oxford and New York: Oxford University Press.

OECD (Organisation for Economic Co-operation and Development) (2015). In It Together: Why Less Inequality Benefits All. Paris: OECD Publishing.

Schumpeter, J. A. (1942). Capitalism, Socialism and Democracy. New York: Harper \& Row. Solow, R. M. (1957). 'Technical Change and the Aggregate Production Function'. Review of Economics and Statistics, 39: 312-20.

Stiglitz, J. E. (1987). 'On the Microeconomics of Technical Progress'. In J. M. Katz (ed.), Technology Generation in Latin American Manufacturing Industries. New York: St. Martin's Press.

Stiglitz, J. E. (1999). 'More Instruments and Broader Goals: Moving Toward the PostWashington Consensus'. In G. Kochendorfer-Lucius and B. Pleskovic (eds), Development Issues in the 21st Century. Berlin: German Foundation for International Development.

Stiglitz, J. E. (2012). The Price of Inequality: How Today's Divided Society Endangers Our Future. New York: W.W. Norton.

Stiglitz, J. E. (2013). 'Macroeconomic Fluctuations, Inequality, and Human Development'. Journal of Human Development and Capabilities, 13(1): 31-58.

Stiglitz, J. E. (2015). Rewriting the Rules of the American Economy: An Agenda for Growth and Shared Prosperity. New York: W.W. Norton.

Stiglitz, J. E., and B. Greenwald (2014a). Creating a Learning Society: A New Approach to Growth, Development, and Social Progress. New York: Columbia University Press.

Stiglitz, J. E., and B. Greenwald (2014b). Creating a Learning Society: A New Approach to Growth, Development, and Social Progress: Readers' Edition. New York: Columbia University Press.

Stiglitz, J. E., and J. Y. Lin (eds) (2014). The Industrial Policy Revolution, vol. 1: The Role of Government beyond Ideology. Houndmills and New York: Palgrave Macmillan.

Stiglitz, J. E., and A. Weiss (1981). 'Credit Rationing in Markets with Imperfect Information'. American Economic Review, 71(3): 393-410.

Stiglitz, J. E., J. Y. Lin, and E. Patel (eds) (2014). The Industrial Policy Revolution, vol. 2: Africa in the 21st Century. Houndmills and New York: Palgrave Macmillan.

World Bank (1999). World Development Report 1998-99: Knowledge for Development. New York: Oxford University Press. 


\title{
3
}

\section{Coordination through an Asian Lens}

\author{
Justin Yifu Lin and Khuong Minh Vu
}

\subsection{Introduction}

Much has been written about the success of Asian economies and the lessons this success offers to developing countries. Among the most comprehensive studies about this topic are The East Asian Miracle (World Bank 1993) and The Growth Report (World Bank 2008), compiled by the Growth Commission, a group led by two Nobel laureates in Economics (Robert Solow and Michael Spence). The East Asian Miracle examines key policy factors underlying the superior performance of eight high-performing Asian economies (HPAEs) between 1965 and 1990; these include Japan, the 'Four Tigers' (Hong Kong, South Korea, Singapore, and Taiwan), and three newly industrializing countries (Indonesia, Malaysia, and Thailand). The Growth Report investigates the stylized facts in an exhaustive list of the world's most successful economies, selected on the basis of their high gross domestic product (GDP) growth rate (7 per cent or more) for a minimum of twenty-five years in the past six decades. This list contains the eight HPAEs, China, and four non-Asian economies (Botswana, Brazil, Malta, and Oman). Together, the two publications identify the important features of successful Asian economies:

i. Fully exploiting the world economy; rapid growth of exports to which manufactured products make the most contribution;

ii. Maintaining macroeconomic stability;

iii. Relying on markets for allocation of resources;

iv. Promoting output and productivity growth in the agricultural sector and its rapid reallocation of resources to other sectors;

v. Mustering high investment and saving rates, with savings exceeding investment; 
vi. Fostering robust human capital formation, for which systems of education and training have experienced dramatic growth and transformation;

vii. Keeping income inequality low while successfully reducing poverty;

viii. Having committed, credible, and capable governments.

This chapter argues that these lessons are particularly meaningful and applicable for low-income countries such as those in sub-Saharan Africa (SSA). Profound changes in the world economy over the past few decades have generated currently favourable conditions for low-income countries to make strides in economic growth. In particular, the widespread diffusion of information and communications technology (ICT) and unrelenting waves of globalization have become major drivers of growth, facilitating unprecedented access to information and knowledge, acquisition of technology and know-how, and formation and development of human capital. Furthermore, in most SSA countries human capital-the main engine of economic growthhas now risen to levels comparable if not higher those in successful Asian countries at their initial stages of development (Figure 3.1).

Therefore, challenges facing the efforts of SSA countries to catch up economically now depend more on the commitment and wisdom of their

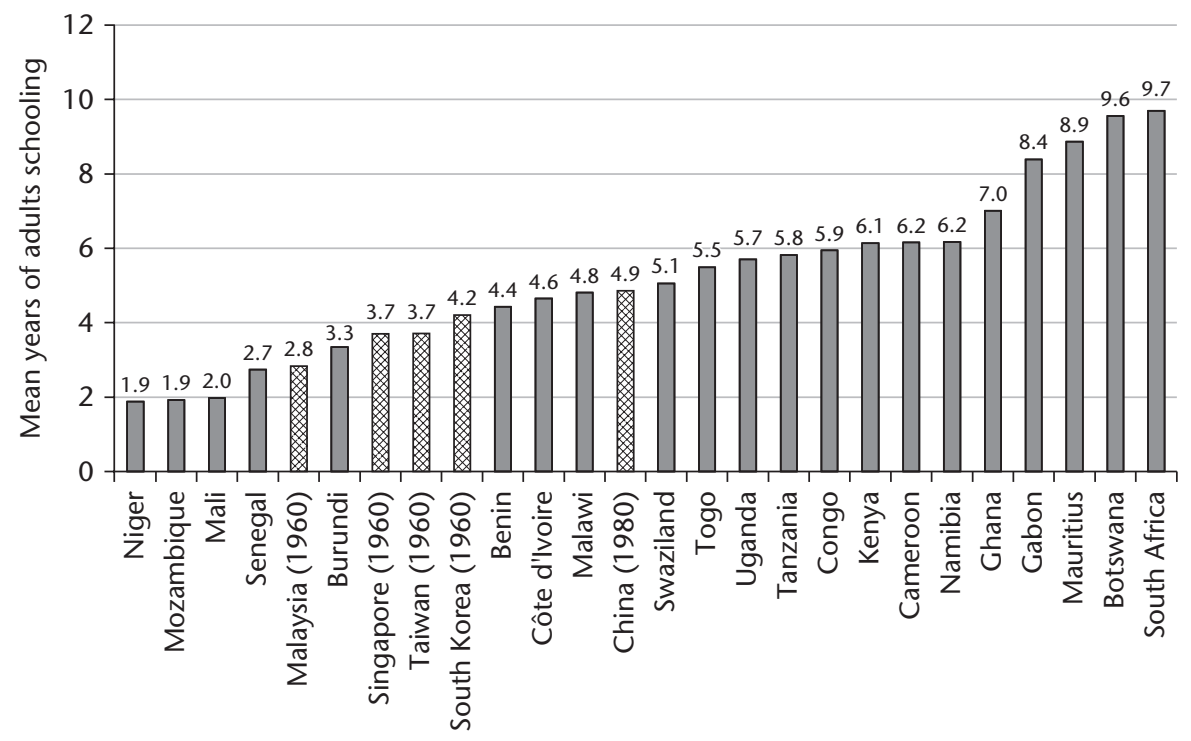

Figure 3.1. Educational attainment: SSA in 2010 vs Asia at the beginning of rapid development

Source: Authors, based on Barro and Lee (2013). 
leadership than on the status of their basic conditions for growth or external environments. The lessons from East Asian development success can be a valuable source of wisdom for African leaders. As Lucas (1993: 270) states, 'If we know what an economic miracle is, we ought to be able to make one.' The challenge, however, is how to help African leaders and governments more deeply understand the nature of Asia's economic growth miracle and more thoroughly master the policy framework for applying its lessons. In this spirit, this chapter aims to provide insights into the nature of the Asian economic miracle and its policy framework through the perspective of new structural economics and the relevant experiences of successful Asian countries.

This chapter proceeds as follows. Section 3.2 highlights the recent dynamics of economic growth in SSA countries and discusses their potential to accelerate the growth process. Section 3.3 briefly introduces the principles of new structural economics, enabling a better understanding about the nature of economic growth and the lessons of successful Asian countries. Section 3.4 presents a strategic framework that underlies the efforts of successful Asian countries to foster economic growth and catch-up endeavours. Section 3.5 makes concluding remarks.

\subsection{Economic Growth in SSA Countries and Potential for Economic Catch-Up}

Growth in SSA countries has been trending upwards over the past few decades. The region's ten-year moving average (10-YMA) of GDP growth rates accelerated significantly between 1990 and 2010: by 2 percentage points, from 2.3 per cent in 1990 to 4.2 per cent in 2012 for the median; by 1 percentage point, from 4 per cent to 5 per cent for the 75 th percentile; and by 2.7 percentage points, from 0.9 per cent to 3.6 per cent for the 25 th percentile (Figure 3.2). This observation suggests that laggard countries (25th percentile) tended to improve their performance more substantially than top-performing countries (75th percentile).

SSA countries' per capita GDP growth has also experienced an upwards trend. The region's 10-YMA of GDP per capita growth rates rose between 1990 and 2010: by 2.1 percentage points, from -0.5 per cent in 1990 to 1.6 per cent in 2012 for the median; by 2.5 percentage points, from 0.9 per cent to 3.3 per cent for the 75 th percentile; and by 2.9 percentage points, from -2.0 per cent to 0.9 per cent for the 25 th percentile (Figure 3.3). It should be noted that the 10-YMA of GDP per capita growth rate for the 25th percentile was not positive until 2003. This indicates that laggards among SSA countries suffered from decrease in their GDP per capita until the most recent decade. 
GDP Growth (10-YMA)

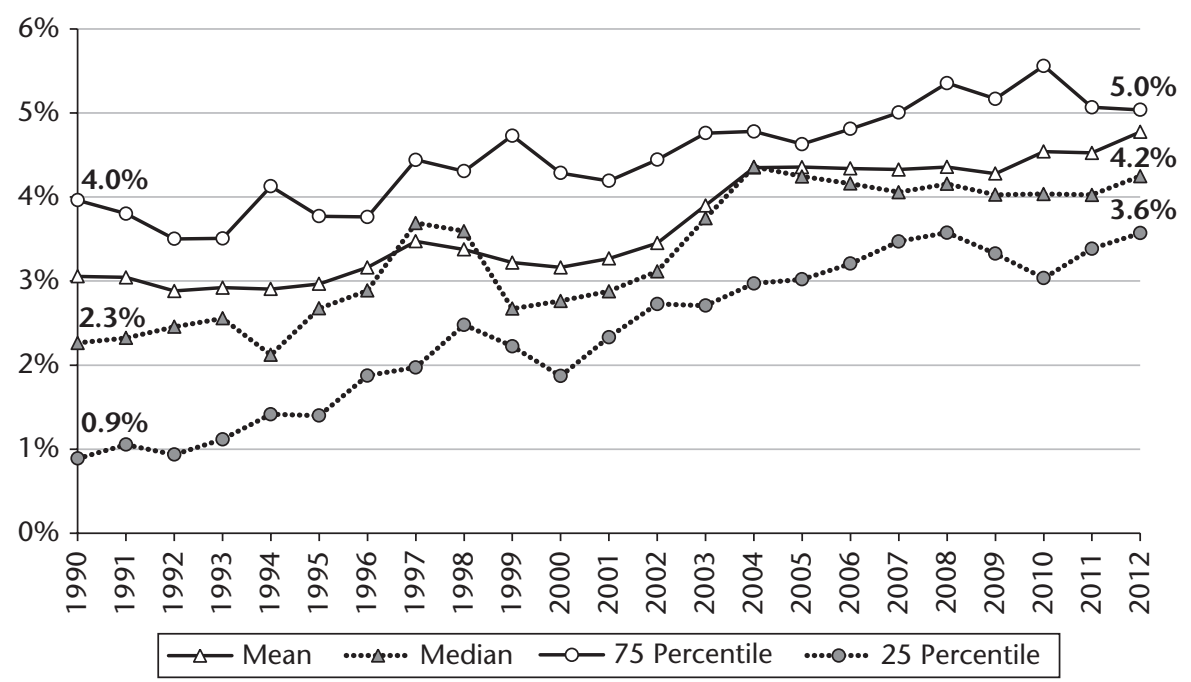

Figure 3.2. SSA countries and GDP growth trends

Source: Authors, based on World Bank (2016).

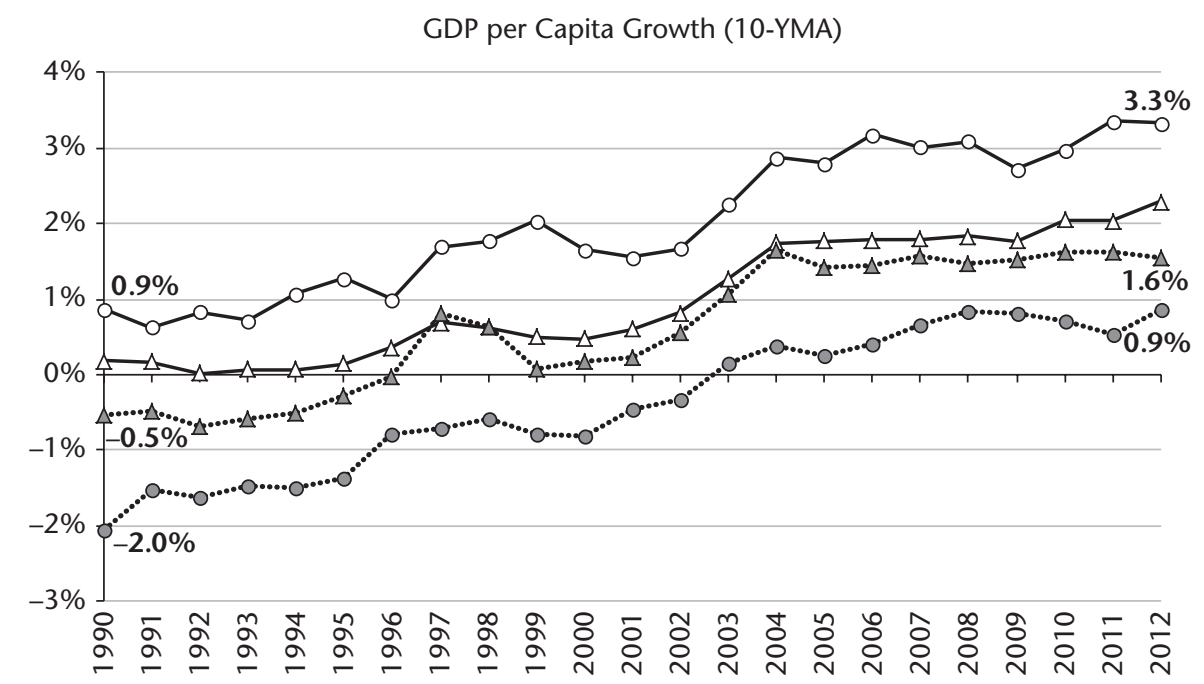

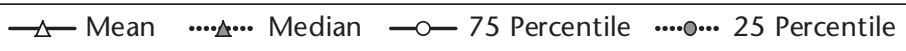

Figure 3.3. SSA countries and GDP per capita growth trends Source: Authors, based on World Bank (2016). 


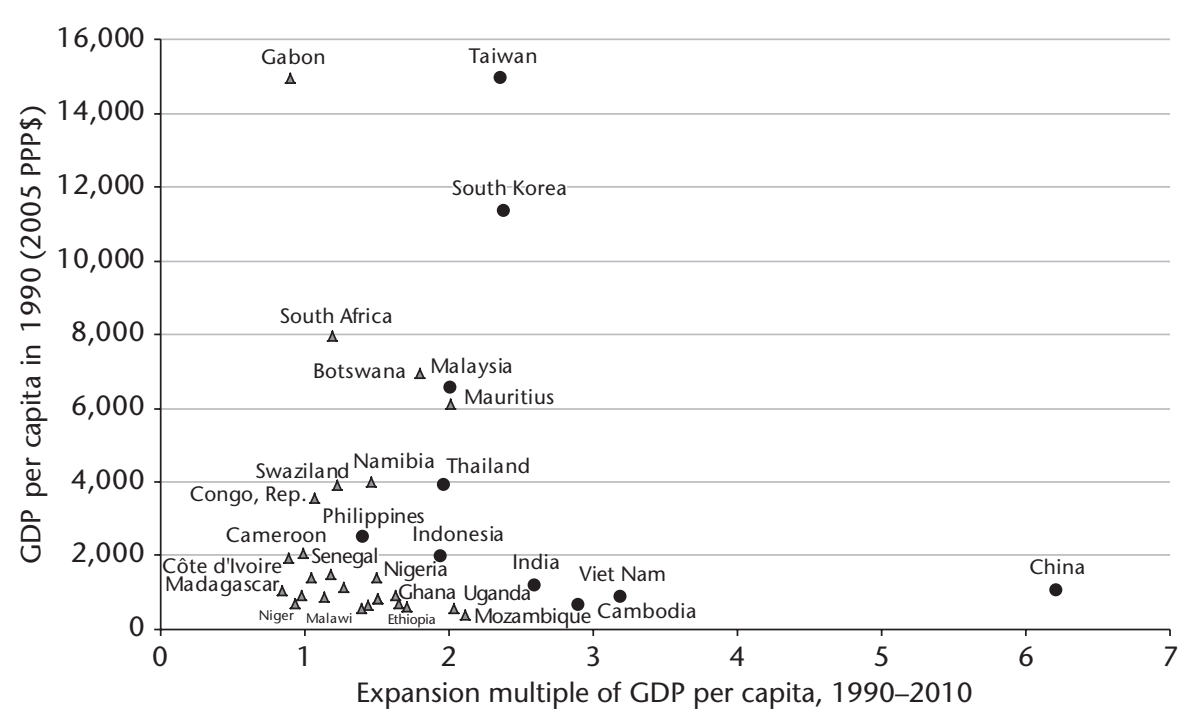

Figure 3.4. Catch-up performance, 1990-2010: SSA vs developing Asia Source: Authors, based on World Bank (2016).

Although SSA countries have experienced increasing economic growth, their catch-up performance continued to lag Asian economies over the same period. The per capita GDP of four Asian countries-China, Viet Nam, India, and Cambodia-was equivalent to that of SSA countries in 1990 (Figure 3.4). However, these four Asian countries raised their income levels by a comparatively higher multiple between 1990 and 2010: China by 6.2 times, Viet Nam by 3.2, Cambodia by 2.9, and India by 2.6. In contrast, over the same period most SSA countries raised income by multiples of only 1.0 to 2.0 (Figure 3.4).

One of the most significant obstacles to the economic growth of SSA countries is its inability to create conditions necessary for exploiting comparative advantages and fostering structural change. In particular, SSA countries notably are facing premature de-industrialization. As shown in Figure 3.5, their average employment share of the industry sector in the economy was lower in 2000 compared with that in the previous year although it was still very low compared to most developing countries.

In summary, the data suggest that SSA countries are experiencing encouraging trends in economic growth. However, major obstacles, which prevent these countries from achieving the robust industrialization and economic growth, remain. It would be helpful for policy makers in SSA countries to better understand the nature of a rapid economic growth process and the experience of successful Asian countries in making it happen. 


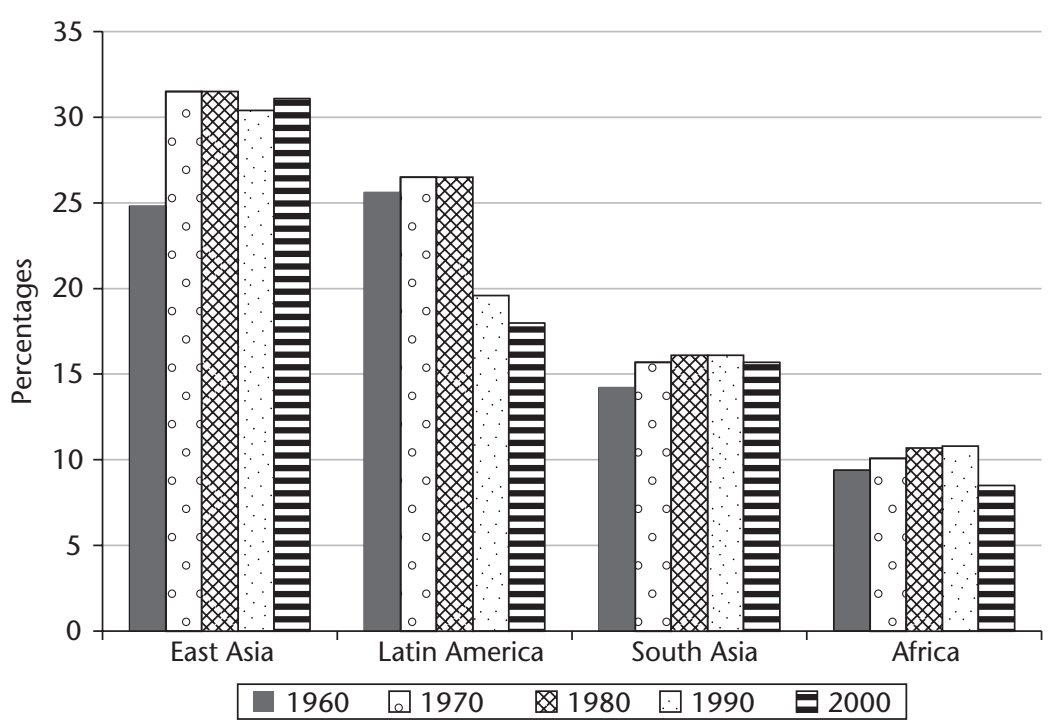

Figure 3.5. Employment share of the industry sector in the economy Source: Authors, based on World Bank (2016).

\subsection{Mastering the Principles of New Structural Economics to Achieve High Sustained Growth}

Mastering the principles of new structural economics can help scholars discern the nature of economic growth and understand why some countries have generated economic miracles. New structural economics, as depicted by Lin (2011, 2012a) can be characterized by three principles: (i) each country at a given time has a certain comparative advantage defined by the evolving potential of its endowment structure in the context of globalization; (ii) to best exploit its comparative advantage for economic development, a country must rely on the market as the optimal resource allocation mechanism at any given stage of development; and (iii) the state can play a proactive role in facilitating the process of industrial upgrading, especially for coordinating/ providing improvements in enabling factors, such as infrastructure, financing, and the promotion of entrepreneurship, clustering, innovation, and foreign direct investments (FDI). New structural economics underscores the idea that a country can grow more rapidly if it better leverages the comparative advantage of an evolving endowment structure at every stage of development and capture the benefits of advantages of backwardness. At the same time, it needs 
to make every effort to foster structural change, shifting resources such as labour, capital, and land to higher productivity activities, users, and sectors. These transformational dynamics enable the country to continuously upgrade its comparative advantage and achieve high economic performance.

\subsection{A Strategic Policy Framework for Fostering Economic Development through Structural Change}

Sustained robust economic development is a transformational process. As argued in new structural economics, it requires effective coordination in fostering structural change to reorient resources towards higher productivity users, sectors, and locations. Successful experiences from Asian countries imply the presence of an effective strategic policy framework, which developing countries can apply to design and implement concerted initiatives for promoting structural change and economic development by facilitating private sectors' development in industries that are consistent with the countries' comparative advantages. This framework consists of five components, which can be referred to as the 'ASIAN framework': (i) Aspiration; (ii) Strategy; (iii) Implementation; (iv) Acquisition of knowledge; and (v) Nurture of human capital formation.

\subsubsection{Aspiration}

Aspiration to catch up is crucial trait for poor nations seeking to leverage growth opportunities in the new global economy. This aspiration inspires a country to adopt ambitious development goals. When based on a robust understanding of the country's comparative advantages and global trends, this ambition is not only the compass for the development process but also a powerful source of energy and dynamism ( $\mathrm{Vu}$ 2013). This is particularly applicable in efforts to restructure from low- to high-endowment structures. Leadership's articulation of the aspiration to catch up in economic development has been a common feature of proactive, commitment governments in Asian countries that have been successful in their development endeavours.

\subsubsection{JAPAN}

In the mid-19th century, the Meiji leaders of Japan were shocked by the superiority of Western military powers and the lingering threat of foreign dominance. The leaders aspired to build a new Japan characterized by strength and influence in the modern world. The Charter Oath, which the Meiji leaders drafted in 1868, expressed a resolute aspiration and determination to succeed 
in this effort through 'enlightened ruling' (Meiji) and vigorous efforts to acquire knowledge throughout the world (Jansen 2000).

\subsubsection{KOREA}

President Park Chung Hee admired Japan for its Meiji Restoration (1868-1912). He expressed a burning aspiration to transform South Korea into a second Japan: 'I am pushing for the modernization of my country as the modernizing elite of the Meiji Restoration did' (Moon and Jun 2011: 118).

Park Chung-Hee also aspired to learn from West Germany, admiring the country's revival after the Second World War. In a speech before his visit to West Germany in 1964, Park stated: 'I intend to witness first-hand the revival of West Germany, a country which has emerged from the ashes of the Second World War as a prosperous nation that has achieved outstanding economic development' (O 2009: 80).

\subsubsection{SINGAPORE}

Beginning in the early 1960s, Prime Minister Lee Kuan Yew and his leadership team harboured a strong desire to grow quickly and comprehensively, consulting with experts and producing a development model that has since proven remarkably effective. Lee Kuan Yew's aspiration was to make Singapore into a 'First World oasis in a Third World' by establishing 'first world standards in public and personal security, health, education, telecommunications, transportation, and services' (Lee 2000: 76).

He also deepened his commitment to build a distinctive and resilient Singaporean character. According to then-Prime Minister Lee, 'We had to make extraordinary efforts to become a tightly knit, rugged and adaptable people who could do things better and cheaper than our neighbors [...]. We had to be different' (Lee 2000: 24).

\subsubsection{CHINA}

The Communist Party of China (CPC) embarked on transformational economic reforms in 1978 with the aim to 'advance courageously to make a fundamental change in the backward state of our country so that it becomes a great, modern, socialist power'. ${ }^{1}$

Setting a high aim is important not only during the inception of reforms but also at critical junctures of the economy's transformation. In 1992, the conservative faction of the CPC feared that China would deviate from its socialist goals, ultimately launching a series of attacks against reform and calling for the elimination of special economic zones. Nevertheless, Deng Xiaoping

1 CPC (1978). 
rallied support for the acceleration of reforms during a trip to Southern China in January 1992, emphasizing China's falling far behind many neighbouring nations and making it clear 'we must seize every opportunity to make the country develop quickly. We have a good opportunity now; if we fail to seize it, it will be gone very soon.' ${ }^{2}$

\subsubsection{VIET NAM}

The recent success of Viet Nam owes much to opportunities generated by ICT, and can serve as an example for how the aspiration of committed leadership can enable a country to quickly seize technology trends in upgrading its endowment structure. Due to this strong ambition and unwavering commitment, the Vietnamese leadership has also been more decisive in dismantling the monopolistic structure in this industry, promoting competition in the private sector and modernizing ICT infrastructure. As a result, in scarcely more than a single decade Viet Nam transformed its dilapidated telecommunication system and negligible ICT production capacity into a highly competitive digital infrastructure, creating a vibrant hub of global ICT manufacturing and outsourcing ( $\mathrm{Vu}$ and Austin 2014).

\subsubsection{Strategy}

After establishing clear and ambitious goals for development, a country needs to formulate an effective strategy to achieve them. An economic development strategy can be seen as a set of tactical choices and guiding principles in pursuit of such goals. At the core of this strategy are the strategic directions, critical economic sectors, major thrusts, and priorities that the country should identify and articulate in order to fully exploit its comparative advantage, fostering structural change and economic growth. ${ }^{3}$

To formulate an effective economic strategy, a country should first thoroughly understand its core competencies and the comparative advantages associated with its current endowment, along with global opportunities and challenges, and major technological and socio-economic trends (Lin 2009, 2011, 2012a). The formulation of an effective economic strategy requires a strong political commitment from top leadership and vigorous engagement of all stakeholders. The strategy must be an indigenous product of the country, firmly rooted in a unique context and informed by feedback from the government, businesses, think tanks, other experts, professionals, and

\footnotetext{
2 Deng's remarks on his trip to the Southern China in 1992, cited in Marti (2002: 104).

3 Page (2012) argues that Africa countries need a strategy for breaking into the global industrial economy, which is focused on three interrelated strategic objectives: tilting towards exports, building capabilities, and encouraging agglomeration.
} 
labour representatives. A strategy is less likely to be effective if it is merely the product of a consulting firm, international organization, or individual government agency.

An effective economic strategy plays a crucial role in identifying the country's comparative advantage associated with its evolving endowment structure and proposing strategic directions and priorities for fostering structural change in an economy. ${ }^{4}$ The formulation of an effective strategy is characterized by three features. First, a strategy aligns the country's economic development efforts across sectors and regions, strengthening their coherence, consistency, efficiency, and coordination effectiveness. For a large developing country, the government may jumpstart the dynamic growth process by pragmatically creating localized enabling environment in industrial parks/ zones for industries of the country's comparative advantages, extending the improvements across regions and sectors gradually in line with the government's available resources and implementation capacity. Second, a strategy enables the country to more effectively monitor and evaluate progress in economic development; hence, it fosters learning, reflection, and adaptability. Finally, a strategy induces businesses and workers to embrace change and prepare for rapid modernization towards a world-class status.

In addition to sound economic strategies, a country also needs systematic and recurrent reviews and reforms to enhance the relevance and effectiveness of such strategies, given the rapid changes in external economic circumstances and the continuing evolution of a country's endowment structure. The review of an economic strategy tends to be more robust when the country's economy faces challenges, as leaders can develop a deeper understanding about emerging economic trends and the forces behind them. On these occasions, the country also has a greater determination to undertake decisive changes and politically contentious restructuring efforts to foster economic competitiveness and transformation. As a country, for which economic success heavily relies on the soundness of its strategy, ${ }^{5}$ Singapore provides a good

\footnotetext{
${ }^{4}$ Only if an industry is consistent with a country's comparative advantages determined by its endowment structure will the industry have the lowest possible factor costs of production. However, to be competitive in the global market, what matter are the total costs, which consist of both factor costs of production and transaction costs. It is thus essential for the state to coordinate or provide the necessary improvement in hard and soft infrastructure to reduce the transaction costs in order to turn a country's comparative advantages into competitive advantages (Lin 2012a, 2012b).

${ }^{5}$ Singapore's effective strategy has transformed Singapore one of the globally fast-growing and most resilient economies in the past five decades. With a population of 5 million and area of 700 $\mathrm{km}^{2}$, Singapore has become a global hub of a variety of industries and services, including aerospace, electronics, chemicals, pharmaceutical, marine, and tourism.
} 
example of such efforts. The government vigorously reviewed existing strategies when the economy was impacted by external shocks associated with major changes in the global and regional economic landscapes:

- 1985 (amidst economic recession): the Economic Committee was established to stimulate Singapore's economy and identify new directions for growth.

- 1991 (seizing momentum): after twenty-five years of rapid development, Singapore drafted the Strategic Economic Plan (SEP) to formulate strategies and programmes for lifting the country to first league developed nation status within thirty to forty years.

- 1997 (Asian financial crisis): the Committee on Singapore's Competitiveness (CSC) was formed to propose strategies for reviving the country's economy and strengthening its competitive position.

- 2001 (amidst the global downturn caused by the 2000 dotcom bust and the 9/11 terrorist attacks): the Economic Review Committee (ERC) was established to address the downturn and shape the direction of Singapore's economy over the following fifteen years.

- 2009 (the global financial crisis): the Economic Strategies Committee (ESC) was established with the mission to develop strategies for Singapore's economic growth in the new global environment.

- 2016 (productivity growth stagnation): the Committee on the Future Economy (CFE) was established to find the direction for Singapore's future economic development.

\subsubsection{Implementation}

A sound economic strategy requires effective implementation to produce desirable outcomes. This requires strenuous efforts in building execution capacity, creating an enabling environment, and ensuring the availability of financial resources for strategic implementation. The process also needs an effective monitoring and evaluation mechanism to closely track progress and inform performance assessments for individual initiatives. This mechanism should be participatory, practical, and reflective, involving intensive learning and adaptation. With effective implementation of a sound economic development strategy, a country can more fully exploit its potential, enhance its resilience against external shocks, and rapidly upgrade its endowment structure.

Putting an economic strategy into a concerted course of action requires not only a strategic vision but also operational skills, not only long-term commitment but also quick responses to change, and not only careful deliberation of implementation measures but also effective management of performance. As 
such, a developing country lacking experience in such growth initiatives needs a highly competent organization to meet the demanding requirements of developmental effectiveness, particularly regarding the effective implementation of economic strategies.

Institutional initiatives that establish and support highly competent organizations dedicated to coordinate efforts for industrial diversification and upgrading, efficiency and productivity improvement, and export promotion, are critical to the success of a developing country's industrial policy implementation. The experiences of successful Asian economies during their 'miracle years' provided exemplary examples. ${ }^{6}$ For Japan, the Ministry of Industry and Trade (MITI), Economic Planning Agency (EPA), and Ministry of Finance (MOF) are considered the key drivers of its economic miracle during 1950 to 1990. In particular, the MITI, in robust consultation with business associations, set up three clear criteria for selecting strategic industries: high-income elasticity, technological progress, and productivity growth. At the same time, EPA focused on monitoring the progress of structural change and productivity growth. Its analysis and policy deliberation help the government make more informed decisions in resource allocation.

South Korea established in the 1960s important vehicles for implementing industrial policy, which ranged from the Korea Institute of Science and Technology (KIST) to the Ministry of Science and Technology (MOST) to Export Promotion Conferences. The KIST was active in helping local firms adapt foreign technology, while MOST effectively coordinated national technology policies.

For Taiwan, the Ministry of Economic Affairs (MOEA) and its affiliated organizations such as the Technology Advisory Committee (TAC) and Industrial Technology Research Institute (ITRI) were behind Taiwan's concerted efforts to transform its industries from textiles and apparel, toys, and agriculture into machinery, petrochemicals, electrical equipment, and electronics. In fact, ITRI was the major contributor to coordinating Taiwan's efforts to become a leading player in the semiconductor and computer industries (Box 3.1).

\footnotetext{
${ }^{6}$ It is also important to point out the recent examples of the agencies/committees in charge of strategy implementation coordination in other Asian countries: Performance Management \& Delivery Unit (PEMANDU) of Malaysia (in taking charge of implementing and monitoring the progress of the Economic Transformation Programme); the Committee on Economic Development Acceleration and Expansion of Indonesia (in charge of coordinating the implementation of the Master Plan for the Acceleration and Expansion of Indonesia's Economic Development); the National Development and Reform Commission (NDRC) of China (for strategizing, coordinating, and monitoring economic reforms); and the National Steering Committee on ICT of Viet Nam (for promoting ICT development).
} 
Box 3.1. THE ITRI'S ROLE IN TRANSFORMING TAIWAN INTO A HIGH-TECH INDUSTRIAL STRUCTURE

The ITRI was founded in 1973 by the government of Taiwan with the mission to help Taiwan acquire and develop cutting-edge technologies, and to transfer them to local firms for commercialization. ITRI is a non-profit $R \& D$ organization under the supervision of MOEA. At its initial stage, ITRI was fully funded by the government.

When ITRI was founded, Taiwan's industry was based on a low-tech structure and dominated by SMEs. Given this reality, domestic and foreign experts at the time believed that a sole reliance on individual enterprises would not allow Taiwan to rapidly develop its high-tech industries, which was essential for Taiwan to succeed in economic development. The establishment of ITRI, therefore, would play a vital role in bridging academic research and commercialization.

In focusing for thirty years (1973-2003) on knowledge acquisition and development for commercial use, ITRI has made exemplary contributions to transforming Taiwan into a world-class developer of semiconductors, personal computers, and other high-tech products.

Sources: Hsu (2005), Chu et al. (2006).

For Singapore, the Economic Development Board (EDB), which has been considered as a major driver of Singapore's economic transformation offers valuable lessons for how a government agency can be a leading driver in implementing a strategy for economic growth and transformation. The lessons include:

1. A developing country should establish an organization dedicated to implementing the country's economic strategy. The organization should have its own clear and well-articulated operational strategy that details the implementation element of the country's economic strategy. The organization should also have business-like flexibility and a special mandate from the government for high effectiveness.

2. The government must take special care in appointing the head of this organization. This person must be well respected for his/her integrity, wisdom, and success in past management engagements. Moreover, this person, according to Schein (1996), must have the motivation and capability to bring out the best from his/her people.

3. The organization should recruit the brightest and best young people from all sectors and inspire them with a mission to help the country escape poverty and advance towards prosperity.

4. As a major link between the government and the business community, the organization must excel in five C-qualities: commitment, competence, credibility, communication, and coordination: 
(i) Commitment is a strong sense of mission and high moral standards.

(ii) Competence is not only defined by high professional standards but also a clear mandate from government leaders and an enabling organizational structure. ${ }^{7}$

(iii) Credibility is a reputation for incorruptibility, honesty, and consistency. ${ }^{8}$

(iv) Communication must occur between the government and investors, and should be characterized by a high level of responsiveness, intensive consultation, and clarity of the organization's strategic intent. 9

(v) Coordination embodies the close link between the organization and other government agencies, and the organization's ability to drive coordinated efforts among agencies in implementing the country's economic strategy.

\subsubsection{Acquisition of Knowledge}

\subsubsection{STRONG COMMITMENT TO LEARNING}

Acquiring knowledge is an essential tool for a developing country to enhance the effectiveness of its coordinated efforts throughout the course of development. Acquiring knowledge is not confined only to importing technology and know-how, but includes learning from international best practices. Furthermore, invaluable knowledge and wisdom can be derived from experimentation, benchmarking against the best performers, and a commitment to continuous improvement. ${ }^{10}$

The successful Asian countries have proven to be great learners, effectively exploiting their 'backwardness' advantage and leveraging their aspiration to catch up. ${ }^{11}$

${ }^{7}$ Like other Singapore government agencies, the EDB used the HAIR framework (Helicopter quality, Analytical skills, Imagination, and Reality) for assessing the competence of its staff.

8 According to Schein (1996), the EDB impressed foreign investors by having clear rules and a commitment to keeping promises; they were determined to meet the needs of investors without compromising their own values and rules; they gained respect of investors for being efficient without being either expedient or corrupt.

9 Schein (1996: 187) noted that the most salient characteristics of the EDB officers is their ability to communicate orally and in writing, ... think things out, articulate one's conclusions and sell them to others'.

${ }^{10}$ See Yeung et al. (1999) provides a rich discussion on this topic.

11 The concept of 'backwardness' advantage was first introduced by Gerschenkron (1962). It has been one of the major comparative advantages low-income countries must fully exploit to succeed on their catch-up endeavours (Lin 2003, 2009, 2012a, 2012b). 


\section{Japan}

Seeking knowledge throughout the world to build a foundation for the country's future was a guiding principle of the Meiji government, as set forth by the 1868 Charter Oath. In putting its strategies into action, the Meiji government dispatched a mission of fifty high-ranking officials to the United States and Europe for a twenty-two-month journey (December 1871 to September 1873) focused on discovering models and lessons for modernization. Remarkably, those on the mission had their jobs available for them when they returned.

As pointed out by Jansen (2000: 360 ), the lessons drawn by the mission were clear and thoughtful, which advocate for Japan focus its learning on American education, British industrialization, French jurisprudence, and German representational institutions.

The Meiji government was also proactive in acquiring knowledge through consultation with foreign experts. For example, Mori Arinori, a diplomat in Washington who later became the architect of the Meiji education system, invited leading American educators to submit their views about how Japan might best build its foundation for prosperity. In his 1873 reply, David Murray, who was a professor at Rutgers College in New Jersey, argued that Japan could be built into 'an equally colossal commercial power' in Asia, as England was to Europe. David Murray was then immediately invited to Japan as adviser to the new Ministry of Education (Jansen 2000: 357).

At the same time, Meiji leaders made laborious efforts to enhance the quality of their decisions concerning policy formulation and institution-building. Throughout this process, they vigorously embraced debate and reflected openly about alternative strategies and implementation efforts. The design of the Meiji state, as a result, was not rigidly established at the beginning but took shape throughout the state's growth (Jansen 2000: 412).

\section{Korea}

Park's government stressed the importance of mobilizing the wisdom and knowledge of scholars in formulating Korea's economic development plans. The government used this approach in the preparation of its first Five-Year Economic Development Plan (FYEDP) (1961-5), treating the approach as a strategic means to enlighten economic development strategy and stimulate the engagement of the country's scholars in national development endeavours. Park organized a planning committee, of which university professors and experts with specialized knowledge played an important role, to mobilize the maximum available expertise for government administration and policymaking, while holding in check the arbitrariness and rashness of the military officers (Park [1971] 2009: 107-8). 
Park himself made relentless efforts to learn. He was 'open to new ideas and capable of transforming them into a detailed workable action programme' and 'studied hard to learn about economic issues and to discover ways to bring about economic development' (Kim and Park 2011: 278). Park was described as a man 'busy studying Japan ... he frequently took clippings from Japanese newspapers and read The History of the Japanese Economy until midnight. A great portion of Park's modernization policy emerged from the emulation of Japan. He compared South Korea's economic situation to that of Japan all the time' (Moon and Jun 2011: 120).

Korea's export expansion meeting, organized and chaired by Park every month since 1965 for nearly fifteen years, was evidence of the Park administration's efforts to enlighten its development strategy with knowledge from experts and lessons from practice. Participants from the governmental, industrial, and academic sectors engaged in vibrant discussions with a shared purpose to devise the best possible solutions. The decisions made during these meetings incorporated the comprehensive and diverse views of participants, and were given top priority (O 2009: 103-4).

\section{Singapore}

Robust acquisition of knowledge has been a prominent feature of Singapore's development strategy throughout the country's brief but remarkable history of economic transformation. As Lee Kuan Yew shared that his government knew little knowledge about how to govern and how to solve economic and social problems when it came to office in 1959 and that their one formula for our success was to constantly study how to make things work, or how to make them work better. His government's learning was based on a few principles: never make a mistake twice and climb on the shoulders of others who have gone before (learn from world best practices and learn from the mistakes others have made) (Lee 2000: 758-9).

Goh Keng Swee, the main architect of Singapore's economy, listed the capability to learn from others as a key ingredient of the country's success. He asserts that Singapore was eager to learn and adapt, not imitate without thinking, on every challenge they faced, from building the metro system to setting up the air force. ${ }^{12}$

Benchmarking has also been a distinct feature of Singapore in its effort to promote economic development. For example, the EDB always 'benchmarks against the very best, it commits to being world-class, and it borrows whatever is best' (Schein 1996: viii).

12 Straits Times (1984). 


\section{China}

China's effort to acquire knowledge is also remarkable, especially regarding experimentation. According to Heilmann (2008: 3), policy experimentation is defined as 'a purposeful and coordinated activity geared to producing novel policy options that are injected into official policymaking and then replicated on a larger scale, or even formally incorporated into national law'. China's policy experimentation has ranged from the establishment of special economic zones to the introduction of trial regulations. During the first two decades of China's economic reforms, over 30 per cent of the government's new regulations were conducted under experimental status (Heilmann 2008).

\subsubsection{ABSORPTIVE CAPABILITIES OF FIRMS}

The acquisition of knowledge is not only vital for the government to improve its performance, but also essential for the private sector to prosper. The vibrancy of the private sector, especially among small and medium-sized enterprises (SMEs), in acquiring knowledge depends on its absorptive capabilities, as determined by three key factors: mindset, competence, and facilitating and incentive mechanisms.

Fostering the type of mindset change that establishes a positive attitude towards learning is a fundamental beginning step. This is not an easy task, especially in poor countries where many tend to think that experiences from successful nations are exceptional and therefore irrelevant.

Enhancing the competence of the private sector is the next step; this includes investing in education, providing support in training, promoting knowledge diffusion, and encouraging learning by doing. Cohen and Levithan (1990: 128) assert that firms' acquisition of knowledge depends on their prior related knowledge, which determines their 'ability to recognize the value of new information, assimilate it, and apply it to commercial ends'. It is also important to note that enhancing the competence of a firm in absorbing tacit knowledge and working practices may enable it to more easily acquire hard knowledge in new technology (Lundvall and Johnson 1994; Von Hippel 1994).

Facilitating and incentive mechanisms coordinated by government play a direct and important role in firms' effort to acquire knowledge, particularly in research and development (R\&D) activity. These mechanisms range from fostering knowledge diffusion to consultancy supports, and from financial support schemes to fiscal incentives.

Singapore's productivity movement provides a good example of the effective role of government in fostering the private sector to acquire knowledge for improvements and growth. The Singapore productivity movement was launched in September 1981 by then Prime Minister Lee Kuan Yew. With effective institutional arrangements and creative policy initiatives, this 
movement has sustained vigorous efforts to promote acquisition of knowledge and adoption of best practices across sectors and companies in order to transform Singapore to a higher productivity economy. To prepare for the launch of the productivity movement, a committee assigned by the government prepared a report about productivity, entitled 'Report of the Committee on Productivity' and released in June 1981. The report thoroughly analysed Japan's promotion experiences in productivity enhancement, work attitude, and labour-management relations. In its recommendations, the study emphasized the importance of human aspects associated with mindset change, and proposed the establishment of a high-level council to review productivity efforts and outline future strategy. Singapore's success on this drive shows that emphasizing mindset change, fostering performance benchmarking, and vigorous support for training are the effective ways to key enhance firms' absorptive capabilities.

\subsubsection{Nurturing Human Capital Formation}

As Lucas (1993: 270) argues, 'the main engine of growth is the accumulation of human capital — of knowledge - and the main source of differences in living standards among nations is differences in human capital'. Human capital plays an important role in both enabling and driving the structural change of an economy. With availability of higher skilled labour, firms are enabled and even lured to move to higher value-added activity. Vibrant human capital formation also enhances the absorptive capabilities of firms and society and fosters their learning and innovation. This helps the economy produce more output with fewer resources and sustain efforts to upgrade production capacity. As a result, investing in education is expected to be an important measure to promote economic growth. Figure 3.6, which show a significant positive relationship between improvement in education (measured in average schooling years of population aged 15 or older ${ }^{13}$ ) and GDP growth over the five-decade period 1960-2010, ${ }^{14}$ can lend support to the important role of education in driving growth. In particular, all five economies with GDP growth exceeding 7 per cent (Botswana, China, Singapore, South Korea, and Taiwan) increased their average schooling of population aged 15 or older by at six years over this period. ${ }^{15}$

\footnotetext{
13 From Barro and Lee Education Dataset, available at <http://www.barrolee.com/>, accessed 15 March 2016.

${ }^{14}$ To make it more readable, only the names of Asian and sub-Saharan economies appear on the chart.

15 Japan's economic stagnation and population ageing since 1990 has made it an average player for the period 1960-2010 although it was an outstanding performer in both education and economic growth during years prior to 1990.
} 


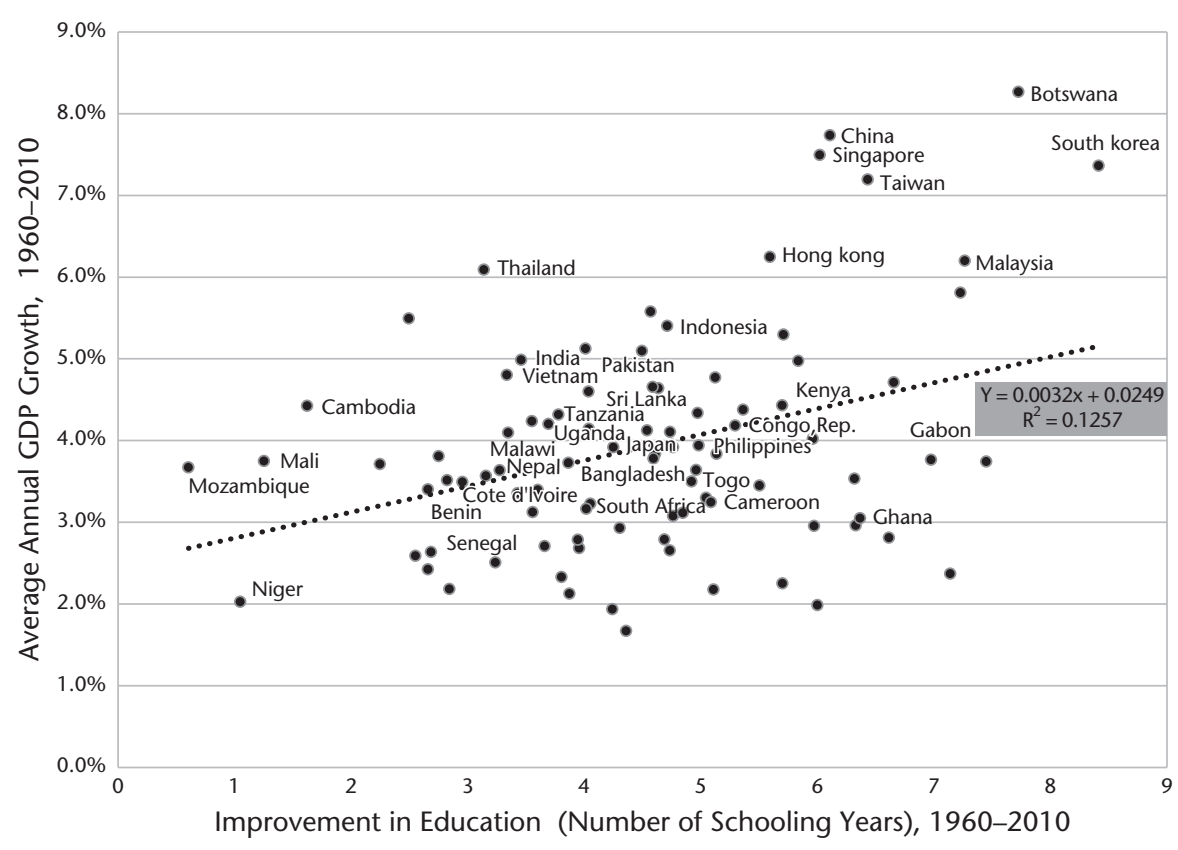

Figure 3.6. Improvement in education and economic growth, 1960-2010: SSA and developing Asia: a global picture

Source: World Bank (2016) for GDP; Barro and Lee (2013) for education.

For successful Asian economies, nurturing human capital formation has historically been a major policy priority. Their efforts in this strategic direction have been carried out in three approaches: proactively attracting diaspora, heavily investing in education and training, and aggressively upgrading innovation capacity. ${ }^{16}$

To better understand the challenges facing the countries of SSA, particularly with regard to nurturing human capital formation, one examines their current levels of human capital development as compared to developing Asian countries (Figure 3.7). Two urgent issues are evident. First, it is urgent for countries with very low education levels, including Niger, Burkina Faso, Chad, Mozambique, and Ethiopia, to make major efforts in improving their basic education systems. Second, SSA countries should make a stronger commitment to health development. In general, SSA markedly underperforms developing Asia in the health development index. Moreover, the slope of this measure as a function of education is also flatter for SSA compared to developing Asia (the coefficient beta is 0.18 for SSA compared to 0.31 for developing Asia). This implies that

16 For example, see World Bank (1993), Yoon (1992), and Zhao and Zhu (2009) for policies and policy initiatives to promote human capital formation in East Asian economies. 
Human Development Index

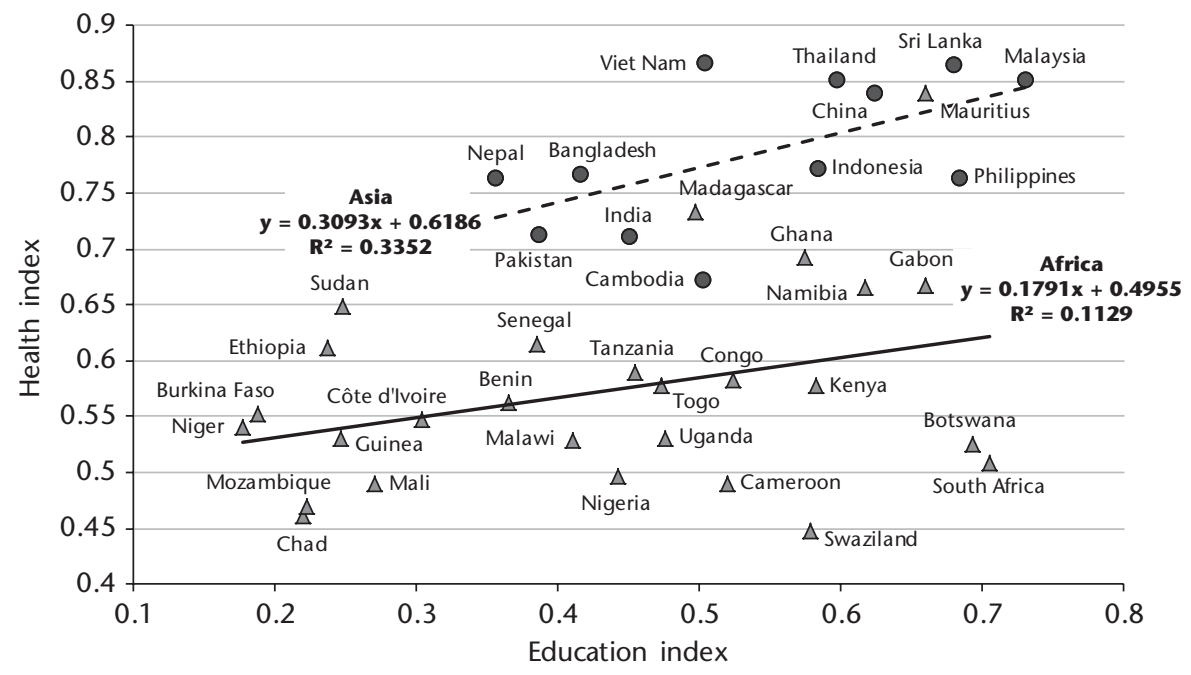

Figure 3.7. Human capital development in 2010: SSA vs developing Asia Source: Authors, based on UNDP (2012).

SSA countries can do a better job of improving public health as they make progress on other aspects of human development such as education.

\subsection{Conclusion}

Lessons and insights from Asia's successful development experiences can be drawn through the lens of new structural economics, a theoretical proposition arguing that modern economic development is by nature a process of continuous structural transformation in technologies, industries, infrastructure, and socio-economic institutions. The experience of Asia demonstrates that developing countries have the potential to grow dynamically, significantly reduce poverty, and reach middle-income or even high-income status in the span of one to two generations, provided the country has an enabling state that can overcome the inherent constraints of inadequate infrastructure and unproductive business environments, and that can generate structural change in technology and industry. The aim of state coordination is to facilitate the private sector's maturation in industries that accord with the country's comparative advantages, turning those industries into the country's competitive advantages, and exploiting late-comer opportunities.

The successful development of Asian countries has been addressed in a variety of studies, including those by the World Bank and the Growth 
Commission. This chapter extends this work in two ways. First, it explores how lessons from successful Asian countries can be applied to SSA countries, particularly with regard to strategic objectives, institutional reform, and human development. The chapter shows that lessons learned from these Asian economies are meaningful and applicable for SSA countries. However, in order for these lessons to be actionable, the leaders of the SSA countries should more thoroughly understand the nature of economic growth and master a strategic policy framework.

Second, this chapter proposes and applies a specific policy framework, demonstrating its value as a versatile and replicable tool. The principles of new structural economics and the five-component strategic frameworkASIAN, as introduced in this chapter-serve this purpose. They provide an analytical tool useful not only for development efforts in other regions at varying stages of growth, but also for scholarly research about countries undertaking modernization and economic catch-up. The ASIAN framework's focus on aspiration, strategy, implementation, acquisition of knowledge, and human capital formation are relevant in both contexts-applied and theoretical-and further operationalize new structural economics. This chapter's contribution aims to enrich development studies from a fresh perspective that addresses continuing transformational changes in information diffusion, the role of knowledge in development, and the impacts on both of a rapidly globalizing economy.

It should also be noted that the ASIAN model applied by the successful Asian economies has evolved overtime in which 'strategy' is the most dynamic component. A continually renewed development strategy enables a nation to effectively respond to rapid changes in the external environment and leverage its new comparative advantages to sustain robust economic growth into the long-term. African policy makers and the donors should pay a special attention to the soundness of the strategy when the ASIAN framework is used to examine the readiness of a nation in embarking on a development journey.

\section{Acknowledgements}

We thank Kris Harley and Nguyen Chi Hieu for research assistance.

\section{References}

Barro, R., and J.-W. Lee (2013). 'A New Data Set of Educational Attainment in the World, 1950-2010'. Journal of Development Economics, 104: 184-98. 
Chu, P. Y., Y. L. Lin, H. H. Hsiung, and T. Y. Liu (2006). 'Intellectual Capital: An Empirical Study of ITRI'. Technological Forecasting and Social Change, 73(7): 886-902.

Cohen, W. M., and D. A. Levinthal (1990). 'Absorptive Capacity: A New Perspective on Learning and Innovation'. Administrative Science Quarterly, 35: 128-52.

CPC (1978). 'Communiqué of the Third Plenary Session of the 11th Central Committee of the Communist Party of China', adopted 22 December, Beijing Review. Available at: <http://www.bjreview.com.cn/special/30yearsofreform/2008-11/29/content_ 167170.htm> (accessed 10 October 2012).

Gerschenkron, A. (1962). Economic Backwardness in Historical Perspective: A Book of Essays. Cambridge, MA: Belknap Press of Harvard University Press.

Heilmann, S. (2008). 'Policy Experimentation in China's Economic Rise'. Studies in Comparative International Development, 43(1): 1-26.

Hsu, C. W. (2005). 'Formation of Industrial Innovation Mechanisms through the Research Institute'. Technovation, 25(11): 1317-29.

Jansen, M. B. (2000). The Making of Modern Japan. Cambridge, MA: Belknap Press of Harvard University Press.

Kim, E. M., and G.-S. Park (2011). 'The chaebol'. In B.-K. Kim and E. F. Vogel (eds), The Park Chung Hee Era: The Transformation of South Korea. Cambridge, MA: Harvard University Press.

Lee, K. Y. (2000). From Third World to First: The Singapore Story 1965-2000: Memoirs of Lee Kuan Yew. Singapore: Singapore Press Holdings.

Lin, J. Y. (2003). 'Development Strategy, Viability, and Economic Convergence'. Economic Development and Cultural Change, 51(2): 276-308.

Lin, J. Y. (2009). Economic Development and Transition. Cambridge: Cambridge University Press.

Lin, J. Y. (2011). 'New Structural Economics: A Framework for Rethinking Development'. World Bank Research Observer, 26(2): 193-221.

Lin, J. Y. (2012a). New Structural Economics: A Framework for Rethinking Development and Policy. Washington, DC: The World Bank.

Lin, J. Y. (2012b). The Quest For Prosperity: How Developing Economies Can Take Off. Princeton, NJ: Princeton University Press.

Lucas, R. E. (1993). 'Making a Miracle'. Econometrica, 61(2): 251-72.

Lundvall, B.-Å., and B. Johnson (1994). 'The Learning Economy'. Journal of Industry Studies, 1(2): 23-42.

Marti, M. E. (2002). China and the Legacy of Deng Xiaoping: From Communist Revolution to Capitalist Evolution. Dulles, MD: Potomac Books.

Moon, C.-I., and B.-J. Jun (2011). 'Modernization Strategy: Ideas and Influences'. In B.-K. Kim, and E. F. Vogel (eds), The Park Chung Hee Era: The Transformation of South Korea. Cambridge, MA: Harvard University Press.

O, W.-C. (2009). The Korea Story: President Park Jung-Hee's Leadership and the Korean Industrial Revolution. Seoul: Wisdom Tree.

Page, J. (2012). 'Can Africa Industrialise?' Journal of African Economies, 21(AERC Supplement 2): ii86-ii124.

Park, C. H. ([1971] 2009). To Build a Nation. Washington, DC: Acropolis Books.

Schein, E. H. (1996). Strategic Pragmatism: The Culture of Singapore's Economic Development Board. Cambridge, MA: The MIT Press. 
Straits Times (1984). 'Dr. Goh's Recipe for Our Success', 7 August.

UNDP (United Nations Development Programme) (2012). Human Development Statistical Tables. New York: UNDP.

Von Hippel, E. (1994). 'Sticky Information and the Locus of Problem Solving: Implications for Innovation'. Management Science, 40(4): 429-39.

Vu, K. M. (2013). The Dynamics of Economic Growth: Policy Insights from Comparative Analyses in Asia. Cheltenham and Northampton, MA: Edward Elgar Publishing.

Vu, K. M., and R. D. Austin. (2014). Vietnam: Embracing ICT for Economic Catch-Up. Singapore: Lee Kuan Yew School of Public Policy Working Paper Series.

World Bank (1993). The East Asian Miracle: Economic Growth and Public Policy. New York: Oxford University Press.

World Bank (2008). The Growth Report: Strategies for Sustained Growth and Inclusive Development. Washington, DC: World Bank.

World Bank (2016). 'World Development Indicators (WDI)', 11 April. Available at: $<$ http://data.worldbank.org/data-catalog/world-development-indicators> (accessed 29 April 2016).

Yeung, A. K., D. O. Ulrich, S. W. Nason, and M. A. Von Glinow (1999). Organizational Learning Capability. New York: Oxford University Press.

Yoon, Bang-Soon L. (1992). 'Reverse Brain Drain in South Korea: State-Led Model'. Studies in Comparative International Development, 27(1): 4-26.

Zhao, L., and J. Zhu (2009). 'China Attracting Global Talent: Central and Local Initiatives'. China: An International Journal, 7(2): 323-35. 


\title{
State-Business Relations as Drivers of Economic Performance
}

\author{
Alberto Lemma and Dirk Willem te Velde
}

\subsection{Introduction}

Whilst there is a clear rationale for growth and industrial policies to support the market in promoting better economic outcomes (Stiglitz 1996), the effects of the same policy can vary greatly in different contexts. For example, Kingombe and te Velde (2016) argue that whilst special economic zones (SEZs) were instrumental in diversifying and upgrading economic production structures in Malaysia, China, and Mauritius, this was much less the case in countries such as Nigeria or Tanzania. A key question is why the practice of industrial policy differs so much across countries: why do some economic policies succeed and others fail?

This chapter examines the theory and evidence on state-business relations (SBRs) and summarizes the results obtained from previous research on Asian and African countries, including the work on SBRs conducted by the Institutions and Pro-Poor Growth Research (IPPG) Consortium from 2005 to 2010 (see e.g. te Velde 2010; Sen 2013) and a recent DFID-ESRC Growth Research Programme (DEGRP) set of essays (te Velde 2013). The aim is to understand whether and how SBRs affect the quality of policy-making and result in better economic performance. The chapter also discusses a set of (measurable) principles behind effective SBRs and provides an agenda for further research on effective SBRs.

The structure of this chapter is as follows. Section 4.2 provides a brief history of industrial policy-thinking, arguing that SBRs have been a key element that has been surprisingly lacking from this debate. Section 4.3 reviews the theoretical debates on SBRs. Section 4.4 reviews typologies behind successful SBRs. 
Section 4.5 discusses the empirical evidence, highlighting micro and macroeconomic studies focused on SBRs, case studies in Africa and Asia on the economic outcomes of SBRs, how SBRs are used to resolve particular issues (i.e., budget setting), lessons at the sectoral level, and the indicators used to measure SBRs. Section 4.6 concludes and discusses possible next steps for research.

\subsection{SBRs and a Brief History of Thinking on Industrial Policy: A Missing Ingredient?}

The debate on industrial policy has evolved considerably in recent decades. From the 1950s to the 1980s, the structuralists (following, e.g., Hans Singer and Raul Prebisch) suggested a policy of import substitution to promote heavy manufacturing and reduce commodity dependence. By the 1990s, it had become clear that the suggestions from the structuralists led to practical problems and the Latin American debt crisis followed. The Washington Consensus (John Williamson) emerged, which suggested a range of key market policies that did not foresee a role for industrial policies. Indeed, the World Bank's World Development Report 2005 on the investment climate did not mention the term 'industrial policy'; instead, it contained a long list of investment climate reforms that would need to be undertaken, although the theoretical underpinning often remained weak. This consensus also ran into problems because some countries that followed these policies (several Latin American countries) grew unsatisfactorily, whilst others that did not follow these policies (China, Viet Nam) grew rapidly.

The 2008 Growth Commission report marked some change. Its review of successful experiences of growth, mentioned, for example, the key role played by leadership in promoting economic growth, along four other key ingredients of growth. Hausmann, Rodrik, and Velasco (2008) made a significant further step, by emphasizing that the binding constraints to growth are country specific. Using a growth diagnostic tree, the method identifies whether growth is held back either by high costs of financing or by low returns to a project. An interesting feature of this model is that appropriate policies to overcome binding constraints are almost by definition targeted at specific issues, often requiring specific industrial policies (whether it is to enhance skills, or place infrastructure) and political economy considerations.

Lin and colleagues (2011:3) discuss 'the role of the state in the dynamics of structural change' and provide a practical procedure to identify and facilitate growth through a six-step procedure for growth identification and facilitation. The process is based on Lin and colleagues' work on structural economics 
(i.e., select industries in comparable countries, identify constraints to technological upgrading of existing domestic firms, attract new firms, scale up successful private innovations in new industries, build SEZs or industrial parks, compensate pioneer firms). However, whilst the key ingredients of growth are known (as argued in the Growth Commission), and Lin and colleagues (2011) suggest that a recipe is close as well, there are severe challenges in finding good cooks. Which individuals and organizations can support and engineer the growth process?

Recently, a range of new policy insights have emerged on promoting growth, some of which are general in nature and others are more specific. Common to both types is the fact that they all seem to argue for a more pragmatic (between the extremes of free market and centrally-led concepts of growth) and gradual approach. Page (2012) discusses three ways for promoting economic growth: tilting production towards exports, supporting agglomerations, and attracting and building firm capabilities. Sutton's enterprise maps (for the International Growth Centre) and follow up work suggest a pragmatic role for investment promotion agencies in addressing specific problems in exiting firms. Bloom, Sadun, and Van Reenen (2012) argue that the quality of management is key for firm productivity, suggesting management training is important. Woodruff (2014) argues that productivity differs across product lines and provides evidence that supervisor training increases performance.

Much of the literature thus points to the importance of policies to actively support the growth process. All of the approaches mentioned require an institutional setting for policies to work properly, one where the state and business can interact to agree on the best direction for the economy. The question is no longer, whether industrial policy is important, but rather how to use such policies and to examine the institutional setting that determines the design and implementation of good policies. With some notable exemptions, this question of how the state and business interact to formulate good policies has been lacking from the literature on growth and industrial policies.

\subsection{The Theory of State-Business Relations}

What are SBRs and what underpins the theoretical basis? SBRs are relations between the public and private sectors. As they are shaped by the way states and businesses interact (Leftwich 2009), SBR forms can vary significantly, ranging from formal, regular coordination arrangements to informal, ad hoc interactions. They can cover the whole economy or target specific sectors, 
types of firms, or policy processes. In some situations, they involve highly organized relationships in others they are loose relationships between the state and business. In some cases the formal aspects matter most (and the forms are highly visible, e.g., a well-known peak association), but in other informal arrangements, rules, norms, and agreements dominate all other institutions (Bardhan 2005).

Whilst the political science literature takes the existence of SBRs as given and analyses how they evolve and how they are shaped, the economics literature actively debates why SBRs might have a welfare-enhancing role. In neo-classical economic theory, where the price mechanism drives efficient allocations, there is no welfare-enhancing role for additional mechanisms such as SBRs. For example, in the invisible-hand model (Frye and Shleifer 1997), the role of the state is limited to providing public goods (e.g., contract enforcement), but leaves allocative decisions to the private sector. However, in a helping-hand model, organized bureaucrats actively promote private sector activity, 'support some firms and kill off others, pursue industrial policy, and often have close economic and family ties to entrepreneurs' (Frye and Shleifer 1997: 354). Taking this to a further extreme, in a grabbing-hand model, bureaucrats are less well organized and pursue their own (corrupt) agendas. The government is above the law and uses its power to extract rents. The rationale for an effective role of SBRs in the growth process is that the invisible-hand model provides sub-optimal outcomes, and the grabbing-hand model leads to inefficient outcomes in the long-run, but the helping-hand model can be an effective way in which state and business can interact.

Thus, te Velde (2010) argues that effective SBRs fulfil a helpful steering role in industrial development by overcoming two concerns: (1) there are market failures (the market alone cannot achieve an optimal allocation of resources (Stiglitz 1996)); markets can fail in areas such as education, innovation, or climate change; and (2) there are government failures (state actors may not be able to address market failures on their own). Governments can fail, as they are unlikely to have perfect information and perfect foresight, suffer from moral hazard problems (Hausmann and Rodrik 2002), or are captured by elites. However, effective SBRs can address market, coordination, and government failures through effective communication and remove binding constraints to growth by improving the investment climate, providing market-enhancing public investment, and reducing policy uncertainty.

The role of agencies and their effective interactions complement the price mechanism in allocating resources and promoting industrial development. Doner and Schneider (2000) discuss a number of market-complementing 
functions of business associations as key agents in the conduct of organized SBRs: macroeconomic stabilization, horizontal and vertical coordination, lowering costs of information, standard setting, and quality upgrading.

\subsection{Typologies of Effective SBRs}

This section reviews a number of studies that examine characteristics or principles behind effective SBRs. For example, the World Bank (2012) suggests that lessons from past successes and failures of standard industrial policies are clear: governments should subject firms to competition, have clear sunset clauses, and focus on well-identified market failures, spill-over or latent comparative advantages.

Evans (1995) discussed 'embedded autonomy' in which the public and private sectors form a strategic relationship. Following the contributions by Evans (1995) and Maxfield and Schneider (1997), good SBRs tend to be based on benign collaboration between business and the state, with positive mechanisms that enable transparency, ensure the likelihood of reciprocity, increase credibility of the state among the capitalists, and establish high levels of trust between public and private agents.

Rodrik (2004) lists three key elements for an appropriate institutional architecture: (1) political leadership at the top, (2) coordination and deliberation councils, and (3) mechanisms of transparency and accountability. Rodrik (2008) has also argued that developing countries should be aiming for second best institutions, which means that developing countries should not be aiming for 'best-practice' institutions as used in developed countries but rather institutions that take into account both the local context as well as issues that cannot be quickly resolved.

More recently, Rodrik has developed (see McMillan and Rodrik 2013) these key elements into three prerequisites required to promote policy reformembeddedness, discipline, and accountability. Of these, the principle of embeddedness is the one most relevant to the SBR discussion as it refers to the idea that policy makers must be close enough to the 'real' economy in order to have the right information and seize potential opportunities. Such close links require the right institutions that promote exchange between policy makers and the private sector (i.e., institutions that set up the groundwork for strategic collaborations between businesses and the state).

Buur and Whitfield (2013) argue that: (1) mutual interests, (2) pockets of efficiency, and (3) learning for productivity are important characteristics for effectiveness of SBRs. Finally, Page (2013) argues that effective SBRs depend on commitment, focus, experimentation, and feedback. 


\subsection{The Empirical Evidence on State-Business Relations}

We review four types of empirical evidence:

1. Econometric studies (macro and micro, e.g., Sen and te Velde 2009; Qureshi and te Velde 2012, 2013). This sets the scene, but the analytical insights from such studies remain limited to broad patterns rather than details on how SBRs can best work.

2. Case study evidence such as from IPPG and other case studies on Mauritius, Ghana, South Africa, Malawi, Egypt, or on Investor State Councils (Page 2013), as well and the more established literature on SBRs in Asia. Much of these studies are case specific.

3. Evidence focusing on specific economic functions (i.e., effective SBR and the budget process in Zambia (Bwalya, Phiri, and Mpembamoto 2009) or Mauritius (Rojid, Seetanah, and Shalini 2010)).

4. Indicators that can be used to measure SBR (World Bank and Organisation for Economic Co-operation and Development (OECD)).

Most successful examples of SBRs come from outside Africa, but over the past decades, more research on SBRs and economic growth has been developed including in Africa.

\subsubsection{Econometric Studies}

There are a number of statistical analyses of SBRs. Such analyses examine SBRs through various lenses-at the macroeconomic level (linking SBRs with economic growth) or at the microeconomic level (correlating SBRs with firm-level total factor productivity (TFP)). The section argues that SBRs seem to have a positive economic effect both at the macroeconomic level (by leading to greater economic growth) and at the microeconomic level (by increasing firm productivity), with evidence emerging from Asia and Africa.

\subsubsection{MACRO-STUDIES}

An analysis of SBRs in twenty different sub-Saharan African (SSA) states was carried out for the period covering 1970 to 2005 (te Velde 2006). The analysis was based on a number of different factors governing relationships between the private sector and the government (see Section 4.5.2 for more details). These factors were used to provide a composite SBR scoring and correlated to economic growth with results suggesting that higher SBR scores lead to faster growth as well as to better governance and investment climate outcomes.

Sen and te Velde (2009) show that effective SBRs contributed significantly to economic growth in a panel of nineteen SSA countries over the period 1970-2004; countries which have shown improvements in SBRs have 
witnessed higher economic growth and control over other determinants of economic growth, independent of other measures of institutional quality.

Macroeconomic evidence from the Mauritius (Rojid, Seetanah, and Shalini 2010) measure SBRs (between 0 and 1 ) at the macro level (following te Velde 2006) and use this as a regressor in a number of equations based on a dynamic time series analysis in a vector auto-regression (VAR) framework between 1970 and 2005. They show that there is a significant and positive effect (with an elasticity of 0.18 ) of SBRs on short- and long-term output in the country. Thus, quantitative findings from Mauritius suggest that effective SBRs in the country are an important contribution to economic growth. The main channels of impact from SBRs work through the amount of private capital, the openness of the economy, and the quality of labour.

Cali (2010) provides evidence on the effects of SBRs (measured in fifteen Indian states between 1985 and 2006) in India and shows that SBRs have improved across nearly all Indian states within the study period. The composite measure of SBRs across all states is also strongly correlated with economic growth thus, providing more evidence on the economic importance of SBRs.

\subsubsection{MICRO-STUDIES}

In Ghana, a panel data analysis of 256 Ghanaian firms (Ackah et al. 2010) covering the 1991 to 2002 period, focusing on the impacts of SBRs on TFP found that effective SBRs positively correlated with better firm performance. The theory put forward was that effective SBRs (through social networking, i.e., better connections between politicians and entrepreneurs) resulted in a more optimal allocation of resources in an economy, leading to better firm productivity.

Qureshi and te Velde (2013) analyse SBRs in relation to firm performance in Zambia using World Bank Enterprise Survey data for 200 firms (specifically on measures of firm productivity and institutional context and perceptions) and find that membership in a business organization increases firm productivity between 37 and 41 per cent. The analysis finds that business association effectiveness is based on their capacity to lobby governments and (to a lesser capacity) the ability to reduce market informational asymmetries and coordination failures. Additionally, the article highlights the fact that foreignowned firms are more effective in lobbying governments than domestic counterparts are. Additional firm-level research from the Zambia food processing sector (Hampwaye and Jeppesen 2014) does however highlight the fact that firm growth can occur in spite of unsupportive (and even hindering) institutional and SBR barriers.

Further research on microeconomic impacts of SBRs on productivity growth in Indian manufacturing firms (Kathuria, Rajesh Raj, and Sen 2010) between 1994 and 2005 using firm-level data for both formal and informal 
manufacturing firms in fifteen Indian states shows that SBRs positively affect productivity growth in the Indian manufacturing sector, more so on the formal sector than in the informal sector.

\subsubsection{Case-Study Evidence}

Whilst subsection 4.5.1 provided quantitative evidence, there is also a range of qualitative studies, which we review here.

The relationship between SBRs and pro-poor growth was examined in South Africa (Nattrass and Seekings 2010). The study found that policy incoherence between government ministries undermined post-apartheid employment growth. Whilst the South African Treasury promoted pro-business policies, the Ministry of Labour favoured policies promoting organized labour organizations, which may have undermined pro-poor growth (through pro-poor employment generation) in the country. The National Economic Development and Labour Council (NEDLAC) did not represent a real consensusseeking forum, owing to defections by key labour organizations and differences of approach and priorities among key state organizations (Treasury and Ministry of Labour), despite some early success in industrial policy.

Research on SBRs in Egypt (Abdel-Latif and Schmitz 2009) highlights how informal relationships between policy makers and business investors can play an important part in increasing business investments as well as contribute to economic growth, especially where there are common social roots and professional backgrounds between policy makers and investors. There are however two circumstances which may dilute the effectiveness of these networks-if personal and professional relationships are blurred as may be the case in the Pacific region (Peiffer 2012a), or where there is limited institutional memory both in the public and private sector (due to high turnover rates) as was the case in Samoa (ADB 2008).

Of interest is the example of Morocco (Boussaid 2010), where the state (through the Moroccan monarchy) initially allowed business to push for economic reform through an umbrella association (the General Confederation of Moroccan Enterprises-CGEM). This setup initially suited the government in order to promote its own liberalization policies but then reaffirmed tight control over the dominant private sector enterprises in the country by neutering the CGEM through a year-long anti-corruption campaign between 1995 and 1996. Although the move was mainly political in nature, it still highlights how SBRs can be used and controlled by either the state or businesses in order to promote their own agenda.

In Viet Nam, the government actively sought to create a dialogue between the public and private sector where state actors would seek private sector inputs on economic reform policies whilst enterprises would lobby for 
responsive and effective government (Schmitz et al. 2012). Even though there was no formal public-private coalition, this proactive engagement meant that many domestic and foreign firms actively collaborated to reform provincial level policies.

More recent lessons from Viet Nam (Vu-Thanh 2014) show that between 1986 and 2012, the success of Viet Nam's industrial development was, in part, determined by the relationship between the state and the private sector. One of the preconditions of success, echoing Buur and Whitfield's (2013) observations, was that the ruling elite formed close ties with the productive forces (i.e., the capitalist firms) to build strong reform coalitions.

Similar lessons on the importance of leaders and elites working together to form 'organic' growth coalitions is provided by Sen (2010), citing the example of Andhra Pradesh in India where a change in state leadership spurred rapid improvement in SBRs and economic growth within the Indian state. The article also highlights the importance of ongoing negotiations and discussions within the SBR process as a determinant of success using the example of West Bengal where the government wanted to kick-start positive SBRs but failed to do so due to decades of hostility from the local state towards the private sector. Complementary research from the region (Alivelu, Srinivasalu, and Reddy 2010) also highlights the fact that business associations can play an important role, in facilitating SBRs, as knowledge disseminators, especially in regards to providing firms with information on changes in and applications of government regulations.

Lessons from South Korea show that when SBRs shifted from top-down planning in the 1960s and 1970s, where the government laid down plans that the private sector needed to adhere to, to one in the 1980s where horizontal collaboration between the private and public sector became the norm, started (or at least contributed to) a process that eventually led to South Korean firms becoming major global players (Kim 2011). A partial component of Korea's successful globalization movement was the formation of the tripartite commission, involving the public sector (through state representation), the private sector, and labour unions. Between 1998 and 2011, more than 80 per cent of the deliberations made by the commission (Economic and Social Development Commission) had been implemented, thanks to the oversight of a specific implementation committee (Committee for Assessment of Implementation) set up to guarantee the effectiveness of the tripartite commission (Nicolas, Thomsen, and Bang 2013).

The example of Presidential Investors' Advisory Councils (PIAC) in Africa also provides important insights into formal SBR outcomes (and especially those put in place with external support). PIACs were set up by governments between 2001 and 2010 across the African continent spurred by a joint World Bank and International Monetary Fund (IMF) initiative launched in 2001. 
These councils acted as fora for SBRs where business representatives could directly interact with governments at the highest level. A review of the effectiveness of these councils (Page 2013) shows that in the early phases (between 2002 and 2005), these were deemed to be effective systems that could spur governments to fast track reforms and counteract government inertia. A subsequent (carried out in 2009) evaluation showed major discrepancies between council performances, with some not working well. Whilst these councils have evolved to take different characteristics, momentum in action determines their success in pushing reforms-however these tend (except Ethiopia) to be mainly used as platforms for donors to push reforms that they are interested in.

The PIACs echo the deliberation councils set-up in East and Southeast Asia (most notably in South Korea, Japan, Singapore, Malaysia, and Thailand), cited as critical components for economic growth (Campos and Root 1996). These councils included representatives of the public and private sector and were tasked with the formulation of policy aimed at enhancing growth, reducing transactional costs, informational asymmetries, and rent-seeking within particular sectors. Some councils were granted legislative powers to implement policy reform. One example is Japan's Ministry of Trade and Industry (MITI-now Ministry of Economy, Trade and Industry-METI), which played an important role in the country's industrialization drive from the 1950s onwards based on strong SBRs. Other councils such as Singapore's National Wages Council (NWC) and Thailand's National Joint Public and Private Consultative Committee (JPPCC) were also based on the ideal of strong SBRs to enhance the pro-growth policy reform process. A major difference between PIACs and deliberation councils is the extent to which the SBRs were institutionalized from within.

The Economic Report on Africa (2014) discusses the design of industrial policy on the basis of a dozen African case studies. They find that industrial policy coordination at higher levels is minimal-and in some countries completely missing. The private sector is often left out. In addition, industrial policy organizations suffer from organizational imperfections leading to institutional problems.

\subsubsection{SBRs and Specific Functions}

Whilst Sections 4.5.1.1 and 4.5.1.2 provided micro and macro evidence of SBR impacts, it did not elaborate on the channels through which impacts occur or the determinants of success. Here we provide some examples.

There is research evidence on how non-state actors lobby government budget outcomes in Zambia (Bwalya, Phiri, and Mpembamoto 2009) through successful changes in tax and expenditure policy following submissions to the Zambian tax policy and expenditure committees (which are allowed by both 
state and non-state actors) for 2008. The research found that submissions by companies and business and professional associations were the second most effective non-state submissions influencing policy (after civil society-led submissions) when measuring percentage of submissions leading to successful changes, but were the most successful in terms of volume. However, the analysis cannot identify what the original source of submissions was; hence, the research posits that there may be a percentage of state-led submissions that were originally proposed either by the private sector or by civil society.

Buur and Whitfield (2013) observe the dynamics between SBRs and industrial policy and argue that for successful industrial policies, three simultaneous conditions need to be met by a country's SBR process:

1. Ruling elites (or factions) need to have an incentive in addressing productivity constraints in (interested) productive sectors and need to have a mutual interest with 'capitalist firms' who want such issues addressed.

2. Ruling elites looking to push reforms need to have enough control on other factions (or even internal factional demands) in order to create a 'pocket of efficiency' (i.e., provide strong political backing) within which state bureaucrats can work to implement reforms.

3. State bureaucrats need to condition capitalist firms towards increasing productivity and upgrading products through a process of 'learning for productivity' that hinges on bureaucrats knowing what productivity constraints firms face, can translate solutions into effective policy, and must be able to enforce any new policies.

An example of where these conditions have not been met is Malawi (Chingaipe and Leftwich 2007) where the institutional practices that were set up post-independence have continued to influence SBRs. Neither the government nor enterprises have accepted a private sector that is fully independent from the state (i.e., the government has decided not to relinquish full control of the private sector whilst private enterprises still operate on a clientelist basis with the government). The research highlights the fact that some SBRs can be based on maintaining the status quo with no push for change either from the ruling elite (i.e., the government) or from enterprises (i.e., capitalist firms).

Coalitions between capitalists and ruling elites can also potentially exist across borders as research from Hong Kong (Fong 2014) shows, where Hong Kong business leaders formed direct partnerships with the ruling elite in Beijing in order to put pressure on the Hong Kong local government to (successfully) alter proposed business enabling environment reforms. Although these links are facilitated by the particular relationship between Hong Kong and Beijing, it does still attest to the fact that international SBRs can be as important as national level SBRs. In a similar vein, the Japanese 
government has attempted to create stronger SBRs between Japanese multinationals and governments in the Association of Southeast Asian Nations (ASEAN) region through the creation of the AEM-MITI Economic and Industrial Cooperation (AMEICC) as a way to increase Japanese multinational influence in policy reform processes in Southeast Asia (Natsuda 2008).

\subsubsection{Indicators to Measure SBRs}

Te Velde (2006) identifies a set of key measurable factors behind effective SBRs. For example, to obtain credibility and reciprocity, both public and private sectors need to be organized or institutionalized. Positive mechanisms for transparency require that some rules or institutions bring the state and business together. Moreover, a set of principles is needed to restrain collusive behaviour. He suggests four factors make for effective SBRs, which can clearly be expanded and improved on in specific research contexts: (1) the way the private sector is organized vis-à-vis the public sector; (2) the way the public sector is organized vis-à-vis the private sector; (3) the practice and institutionalization of SBRs; (4) the avoidance of harmful collusive behaviour.

Sen and te Velde (2009) posit three different measures that can be used to analyse SBRs:

1. An average indicator measuring the presence and length of service of existing umbrella organizations (i.e., chambers of commerce or sectoral associations) that link enterprises with the government. The indicator would measure the membership period of firms within the organization as a proxy for the maturity and level of collaboration between businesses and government.

2. Measuring the number of businesses that are members of umbrella business organizations vis-à-vis the total number of firms within an economy. The idea is that higher membership rates give greater strength to umbrella organizations' discussions with the government (with the caveat that this would be an input indicator and that mature SBRs are more about dialogue than confrontation).

3. An output-based indicator that looks at the economic function of SBRs. The indicator measures the effectiveness (in percentage) of umbrella organizations to have its demands met.

Macroeconomic and microeconomic systems can be used to measure the impact of SBRs on economic performance-the Mauritius case study (Rojid, Seetanah, and Shalini 2010) uses a macroeconomic approach whilst the Ghana (Ackah et al. 2010) and Zambia (Qureshi and te Velde 2013) case studies take a microeconomic approach (firm panel data and World Bank Enterprise Survey data respectively). Macroeconomic measurement in the Mauritius case study is based on the indicators initially proposed (see Section 4.5.1.1) by Sen and te Velde (2009). 
Table 4.1. Implementation of budget proposals by the Mauritius JEC to the government

\begin{tabular}{|c|c|c|c|}
\hline Budget Proposals of Mauritius JEC (2006-7) & $\begin{array}{l}\text { Fully } \\
\text { Implemented }\end{array}$ & $\begin{array}{l}\text { Partly } \\
\text { Implemented }\end{array}$ & $\begin{array}{l}\text { Not } \\
\text { Implemented }\end{array}$ \\
\hline $\begin{array}{l}\text { Transformation of Mauritius into one seamless, } \\
\text { integrated business platform }\end{array}$ & & $x$ & \\
\hline $\begin{array}{l}\text { Adoption of transparent, simple, and minimum } \\
\text { procedures to start and operate businesses }\end{array}$ & $x$ & & \\
\hline $\begin{array}{l}\text { Establishment of a competitive air access policy } \\
\text { Introduction of competitive pricing policies for } \\
\text { international bandwidth }\end{array}$ & $x$ & $x$ & \\
\hline $\begin{array}{l}\text { Establishment of an open policy to import } \\
\text { high skills }\end{array}$ & & & $x$ \\
\hline $\begin{array}{l}\text { Operationalizing of the public-private } \\
\text { partnership (PPP) legislation; and mainstreaming of } \\
\text { small and medium-sized enterprises (SMEs) in the } \\
\text { new economic model }\end{array}$ & & & $x$ \\
\hline $\begin{array}{l}\text { Transforming the labour environment into a more } \\
\text { flexible one }\end{array}$ & $x$ & & \\
\hline $\begin{array}{l}\text { Establishing the right balance between legislative } \\
\text { control and 'space' for investment }\end{array}$ & & & $x$ \\
\hline
\end{tabular}

Source: te Velde (2006).

An example, for the output-based indicator, can be seen in Table 4.1. The table shows what Mauritius Joint Economic Council (JEC) proposals were submitted to the government (between 2006 and 2007) and which were accepted. A score of 1 was given to fully implemented proposals, 0.5 for partly implemented proposals and 0 for not implemented proposals. The total for the table comes to 4 (i.e., 3 points for the 3 fully implemented proposals and 1 point for the 2 partly implemented proposals) out of 8 total proposals, thus the SBR score is 4/8 or 0.5 for Mauritius within the 2006-7 timeframe.

The OECD uses a toolkit to measure the public-private dialogue (PPD) component of SBRs. The toolkit is a collection that uses the PPD diamond and the PPD wheel, both of which have been developed by the PPD organization as a joint collaboration between the OECD, the World Bank, and DFID (see Box 4.1 for more details on the existing PPD Handbook). In addition, they are currently developing a more comprehensive toolkit that aims to assess the quality of PPD as a proxy for public-private cooperation as well as measure the level of private sector engagement in public policy-making (Herzberg and Sisombat 2013). The toolkit would measure various dimensions of publicprivate cooperation including the capacity and commitment of both the private and public sector, the presence of champions (on both sides), and the quality of instruments (i.e., mechanisms and programmes) that facilitates PPD.

A note of caution on studies is in order. Economic studies are based on measures that describe only certain aspects but perhaps not the ones that 
Box 4.1. THE OECD PPD HANDBOOK

The OECD and the World Bank developed the PPD handbook in order to help PPD practitioners promote and evaluate PPD. The handbook includes methods to map PPD within a country aimed at diagnosing the current state of PPD, a PPD 'diamond', which is a conceptual framework used to map the strength of PPD through four variables (strength of public and private sector, champions of PPD, and PPD instruments), as well as the PPD evaluation wheel, which measures PPD organizational process and its effectiveness as well as the impact of the PPD reform process.

Sources: <http://www.publicprivatedialogue.org/tools/ANNEXES/evaluation_tool/> (accessed December 2014).

matter, or those that are hard to measure. The detailed case studies may find it hard to uncover cause and effect (e.g., Peiffer 2012b), construct counterfactuals, describe the essence of SBRs, or abstract from policy suggestions.

\subsection{Conclusions and Implications}

In this final section, we discuss what we know and what we need to know. First, it is clear that the study of SBRs has emerged only recently, starting seriously in the mid-1990s, developing further in the 2000s and gaining more general acceptance in the 2010s. Much of the earlier discussions on effective growth and industrial policies had ignored the pragmatic 'how' question and focused instead on the more ideological 'whether at all' question.

The evidence that exists suggests that effective SBRs can matter a lot. The case studies based on careful, qualitative analysis suggest that SBRs can be effective (Mauritius) but also ineffective (Malawi). The quantitative evidence further suggests that high scores on SBRs measures are related to higher economic growth and firm-level productivity.

However, we need consider in more detail possible ways how to assess the effectiveness of SBRs in practice. Te Velde (2013) suggests several areas of further policy research. For example, we know little on which type of SBR principles matter most. Systematic analysis on the characteristics of effective SBRs across case studies in low-income countries (LICs) (e.g., historicalinstitutionalist empirical studies on successful economic functions of SBRs) could examine how they affect economic policy-making. There is also surprisingly little quantification of SBRs. It is a difficult task but it needs to be done to understand how industrial policy (including SEZs as mentioned in Chapter 1) can work best. In undertaking this analysis, it is important: (1) to be clear about the conceptual underpinning of SBR functions because without it we end up in a similar position as the investment climate indicators, which lacked 
a theoretical underpinning generally; (2) to separate objectively measurable attributes of SBRs, perceptions of SBRs, and its impact; and (3) use careful analysis separating out cause and effect.

\section{Acknowledgements}

We are grateful to UNU-WIDER for support, and to John Page in particular for his encouraging comments.

\section{References}

Abdel-Latif, A., and H. Schmitz (2009). State-Business Relations and Investment in Egypt, IDS Research Report 61. Brighton: Institute of Development Studies, University of Sussex.

Ackah, C., E. Aryeetey, J. Ayee, and E. Clottey (2010). State-Business Relations and Economic Performance in Ghana, IPPG Discussion Paper Series 35. Manchester: IPPG.

ADB (Asian Development Bank) (2008). 'Samoa: Consolidating Reform for Faster Economic Growth', Asian Development Bank, Manila.

Alivelu, G., K. Srinivasalu, and M. G. Reddy (2010). State Business Relations and Performance of Manufacturing Sector in Andhra Pradesh, Working Paper 82. Hyderabad: Centre for Economic and Social Studies.

Bardhan, P. (2005). 'Institutions Matter, but which Ones?' Economics of Transition, 13 (3): 499-532.

Bloom, N., R. Sadun, and J. Van Reenen (2012). 'The Organization of Firms across Countries'. Quarterly Journal of Economics, 127(4): 1663-705.

Boussaid, F. (2010). State-Business Relations in Morocco, Knowledge Programme Civil Society in West Asia Working Paper 6. Amsterdam: University of Amsterdam.

Buur, L., and L. Whitfield (2013). 'Industrial Policy and State-Business Relations: Towards a Heuristic Approach'. In D. W. te Velde (ed.), State-Business Relations and Industrial Policy: Current Policy and Research Debates. London: Growth Research Programme.

Bwalya, S. M., E. Phiri, and K. Mpembamoto (2009). How Non-State Actors Lobby to Influence Budget Outcomes in Zambia, IPPG Discussion Paper 27. Manchester: IPPG.

Cali, M. (2010). 'Measuring State-Business Relations in Indian States', IPPG, Manchester.

Campos, J. E., and H. L. Root (1996). The Key to the Asian Miracle: Making Shared Growth Credible. Washington, DC: Brookings Institution.

Chingaipe, H., and A. Leftwich (2007). The Politics of State-Business Relationships in Malawi. Manchester: IPPG.

Doner, R., and B. Schneider (2000). 'Business Associations and Economic Development: Why Some Associations Contribute More than Others'. Business and Politics, 2(3): 261-88. 
Evans, P. (1995). Embedded Autonomy: States and Industrial Transformation. Princeton, NJ: Princeton University Press.

Fong, B. C. H. (2014). 'The Partnership between the Chinese Government and Hong Kong's Capitalist Class: Implications for HKSAR Governance, 1997-2012'. China Quarterly, 217: 195-220.

Frye, T., and A. Shleifer (1997). 'The Invisible Hand and the Grabbing Hand'. American Economic Review, 87(2): 354-8.

Hampwaye, G., and S. Jeppesen (2014). 'The Role of State-Business Relations in the Performance of Zambia's Food Processing Sub-sector'. Bulletin of Geography, SocioEconomic Series, 26: 83-92.

Hausmann, R., and D. Rodrik (2002). Economic Development as Self-Discovery, NBER Working Paper 8952. Cambridge, MA: NBER.

Hausmann, R., D. Rodrik, and A. Velasco (2008). 'Growth Diagnostics'. In N. Serra and J. E. Stiglitz (eds), The Washington Consensus Reconsidered: Towards a New Global Governance. New York: Oxford University Press.

Herzberg, B., and L. Sisombat (2013). 'An Attempt to Develop a Global Indicator on Private-Sector Involvement in Public Policies and Strategies'. In D. W. te Velde (ed.), State-Business Relations and Industrial Policy: Current Policy and Research Debates. London: Growth Research Programme.

Kathuria, V., S. N. Rajesh Raj, and K. Sen (2010). State Business Relations and Manufacturing Productivity Growth in India, MPRA Paper 20314. Munich: Munich Personal RePEc Archive.

Kim, W. (2011). 'Korea's State-Business Partnership and the Growth of chaebols', Social Science Research Network, Rochester, NY.

Kingombe, C., and D. W. te Velde (2016). 'The Role of Special Economic Zones in Manufacturing Development in sub-Saharan Africa: Structural Transformation and Employment Creation'. In J. Weiss and M. Tribe (eds), Handbook on Industry and Development. London: Routledge.

Leftwich, A. (2009). Analysing the Politics of State-Business Relations: A Methodological Note on the Historical Institutionalist Approach, IPPG Discussion Paper Series 23. Manchester: IPPG.

Lin, J., C. Monga, D. W. te Velde, S. Tendulkar, A. Amsden, K. Y. Amoako, H. Pack, and W. Lim (2011). 'Growth Identification and Facilitation: The Role of the State in Dynamics of Structural Change'. Development Policy Review, 29(3): 259-310.

McMillan, M., and D. Rodrik (2013). 'State-Business Relations: Structural Change and Industrialisation in Africa'. In D.W. te Velde (ed.), State-Business Relations and Industrial Policy: Current Policy and Research Debates. London: Growth Research Programme.

Maxfield, S., and B. R. Schneider (eds) (1997). Business and the State in Developing Countries. Ithaca, NY: Cornell University Press.

Natsuda, K. (2008). Deliberation Councils in Southeast Asia: How Three-Party Institutional Arrangements Benefit MNCs and State Development, RCAPS Working Paper 08-1. Beppu: Ritsumeikan Center for Asia Pacific Studies (RCAPS), Ritsumeikan Asia Pacific University.

Nattrass, N., and J. Seekings (2010). State, Business and Growth in Post-Apartheid South Africa, IPPG Discussion Paper Series 34. Manchester: IPPG. 
Nicolas, F., S. Thomsen, and M. Bang (2013). Lessons from Investment Policy Reform in Korea, OECD Working Papers on International Investment, 2013/02. Paris: OECD.

Page, J. (2012). Aid, Structural Change and the Private Sector in Africa, WIDER Working Paper 2012/021. Helsinki: UNU-WIDER.

Page, J. (2013). 'Industrial Policy in Practice: Africa's Presidential Investors' Advisory Councils'. Paper presented at the UNU-WIDER conference on 'Learning to Compete: Industrial Development and Policy in Africa', Helsinki, Finland, 24-25 June.

Peiffer, C. (2012a). The Politics of State Business Relations in the Pacific: What is Already Documented and What Do We Need to Know?, DLP Background Paper 13. Australia: DLP.

Peiffer, C. (2012b). 'Reform Coalitions': Patterns and Hypotheses from a Survey of the Literature, DLP Concept Paper 03. Australia: DLP.

Qureshi, M., and D. W. te Velde (2012). 'State-Business Relations, Investment Climate Reform and Firm Productivity in Sub-Saharan Africa'. Journal of International Development, 25(7): 912-35.

Qureshi, M., and D. W. te Velde (2013). 'State-Business Relations and Firm Performance in Zambia'. In K. Sen (ed.), State-Business Relations and Economic Development in Africa and India. London: Routledge.

Rodrik, D. (2004). Getting Institutions Right. Cambridge, MA: Harvard University.

Rodrik, D. (2008). Second Best Institutions, NBER Working Paper Series 14050. Cambridge, MA: NBER.

Rojid, S., B. Seetanah, and R. Shalini (2010). Are State Business Relations Important to Economic Growth? Evidence from Mauritius, IPPG Discussion Paper Series 36. Manchester: IPPG.

Schmitz, H., D. A. Tuan, P. T. T. Hang, and N. McCulloch (2012). 'Drivers of Economic Reform in Viet Nam's Provinces', DFID, London.

Sen, K. (2010). 'From Collusion to Collaboration: State-Business Relations and Economic Performance in India', IPPG, Manchester

Sen, K. (ed.) (2013). State-Business Relations and Economic Development in Africa and India. London: Routledge.

Sen, K., and D. W. te Velde (2009). 'State-Business Relations and Economic Growth in Sub-Saharan Africa'. Journal of Development Studies, 54(8): 1267-83.

Stiglitz, J. E. (1996). Whither Socialism. Cambridge, MA: The MIT Press.

te Velde, D. W. (2006). Measuring State-Business Relations in sub-Saharan Africa, IPPG Discussion Paper 4. Manchester: IPPG.

te Velde, D. W. (2010). Effective State-Business Relations, Industrial Policy and Economic Growth. London: ODI.

te Velde, D.W. (ed.) (2013). State-Business Relations and Industrial Policy: Current Policy and Research Debates. London: DFID ESRC Growth Research Programme.

Vu-Thanh, T. A. (2014). The Political Economy of Industrial Development in Viet Nam: Impact of State-Business Relationship on Industrial Performance 1986-2012, WIDER Working Paper 2014/158. Helsinki: UNU-WIDER.

Woodruff, C. (2014). 'Managing for Efficiency: Enhancing Productivity in Bangladesh's Garment Sector', Growth Research Programme, London.

World Bank (2012). World Development Report 2013: Jobs. Washington, DC: World Bank. 


\section{5}

\section{State Capability and Prospects for Close Coordination}

\section{Considerations for Industrial Policy in Africa}

Rachel M. Gisselquist

\subsection{Introduction}

Recent research highlights the considerable potential of industrial policy to support structural transformation in sub-Saharan Africa (SSA) (see Ajakaiye and Page 2012; Chang 2012; Stiglitz et al. 2013). A key gap in this literature however is the failure to grapple fully with other work on the state in Africa which highlights the challenges posed by state weakness. This chapter speaks to this gap. Its basic argument is simple: we should be careful in attempting industrial policy in 'fragile' or 'weak' state settings_-and SSA has many such settings. ${ }^{1}$ Standard metrics suggest at least half of SSA countries can be characterized as such-a higher proportion than in any other world region. Furthermore, while industrial policy historically has had success even in states that could be characterized today as 'fragile', research suggests that state capabilities in these contexts differed in potentially significant ways from those in many African countries today. In short, the potential for state-supported industrial transformation is much clearer in relatively robust SSA states, such as South Africa and Ghana, than in more fragile states, such as Nigeria, Côte d'Ivoire, and Sudan. Thus, industrial policy has the potential to support structural transformation in the region as a whole, but it holds much more promise for some countries than others.

\footnotetext{
1 'Fragile' and 'weak' are used interchangeably here to refer to states that lack legitimacy, authority, and capacity to fulfil basic state functions, as discussed further in Section 5.3. The opposite is referred to as a 'capable' or 'robust' state.
} 
In order to more fully understand the practice and promise of industrial policy in SSA, therefore, more attention should be paid to the systematic study of weak state capability and strategies to address the challenges it poses, in particular through so-called 'islands of success' (Dinh et al. 2013). This can help both national governments and donors in better crafting of more flexible and country-specific approaches to industrial strategy (see UNIDO 2013: 144-50).

Bringing together key findings from work on industrial policy and on state fragility, this chapter explores promising avenues for deepening research along these lines. These recent literatures have each highlighted a central role for the state, but the treatment of the state differs remarkably from one to the other. ${ }^{2}$ Recent work on fragility, on the one hand, pays particular attention to the causes, consequences, and contours of state weakness. It conceptualizes and measures the dimensions of state strength/weakness and explores the role of the state with respect to security, the rule of law, and the provision of public goods and services (see Engberg-Pedersen, Andersen, and Stepputat 2008; Brinkerhoff 2014). Significant related work considers the impact on economic development of patrimonialism, corruption, economic mismanagement, internal divisions, and weak institutional capacity (see, e.g., Naudé, Santos-Paulino, and McGillivray 2011; Addison 2012).

On the other hand, recent research on industrial policy—and in particular, the New Structural Economics (NSE)—highlights how states in developing countries can take better advantage of opportunities and design appropriate strategies for structural transformation (Lin 2011). The focus is decidedly not on how a state's characteristics might impact its ability to implement such a strategy. The state, as treated in the NSE, appears as basically a unitary actor, supportive of national development (or at least not inimical to it), and capable 'enough' - almost the mirror image of the fragile state. That said, earlier work on industrial policy has explored the relationship between state weakness and industrial transformation (e.g., Amsden 1989; Wade 1990; Evans 1995; Kohli 2004) and offers useful frameworks to guide further research in this area.

This chapter has five sections. Section 5.2 makes a case for further consideration of the state-and of state fragility in particular-in current research on industrial policy. Section 5.3 considers dimensions of state fragility, presenting evidence that contemporary SSA is an outlier relative to other regions and thus deserving of special focus in discussion of the state and industrial policy. It relatedly critiques the claim in recent work on industrial policy that contemporary state fragility in SSA is no different to historical state fragility in many of today's industrialized countries. Section 5.4 reviews key hypotheses

2 Two exceptions are Briscoe (2009) and Hoeffler (2012). See also Fritz and Menocal (2007). 
about the relationship between state capability and ineffective industrial policy, building from Evans' (1995) juxtaposition of archetypical predatory and developmental states and Kohli's (2004) discussion of state types. This work provides useful frameworks upon which to build, while underscoring the need for better understanding of the precise channels or processes through which state weakness hampers industrial transformation. Section 5.5 concludes and considers areas for future research.

\subsection{The State and Industrial Policy}

The relationship between states and markets is at the heart of competing theories of economic growth and industrial transformation. ${ }^{3}$ In the simple neoclassical view, markets work best when the state's role is limited. The state should act primarily as a 'rule maker' and 'umpire' to maintain macroeconomic stability and to provide secure property rights, the rule of law, and certain essential public goods to facilitate market functioning (Friedman 1982: 25-7; Wade 1990: 11). In structuralist economics, by contrast, states are necessary to create well-functioning markets and development. Beginning with Rosenstein-Rodan (1943), this role has been emphasized especially for late industrializing countries. Economic sociology likewise built on Polanyi's ([1944] 1967) analysis of the emergence of industrial capitalism in 19thcentury England to emphasize both the economic and political factors underlying capitalist development.

Industrial policy by definition implies a central state role, thus it has been linked historically to a more structuralist approach, although neoclassical arguments also have been advanced for industrial policy (see Krueger 1993; Rodrik, Grossman, and Norman 1995; Stiglitz and Greenwald 2015). ${ }^{4}$ As Warwick (2013: 16) defines it:

Industrial Policy is any type of intervention or government policy that attempts to improve the business environment or to alter the structure of economic activity toward sectors, technologies or tasks that are expected to offer better prospects for economic growth or societal welfare than would occur in the absence of such intervention.

\footnotetext{
3 This topic has been covered in considerable depth in other work and is reviewed only briefly here. See, e.g., Woo (2011), Lin (2012), and Wade (1990).

4 'State' refers here to the sovereign territory and institutions through which it is governed, while 'government' refers to the group of individuals in office at a point in time. In Wade (1990: 8, n. 1), 'government' refers to the executive branch and 'state' to the wider structure of governance institutions, so much of his discussion of the role of 'government' in industrial transformation relates to the role of the 'state' as the term is used here.
} 
As the United Nations Industrial Development Organization (UNIDO) describes:

The state can promote policy either as a regulator, financier, producer or consumer, using policy instruments that target key drivers of structural change: education and skills, capital and technology, and material inputs. In this targeting the state should oversee close coordination with other policies such as those on competition, trade and foreign direct investment (FDI), as well as the exchange rate, as they can undermine the objectives of industrial policy if misaligned. (UNIDO 2013: 132)

While the first wave of modern development thinking after the Second World War had a more structuralist bent, by the late 1960s and 1970s mainstream economists had become suspicious of the role of the state and industrial policy (Wade 1990: 8-14; Lin 2012: 3-5). This more neoclassical approach came to dominate multilateral development policy, with emphasis on economic liberalization, privatization, stabilization, and rejection of import substitution industrialization.

The Washington Consensus held in policy circles through the 1990s (Birdsall, de la Torre, and Valencia Caicedo 2010), but the 1980s also saw increasing research attention to 'bringing the state back in' (Evans, Rueschemeyer, and Skocpol 1985). In Governing the Market, Wade (1990) presented a defence of industrial policy, highlighting the state's central role in industrialization. Building on Wade, subsequent work explored in more depth how different types of states influence industrialization. Evans' (1995) analysis of 'embedded autonomy' in particular highlighted how the state's internal organization and the structure of its ties to society distinguish 'developmental' states that successfully employed industrial policy from 'predatory' states that did not. While much of this literature focused on successful industrializers-with particular attention to the East Asian Tigers (Hong Kong, South Korea, Singapore, and Taiwan) - the role of the state in 'intermediate' cases, such as Brazil and India, also received focused attention.

In more recent years, industrial policy has received new attention through Justin Lin's research program on NSE during his tenure as World Bank Chief Economist (2008-11). NSE might be understood as a middle ground between neoclassical and structural approaches. Building on a neoclassical approach to economic structure, it argues that states and governments in developing countries should play an active role in industrial transformation. Advantages to late development can be achieved if states help to mitigate the coordination and externality problems inherent in upgrading the industrial structure and infrastructure.

'New structural' economists further argue against the so-called 'Afropessimist' position that industrial policy is unwise and impractical for SSA 
countries due to a variety of constraints-both structural factors (such as climate, geography, history, culture, and natural resources) and political and institutional factors (such as state coherence, bureaucratic capabilities, and political leadership) (Chang 2012). With respect to the latter in particular, the new structural position highlights that such problems should not hinder industrial policy in the region because: (1) they are not unique to SSA countries; and (2) 'the advanced economies all suffered from these problems in the past' (Chang 2012). As Section 5.3 explores, it is true that such problems are not unique to SSA countries, but SSA countries appear to be disproportionately affected by them. The second point also requires further empirical examination for several reasons:

First, the literature has paid relatively little systematic attention to contemporary state weakness. In particular, the argument that state weakness in developing countries today can be equated with historical state weakness in developed countries is supported much more by historical analysis than empirical examination of contemporary cases. Chang's (2003) book, Kicking Away the Ladder, for instance, explores how the rich countries became rich. Likewise, the empirical analyses in Chang (2007) focus on Britain, the US, Switzerland, Brazil, Taiwan, China, and "three "successful" African economies'-Mauritius, Botswana, and Uganda. This work tells us a lot about institutional change in once-weak states, but we still cannot be sure that contemporary state weakness is the same as historical state weakness unless we also study contemporary state weakness.

Second, as these examples suggest, the extant literature speaks more to understanding development success than development failure. Classic work on East Asia also focused more on understanding their remarkable industrial transformation and economic growth, rather than failed transformations (Amsden 1989; Wade 1990; Evans 1995). Lin (2011) similarly draws lessons mainly from countries that achieved sustained growth and high incomes through industrialization: Western European countries, the US, Japan, Hong Kong, China, South Korea, Singapore, and Taiwan.

For social science methodologists, learning from success alone represents a classic problem: selecting on the dependent variable (Geddes 1990). Failing to study both instances in which a phenomenon occurs and those in which it does not, means that we cannot know which factors are common to both, and this weakens our ability develop and test causal hypotheses (see Gisselquist 2014c). Indeed, some scholars go so far as to argue that 'nothing whatsoever can be learned about the causes of the dependent variable without taking into account other instances when the dependent variable takes on other values' (King, Keohane, and Verba 1994: 129).

The new structuralists are certainly correct that many of today's developed countries were historically weak states and that they were nevertheless able to 
successfully employ industrial policy. However, it may be that countries that failed to develop historically were even weaker states or were weak in particular ways that hindered industrial transformation. Thus, without analysis of failed industrialization, we cannot test Chang's contention that challenging political and institutional factors are largely irrelevant to the success of industrial policy in today's fragile states. Nor, by extension, do we have much traction on understanding precisely how political and institutional variables may matter-and how policies might be designed to mitigate their effects.

Earlier work on industrialization, such as Evans (1995) and Kohli (2004), does speak to the relationship between different state types and successful industrial transformation, as discussed in Section 5.4. By themselves, however, they are also incomplete: in Evans (1995: 43-7), for instance, state fragility and institutional weakness are clearly not the focus. The main case of failure-Zaire-is reviewed in just five (of 323) pages. Kohli (2004) offers more-a quarter of his book is devoted to 'dashed expectations' in Nigeriaand developing further analyses along these lines is an important area for future work.

Third, the emerging literature in the NSE is especially open to criticism by scholars of weak states. In contrast to the historical institutionalist approach to the state adopted by Wade, Evans, Kohli, and others, the NSE has adopted a distinctly more rationalist approach. In the NSE, the state appears as a largely unitary actor interested in national development. The central challenge is in identifying the opportunities and strategies that such a state should take advantage of in supporting structural transformation, not in understanding why and how some states take advantage of such opportunities and some do not. This view of the state-as unitary, supportive of national development, and basically capable-is almost the mirror image of the fragile state.

\subsection{State Fragility in SSA}

Fragile states are defined by what they lack: legitimacy, authority, and capacity to fulfil basic state functions, such as the provision of security, the rule of law, and core public services (see World Bank 2011; Addison 2012; Gisselquist 2014a; UNU-WIDER 2014). In a much cited definition, 'states are fragile when state structures lack political will and/or capacity to provide the basic functions needed for poverty reduction, development and to safeguard the security and human rights of their populations' (OECD/DAC 2007: 2). ${ }^{5}$

\footnotetext{
5 This definition has the benefit of simplicity but is now a bit out of fashion in policy circles. A more recent definition from OECD (2012: 85) is: 'A fragile region or state has weak capacity to carry out basic governance functions, and lacks the ability to develop mutually constructive relations with society.
} 
Fragility then implies the state's inability and/or lack of interest in fully supporting national development. The depth of social, communal, and political divisions in many fragile states is also notable, suggesting the importance of not treating states as unitary actors but instead considering how factional politics within the bureaucracy and polity influence political outcomes. Such political economy approaches are now considered best practice for development policy in fragile states (see Booth 2012).

Notwithstanding considerable debate in the literature over how state capability should be measured (Fabra Mata and Ziaja 2009), it is clear that SSA is an outlier. According to standard metrics, not only are a disproportionate share of SSA states fragile, but the region is also home to most of the world's fragile states. This is illustrated in Table 5.1, a list of all states classified as 'fragile' in both the OECD's Fragile States 2014 and the World Bank's 2014 Harmonized List of Fragile States and Situations. It includes twenty-nine SSA states-that is, well over half of all forty-nine countries in the region and well over half of all fifty-one fragile states and situations on the list.

If we dig a bit deeper into such standard measures, we can also see that SSA countries on average are considered to have worse performance than other regions in a variety of specific areas relevant to industrial policy. This is illustrated for one in the World Bank's Country Policy and Institutional Assessment (CPIA) ratings, which are used by the World Bank to identify fragile states. CPIA ratings offer assessment across sixteen areas, grouped into four categories: economic management, structural policies, policies for social inclusion/equity, and public sector management and institutions. Simple comparison of average 2013 scores for SSA as compared to non-SSA countries shows that the region tends to have lower scores on average in all but two of the sixteen areas (fiscal policy, and policy and institutions for environmental sustainability), as Table 5.2 shows. Furthermore, looking at overall CPIA scores, the World Bank identifies as fragile those countries with ratings of 3.2 and below, and the 'average' SSA country is fragile according to this threshold. ${ }^{6}$

Variation in state capabilities between SSA and other world regions is also suggested by other standard measures. Figure 5.1 presents another example, this from the Worldwide Governance Indicators (WGI), showing 2014 averages for all world regions across WGI indicators for government effectiveness,

Fragile regions or states are also more vulnerable to internal or external shocks such as economic crises or natural disasters. More resilient states exhibit the capacity and legitimacy of governing a population and its territory. They can manage and adapt to changing social needs and expectations, shifts in elite and other political agreements, and growing institutional complexity. Fragility and resilience should be seen as shifting points along a spectrum.'

${ }^{6}$ It also includes International Development Association (IDA)-eligible countries with United Nations (UN) and/or regional peacekeeping or peace-building missions. 
Table 5.1. Fragile states in 2014

\begin{tabular}{|c|c|}
\hline In SSA & In Other Regions \\
\hline Angola* & Afghanistan \\
\hline Burkina Faso* & Bangladesh* \\
\hline Burundi & Bosnia and Herzegovina \\
\hline Central African Republic & Egypt* \\
\hline Cameroon* & Haiti \\
\hline Chad & Iraq \\
\hline Comoros & Kiribati \\
\hline Congo, Democratic Republic & Korea, DPR* \\
\hline Congo, Republic of & Kosovo \\
\hline Côte d'Ivoire & Libya \\
\hline Eritrea & Marshall Islands \\
\hline Ethiopia* & Micronesia, Federated States \\
\hline Guinea* & Myanmar \\
\hline Guinea-Bissau & Nepal \\
\hline Kenya* & Pakistan* \\
\hline Liberia & Solomon Islands \\
\hline Madagascar & Sri Lanka* \\
\hline Malawi & Syria \\
\hline Mali & Timor-Leste \\
\hline Mauritania* & Tuvalu \\
\hline Niger* & Yemen \\
\hline Nigeria* & West Bank and Gaza \\
\hline \multicolumn{2}{|l|}{ Sierra Leone } \\
\hline \multicolumn{2}{|l|}{ Somalia } \\
\hline \multicolumn{2}{|l|}{ South Sudan } \\
\hline \multicolumn{2}{|l|}{ Sudan } \\
\hline \multicolumn{2}{|l|}{ Togo } \\
\hline \multicolumn{2}{|l|}{ Uganda* } \\
\hline Zimbabwe & \\
\hline
\end{tabular}

Note: The World Bank's list includes only IDA eligible countries. All countries included in World Bank (2014) are also included in OECD (2014). *indicates listed in OECD (2014) but not World Bank (2014).

Source: Author, based on OECD (2014) and World Bank (2014).

regulatory quality, and control of corruption. With one exception, SSA lags behind all regions in all three indicators.

While we should be careful in reading too much into such comparisons given ample critiques of both these and other such measures (e.g., Arndt and Oman 2006; Gisselquist 2014b; Rocha De Siqueira 2014), they illustrate clearly the simple point that SSA states are characterized disproportionately as 'fragile'. Thus, given the important role of the state in industrial policy, we should be cautious in applying findings and expectations about industrial policy from other world regions to contemporary SSA.

It is also worth highlighting the variation in state capabilities within SSA, as well as the similarities in state capabilities between many SSA countries and those in other world regions. This is illustrated also in the CPIA ratings. Table 5.3 uses the 2013 overall CPIA scores as an indicator of the comparative 
Table 5.2. Average 2013 CPIA scores for SSA as compared to other regions (on a scale of 1-6)

\begin{tabular}{|c|c|c|c|}
\hline & & $\begin{array}{l}\text { SSA Countries } \\
\text { (Average) }\end{array}$ & $\begin{array}{l}\text { Other } \\
\text { Countries } \\
\text { (Average) }\end{array}$ \\
\hline \multirow[t]{4}{*}{ Economic management } & Monetary and exchange rate policy & 3.5 & 3.6 \\
\hline & Fiscal policy & 3.3 & 3.3 \\
\hline & Debt policy & 3.3 & 3.5 \\
\hline & Average for 'economic management' & 3.4 & 3.5 \\
\hline \multirow[t]{4}{*}{ Structural policies } & Trade & 3.7 & 4.0 \\
\hline & Financial sector & 2.9 & 3.0 \\
\hline & Business regulatory environment & 3.1 & 3.3 \\
\hline & Average for 'structural policies' & 3.2 & 3.4 \\
\hline \multirow{6}{*}{$\begin{array}{l}\text { Policies for social inclusion/ } \\
\text { equity }\end{array}$} & Gender equality & 3.2 & 3.5 \\
\hline & Equity of public resource use & 3.3 & 3.6 \\
\hline & Building human resources & 3.5 & 3.7 \\
\hline & Social protection and labour & 2.9 & 3.1 \\
\hline & $\begin{array}{l}\text { Policy and institutions for } \\
\text { environmental sustainability }\end{array}$ & 3.1 & 3.1 \\
\hline & $\begin{array}{l}\text { Average for 'policies for social inclusion/ } \\
\text { equity' }\end{array}$ & 3.2 & 3.4 \\
\hline \multirow[t]{6}{*}{$\begin{array}{l}\text { Public sector management } \\
\text { and institutions }\end{array}$} & $\begin{array}{l}\text { Property rights and rule-based } \\
\text { governance }\end{array}$ & 2.7 & 3.0 \\
\hline & $\begin{array}{l}\text { Quality of budgetary and financial } \\
\text { management }\end{array}$ & 3.0 & 3.4 \\
\hline & Efficiency of revenue mobilization & 3.4 & 3.5 \\
\hline & Quality of public administration & 2.8 & 3.0 \\
\hline & $\begin{array}{l}\text { Transparency, accountability and } \\
\text { corruption in public sector }\end{array}$ & 2.7 & 3.1 \\
\hline & $\begin{array}{l}\text { Average for 'public sector management } \\
\text { and institutions' }\end{array}$ & 2.9 & 3.2 \\
\hline \multicolumn{2}{|l|}{ Overall rating } & 3.2 & 3.4 \\
\hline
\end{tabular}

Source: Author, based on World Bank's CPIA 2013. Available at: <http://datatopics.worldbank.org/cpia/> (accessed 14 November 2015).

capability of SSA states. The second column lists the thirty-nine SSA countries assessed in the 2013 CPIA in order of highest to lowest overall score. The twenty listed in bold are fragile according to the 3.2 threshold. As shown, if we focus on overall scores that fall within one standard deviation of the world mean (3.3), most SSA countries in fact have comparatively average institutional capability. Nine have scores below this middle band ('relatively weak'), while six have scores above it ('relatively robust').

In discussions about industrial policy in SSA, we generally hear more about countries at the top of the list in Table 5.3. We should also keep in mind the countries more towards the bottom of the list. What specifically are the expected prospects for industrial policy in these countries?

Finally, it is important to note that none of the standard indicators of state capability allow for historical comparison. The WGI, for instance, is available from 1996, and the CPIA currently from 2005. None of these indicators can 


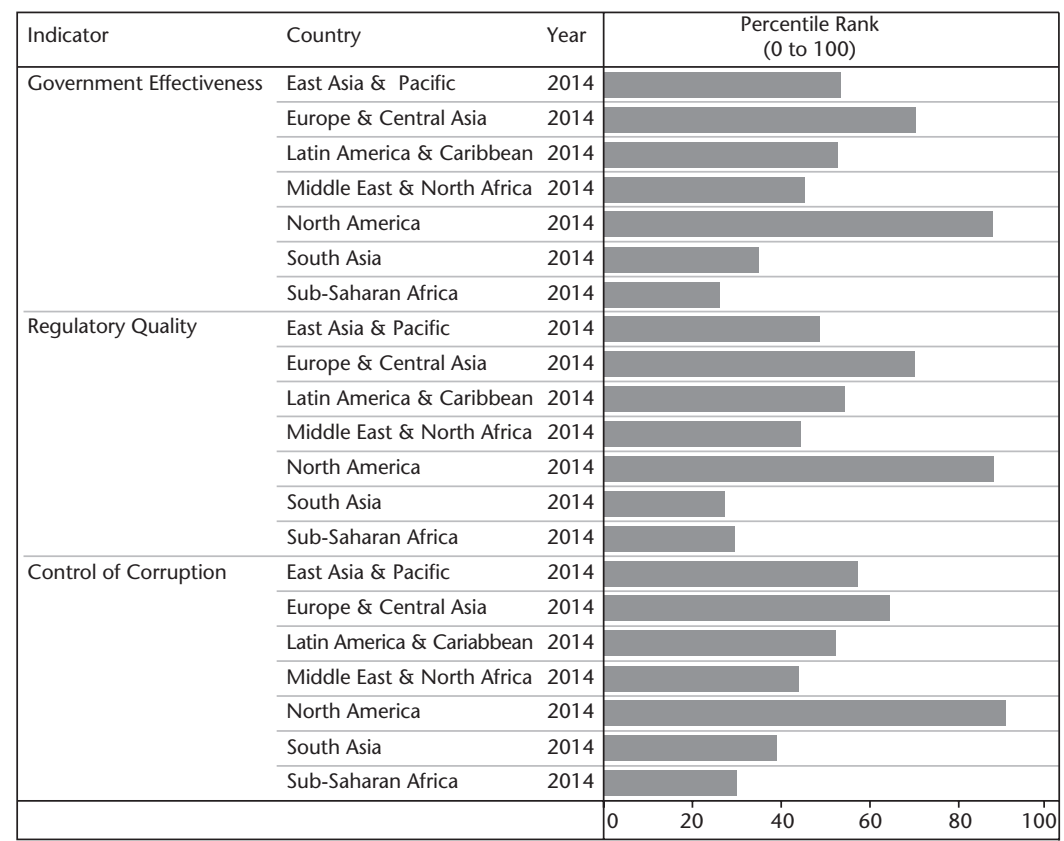

Figure 5.1. Selected WGI, 2014: a comparison of regional averages

Source: Figure from the Interactive Data Access tool for the WGI at <http://info.worldbank.org/ governance/wgi/index.aspx\#reports> (accessed 14 November 2014), based on Kaufmann et al. (2010).

Table 5.3. Comparative capabilities of African states based on 2013 overall CPIA scores

\begin{tabular}{|c|c|}
\hline CPIA score & Countries \\
\hline $\begin{array}{l}\text { Relatively robust (CPIA }>3.7 \text {, or } 1 \\
\text { standard deviation above world mean) }\end{array}$ & $\begin{array}{l}\text { Cape Verde, Rwanda, Kenya, Senegal, Burkina Faso, } \\
\text { Tanzania }\end{array}$ \\
\hline Average $(3.7<=\mathrm{CPIA}<2.8)$ & $\begin{array}{l}\text { Uganda, Ghana, Mozambique, Nigeria, Benin, Lesotho, } \\
\text { Niger, Ethiopia, Zambia, Mali, Mauritania, The Gambia, } \\
\text { Sierra Leone, Burundi, Cameroon, Côte d'Ivoire, Liberia, } \\
\text { Malawi, São Tomé and Príncipe, Republic of Congo, } \\
\text { Madagascar, Guinea, Togo, Democratic Republic of the } \\
\text { Congo }\end{array}$ \\
\hline Relatively weak $($ CPIA $<=2.8)$ & $\begin{array}{l}\text { Comoros, Angola, Chad, Guinea-Bissau, Central African } \\
\text { Republic, Sudan, Zimbabwe, South Sudan, Eritrea }\end{array}$ \\
\hline
\end{tabular}

Source: Author, based on World Bank's CPIA 2013. Available at: <http://datatopics.worldbank.org/cpia/> (accessed 14 November 2015).

thus be used to examine the claim that today's developed countries had similarly weak state capability to today's fragile states. The discussion in Section 5.2 reviews several methodological reasons for why this claim requires further empirical analysis. The literature on fragility and state weaknesses underscores several further reasons: 
The first has to do with qualitative differences in fragility and comparisons between the East Asian Tigers and SSA (see Aryeetey and Moyo 2012). East Asian countries experienced periods of significant political instability and violence prior to their rapid growth and thus some might be classified retrospectively as 'fragile' during these periods. However, as Gisselquist (2014a) argues, they were not fragile in the same way as many contemporary SSA states as they had generally significant and extended experiences with effective statehood prior to their periods of conflict (see Gray 2014; Kim 2015). Many SSA countries-in conflict, postconflict, or outside of conflict-have never had effective states; only rarely do historical SSA polities coincide with contemporary state boundaries (Rwanda is a key exception) (see McDoom 2009). In other words, while East Asian states might be classified in retrospect as temporarily fragile, chronic fragility is the challenge in contemporary SSA (see also Englebert and Tull 2008; Gisselquist 2015).

Second, the literature on the state in Africa highlights additional ways in which states in the region may be relatively distinct, even when compared to other historical and contemporary states at similar levels of development. Placing the African state-building process in comparative perspective, Herbst (2000) in particular finds differences with the European experience stemming from the particular geography and settlement patterns in the region. In SSA, Herbst argues, relatively lower population density across vast regions with more varied topography meant that states never had the same territorial control as in Europe, making state authority characteristically different. Other work has emphasized the distinct influence of colonial institutions on state capabilities and legitimacy in some SSA countries (see Migdal 1988; Kohli 2004; Acemoglu and Robinson 2006).

Third, drawing lessons about contemporary state weakness from historical state weakness may also be problematic due to changes in the international system. Jackson and Rosberg (1982) argue that whereas state jurisdictions historically resulted in Europe from effective statehood, the modern state system provides juridical recognition and longevity to entities in SSA that de facto are not effective states. More recent work has highlighted the contemporary international norm of 'border fixity' in maintaining weak states and contributing to political instability (Atzili 2011). Highlighting the role of development agencies in the modern international system, Pritchett, Woolcock, and Andrews (2013) further contend that aid has served to support 'state capability traps' in some contexts by providing a continued flow of development resources and legitimacy to states that 'look like' states without 'delivering' like states.

Putting these various pieces together, Mann's (1984) discussion of state power offers a useful preliminary way of thinking about the nature of diverse state capabilities to successfully implement industrial policy for national structural transformation. Mann highlights two dimensions of state power vis-à-vis non-state actors. The first he describes as the 'despotic' power of the 
state elite over civil society, and the second the 'infrastructural' power of the state 'to penetrate and centrally coordinate the activities of civil society through its own infrastructure' (Mann 1984: 114). Putting these two dimensions together gives four ideal types based on 'low' or 'high' power on each dimension: 'feudal' (low infrastructural power, low despotic power), 'imperial' (low infrastructural power, high despotic power), 'bureaucratic' (high infrastructural power, low despotic power), and 'authoritarian' (high infrastructural power, high despotic power) (Mann 1984: 115).

The CPIA measures summarized in Section 5.3 underscore the generally low infrastructural power of SSA states (setting aside important inter-country variation). Likewise, 'despotic power' is low-in Mann's sense-if the state is not autonomous from society, that is, if private, non-state interests such as family, clan, ethnic, or communal group loyalties exercise a high degree of influence in public affairs. This suggests the typical fragile state would fall in the 'feudal' quadrant of Mann's typology.

By contrast, as explored more fully in Section 5.4, the literature on the state in successful industrializers suggests relatively high infrastructural power and a middling level of despotic power (as the concept of 'embedded autonomy' suggests, Evans (1995)). This suggests states that fall somewhere between the 'bureaucratic' and 'authoritarian' quadrants of Mann's typology. Think of Baeg Im's (1987) discussion of the bureaucratic-authoritarian model of South Korean industrialization.

\subsection{Variations in Statehood and Industrial Policy: Two Frameworks}

How precisely should we expect such differences in states to influence the success or failure of industrial policy? What particular institutional characteristics or weaknesses are associated with ineffective industrial policy? Through what channels do such processes play out? Evans (1995) and Kohli (2004) provide two approaches upon which to build.

Evans' (1995: 50) analysis highlights two ideal state types: developmental states that foster industrial transformation and predatory states-their 'mirror image' - that do not. The archetypical example of a predatory state is Mobutu Sese Seko's Zaire (now the Democratic Republic of the Congo (DRC)). In Mann's terms, the Zairian state under Mobutu might be characterized as 'feudal': it had weak infrastructural power to coordinate and address the needs of diverse interests, and it had weak despotic power in the sense that

\footnotetext{
7 Evans (1995: 45-7) discusses Mann's approach to state power with reference to predatory states, but characterizes it slightly differently.
} 
the state's actions under Mobutu were indistinguishable from the private interests of the ruling junta-at the core of which was a 'presidential clique' of some fifty kinsmen (Gould 1979: 93; Evans 1995: 46). But in classifying Mobutu's Zaire as a predatory state, Evans' analysis goes further. Beyond its poor development performance, key to this classification are its internal organization and the structure of its ties to society, characterized both by the lack of a state bureaucracy and the government's efforts toward the (violent) destruction of civil society:

While the Zairian state's ability to penetrate and reshape civil society is certainly imperfect, the Mobutu regime has been quite effective at disorganizing civil society. It has systematically worked at weakening the cohesion of traditional collectivities.... Zaire confirms our initial suspicion that it is not bureaucracy but its absence that makes the state rapacious. At the same time, Zaire suggests that is it not so much 'weakness' in relation to civil society that prevents the state from fostering transformation. Instead the state's energies are directed toward preventing the emergence of social groups that might have an interest in transformation. (Evans 1995: 47)

Predatory states for Evans are defined by what they lack, embedded autonomy, which 'combines Weberian bureaucratic insulation with intense connection to the surrounding social structure' and is 'the key to the developmental state's effectiveness':

Given a sufficiently coherent, cohesive state apparatus, isolation is not necessary to preserve state capacity. Connectedness means increased competence instead of capture. How autonomy and embeddedness are combined depends, of course, on both the historically determined character of the state apparatus and the nature of the social structure... (Evans 1995: 50)

For weak states, Evans' analysis thus highlights the problems posed for industrial policy by the lack of a 'modern' state bureaucracy in the Weberian sensea 'coherent, cohesive state apparatus'. It implies constraints, for one, in terms of the administrative, logistical, and technical ability of the state to implement policies. Equally important, Evans suggests, it implies state capture by private interests and thus the state's inability to act in the broader national interest. In short, Evans' analysis highlights that the absence or weakness of a coherent state bureaucracy is at the core of understanding the prospects for successful industrial policy by fragile states; this suggests that figuring out how to mitigate this bureaucratic absence or weakness-in whole or (more likely) in part-is the central challenge for proponents of industrial policy for structural transformation in SSA.

Precisely how incoherent does a bureaucracy have to be for it to stand in the way of successful industrial policy? There is considerable variation in the coherence of bureaucracies across SSA states, even across those considered fragile. Evans offers a partial response in his analysis of intermediate states. 
Brazil and India, his two examples, present different models and suggest several ways forward for industrial policy in weaker states:

Brazil, Evans (1995: 64) argues, 'is testimony to the fact that it takes only a very rough approximation of the Weberian ideal type to confer advantage. Even developmental states are only approximations of the ideal type, but intermediate states show that the basic bureaucratic model can be stretched further and still deliver.' Despite the incoherence of the system as a whole, Weberian bureaucracy can be found in many Brazilian state agencies. In addition, Brazilian leaders from the 1950s worked to mitigate weaknesses in the state bureaucracy by creating 'pockets of efficiency' (Evans 1995: 61), that is, 'insulated agencies outside the traditional bureaucracy, charged with specific, usually developmental, tasks and accountable to the executive' (Geddes 1994: 61). Key examples include the National Development Bank (BNDE, founded in 1952); the grupo executivo, groups created by presidential decree to implement particular development goals; and Petrobrás, the state oil company (Geddes 1994: 61-9). These agencies implemented 'some of Brazil's most impressive pre-1964 economic achievements' (Geddes 1994: 61).

India, Evans finds, has a bureaucratic apparatus much closer to the Weberian ideal than Brazil, but its developmental prospects are challenged by its social structure and state-society relations which are more complex than those in East Asia's developmental states. This complexity factors in to India's intermediate state status in several ways. For one, it means higher demands on the bureaucracy: 'ethnic, religious, and regional divisions add to the administrative nightmare of trying to govern (say nothing of develop)' the country (Evans 1995: 67). It also implies more complexity in the state's relationship with society, with implications for industrial policy: the survival of political elites relies both on the support rural landowning elites (even more than in Brazil) and of highly concentrated industrial capitalists, a delicate balancing act. Despite such challenges, Evans assessed the Indian state as having contributed to structural transformation largely through state investment in basic agricultural inputs and basic and intermediate industries like steel and petrochemicals.

In thinking about industrial prospects in SSA, the Indian example may be especially apt in one sense: like India, SSA countries on average stand out in terms of their ethno-linguistic and regional diversity (see Alesina et al. 2003). Evans' consideration of the Indian experience suggests that the historical coherence of the Indian state bureaucracy-which is in contrast to the state's incoherence in many fragile states-played a key role in mitigating these societal challenges.

A second approach is developed in Kohli (2004)'s work on state-directed development. Kohli highlights three state types in the contemporary developing world: 'cohesive-capitalist' or developmental states, 'fragmented- 
multiclass', and 'neopatrimonial', a declining spectrum of political effectiveness. In Kohli's schema, the three types are defined by the cohesion of state authority among elites and at the elite-mass level, and by state-class relationships. Like Evans' predatory states, neopatrimonial states lack the modern state bureaucratic apparatus held by the other two and his more detailed consideration of these weakest states, in particular, adds important elements to our consideration of industrial policy in SSA.

Like cohesive-capitalist and fragmented-multiclass states, neopatrimonial states have sometimes intervened heavily in their economies-but had 'disastrous' results (Kohli 2004: 15). Weak private sectors are characteristic of neopatrimonial states. These states themselves may further weaken the private sector by appropriating economic resources and employing inconsistent economic policies. Instead of working with domestic capitalists, neopatrimonial states thus tend to invite in foreign capitalists or act directly in the economy themselves. The latter strategy tends to have little success due to the weakness of the state's administrative capabilities.

Kohli's key example of a neopatrimonial state is Nigeria, whose efforts towards industrialization he describes as 'a dismal failure' (Kohli 2004: 329). The key problem has been the nature of the Nigerian state and state capture: 'Whatever the current regime, the Nigerian state has repeatedly lacked the commitment and the capacity to facilitate economic transformation, as state elites focused their energies on maintaining personal power and on privatizing public resources'(Kohli 2004: 329).

Basic challenges of administrative capacity also impede the design and implementation of policy. The Economist's observation in its 1982 survey of Nigeria suggests just some of them: 'This is the first survey published by the Economist in which every number is probably wrong. There is no accurate information about Nigeria. ${ }^{\prime 8}$ Analogous challenges with basic national statistics in many SSA countries have recently received considerable attention (see Round 2012; Jerven 2013).

It is worth noting that other analyses of Nigeria in particular offer different perspectives on industrial prospects. Lin and Treichel (2012: 219, 221-2), for instance, note Nigeria's sustained expansion since 2001 across all sectors of the economy, although 'notwithstanding Nigeria's strong economic performance over the past 10 years, its export and production structure has shown little diversification'.

\footnotetext{
8 The Economist (31 January 1982), p. 4, as quoted in Kohli (2004: 331).
} 


\subsection{Conclusion and Areas for Future Research}

Industrial policy has considerable potential to promote structural transformation in SSA, but as this chapter shows, weak state capability also influences industrial prospects and SSA faces particular challenges in this regard. Care should be taken in attempting industrial policy in fragile settings-and SSA has many such settings. Further, while new structural economists are correct that many advanced industrialized countries were once weak states, state weakness today, particularly in SSA, may be different in kind and thus require more focused research in several key areas:

The first is more theoretically grounded empirical analysis of the state and industrial policy along the lines outlined in Section 5.4, to flesh out the distinction between intermediate/fragmented-multiclass and predatory/neopatrimonial states. Analyses should provide, on the one hand, empirical documentation of diverse experiences with industrial policy (successful and failed) in states in the lower half of Table 5.3. These analyses should be designed explicitly to provide traction on more precise hypotheses about the relationship between weak state capabilities and industrial prospects: in Evans' analysis, for instance, the comparison of the Indian and Brazilian experiences suggests that a coherent state apparatus alone is not enough. Extremely factionalized societies can mean the difference between developmental and intermediate statehood. But how factionalized does a society need to be to push a state from the intermediate to the predatory type? Alternatively, what happens when the state apparatus is less coherent and the social structure equally complex? Or, building on Kohli, can we expect different outcomes in neopatrimonial states in which stronger private sectors have emerged? How strong would the private sector need to be to balance the neopatrimonialism of the state?

A second key area for future research concerns how various international and domestic actors might support accelerated state construction or strengthening. The literature on state-building suggests reasons for both optimism and pessimism in terms of this project (see Fukuyama 2004). Both Evans' and Kohli's analyses of the factors that influence state types point toward the latter, highlighting historical trajectories and institutional path dependency (i.e., the difficulty of rapidly altering state type).

In a related vein, one interesting approach points to efforts to improve business-government collaboration (UNIDO 2013: 145-6). As the discussion of Brazil and India suggests, this can be a key sticking point for intermediate states in pursuing industrial policy. Drawing on Latin American experiences, Schneider (2013: 1) explores three key functions of such efforts: 'i) maximizing the benefits of dialogue and information exchange; ii) motivating participation through authoritative allocation; and iii) minimizing unproductive 
rent seeking'. Further work could be done along these lines to explore SSA experiences in facilitating business-government collaboration.

Finally, as Section 5.4 suggests, perhaps the most promising approach to state capacity-building highlighted by the Brazilian case is focus on 'islands of success' or 'pockets of efficiency'. Nevertheless, existing research also suggests some challenges and drawbacks. In Brazil, Evans (1995: 61-3) highlights the following:

- Their reliance on presidential support made them vulnerable (in terms of their existence and mission) to changes in executive leadership.

- They further served to reinforce paternalistic ties (see Schneider 1991).

- Their existence itself contributed to the state's incoherence: 'trying to modernize by piecemeal addition ... undercuts the organizational coherence of the state apparatus as a whole' (Evans 1995: 62).

- The unstable nature of their political support had negative effects on the career trajectories of civil servants-who could not count on long-term state employment-and thus on the development of the professional bureaucracy.

- Finally, because the Brazilian political leaders in the executive branch who supported these agencies relied on landed elites for support, they effectively fused the interests of the state with traditional oligarchic power, thus impeding collaboration with industrial capital.

Future research would do well to explore these challenges in greater depth and in light of experience with islands of success in diverse country contexts. Such work would speak directly to both major theoretical and policy concerns, including the challenge of supporting transformation and building state capability in fragile states.

\section{Acknowledgements}

I am grateful to the participants in the authors' workshop on 'The Practice of Industrial Policy: Lessons for Africa', 9-10 March 2015-in particular Hinh T. Dinh, Eun Mee Kim, Lotta Moberg, John Page, and Finn Tarp, for valuable comments and support.

\section{References}

Acemoglu, D., and J. A. Robinson (2006). Economic Origins of Dictatorship and Democracy. Cambridge: Cambridge University Press. 
Addison, T. (2012). 'The Political Economy of Fragile States'. In G. K. Brown and A. Langer (eds), The Elgar Handbook of Civil War and Fragile States. Cheltenham: Edward Elgar.

Ajakaiye, O., and J. Page (2012). 'Industrialisation and Economic Transformation in Africa: Introduction and Overview'. Journal of African Economies, 21(Supplement 2): ii3-ii18.

Alesina, A., A. Devleeschauwer, W. Easterly, S. Kurlat, and R. Wacziarg (2003). 'Fractionalization'. Journal of Economic Growth, 8(2): 155-94.

Amsden, A. H. (1989). Asia's Next Giant: South Korea and Late Industrialization. New York: Oxford University Press.

Arndt, C., and C. Oman (2006). Uses and Abuses of Governance Indicators. Paris: OECD Development Centre.

Aryeetey, E., and N. Moyo (2012). 'Industrialisation for Structural Transformation in Africa: Appropriate Roles for the State'. Journal of African Economies, 21(Supplement 2): ii55-ii85.

Atzili, B. (2011). Good Fences, Bad Neighbors: Border Fixity and International Conflict. Chicago: University of Chicago Press.

Baeg Im, H. (1987). 'The Rise of Bureaucratic Authoritarianism in South Korea'. World Politics, 39(2): 231-57.

Birdsall, N., A. de la Torre, and F. Valencia Caicedo (2010). The Washington Consensus: Assessing a Damaged Brand, Working Paper 211. Washington, DC: Center for Global Development.

Booth, D. (2012). 'Aid Effectiveness: Bringing Country Ownership (and Politics) Back In'. Conflict, Security and Development, 12(5): 537-58.

Brinkerhoff, D. W. (2014). 'State Fragility and Failure as Wicked Problems: Beyond Naming and Taming'. Third World Quarterly, 35(2): 333-44.

Briscoe, I. (2009). 'Chasing the Tigers: Can Fragile States Copy the Asian Miracle?' Fondacion para las Relaciones Internacionales y el Dialogo Exterior (FRIDE) Conference Report, Madrid, 6-7 October 2008.

Chang, H.-J. (2003). Kicking Away the Ladder: Development Strategy in Historical Perspective. London: Anthem Press.

Chang, H.-J. (ed.) (2007). Institutional Change and Economic Development. Tokyo: United Nations University Press.

Chang, H.-J. (2012). 'Industrial Policy: Can Africa Do It?' Paper presented at the IEA/ World Bank Roundtable on Industrial Policy in Africa, Pretoria, South Africa, 3-4 July.

Dinh, H. T., T. G. Rawski, A. Zafar, L. Wang, E. Mavroeidi, X. Tong, and P. Li (2013). Tales from the Development Frontier: How China and Other Countries Harness Light Manufacturing to Create Jobs and Prosperity. Washington, DC: World Bank.

Engberg-Pedersen, L., L. Andersen, and F. Stepputat (2008). Fragile Situations: Current Debates and Central Dilemmas: DIIS Report. Copenhagen: Danish Institute for International Studies (DIIS).

Englebert, P., and D. M. Tull (2008). 'Postconflict Reconstruction in Africa: Flawed Ideas about Failed States'. International Security, 32(4): 106-39. 
Evans, P. B. (1995). Embedded Autonomy: States and Industrial Transformation. Princeton, NJ: Princeton University Press.

Evans, P. B., D. Rueschemeyer, and T. Skocpol (eds) (1985). Bringing the State Back In. Cambridge: Cambridge University Press.

Fabra Mata, J., and S. Ziaja (2009). Users' Guide on Measuring Fragility. Bonn and Oslo: German Development Institute and United Nations Development Programme. Available at: <http://www.undp.org/content/dam/undp/library/Demo cratic\%20Governance/OGC/usersguide_measure_fragility_ogc.pdf $>$ (accessed 15 September 2016).

Friedman, M. (1982). Capitalism and Freedom. Chicago: University of Chicago Press.

Fritz, V., and A. R. Menocal (2007). 'Developmental States in the New Millennium: Concepts and Challenges for a New Aid Agenda'. Development Policy Review, 25(5): 531-52.

Fukuyama, F. (2004). State-Building: Governance and World Order in the 21st Century. Ithaca, NY: Cornell University Press.

Geddes, B. (1990). 'How the Cases You Choose Affect the Answers You Get: Selection Bias in Comparative Politics'. Political Analysis, 2(1): 131-50.

Geddes, B. (1994). Politician's Dilemma: Building State Capacity in Latin America. Berkeley, CA: University of California Press.

Gisselquist, R. M. (2014a). 'Aid and Institution-Building in Fragile States: What Do We Know? What Can Comparative Analysis Add?' Annals of the American Academy of Political and Social Science, 656(1): 6-21.

Gisselquist, R. M. (2014b). 'Developing and Evaluating Governance Indexes: 10 Questions'. Policy Studies, 35(5): 513-31.

Gisselquist, R. M. (2014c). 'Paired Comparison and Theory Development: Considerations for Case Selection'. PS: Political Science and Politics, 47(2): 477-84.

Gisselquist, R. M. (2015). 'Varieties of Fragility: Implications for Aid'. Third World Quarterly, 36(7): 1269-80.

Gould, D. (1979). 'The Administration of Underdevelopment'. In G. Gran (ed.), Zaire: The Political Economy of Underdevelopment. New York: Praeger.

Gray, K. (2014). 'U.S. Aid and Uneven Development in East Asia'. ANNALS of the American Academy of Political and Social Science, 656(1): 41-58.

Herbst, J. (2000). States and Power in Africa: Comparative Lessons in Authority and Control. Princeton, NJ: Princeton University Press.

Hoeffler, A. (2012). Exporting from Fragile States: Challenges and Opportunities. Paris: OECD.

Jackson, R. H., and C. G. Rosberg (1982). 'Why Africa's Weak States Persist: The Empirical and the Juridical in Statehood'. World Politics, 35(01): 1-24.

Jerven, M. (2013). Poor Numbers: How We Are Misled by African Development Statistics and What to Do about It. Ithaca, NY: Cornell University Press.

Kaufmann, D., A. Kraay, and M. Mastruzzi (2010). The Worldwide Governance Indicators: Methodology and Analytical Issues, World Bank Policy Research Working Paper 5430. Washington, DC: World Bank.

Kim, J. (2015). 'Aid and State Transition in Ghana and South Korea'. Third World Quarterly, 36(7): 1333-48. 
King, G., R. O. Keohane, and S. Verba (1994). Designing Social Inquiry: Scientific Inference in Qualitative Research. Princeton, NJ: Princeton University Press.

Kohli, A. (2004). State-Directed Development: Political Power and Industrialization in the Global Periphery. Cambridge: Cambridge University Press.

Krueger, A. O. (1993). Political Economy of Policy Reform in Developing Countries. Cambridge: The MIT Press.

Lin, J. Y. (2011). From Flying Geese to Leading Dragons: New Opportunities and Strategies for Structural Transformation in Developing Countries. WIDER Annual Lecture, 4 May, Maputo, Mozambique. Available at: <https://www.wider.unu.edu/sites/default/ files/AL15-2011.pdf $>$ (accessed 15 September 2016).

Lin, J. Y. (ed.) (2012). New Structural Economics: A Framework for Rethinking Development and Policy. Washington, DC: World Bank.

Lin, J. Y., and V. Treichel (2012). 'Applying the Growth Identification and Facilitation Framework: The Case of Nigeria'. In J. Y. Lin (ed.), New Structural Economics: A Framework for Rethinking Development and Policy. Washington, DC: World Bank.

McDoom, O. S. (2009). 'The Micro-Politics of Mass Violence: Authority, Opportunity, and Security in Rwanda's Genocide'. PhD thesis, London School of Economics.

Mann, M. (1984). 'The Autonomous Power of the State: Its Origins, Mechanisms and Results'. European Journal of Sociology/Archives Européennes de Sociologie, 25(2): 185-213.

Migdal, J. S. (1988). Strong Societies and Weak States: State-Society Relations and State Capabilities in the Third World. Princeton, NJ: Princeton University Press.

Naudé, W., A. U. Santos-Paulino, and M. McGillivray (eds) (2011). Fragile States: Causes, Costs, and Responses. Oxford: Oxford University Press.

OECD (Organisation for Economic Co-operation and Development) (2012). Improving International Support to Peace Processes: The Missing Piece. Paris: OECD.

OECD (Organisation for Economic Co-operation and Development) (2014). Fragile States 2014: Domestic Revenue Mobilization in Fragile States. Paris: OECD.

OECD/DAC (Organisation for Economic Co-operation and Development/ Development Assistance Committee) (2007). Principles for Good International Engagement in Fragile States and Situations. Paris: OECD.

Polanyi, K. ([1944] 1967). The Great Transformation: The Political and Economic Origins of Our Time. Boston, MA: Beacon Press.

Pritchett, L., M. Woolcock, and M. Andrews (2013). 'Looking like a State: Techniques of Persistent Failure in State Capability for Implementation'. Journal of Development Studies, 49(1): 1-18.

Rocha De Siqueira, I. (2014). 'Measuring and Managing "State Fragility": The Production of Statistics by the World Bank, Timor-Leste and the G7+'. Third World Quarterly, 35(2): 268-83.

Rodrik, D., G. Grossman, and V. Norman (1995). 'Getting Interventions Right: How South Korea and Taiwan Grew Rich'. Economic Policy, 10(20): 55-107.

Rosenstein-Rodan, P. N. (1943). 'Problems of Industrialisation of Eastern and SouthEastern Europe'. Economic Journal, 53(210/11): 202-11.

Round, J. I. (2012). Aid and Investment in Statistics for Africa, WIDER Working Paper 2012/93. Helsinki: UNU-WIDER. 
Schneider, B. R. (1991). Politics within the State: Elite Bureaucrats and Industrial Policy in Authoritarian Brazil. Pittsburgh, PA: University of Pittsburgh Press.

Schneider, B. R. (2013). Institutions for Effective Business-Government Collaboration: Micro Mechanisms and Macro Politics in Latin America. Washington, DC: Inter-American Development Bank.

Stiglitz, J. E., and B. C. Greenwald (2015). Creating a Learning Society: A New Approach to Growth, Development, and Social Progress. New York: Columbia University Press.

Stiglitz, J., J. Lin, C. Monga, and E. Patel (2013). 'Industrial Policy in the African Context', World Bank Policy Research Working Paper, Washington, DC.

UNIDO (United Nations Industrial Development Organization) (2013). Industrial Development Report 2013: Sustaining Employment Growth: The Role of Manufacturing and Structural Change. Vienna: United Nations Industrial Development Organization (UNIDO).

UNU-WIDER (United Nations University World Institute for Development Economics Research) (2014). 'Aid, Governance, and Fragility', Position Paper, UNU-WIDER, Helsinki.

Wade, R. (1990). Governing the Market: Economic Theory and the Role of Government in East Asian Industrialization. Princeton, NJ: Princeton University Press.

Warwick, K. (2013). Beyond Industrial Policy: Emerging Issues and New Trends, OECD Science, Technology and Industry Policy Papers No. 2. Paris: OECD.

Woo, W. T. (2011). 'The Changing Ingredients in Industrial Policy for Economic Growth'. Paper presented at the Asia-Pacific Research and Training Network (ARTNeT) Symposium 'Towards a Return of Industrial Policy?', United Nations Economic and Social Commission for Asia and the Pacific, Bangkok, Thailand, 25-26 July. Available at: <http://www.econ.ucdavis.edu/faculty/woo/Woo-Articles\% 20from\%202012/2011-11-27.Woo-Industrial\%20Policy-ESCAP.sent.pdf> (accessed 12 November 2015).

World Bank (2011). World Development Report: Conflict, Security, and Development. Washington, DC: World Bank.

World Bank (2014). 'Harmonized List of Fragile Situations FY14'. Available at: <http://siteresources.worldbank.org/EXTLICUS/Resources/511777-1269623894864/ HarmonizedlistoffragilestatesFY14.pdf> (accessed 13 March 2015). 


\section{Part II}

Coordination Mechanisms in Asia 



\title{
6
}

\section{Korea's Evolving Business-Government Relationship}

\author{
Eun Mee Kim
}

\subsection{Introduction}

South Korea's rise from one of the poorest countries in the world in the early 1960s with a gross domestic product (GDP) of US\$2.36 billion to US\$1,304.55 billion in 2013 is an expansion of economic magnitude rarely seen in world history (World Bank 2014). More impressive is the rise in gross national product (GNP) per capita from US\$82 in 1961 to US\$25,977 in 2013, which tells the story of dramatic poverty elimination and economic development (World Bank 2014). South Korea has gained economic development despite the obstacles it has faced as a war-torn country with little natural resources and capital. Poverty, lack of democracy, as well as war and conflict were challenges that South Korea faced in the early 1960s; issues not very different from what many developing countries face in the 21st century. In 2010, South Korea joined the Organisation for Economic Co-operation and Development (OECD)'s Development Assistance Committee (DAC), and is currently the fifteenth largest economy in the world. It has become active on the world stage by sharing its own experiences of social, economic, and political development to developing countries as well as through foreign assistance.

Korea suffered from Japanese colonialism (1910-45), and the Korean War (1950-3), which left the country divided in two-to South Korea or the Republic of Korea in the south and North Korea or the Democratic Republic of Korea in the north-and nearly destroyed all the industrial and agricultural bases for development. The obstacles for development appeared insurmountable, and pundits remarked that South Korea was a 'hopeless case'.

However, South Korea made a dramatic transition from a hopeless case to a success case. Although its rapid economic development occurred in the latter 
half of the 20th century, its experiences are still relevant for developing countries in the 21 st century since there are few contemporary cases of such successful social and economic development and poverty eradication.

Some have argued that South Korea's post-war development was due to the enormous foreign assistance it received economically and militarily as well as to the United States' markets that were open for foreign imports. South Korea received a total of US $\$ 12.78$ billion in official development assistance (ODA) from 1945 to 1995 . Although many other countries received large amounts of foreign aid, only few countries have made the transition from an aiddepending nation to an aid-donating one. Thus, we start with the assumption that foreign assistance itself is not necessarily the answer for a nation's development, and focus on the domestic institutions that took advantage of foreign aid as well as the global market. In South Korea the developmental state and private businesses were the two main engines of development. We will examine the nature of these two institutions, and how their relationship changed over time with successful development.

This chapter focuses on the following topics during the most dynamic period in South Korea's economic development from 1960s to 1980s: the developmental state and industrial policies; the role of the private businesses; and state-business relationship (SBR). We will conclude the chapter with lessons for sub-Saharan African (SSA) nations, and recommend the 'democratic developmental state'.

\subsection{The 1960s: Overcoming Insurmountable Challenges with the Developmental State for Rapid Industrialization}

South Korea's rise from one of the poorest countries in the world to an industrial powerhouse began from the early 1960s. Thirty-five years of the Japanese colonial period left the country in economic imbalance since its growth was not in the interest of Japan. Korea was forced to provide raw material and agricultural products to Japan, and the Korean peninsula's railway and other transport systems were geared towards war efforts with China. In November 1943, with the hope to see the end of the Second World War, the heads of allied forces, President Franklin Roosevelt of the US, Prime Minister Winston Churchill of the United Kingdom, and Chiang Kai-shek of China, met at the Cairo Conference to discuss how Japan's colonies would be managed after the war. They decided that Japan should lose all territories, and that Korea should become free and independent. In early August 1945, the Soviet Union forces invaded Manchuria according to the agreement at the Yalta Conference in February 1945. The Soviet forces also arrived on the Korean peninsula immediately after Japan's defeat in the Second World War. The US 
also arrived on the Korean peninsula concerned that the Soviet Union could make Korea a Communist country. As a result, the Soviet Union occupied the northern part of the peninsula while the US occupied the southern part. Since the two countries could not agree upon forming one government on the Korean peninsula, the two nations decided to divide the country roughly in half along the 38th parallel line. The southern part of the 38th parallel would be under the provisional government of the US, while the northern part would be under that of the Soviet Union. This decision to divide the country in half has had lasting consequences to this day.

In 1948, after the two provisional governments could not agree upon one nation, the US-supported south held a national election, and President Rhee Syngman was elected as the first president of the Republic of Korea on 15 August 1948. In the north, Kim Il-sung became the prime minister (and, later president and the 'Great Leader') and the Democratic People's Republic of Korea was established on 9 September 1948. On 25 June 1950, North Korea led a sudden attack on South Korea, and the entire Korean peninsula became a hot war zone. As the front line moved up and down the peninsula several times, the whole area suffered great damages and human casualties. South Korea lost nearly 80 per cent of its industrial capability with a total of over US $\$ 2.28$ billion in damages when the war was over (Daggett 2010). Over 200,000 military personnel and over one million civilians were killed or were missing after the war. The US also lost over 36,000 military personnel and over 103,284 civilians (Daggett 2010). North Korean human casualties reached over 406,000 military personnel and over 600,000 civilians. China also lost over 716,000 military personnel when it helped the North Korean army during the war (Daggett 2010).

The war came to an end when the Armistice Agreement was signed in July 1953. However, the Armistice was not an official end to the war since it is not a permanent peace treaty; the two Koreas remain at war even to this day. There have been numerous military incidents along the border, at sea, and inside South Korea when North Korean infiltrators invaded the South Korean territory. The threat of another military attack had been perceived to be quite palpable during the early phase of South Korea's industrialization, especially when its level of economic development was considered to be inferior to that of North Korea. This state of military instability and threat of war represent one of many obstacles South Korea has faced.

The devastation of the Korean War has also left emotional scars to the people. Korea had boasted a history of over 5,000 years as one nation and one people. Division of the country after Second World War, establishment of two different governments, and the Korean War has divided Korea into two. The Korean War brought the military forces and the people pitted against each other. Although the war ended at least temporarily in 1953, there are no 
channels of communication for the ordinary citizens even to this datephone calls, letters, and visits are not permitted. The challenges of the war go beyond economic and political issues and run deeply in the psyche of the Korean people.

In the aftermath of the devastation of the Korean War, the South Korean economy was in ruins. Its GNP per capita was recorded as one of the lowest in the world, and the economic damage exceeded the entire GNP of 1949, which is the year before the war (Daggett 2010). President Rhee was unable to lift the country out of extreme poverty and his administration was mired with political scandals due to collusive ties between politicians and businesses. Foreign aid was an important source of government revenue, and there were suspicion that a substantial share of foreign aid was pocketed by the businesses with collusive ties with the politicians. The government put together economic development plans, but the inept government was not able to lead the private businesses to engage in industrialization. The economy staggered as inequality rose and inflation ran high.

The people's dissatisfaction grew with the rigged election on 15 March 1960 when President Rhee used illegal means to have his close ally to become the Vice President. The people's outcry exploded when a student's body was found in Masan Harbour with a tear-gas shell lodged in his body from the Masan demonstration following the election. University and high school students took to the streets in several cities on 19 April 1960 and demanded that the government should investigate the death of the student as well as the election fraud. However, the military opened fire on the demonstrating students as they marched to the president's residence, which triggered a nationwide demonstration. These series of events have been named as the April 19 Revolution or the April 19 Movement. On 26 April 1960, President Rhee announced his resignation and went into exile.

President Yoon Po Son was elected soon after, but his administration had to accept a major change in the political system into a parliamentary one with Chang Myon as the Prime Minister. Thus, the era following President Rhee is named the Chang Myon Administration (1960-1). Prime Minister Chang had two mandates from the people: democracy and economic growth. However, great political instability continued, and the economy was not in any better shape. Even with a newly revised economic development plan, the Chang regime could not turn the economy around.

On 16 May 1961, Major General Park Chung Hee led a military coup with a declaration that he felt compelled to take control of the nation to bring 'economic self-sufficiency and prosperity' in order to end poverty (Park 1966). The coup was a bloodless one, and the public accepted the coup in recognition that something had to divert the country from the course of political instability, poverty, and chaos. Although a military coup is never 
an answer to a chaotic situation, this is what happened in South Korea. In 1963, General Park ran for President and was elected as President.

The Park administration focused on economic development immediately following the coup. Two important strategies were announced: (1) creation of a comprehensive developmental state to lead the process of economic development; and (2) transformation of the SBR from corruption and personal ties to a working partnership with formal relations (see Kim 1997).

\subsubsection{The Developmental State}

The Park administration decided that the government will be in control of the economic development process since private businesses or other sectors of the society were deemed to be inappropriate to lead. In particular, the private businesses were considered to be mired in corruption, and were subject to a major overhaul to transform the working relationship with the government. As the first step, the government was reorganized with economic development as its top priority. The Economic Planning Board (EPB) was created on 22 July 1961 as the 'super-ministry' to lead the other economy-related ministries of the Ministry of Finance (MOF) and the Ministry of Trade and Industry (MOTI). These three economic ministries formed the troika of the South Korean developmental state (Kim 1997). The EPB was the lead ministry among all the line ministries since it controlled the government budget. The EPB's principle functions included comprehensive development planning for the national economy; industrial policies; and government budget (EPB 1982). It was the leading ministry in the 1960s and 1970s, while the minister was also the deputy prime minister.

The developmental state in the 1960s and 1970s was characterized as comprehensive since its primary goal was economic development. Other goals of the government, including national security and social services, remained as secondary (Kim 1997). The developmental state is characterized with the following traits: (1) provision and implementation of comprehensive development planning, that is, Five-Year Economic Development Plans (FYEDPs); (2) leading the private sector with direct support (carrots) including access to domestic capital, foreign aid, and technology; and (3) disciplining of the private sector through control of licenses, taxes, and audits (see Amsden 1989; Woo 1991; Kim 1997). The domestic banks were nationalized and put under state control, which enabled the developmental state to use domestic bank credit as carrots. Foreign capital loans and ODA to South Korea were also under the state's incentives. The developmental state provided guarantees for repayment when South Korean private enterprises sought foreign loan capital. The developmental state was also in control of the disbursement of ODA, which was a large source of foreign capital throughout the 1960s and 1970s. 
Thus, the developmental state was very effective in pursuing its national development plans since it had good ideas, but more importantly, sound instruments for intervention, that is, carrots and sticks. The predecessor Rhee and Chang regimes also had designed national development plans; however, they were not able to implement them. It was only in the Park administration, when the development plans were implemented with great success. Both the capacity and autonomy of the South Korean state were enhanced in the Park administration compared to the past administrations (Rueschemeyer and Evans 1985). The government ministries were reorganized and the corrupt government bureaucrats were prosecuted. Government reform was an important goal of the Park administration, and was quite a successful one.

Many attribute this success to the Park administration's autonomy from the elites of the nation that controlled the government, national assembly, and private businesses. The two leaders of the Park administration, President Park Chung Hee and Prime Minister Kim Chong Pil (former lieutenant colonel who assisted Park in the 1961 military coup), had no ties to the elites (Koo 1987). Thus, the state's capacity and autonomy, which are the two key elements of state's effectiveness, were both enhanced in the aftermath of the military coup in the Park administration (Rueschemeyer and Evans 1985). The Illicit Wealth Accumulation Charges were a prime example of how the Park administration tamed private businesses into a working relationship with the government. The developmental state was in charge.

In addition, the developmental state of the 1960s and 1970s used the authoritarian means to control and discipline the private businesses, that is, sticks. The Park regime effectively used the threat of tax audits, investigation of illicit accumulation of wealth and corruption, and sometimes North Korean sympathizing activities to investigate and prosecute the chaebols and the private businesses that were not in line with the developmental state's FYEDPs and industrial policies. ${ }^{1}$ The most widely used threat was withdrawal of preferential domestic bank loans if the target goals including manufacturing and export volume as well as growth rates were not reached. The discipline and use of sticks were widely and effectively used by the developmental state.

Nevertheless, we have to differentiate the developmental from the authoritarian dimensions of the state; they are not two sides of the same coin. Rather, they are distinct dimensions that are sometimes paired together. This is an important point when we examine the developmental state and its effectiveness in achieving the goal of economic development (see Kim 1993). Since the South Korean developmental state was also an authoritarian state during the 1960s and 1970s, we tend to assume that the combination of the

1 South Korea's family-owned and managed business groups. 
developmental and authoritarian state is the winning formula for successful development. However, numerous examples from around the world show that an authoritarian state that is developmental does not necessarily attain the goal of development, and there are many more cases in which such a state brings rent-seeking, corruption, and stagnant economy. The cases of South Korea during the Rhee Syngman and Chang Myon administration are such examples, as well as many other authoritarian regimes around the world including the Marcos regime in the Philippines and countless other authoritarian regimes that failed to bring national development. We will demonstrate later in Section 6.4.3 that the South Korean economy grew even more robustly under a democratic developmental state.

\subsubsection{The FYEDPs and Industrial Policies}

The developmental state announced and successfully implemented a series of FYEDPs. As discussed in Section 6.2.1, earlier administrations also had development plans, but they were not implemented. It was only in the Park administration when the Plans could be implemented with a government reform to establish a developmental state with capacity and autonomy.

The first FYEDP was announced in late 1961 and took effect from 1962 to 1966. The main goal was to create a self-reliant economy by transforming the agrarian economy to an industrial one by securing resources, expanding basic industry and infrastructure, improving the balance of payments (including negotiations for foreign aid), and promotion of technology (FKI 1987). The target for the annual economic growth rate was set at 7.1 per cent (FKI 1987). Although the first FYEDP ran into some problems, the economy grew at an average of 8.9 per cent and the manufacturing sector grew at 29.2 per cent (EPB 1978; IMF 1979). These were impressive growth rates that were unprecedented in South Korea. The developmental state was created to lead this process, the domestic private businesses were selected as the state's partners, and the modus operandi of SBR had changed from the previous decades of corruption and economic stagnation.

The second FYEDP focused on exports. Export-oriented industrialization (EOI) had been chosen as the South Korean development strategy based on the fact that South Korea needed foreign capital for development. Given the country's lack of natural resources, capital, and technology combined with only a relatively well-educated labour force, Japan's example of EOI was adopted. South Korea decided to focus on the light manufacturing sector for its industry and exports, particularly due to its rather short history of industrialization, as well as lack of capital and technology.

The goals were again set at impressive rates: 7 per cent for annual average growth rate, US $\$ 700$ million in export sales, and the industrial structure was to 
be modernized. Specific strategies included self-sufficiency in food production, self-sufficiency in water resources for energy, increase in employment, restraint of population growth through family planning, and promotion of science and technology (FKI 1987). The targets were set high and strategies were very broad from industrial planning to family planning.

The second FYEDP proved to be even more successful than the first. Light manufacturing sector products including textiles, clothing, footwear, ply wood, wigs, and stuffed toys were leading exports. The EOI based on light manufactured products turned out to be hugely successful. The international market, and most importantly, the US market were wide open for foreign imports. South Korea's cheap light-manufactured products successfully penetrated the US market and occupied the large discount stores in the US (see Woo 1991; Kim 1997).

The economy grew faster than what the government announced, and reached 11.1 per cent average annual growth rate and the manufacturing sector grew at an average annual growth rate of 21.1 per cent (EPB 1978; IMF 1979). Exports grew at 28.7 per cent per annum, which was the fastest in the world at that time (EPB 1978; IMF 1979). Exports were occupying 15.8 per cent of South Korea's GNP in 1971, compared to the mere 5.3 per cent in 1961 (ЕPB 1978; IMF 1979).

\subsubsection{Changing State-Business Relationship}

The Park administration sought to transform the SBR: (1) the state would become the dominant partner; and (2) the private businesses would be tamed with carrots and sticks, that is, with access to resources and/or with sanctions and licenses. The most dramatic measure that signalled a qualitative change in the SBR was the Illicit Wealth Accumulation Charges in the immediate aftermath of the 16 May 1961 military coup. Although similar measures were also in effect during the Chang administration, they were finally executed with force when Park came to power. During the Rhee and Chang administrations, the corrupt politicians doled out favours to private businesses with whom they had personal ties, and private businesses provide political kickbacks (Jones and Sakong 1980). These corrupt businesses made profits based on rent-seeking rather than in productive manufacturing or in services (Jones and Sakong 1980).

Thus, only twelve days after the military coup on 28 May 1961, the Supreme Council for National Reconstruction, which was headed by General Park, announced that the charges of Illicit Accumulation of Wealth would be investigated and executed (Kim 1997). That same day, major business leaders were arrested and charged under the same charges, which included the following allegations: illegal acquisition of government properties, tax evasion, 
capital flight, unjust profiting from foreign aid, political kickbacks, and so on (Korea Yearbook 1961, 1962). All the major large businesses' heads were jailed except for Samsung's Lee Byung-chull, who happened to be on a business trip to Japan (Korea Yearbook 1962). Lee was also subject to the charges, and he returned to South Korea with a deal that was reached for him to donate a large share of his businesses to the South Korean government and his pledge to support the Park administration's development plans (Kim 1997). On 9 May 1962, MOTI announced which of the Samsung companies would be donated to the government in lieu of fines (Korea Yearbook 1962, 1963). Other businesses were also given verdicts to donate businesses in lieu of fines and prolonged jail sentences to the CEOs of businesses.

The charges also targeted corrupt politicians and government officials. They were prosecuted with a strong moralistic tone of the Park administration with an implicit message that even democratically elected politicians could be subject to corruption charges and were the culprits with private businesses for the economic failure of the previous administrations (Korea Yearbook 1962, 1963). The swift and unequivocal prosecution of the charges also sent a clear message to the public: corruption would not be tolerated; the SBR will change to a productive partnership based on formal working relationship rather than on personal and corrupt ties; and the developmental state was in charge.

\subsubsection{Private Businesses}

The Park administration had choices to make in terms of whom to consider as the primary partner for economic development. Before deciding on domestic private businesses, several other groups were eliminated from potential partnership. First, the multinational corporations (MNCs) were eliminated from the running. Due to South Korea's history, foreign powers were not to be wholly trusted as primary institutions for national development. Historical relationship with China and Japanese colonialism resulted in South Korea's strong yearning for independence from foreign powers. Moreover, South Korea was of little interest to MNCs. Unlike Brazil or Mexico in Latin America, where the MNCs found natural resources, large domestic market, and lucrative investment opportunities, South Korea presented none of these attributes. South Korea's economy was in near ruins after the Korean War and years of economic stagnation; there were no natural resources; the market was relatively small; and there was great political instability. There was nothing to make South Korean an attractive investment site for MNCs. Thus, it was mutually agreed that MNCs would not be viable partners for South Korea's economic development.

State-owned enterprises (SOEs) were also eliminated from the running. Due to the corruption and collusive ties between politicians and private businesses 
that resulted in economic stagnation of the previous Rhee and Chang administrations, the Park administration needed a break from the past. The SOEs were seen with suspect that they could become fertile ground for corruption, and thus the SOEs were not seen as politically viable candidates. Thus, in South Korea, compared to Taiwan, for example, there were relatively fewer SOEs even in the beginning phase of its economic development.

Small and medium-sized enterprises (SMEs) were also not seen as the most effective partners. The Park administration had very little time on its hands since it needed to earn the public's trust and legitimacy with economic returns and SMEs were seen as not big enough to lead rapid economic development. This became even more important in the 1970s when the South Korean government led the heavy and chemical industrialization (HCI) drive.

Finally, the large private domestic businesses were selected as viable business partners for the South Korean developmental state. Amsden $(1989,2010)$ argues that South Korea's developmental state's decision to nurture domestic enterprises was a key to its sustained economic development. Without domestic enterprises, she argues that a late industrializing nation cannot effectively catch up and bring about economic development for a long term (Amsden 1989, 2010).

South Korea's leading large businesses went through major changes when the Park regime came into power in 1961. As the developmental state took charge of the economy and controlled the private businesses with the effective use of carrots and sticks, many of the private businesses could no longer compete and went bankrupt. And a new group of Park-era private businesses was born.

\subsection{The 1970s: Strong State-Business Developmental Partnership in the $\mathrm{HCI}$ Drive}

After only a decade of rapid economic development, which was led by EOI with the light manufacturing sector, the South Korean government announced a major shift in its economic development strategy. Citing the imbalances in its economy favouring the light manufacturing sector and urban areas, the South Korean government announced that the third FYEDP would focus on 'balance' between the light and heavy industries and between the urban and rural areas. Thus, HCI and rural development became two primary goals of the third FYEDP (EPB 1972; FKI 1987). The HCI was promoted with the 1973 announcement of the HCI drive by President Park and rural development was pursued with the Saemaul Undong (New Village Movement) since 1970. The target growth rates were set at GNP per capita of US $\$ 1,000$ by 1981 and US\$10 billion in exports (Koo and Kim 1992). 
However, South Korea's ambitious plans for HCI met with great scepticism from the US and other donors. When it presented plans for an iron and steel mill, the US, West Germany, and other donors turned down the South Korean government's proposal. It was seen as premature for a nation with only a decade of industrialization based on light manufacturing sectors to begin HCI with iron and steel, automobile, and heavy machinery.

The Park government was determined to promote HCI. Since the US and other Western donors did not support its ambitious goals, South Korea negotiated with Japan, which it had severed diplomatic ties since the end of the Second World War, to normalize diplomatic relations and to be given reparation funds for the colonial period. In 1965, South Korea normalized its diplomatic ties with Japan, and received the reparation funds, which were used to establish the Pohang Iron and Steel Company in 1968, which later became POSCO.

The experience of HCI demonstrates how South Korea took ownership of its own destiny and negotiated in spite of its limited leverage. South Korea's strong desire to promote HCI was driven not by economic needs, but by political and military strategies. The South Korean government was deeply concerned about its ability to defend its nation given the threats of North Korea for another invasion, and the defence industry was seen as vital for national security. North Korea military officers infiltrated South Korea on spy missions, and in 1968 a group of highly trained North Korean military officers reached very close to the Blue House. North Korea's threat to national security was serious. A former military general, President Park was determined to have a strong defence industry controlled by domestic businesses.

President Nixon of the US announced in the Guam Islands on 25 July 1969 that the defence of the Asia Pacific must be in the hands of the people of the Asia Pacific, which later became known as the Guam Doctrine. President Nixon also announced future plans for the partial withdrawal of the US troops in the Korean peninsula. The Guam Doctrine sent shock waves throughout Asia, and President Park reaffirmed his zeal for a self-reliant military and defence industry (see Kim 1997). The domestic political situation was also precarious. President Park narrowly won another presidential term in 1971, and he needed to secure a firm support base with the private businesses.

The HCI was selected as a strategy that would help solve many challenges faced by Park: (1) secure domestic political support by nurturing large private businesses; (2) develop the defence industry; and (3) overcome national security challenges. And, the Park administration decided to work with large business enterprises, since they were the ones with larger capital bases and access to technology necessary for heavy and chemical industries compared to SMEs. Thus, it was in the 1970s when the large private businesses were transformed into major conglomerates known as chaebol in Korean. 
The chaebols have distinct business traits: (1) diversified businesses in several distinct sectors including light and heavy manufacturing sectors, services including non-banking financial services, and retails; (2) vertical business structure with strong ownership exercised by the founder and his family even through successions; and (3) global brands. Although the name, chaebols dates back to the Japanese Colonial Period, and many were established during the Rhee and Chang regimes, it was not until the 1970s when a few large enterprises reached the chaebol-dom with strong state support for HCI.

\subsubsection{The Developmental State}

The developmental state needed partners that could deliver heavy and chemical industries, and the private businesses needed the state to take advantage of the state's provision of preferential access to capital and technology through HCI. Thus, a symbiosis between the developmental state and the private businesses was forged. The developmental state provided the preferential subsidies to the hand-picked private businesses for HCI: (1) low interest rate domestic capital; (2) access to foreign capital loans with government repayment guarantees and provision for 100 per cent foreign direct investment (FDI); and (3) protection of monopoly or oligopoly in domestic market (see Amsden 1989; Kim 1997; Woo 1991). The developmental state continued to strengthen during the 1970s with strong control of both the carrots and sticks in their relationship with the private businesses.

The developmental state sometimes used coercive measures to discipline the private businesses including tax audits, withdrawal of bank credit, and use of secret service to track down possible connections with North Korea for national security breaches (see Kim 1997 for details). Labour was also repressed with regards to labour rights including assembly, unionization, and wages.

\subsection{2 $\mathrm{HCl}$ Drive with Industrial Policies}

President Park made the Pronouncement for the Development of the Heavy and Chemical Industries during the State of the Nation message on 13 January 1973, which showed how strongly President Park regarded HCI. Unlike other economic development plans, this was highlighted during the State of the Nation message, and President Park convened regular meetings to make sure that the HCI drive was implemented effectively and on time (see Kim 1997).

Six target industries were selected for HCI by the developmental state: (1) iron and steel; (2) non-ferrous metal; (3) machinery; (4) shipbuilding; (5) electrical appliances and electronics; and (6) petrochemicals. These six target industrial sectors were carefully chosen by the developmental state with strong potential for backward and forward linkages; multiplier effect for 
the national economy; and foreign capital earnings through exports (Kim 1997). Except for the iron and steel, which was chosen for a SOE, all other sectors were destined for the private sector. In fact, President Park and his close confidants were known to have hand-picked the private businesses for each of the six target industrial sectors with the exception of the iron and steel, and electrical appliances and electronics. The former was established as a SOE, and the latter was seen as already having a number of viable private businesses that would require less state support than the other five sectors (Kim 1997).

President Park's strong support for the HCI was important for the success of the HCI drive. The hand-picked chaebols tremendous growth also contributed to the economic development and industrial deepening in the 1970s. In spite of two oil shocks in the 1970s, the South Korean economy grew at an average of 7.9 per cent and its GNP per capita increased from US\$285 in 1971 to US $\$ 1,589$ in 1980 (EPB 1986).

Among the largest ten chaebols, the ones that were selected for the state's target HCI sectors and given preferential treatment outgrew their counterparts. The average annual growth rate of total assets in 1971-80 shows how dramatic the growth of the hand-picked chaebols was: Hyundai grew on average of 38 per cent, Daewoo at 53.7 per cent, and Sunkyong (later SK) at 36.7 per cent (Kim 1997: 153). Although the developmental state's goal was focused on heavy and chemical industries, the continued strong export performance of the light manufacturing sector throughout the 1970s helped sustain South Korea's rapid economic development in the 1970 s and did not bring lower employment rates, which are typical of HCI sectors.

However, the growth of the hand-picked chaebols growth in the 1970s is not just a developmental state-led growth story. There are legendary stories of the chaebols founders such as Chung Ju-yung of Hyundai, who showed strong entrepreneurship beyond state sponsorship. The growth of the chaebol in the 1970s'- HCI drive should be understood as a partnership between the developmental state and private businesses. The relationship has evolved from a clear state dominance in the 1960s to symbiosis in the 1970s: both the developmental state and the chaebol had evolved and the latter was becoming a force on its own.

The end of the 1970s saw important changes in South Korea's political economy. President Park was assassinated on 26 October 1979 ending his long authoritarian rule. Prime Minister Choi Kyuha succeeded the presidency according to the South Korean law for succession. The second Oil Crisis in 1979 swept through the world and also hit the South Korean economy.

On 12 December 1979, another military general, Chun Doo Hwan led a coup within the military barracks - he became the president in 1980. Factory workers and students took to the streets protesting the suspicious 
circumstances surrounding President Chun, which has been known as the May 1980 uprisings. The City of Kwangju suffered the greatest in the crackdown by the military forces with civilian casualties ranging from a couple hundreds to thousands. The yearning for democracy escalated throughout the 1980s in spite of the oppressive Chun administration.

\subsection{The 1980s: Changing State-Business Power Dynamics}

'The 1980s were a time of great social, economic and political upheaval in South Korea' (Kim 1997: 167). Successful economic development in the 1960s and 1970s was due to the strong developmental state, and also the large business groups known as the chaebol. The labour, which was largely suppressed in terms of their political rights and wages in the 1960s and 1970s, also grew in number and labour unionization. Thus, the pressure toward the developmental state came from all corners of the economy and society: (1) the chaebol requested that the developmental state relax its tight control over the private businesses_-sticks-while it maintain the state's subsidiescarrots; (2) the labour requested that their political rights for assembly should be honoured and their wages should be increased; and (3) students, workers, and the middle-class demanded that democracy should be installed, that is, with free and open presidential elections.

\subsubsection{From a Comprehensive to a Limited Developmental State}

President Chun responded to the changing global market and domestic pressure to loosen the developmental state's tight control of businesses and labour. The Chun regime embarked on a series of economic stabilization and liberalization measures that also helped to differentiate from his predecessor President Park Chung Hee. The Chun regime's economic stabilization and liberalization measures included: (1) industrial targeting would change from selecting target sectors for heavy government subsidies to supporting sunset industries for soft landing; (2) developmental policies and industrial policies would take back stage compared to regulatory policies; and (3) important carrots of the developmental state including state-owned banks, policy loans, and industrial licensing would be abolished (Kim 1997: 174). Furthermore, the developmental focus was weakened with welfare services taking a greater policy emphasis in the FYEDPs. In fact, the FYEDP was renamed as the Five-Year Economic and Social Development Plan in the 1982 fifth plan. Development was no longer the primary and sole goal, and regulatory offices were created and existing ones were expanded. In 1981 the Fair Trade Commission and the Office of Fair Trade were established within the EPB, and the 
MOF began to privatize domestic state-owned banks that were under state control for nearly two decades (EPB 1989).

The EPB was disbanded in 1994 after its establishment in 1961. The planning function was reduced to a minimum, and the national government budget was moved to a separate National Budget Administration on 28 February 1998. The EPB was merged with the MOF and became the Ministry of Finance and Economy.

The industrial policies also took a qualitatively different character, and the MOTI, which administered industrial policies, went through great changes. For example, industrial targeting changed from picking private businesses for state's preferential treatment to one supporting sunset industries with a finite time limit of three years with reduction in total support (Kim 1997). Industrial licensing for private businesses was eliminated in most industries. Thus, the corridors of the MOTI were no longer swarming with representatives from private businesses looking to secure industrial licenses (Kim 1997). The troika of the developmental state went through changes from leading the private businesses in the national development plans to following the lead of private businesses. The developmental state transformed from a comprehensive to a limited developmental state in the 1980s.

Although the Chun administration did not budge for democratic political changes when it first took office, it responded to the changes for economic liberalization from the chaebol, labour, and the middle-class. The limited developmental state had also devoid itself of using authoritarian measures as the Park administration. The developmental state was no longer dictating or leading, but supporting and regulating the private sector.

In spite of the second Oil Crisis that affected the whole world, the South Korean economy continued to outperform its counterparts. The average annual growth rate of GDP was the second fastest in the world with 9.7 per cent (National Statistical Office 1991). The annual growth rate of GNP per capita reached 13.8 per cent, with the amount increasing from US $\$ 1,734$ to 5,569 (National Statistical Office 1991). These impressive growth rates were achieved in spite of the negative growth rate in 1980 following the second Oil Crisis and the assassination of President Park in 1979.

\subsubsection{The Democratic Developmental State}

The change in the comprehensive developmental state to a limited developmental state was concomitant with the democratization movement. The developmental state also was forced to listen to the chaebol and labour, which grew with successful economic development. The irony for the developmental state was that it was forced to relinquish its control in the market because of its success, and not because of its failure (see Kim 1993). The 
developmental state gave carrots to persuade private businesses to comply with the state's developmental plans. The private businesses in general and the chaebol in particular had become too big and mature to be dependent on the state for resources. The power dynamic between the state and businesses changed from dominance, to symbiosis, and now to competition.

The chaebols appeared to be in the driver's seat as they became less dependent on the developmental state's subsidies and the chaebols and their products and services have become so dominant that no one could afford the collapse of the chaebols.

The limited developmental state also relinquished some of the authoritarian apparatus to implement development plans and industrial policies. The people's voices for democratization culminated in the June 1987 democratization movement, and President Chun finally acquiesced and agreed to allow democratic presidential elections.

The democratic developmental state can be characterized to have the following functions: (1) limited developmental state, that is, (i) the developmental state's priorities included development as well as other goals, (ii) industrial policies were limited in nature with the state supporting private businesses rather than vice versa, and (iii) the developmental state's focus shifted from developmental to regulatory; (2) the use of authoritarian apparatus for the implementation of developmental plans and industrial policies were limited; and (3) the developmental state's dominance over the private businesses and labour became limited.

The South Korean economy continued to grow in spite of the change in the developmental state and democratization. In fact, the economy continued to expand rapidly, and the chaebol had become global brand names, which is different from the economic trajectory of other late comer industrial nations.

\subsubsection{The chaebols become Global Powerhouses with Global Brands}

The major chaebols continued their impressive growth even when the developmental state's support was reduced. Their dominance in the domestic market expanded with Samsung's 2013 revenue to be equivalent to 26 per cent of South Korea's GDP and the next four largest chaebols at 39 per cent (Lee 2012). The share of the largest chaebols in South Korea's GDP has steadily increased over time from less than 10 per cent in the 1970s.

The chaebols are omnipresent in South Korea-you cannot live even one day without coming into direct contact with the chaebols' products and services. From the minute you wake up, you brush your teeth with LG toothpaste, take a shower using LG soap and shampoo, watch Samsung TV while checking your Samsung smartphone for the latest phone calls and news, take the subway train built by Hyundai, shop at the Lotte Department Store, go to 
work in a Hyundai-built building, have lunch at a CJ-franchise restaurant, and meet your client at Samsung's hotel.

Many of the largest South Korean chaebols are now well-known household names around the world such as Samsung, Hyundai, and LG. Samsung Electronics was ranked thirty-two in the Fortune Global Rankings in 2010 followed by LG at sixty-seven, and Hyundai Motor at seventy-eight, followed by four other chaebol companies in the top Fortune Global 500. Some chaebol companies' products have one of the largest three global market shares including semiconductors, smart phones, TV, and monitors. Few businesses in developing countries have produced major global companies and global brands as have South Korea's chaebols.

Although the rapid growth of South Korea's chaebols in the 1960s and 1970s was owed to the developmental state's preferential treatment and support, we should not dismiss the entrepreneurship of the chaebols. The legendary success stories of visionary risk-taking entrepreneurship of the leading chaebols, and their impressive growth even when the state's support was largely diminished, attest to their business acumen.

\subsubsection{Chaebol-Dominated SMEs in the South Korean Economy}

South Korea's SMEs have received less direct subsidies in the earlier phase of its development due to the government's strategic national development planning that were not conducive to SMEs. The HCI drive in the 1970s required that capital- and technology-intensive chaebol companies became more attractive business partners to the developmental state.

However, SMEs occupy a very important place in the South Korean economy and society. SMEs produce about 45.7 per cent of South Korea's manufacturing products, there are over 3.35 million SMEs ( 99.9 per cent) compared to 2,916 large enterprises ( 0.1 per cent), and most importantly SMEs hire 87.7 per cent of the labour force (Kim 2014). In terms of exports, they have surpassed the chaebols in terms of export growth in the 2000s although their volume remains small compared to the chaebols at about 32.9 per cent in 2013 (Kim 2014).

There have been many efforts by the South Korean developmental state to support SMEs with access to domestic bank loans, SME-designated manufacturing, service sectors that prohibit chaebols from entering, as well as support in technology. The Korean Commission for Corporate Partnership was created in 2010 in order to help mitigate social conflict between large enterprises (many of them are chaebol enterprises) and SMEs as the former group was seen as having an inordinately large share of the market and thus having the power of monopoly and oligopoly in the market. Thus, this commission was created to help ease the tension between the two groups, and most 
importantly to find creative ways for the chaebols to assist the growth of the SMEs. This commission and other measures by the South Korean developmental state show the significance of the problems faced by SMEs working in a market dominated by large business groups. This has been considered as a social problem by the president, government officials, and politicians, as well as the general public. Thus, the work by the Commission, the chaebols, and the developmental state along with the SMEs themselves has received great attention from the public and this issue will continue to receive support from the government since the developmental state itself is part of the problem.

\subsection{Conclusion and Recommendations for Sub-Saharan African Nations}

South Korea's dramatic economic development was achieved with the institutions of the developmental state, which at times was also under military authoritarian regime. The state used carrots in the form of preferential access to domestic and foreign capital, and sticks in the form of harsh punishments for corruption and inability to meet the performance standards. The latter measures helped South Korea's businesses from becoming rent-seekers in spite of a high possibility of corruption due to the generous incentives provided by the state. The mix of sound institutions, such as developmental state and strategic industrial policies, provided the formula for success for South Korea's early phase of development.

Nevertheless, an authoritarian state is hardly a recipe for successful economic development. As amply demonstrated in world history, far more countries fail to achieve economic development and reduce poverty for its people if the state is authoritarian.

Thus, we argue that South Korea's developmental state, which was at times authoritarian, should not be used as an excuse to justify an authoritarian state in the 21st century's developing countries. Instead, a democratic developmental state should be studied to provide a developmental state that could bring about poverty reduction and economic development (see Edigheji 2010). In fact, South Korea's own economic development history shows that its economic growth actually accelerated with democratization since the late 1980s.

Several lessons can be drawn from the South Korean experience that can be relevant for SSA nations in the 21st century: (1) comprehensive developmental state is useful in the early phase of economic development when other institutions including private businesses are not yet developed; (2) the comprehensive developmental state must have some carrots under its control, which can be used to attract private enterprises to comply with national development plans; and (3) the comprehensive developmental state would 
need to reduce its control and direct support to private businesses when economic development is strengthened and when private businesses have matured enough to be less dependent on the developmental state for support and protection.

The democratic developmental state should be considered for 21st-century developing countries. Although the South Korean history had a period in which the developmental state was also an authoritarian state, the two are not synonymous and should be considered as two distinct attributes of a state. World history has shown numerous more cases where an authoritarian developmental state failed miserably in achieving economic development and had fallen to corruption and rent-seeking. South Korea's democratization movement that culminated in the late 1980s for democratic consolidation affected the developmental state to surrender the authoritarian apparatus. The South Korean economy and private businesses continued to prosper in the era of democratic developmental state. In fact, during this period, we have witnessed the impressive growth of the chaebols in the global market place as global brands. Thus, we should take away from the South Korean developmental story that a democratic developmental state is an important lesson to be shared with SSA nations as well as other developing countries.

\section{Acknowledgements}

Research support was provided by Yunjeong Kim and Gee-hyun Bang of the Graduate School of International Studies at Ewha Womans University. I would like to thank John Page and Finn Tarp for their valuable comments to an earlier draft.

\section{References}

Amsden, A. H. (1989). Asia's Next Giant: South Korea and Late Industrialization. New York: Oxford University Press.

Amsden, A. H. (2010). 'Say's Law, Poverty Persistence, and Employment Neglect'. Journal of Human Development and Capabilities, 11(1): 57-66.

Daggett, S. (2010). 'Costs of Major U.S. Wars', CRS Report for Congress, Congressional Research Service, Washington, DC.

Edigheji, O. (2010). 'Constructing a Democratic Developmental State in South Africa: Potentials and Challenges'. In O. Edigheji (ed.), Constructing a Democratic Developmental State in South Africa: Potentials and Challenges. Cape Town: HSRC Press.

EBP (Economic Planning Board) (1972). Five-Year Economic Development Plans II. Seoul: Economic Planning Board. 
EBP (Economic Planning Board) (1978). Major Statistics of the Korean Economy. Seoul:

Economic Planning Board.

EBP (Economic Planning Board) (1982). Kaebal Nyondae ui Kyongje Chongchaek: Kyongje Kihoekwon 20 Nyonsa [Economic Policies of the Development Era: The Twenty-Year History of the Economic Planning Board]. Seoul: Economic Planning Board.

EBP (Economic Planning Board) (1986). Major Statistics of the Korean Economy. Seoul: Economic Planning Board.

EBP (Economic Planning Board) (1989). Monopoly Regulation and Fair Trade in Korea. Seoul: Economic Planning Board.

FKI (Federation of Korean Industries) (1987). Korea's Economic Policies (1945-1985). Seoul: Federation of Korean Industries.

IMF (International Monetary Fund) (1979). International Financial Statistics. Washington, DC: International Monetary Fund.

Jones, L., and I. Sakong (1980). Government, Business, and Entrepreneurship in Economic Development. Cambridge, MA: Harvard University Press.

Kim, E. M. (1993). 'Contradictions and Limits of a Developmental State: With Illustrations from the South Korean Case'. Social Problems, 40(2): 228-49.

Kim, E. M. (1997). Big Business, Strong State: Collusion and Conflict in South Korean Development, 1960-1990. Albany, NY: State University of New York Press.

Kim, J. (2014). 'Small Firms Drive Exports'. Korea Joongang Daily, 22 January.

Koo, H. (1987). 'The Interplay of State, Social Class, and World System in East Asian Development: The Cases of South Korea and Taiwan'. In F. C. Deyo (ed.), The Political Economy of the New Asian Industrialism. Ithaca, NY: Cornell University Press.

Koo, H., and E. M. Kim (1992). 'The Developmental State and Capital Accumulation in South Korea'. In R. P. Appelbaum and J. Henderson (eds), States and Development in the Asian Pacific Rim. Newbury Park: Sage.

Korea Yearbook (1961). Hanguk Yongam (Korea Yearbook). Seoul: Hanguk Yongamsa. Korea Yearbook (1962). Hanguk Yongam (Korea Yearbook). Seoul: Hanguk Yongamsa. Korea Yearbook (1963). Hanguk Yongam (Korea Yearbook). Seoul: Hanguk Yongamsa. Lee, J. (2012). 'chaebol's Economic Dominance Increases'. Korean Herald, 7 February. National Statistical Office (1991). Major Statistics of Korean Economy. Seoul: National Statistical Office.

Park, C. H. (1966). The Road toward Economic Self-Sufficiency and Prosperity. Seoul: Ministry of Public Information.

Rueschemeyer, D., and P. Evans (1985). 'The State and Economic Transformation: Toward an Analysis of the Conditions Underlying Effective Intervention'. In P. B. Evans, D. Rueschmeyer, and T. Skocpol (eds), Bringing the State Back In. Cambridge: Cambridge University Press.

Woo, J. (1991). Race to the Swift: State and Finance in Korean Industrialization. New York: Columbia University Press.

World Bank (2014). World Bank Database. Washington DC: World Bank. 


\title{
7
}

\section{The Industrial Policy Experience of the Electronics Industry in Malaysia}

\author{
Rajah Rasiah
}

\subsection{Introduction}

Malaysia is among the countries that shifted its industrial focus from importoriented to export-oriented industrialization since the enactment of the investment Incentives Act of 1968 (Ma laysia 1971). Foreign direct investment (FDI) figured prominently in the New Economic Policy (NEP), which was launched through the Second Malaysia Plan in 1971 (Malaysia 1971). Since 1972, free-trade zones (FTZ) were opened to attract export-oriented FDI in light of manufacturing activities to expand employment opportunities following the identification of manufacturing as the engine of growth in the Second Malaysia Plan of 1971-5. Firms seeking to locate in areas that required specific infrastructure that could not be provided in FTZs were offered licensed manufacturing warehouse (LMW) status. As early as the 1970s, giant multinational corporations (MNCs) consequently relocated textile and electronics operations in Malaysia.

While unemployment levels in Peninsular Malaysia fell as a consequence of FDI inflows, the nature of demand facing electronics manufacturing, which is characterized by short boom-bust cycles, meant that retrenchments were also common whenever economic downswings hit the industry (Rasiah 1988). Nevertheless, employment, exports, and manufacturing value-added in the electrical-electronics industry expanded sharply in trend terms until 2000 to become the leading manufacturing industry in Malaysia. From the initial focus on investment and employment, the government earmarked the electrical-electronics industry as a strategic industry since 1986 to spearhead the industrial transformation of the country. The 1985-6 economic crisis, when gross domestic product (GDP) growth hit negative figures, 
delayed the introduction of technological upgrade policies, which were introduced starting in 1991 (Malaysia 1991a). The Action Plan for Industrial Technology Development (APITD) became the pivot to lead Malaysia's transformation into a developed country by $2020 .{ }^{1}$ Major meso-organizations targeted at solving collective action problems were launched to spearhead the transformation.

However, poorly coordinated technological deepening, industrial plans, and the lack of strong human capital development policies, including on schools and universities, and low utilization of human capital endowed with tacit knowledge from abroad, discouraged structural change from low to high value-added activities in the industry. While a massive inflow of FDI from East Asia since the late 1980s and exchange rate depreciation since 1997 stimulated strong expansion of employment, exports, and value-added activities, the contribution of the industry in the national economy has gradually declined since 2000. The provision of grants particularly since 2005 has helped stimulate some functional upgrading into chip design, wafer fabrication, and research and development $(\mathrm{R} \& \mathrm{D})$. This development has stimulated a positive trade balance in the industry after 2005. However, such initiatives have not been successful in driving Malaysia's ability to compete globally at the technological frontier.

Thus, this chapter seeks to examine government initiatives to promote the electrical-electronics industry, including the objectives and how they translated into firm-level technological advancement. The electrical-electronics industry was selected because it has been the most important manufacturing industry in Malaysia since the late 1980s. In so doing, we seek to deploy some robust methodology to evaluate the extent of success Malaysia's industrial policies have enjoyed in spearheading firm-level technological change.

\subsection{Importance of the Electrical-Electronics Industry}

The electrical-electronics industry grew rapidly in Malaysia following the opening of FTZs in 1972 (Lim 1978; Rasiah 1988). Three waves of relocation took place in the industry, namely, in 1972-4, 1988-93, and 2005-8 (Rasiah 2010). Whereas the first two waves were characterized by capital accumulation from FDI inflows, the third arose from the relocation of chip design, wafer fabrication, and supportive R\&D activities.

Except for the cyclical fluctuations associated with the industry-wide boombust cycles (Rasiah 1988), employment rose in the electrical-electronics

\footnotetext{
${ }^{1}$ This was contained in the government blueprint, The Way Forward (Malaysia 1991b).
} 


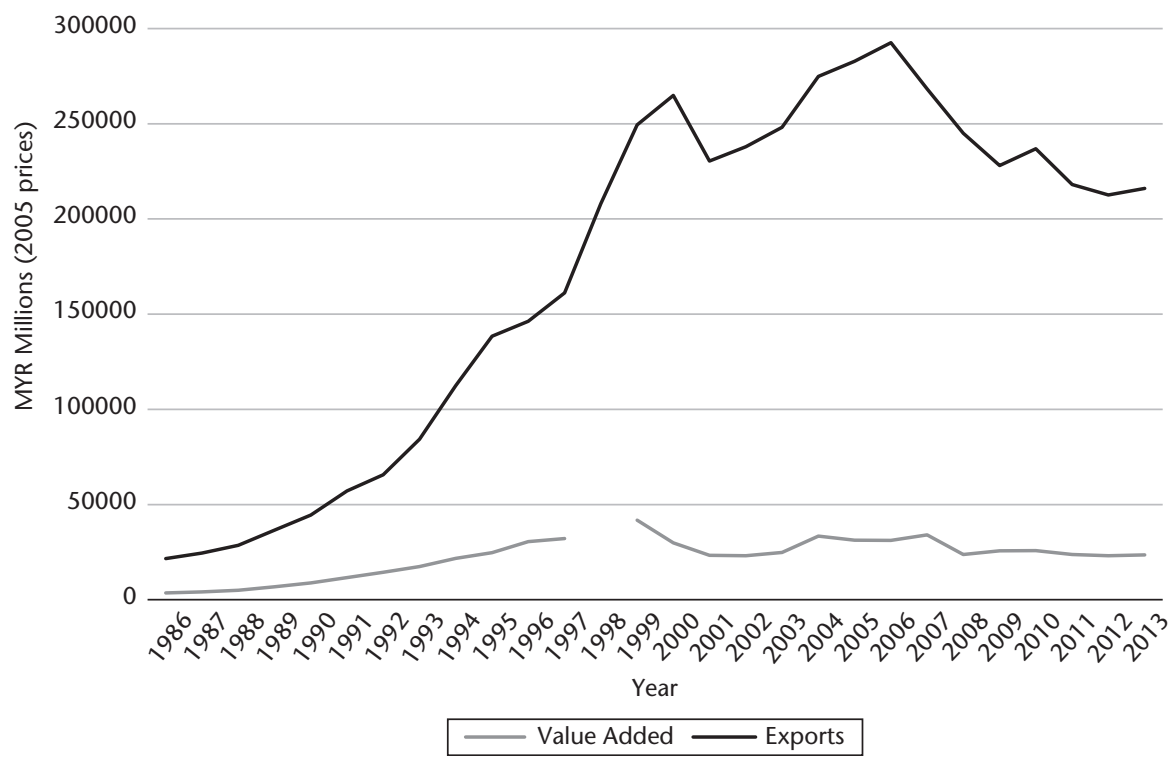

Figure 7.1. Exports and value-added activities in electrical-electronics industry, Malaysia, 1986-2013

Note: Value added (VA) in 2005 prices.

Sources: Compiled from Malaysia, External Trade Statistics, various issues; Malaysia, Industrial Surveys, Department of Statistics, various issues.

industry in trend terms from 1970 until 1984 (Malaysia 1986). The industrywide crisis of 1984-5 resulted in a fall in employment. After the shakeout, employment grew sharply since 1988 following a massive inflow of FDI from Japan, Taiwan, South Korea, and Singapore. This expansion continued over the Asian financial crisis in 1997-2000, as the fallen Ringgit lowered production costs in the country. The slight fall in 1997 was a consequence of firms' taking advantage of privileges given to firms to retrench workers, as it was not clear how the crisis would pan out when it first struck in 1997. However, since its peak of 2000, employment in the industry has fallen in trend terms.

To obtain an informed analysis we confine the presentation of data to the period from 1986 when the first Industrial Master Plan (IMP) was launched (Malaysia 1986). However, following the 1984-5 downturn, the plan relaxed all pressures on upgrades so as not to scare away existing firms. The industry expanded sharply again as a consequence. Value-added activities and exports from the industry rose until 2000 but began to fall thereafter in trend terms (see Figures 7.1 and 7.2). The industry's share of manufacturing value-added activities rose to its peak of 37.2 per cent in 1999 and manufactured exports to 


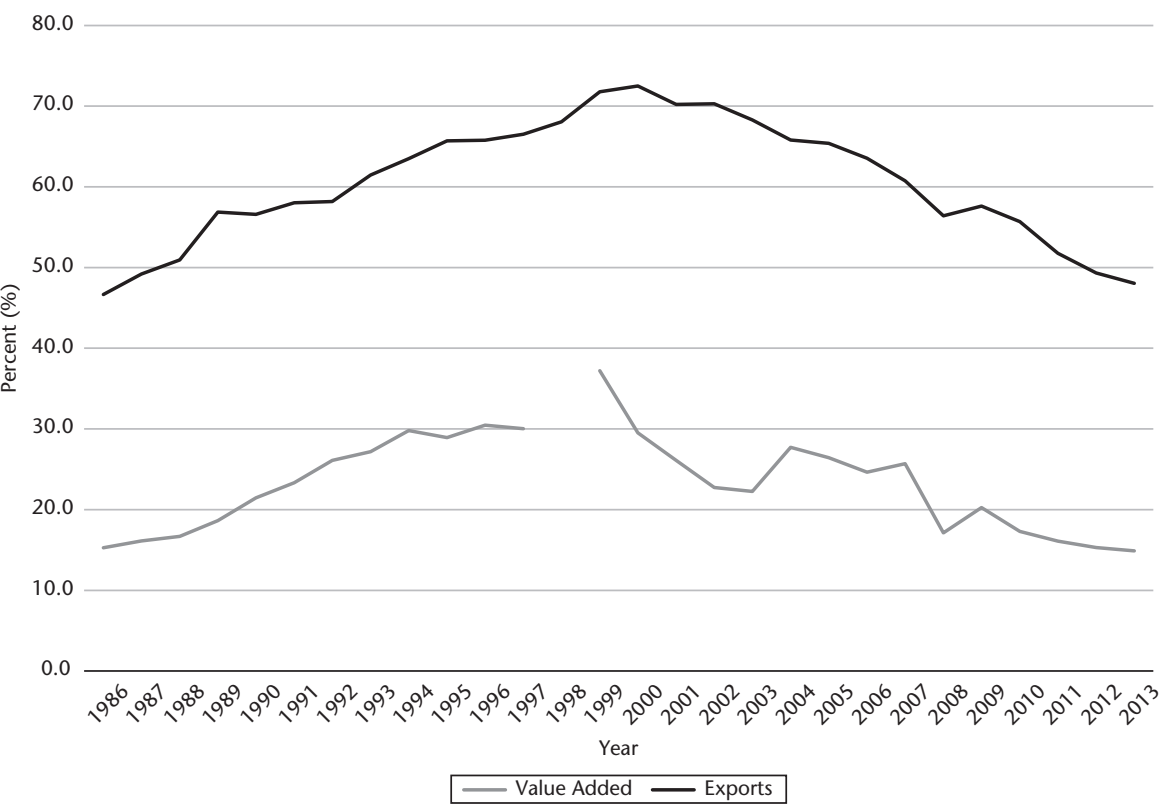

Figure 7.2. Contribution of electric-electronics to manufacturing, Malaysia, 1986-2013 Note: VA-value added.

Sources: Compiled from Malaysia, External Trade Statistics, various issues; Malaysia, Industrial Surveys, Department of Statistics, various issues.

its summit of 72.5 per cent in 2000. The Asian financial crisis boosted electronics exports, which was caused by falling production costs from a sharply fallen Ringgit, and a rapidly growing American market (Rasiah, Yap, and Chandran 2014).

However, exports, and value-added activities began to slow down after 2000, as the industry expanded further into China and Viet Nam until the 2008-9 global financial crisis, which affected exports to the major markets of the United States and Europe (see Figures 7.1 and 7.2). Thus, the industry's share in manufacturing value-added activities and exports fell to 14.9 per cent and 48 per cent respectively in 2013.

While one would expect the share of particular industries in an economy to rise and fall as the economy matures even, one would expect productivity to rise.

\subsection{Theoretical Considerations}

Industrial policy has been defined in many ways by various authors. The common one refers to industrial policy as one targeted at the expansion of 
industry in general, and manufacturing in particular (Kaldor 1967). While structural economists, such as Young (1928) and Kaldor (1967), focused on the increasing returns characteristics of industrialization and its impact on the division of labour and economic expansion, they did not analyse specifically technological deepening issues. Chenery, Robinson, and Syrquin (1986) and later Lall (1992) attempted to do this but confined structural change to categorizations by capital goods, consumer durables, intermediate goods, raw materials, heavy, medium, and light industries, high-, medium-, and lowtechnology industries. Such classifications do not address innovation and technology directly.

The transformation of production into different stages and the evolution of embodied knowledge in which innovation depth has transcended the boundary of the nature and type of goods and services means that it no longer matters whether countries experience structural transformation from a specialization in consumer and intermediate goods to capital goods, or from low and medium technology to high technology goods. For example, Taiwan and Singapore show strong specialization in components and intermediate goods than Malaysia but the former two are technologically far superior to the latter, which is reflected in their respective value-added activities. Hence, a successful industrial policy should be viewed as an exercise in which it successfully stimulates sustainable economic transformation from low to high valueadded activities.

Marx (1957), Veblen (1915), and Schumpeter (1943, [1943] 1961) created the foundations for the real assessment of technology through the unbundling of the black box by Rosenberg $(1976,1982)$, which led to a plethora of work defining technological capabilities (Dahlman 1984; Lall 1992).

The catch-up literature, which has its historical origins in Marx's (1957) notion of capitalist integration and accumulation, was expounded further through the work of Gerschenkron (1952), and Abramowitz (1956). These works gave rise to the developmental functions of the state, which goes beyond the regulatory role of the state. The empirical foundations of the developmental state articulating the role of government in stimulating industrial structural change can be found in works explaining industrial catch-up by Japan (Johnson 1982), Korea (Amsden 1989), and Taiwan (Wade 1990). However, while Amsden (1989) and Amsden and Chu (2003) provided explicit accounts of catching up in particular industries, Johnson (1982) and Wade (1990) did not present the empirical evidence on innovation and technology against the particular industrial policy pursued in Japan and Taiwan respectively.

Hence, the work of Rosenberg (1982), Dahlman (1984), and Lall (1992) becomes important in attempting to examine the evolution of technological 
capabilities in the developing economies. It is also important to see how government-initiated institutional change affected firm-level technological upgrading in particular countries.

Figueiredo (2001), Rasiah (2003), and Ariffin and Figueiredo (2004) attempted to examine firm-level technological capabilities but their focus was overly confined to firms. Also, they did not locate their observed firms against the lead firm at the globe's technology frontier. Rasiah (2004) linked technological capabilities with institutional support but the approach included too many institutions to distinguish the importance of industrial policy. Hence, this chapter seeks to examine the evolution of technological capabilities against the particular type of industrial policy by using the electronics industry as a case study. The confinement of analysis specifically to the electronics industry and to Malaysia is consistent with the evolutionary argument that institutional and technological change are industry, location, and time specific (Nelson 2008).

Taking these accounts, we analyse the application of industrial policy in this chapter by first examining the instruments used to promote industrialization, its impact on the share of manufacturing in the national economy, industrial structural change experienced in the economy (value added, employment, and exports), and technological upgrading.

\subsection{Methodology and Data}

The methodology deployed in this study is based on examining changes in value-added activities, employment, exports of electrical and electronics goods in absolute terms and as a share in manufacturing, and an assessment of changes in technological capabilities in the electronics industry since 1970 using firm-level surveys. Because of the difficulty in attempting to evaluate changes in technological capabilities, especially as one gets deep into history, the latter is confined to the semiconductor industry, which constitutes the core component of technology in the electronics industry. The meta-physical datasets are drawn from government compiled aggregate statistics, and a firmlevel survey, while the qualitative information is drawn from interviews with company officials.

The analytic framework for analysing technological upgrading in the semiconductor industry is shown in Figure 7.3. The first dimension of technological upgrading follows the functional elements of catch up in which semiconductor firms integrate front- and back-end operations, while some relocate or upgrade to participate in $R \& D$, integrated circuit (IC) design, and wafer fabrication. The former can be referred to as functional integration and the latter as functional upgrading. Integration activities are not classified as functional upgrading if 


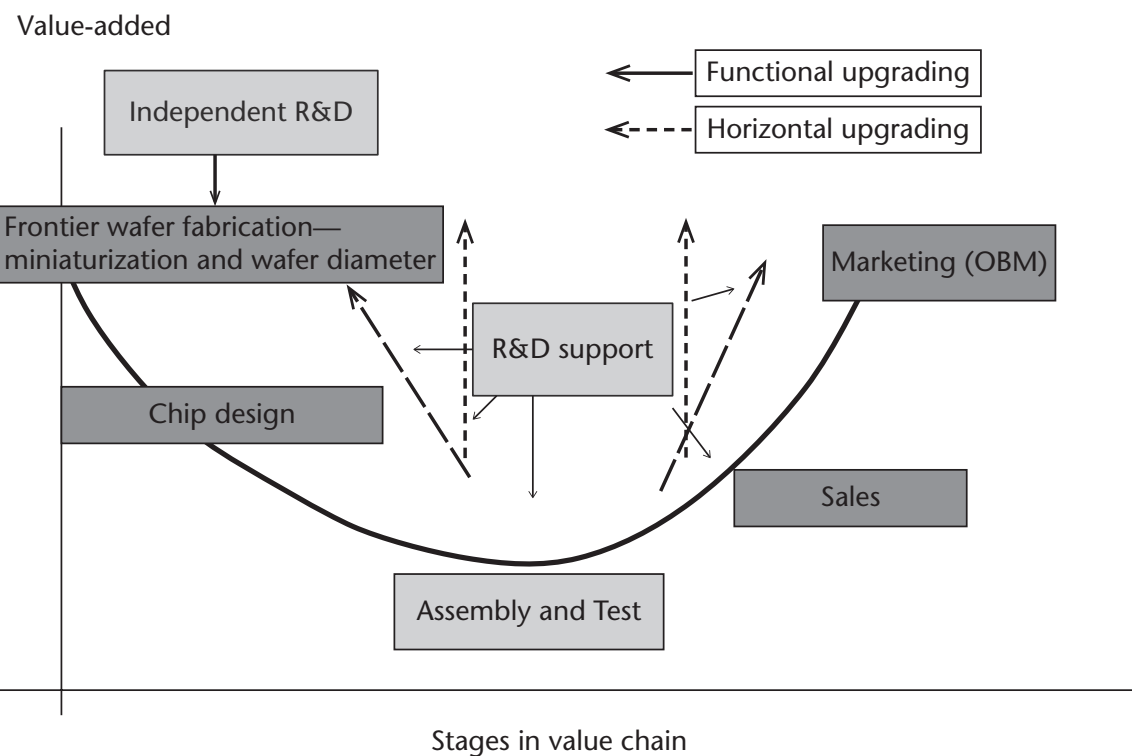

Figure 7.3. Value chain of ICs, 2014

Source: Drawn by author from interviews with firms.

they are limited to the merging of low value-added activities-for example, the addition of assembly to test activities in wafer fabrication. Instead, they are referred to as functional integration without upgrading.

The second dimension of technological upgrading follows from the deepening of the same functional activities as semiconductor firms absorb best practices, which include cutting edge inventory and quality control systems, and adaptive engineering and R\&D support to upgrade functional activities to raise plant productivity. Training and skills development ensure high level of competency among the workers to perform continuous improvement at the workplace.

Combining both dimensions of technological upgrading, it is possible to define the technological depth of semiconductor firms by process and product technologies. Hence, it is possible to evaluate the success of industrial policy by first examining if firm-level upgrading took place and if it was influenced by industrial policy, or if a lack of such upgrades was a consequence of the absence of dynamic industrial policies.

To ensure that the sample drawn is representative of the population, we took a stratified random sample by ownership. Of the thirty-nine semiconductor firms in Malaysia in 2014, six were Malaysian owned. Since the study required firm visits to explain adequately to the respondents the typology 
Table 7.1. Technological competency and capability, semiconductor firms, Malaysia, 2014

\begin{tabular}{|c|c|c|c|c|}
\hline & & Human Resource & Process & Product \\
\hline 1 & Simple activities & $\begin{array}{l}\text { On-the-job and in- } \\
\text { house training }\end{array}$ & $\begin{array}{l}\text { Dated machinery } \\
\text { with simple } \\
\text { inventory control } \\
\text { techniques }\end{array}$ & $\begin{array}{l}\text { Assembly of } \\
\text { components }\end{array}$ \\
\hline 2 & Minor improvements & $\begin{array}{l}\text { In-house training and } \\
\text { performance awards }\end{array}$ & $\begin{array}{l}\text { Advanced } \\
\text { machinery, layouts, } \\
\text { and problem } \\
\text { solving }\end{array}$ & Precision engineering \\
\hline 3 & Major improvements & $\begin{array}{l}\text { Extensive focus on } \\
\text { training and retraining; } \\
\text { staff with training } \\
\text { responsibility }\end{array}$ & $\begin{array}{l}\text { Cutting-edge } \\
\text { inventory control } \\
\text { techniques, SPC, } \\
\text { JIT, and TPM }\end{array}$ & $\begin{array}{l}\text { Cutting-edge quality } \\
\text { control systems (QCC, } \\
\text { TQM) with OEM } \\
\text { capability }\end{array}$ \\
\hline 4 & Engineering & $\begin{array}{l}\text { Focus on engineers for } \\
\text { absorbing best } \\
\text { practices }\end{array}$ & $\begin{array}{l}\text { Process, layout, } \\
\text { equipment, and } \\
\text { technique } \\
\text { adaptation }\end{array}$ & Product adaptation \\
\hline 5 & Early R\&D & $\begin{array}{l}\text { Focus on engineers for } \\
\text { process and product } \\
\text { development activities }\end{array}$ & $\begin{array}{l}\text { Process } \\
\text { development }\end{array}$ & $\begin{array}{l}\text { Product development } \\
\text { with ODM capability }\end{array}$ \\
\hline 6 & Mature R\&D & $\begin{array}{l}\text { Focus on specialized } \\
\text { R\&D engineers }\end{array}$ & $\begin{array}{l}\text { New process } \\
\text { development }\end{array}$ & $\begin{array}{l}\text { New product } \\
\text { development, some } \\
\text { with OBM capability }\end{array}$ \\
\hline 7 & Frontier technology & $\begin{array}{l}\text { Strong links between } \\
R \& D \text { engineers and } \\
\text { frontier research in } \\
\text { universities }\end{array}$ & $\begin{array}{l}\text { Process } \\
\text { development to } \\
\text { accommodate } \\
\text { frontier products }\end{array}$ & Frontier products \\
\hline
\end{tabular}

Notes: SPC—statistical process control; JIT—just-in-time; TPM—-total preventive maintenance; QCC—quality control circles; TQM—-total quality management; OEM—original equipment manufacturing; ODM—original design manufacturing; OBM—original brand manufacturing.

Source: Rasiah (forthcoming).

used for the study, the question of missing values did not arise. Indeed, we managed to get 100 per cent of the sampled firms to respond to the study.

Table 7.1 shows the template used to locate the sampled semiconductor firms by technological capabilities. Whereas we refer to technology embodied in human resources (HR) as competencies, we classify process and product as capabilities. The classification criteria for the different activities are based on interviews conducted with the leading firms in the industry (Rasiah, Yap, and Yap 2015).

\subsection{Promotion of Electronics Manufacturing}

Government promotion of manufacturing in Malaysia was initiated through the Pioneer Industry Ordinance (PIO) of 1958, which sought to stimulate 
inward-oriented manufacturing targeted at substituting imports. It was during this time that Malaysia's first electronic-electrical firms were started when Matsushita Electric relocated its manufacture of electrical appliances in 1965. However, because of the small domestic market, manufacturing stagnated by 1965, by which time the Malaysian Industrial Development Authority (MIDA) was launched to spearhead industrial promotion. The conditions for export orientation were started when the Investment Incentives Act was promulgated in 1968. Labour laws were tightened to restrict the role of trade unions through amendments to the Industrial Relations Act in 1967. Hence, since the late 1960s, export-oriented foreign MNCs relocated assembly and processing activities as they were seeking to relocate labour-intensive operations to countries endowed with surplus of trainable labour (Scibberas 1977; Lim 1978).

Over the period 1986 to 2015, Malaysia experienced the introduction of three IMPs, and two rounds of export orientation. The first period of promotion following the PIO saw virtually no expansion of electronics manufacturing because of the small domestic market and because the state confined its role strictly to the regulatory function of approving foreign investment applications and incentives targeted at supplying final goods to the domestic market. Significant expansion in electronics manufacturing only began in 1971, following the launch of export-oriented manufacturing.

\subsection{First-Round Export Orientation}

Electronics manufacturing expanded sharply in Malaysia only after the introduction of export-oriented manufacturing in 1971, which was promoted through the second Malaysia Plan of 1971-5, and the opening of FTZs and LMWs in 1972. The prime objective of these zones was to attract FDI to generate jobs, which the government managed through the development of export-processing zones to house giant firms from abroad engaged in light manufacturing activities. To facilitate the inflow of FDI, the government offered financial incentives (tax and tariff operations through tax holidays and investment tax credits for a period of five years) to firms locating at FTZs and LMWs, which were renewable for another five years.

While economic restructuring by ethnicity became the prime focus of the NEP, the export-oriented manufacturing sector was spared from such requirements as incentives, including tax exemptions and tariff-free operations, were offered to firms on the basis of investment and employment generated (Malaysia 1971). The Philippines became the main competitor to Malaysia in the 1970s, as it had a much larger English-speaking labour reserve that was willing to work for low wages. China and the transition economies of 
Indo-China and Myanmar were not open to capitalist organization until 1978 and the late 1980s respectively. South Korea, Taiwan, and Indonesia also did not pose serious competition to attract FDI as these countries in the 1970s had placed stronger emphasis on national firms. Malaysia's ability to play the regulatory role by simplifying approvals and offering security and stability at the FTZs gave it an edge over the Philippines.

Hence, the FTZs and LMWs began to enjoy a massive influx of foreign electronics MNCs. Clarion and National Semiconductor were the earliest export-oriented MNCs in Malaysia when they built their factories at the Bayan Lepas FTZ in Penang in 1971. By the mid-1970s, Intel, Advanced Micro Devices, Texas Instruments, Hitachi, Motorola, HP, and Siemens (Litronix) had relocated massive assembly operations to Malaysia. While Motorola and Siemens have since sold their semiconductor plants in Malaysia to Freescale and Qimonda respectively, Hitachi transformed into Renesas, and National Semiconductor acquired the brand name of Fairchild. Most foreign semiconductor firms that relocated operations in the 1970s have retained operations in Malaysia. Other semiconductor firms to relocate operations to Malaysia since 1990 include Integrated Device Technology, Infineon, ST Microelectronics, Unisem, Carsem, Globetronics, Silterra, X-Fab, Avago, Alterra, Osram, and Onn Semiconductor. The expansion in electronics production was so swift that the industry had become the largest generator of manufacturing employment, value-added activities, and exports in Malaysia by the late 1980s (Rasiah 2010: figure 7.3). However, most consumer electronics firms left Malaysia by the late 1990s owing to a tightening labour market from the mid-1990s as a surplus of FDI caused economic overheating.

Because the government also had in place an import-substitution sector that supplied the domestic sector, it stipulated originally that firms locating at FTZs and LMWs export all their items irrespective of the share of inputs enjoyed domestically. Since 1986, these firms were allowed to sell 20 per cent of their output in the principal customs area of Malaysia when attempts were made to promote domestic linkages. The provision of excellent basic infrastructure, security, political stability, and the quick handling of related issues helped make the FTZs and LMWs safe production bases in the global division of labour of foreign MNCs.

While the first-round export-orientation policies proved successful, it did not meet the key objective of industrial policy, which is to stimulate the structural transformation of the electronics industry from low to high valueadded activities. In fact, Singapore managed to attract Hewlett Packard to relocate some aspects of wafer fabrication in the late 1980s only because Malaysia refused to provide capitalization grants upfront (Rasiah 1987). Hence, while manufacturing was identified as the engine of growth and incentives were offered to attract MNCs since 1971, until the early 1990s, 
the government did not attempt to introduce the active instruments of industrial policy to promote technological deepening.

As a consequence, electronics manufacturing faced enormous pressure by the end of the first-round of export orientation from two fronts. On the first front, the government had begun to favour national capital over foreign capital in the provision of incentives following the introduction of its heavy industrialization programme in 1981. Hence, the government began delaying efforts by MNCs such as, Advanced Manufacturing Devices, Intel, and Motorola, to have their incentives renewed (Rasiah 1987). On the second front, the semiconductor industry began facing a severe cyclical crisis. Overproduction and cutthroat competition caused major shakeouts in the industry over the period 1984-7 (Rasiah 1989). A few MNCs with operations in Malaysia were acquired by other firms-for example, Mostek by Thomson-CSF, which was eventually sold to International Device Technology. Malaysia was also experiencing a severe balance of payments crisis as the prices of primary commodities had fallen considerably in the mid-1980s in the face of mounting external loans taken to finance infrastructure construction (Jomo 1990).

Nevertheless, over the period 1971-80, the electrical-electronics industry achieved the objectives expected of government policy, which was to attract export-oriented FDI to create jobs. Indeed, Penang's rapid growth is very much a consequence of FDI inflows. The unemployment rate fell from 8.1 per cent in 1971 to 4.0 per cent in 1980 (Malaysia 1991c). Employment fell in the crisis years of 1985-7 but rose sharply again since 1987 to 2.5 per cent in 1998 . The major developmental role the state played in this phase was to approach directly potential investors among MNCs from the United States, Japan, and Europe to relocate in Malaysia, and to develop basic infrastructure. Qualifying firms enjoyed financial incentives, which the federal state offered through its regulatory function.

\subsection{Second-Round Export Orientation}

The second round of export-orientation can be traced to 1986, when the government resumed the active promotion of exporting firms. The first Industrial Master Plan (IMP1) was introduced in 1986 but because of the 1984-5 recession, the government targeted only easily achievable milestones. A few developments assisted the rapid recovery and subsequent expansion of the electronics industry in Malaysia. While the production experience of more than a decade was useful when the cyclical recovery began in the industry in 1987, appreciation of the Yen, Won, the New Taiwan dollar, and the Singapore dollar following the Plaza Accord of 1985, and the withdrawal of the Generalized System of Preferences (GSP) in February 1988 (from Korea, 
Taiwan, Hong Kong, and Singapore) acted as a major driver of FDI outflow from these countries to the market economies of Southeast Asia (Rasiah 1988). Meanwhile, following negative GDP growth rates recorded in 1985-6, the Malaysian government devalued the Ringgit and extended the investment tax credit to electronics MNCs. Hence, until the early 1990s, the government returned to perform its regulatory role to stimulate FDI inflows in the electronics industry. The aggressive promotion of FDI inflows and push-driven FDI outflows from northeast Asian economies attracted massive inflows of equipment and parts, industrial and commercial, and consumer electronics firms into Malaysia to push up exports from these industries (see Figure 7.4).

Although the government started Malaysian Institute of Microelectronics Systems (MIMOS) in 1985 to support the development of national firms, it was not until 1991 that the government began promoting functional upgrading to stimulate the transformation of the industry to high value-added operations, such as wafer fabrication, chip design, and $R \& D$, following the launch of the APITD. Silterra was conceived within the premises of MIMOS in 1995 and launched at Kulim High Tech Park in 2000 to fabricate wafers using the Taiwanese framework of buyer-supplier alliances. Meanwhile, Carsem, Unisem, and Globetronics emerged as private Malaysian firms with their managements dominated by former employees of foreign semiconductor

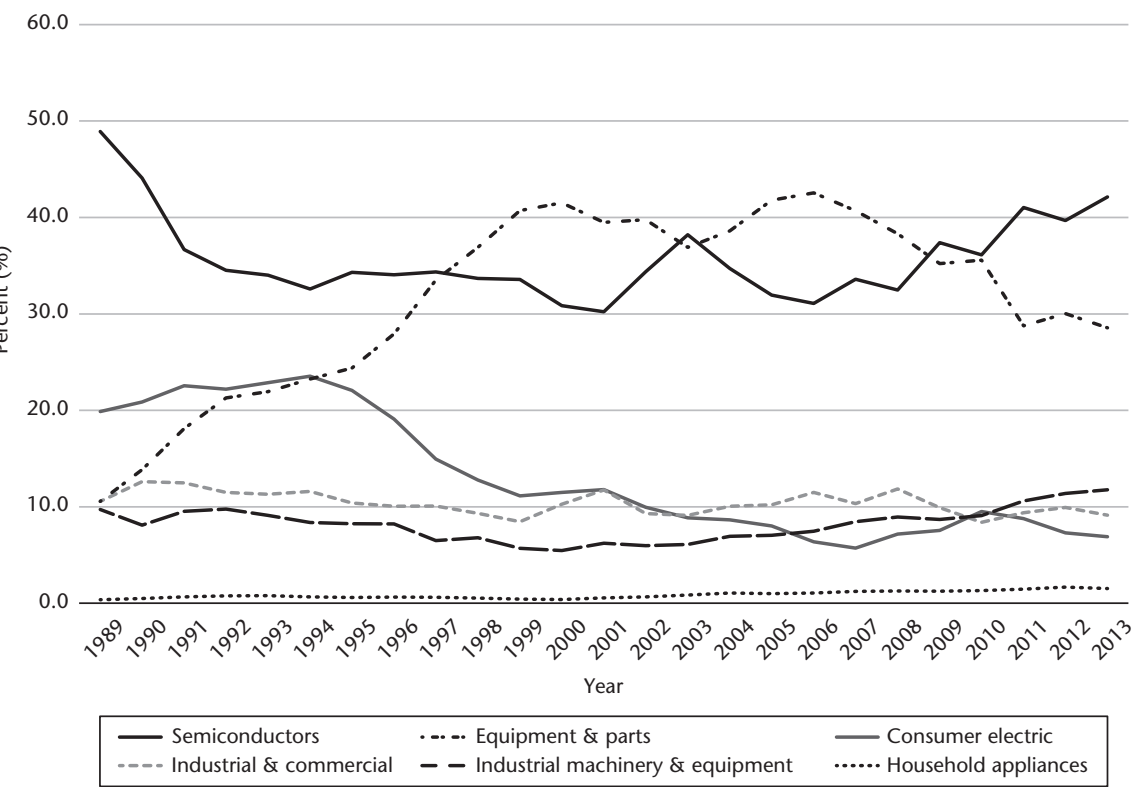

Figure 7.4. Composition of the electrical-electronics industry in electronics valueadded activities in per cent, Malaysia, 1989-2013

Source: Compiled from Malaysia, Industrial Surveys, Department of Statistics, various issues. 
MNCs in Malaysia. The government also extended the provision of grants to foreign firms in 2005, which helped attract wafer fabrication plants by Infineon, Onn Semiconductor, and Osram.

The first and second IMPs of 1996 and 2006 stepped up the focus on stimulating structural transformation from low to high value-added activities but the government's role did not shift much from regulatory to developmental (Malaysia 1996, 2006). There was a call for targeting financial incentives to capital-intensive and strategic industries in the second Industrial Master Plan (IMP2) but that was stopped when the Asian financial crisis struck in 1997. Clustering was promoted in IMP2 and the third Industrial Master Plan (IMP3) but the regulatory instruments did not differentiate between value chains, buyer-supplier firms, or meso-organizations that were required to synergize promoted industries.

The government acquired Very Large-Scale Integration (VLSI) in 1995 to initiate wafer fabrication but did not appoint leaders with the tacit and experiential knowledge of working in lead firms to orchestrate technological catch up the way Morris Chang engineered both the Hsinchu Science-based Industrial Park and Taiwan Semiconductor Manufacturing Corporation. The acquisition of VLSI technology offered the opportunity to skip stages in the technological ladder but the lack of leaders to manage the process gave Silterra no opportunity to embark on a clear catch up path. Yet, Rasiah (1988) had demonstrated how crises have given opportunities for latecomer firms, such as Samsung Semiconductor and TSMC to catch up.

A wide range of meso-organizations were created to provide public goods to solve collective action problems. However, political colouring in the creation and management of these organizations restricted their capacity to stimulate technological upgrading. Hence, while Korea and Taiwan successfully attracted their diaspora endowed with tacit and experiential knowledge to lead, Malaysians with such capabilities were overlooked. Examples of Malaysians overlooked include Loh Kin Wah, the managing director of Qimonda in 2008. Also, while 'carrots' were given to national firms during the Dr Mahathir regime, the 'stick' was never applied, and the replacements never proved capable because of the absence of tacit and experiential knowledge among the criteria in their appointments. The IMP2 of 1996 earmarked efforts to stimulate clustering, though its application was misdirected sectorally (Rasiah 1999). The instruments of technological deepening were not implemented because of the government's reluctance to offer grants to foreign and ethnic Chinese firms, which was compromised by political considerations.

Although functional integration evolved since 1990, it took place largely in the low value-added equipment and parts segment of the electrical-electronics industry (see Figure 7.4). Such integration actually led to functional downgrading. Both the IMP1 and the IMP2 failed to stimulate functional upgrading 
into higher value-added segments of the industry as the government neither offered the grants nor had in place effective human capital development policies to step up the supply of quality engineers and scientists. Indeed, Cheong, Selvaratnam, and Goh (2011) provided evidence to show that the poor quality of education in Malaysia has inhibited rapid economic transformation in the country. Without a critical mass of human capital, the increasing competition from China, Philippines, and Indonesia has forced imports of foreign labour, which helped keep wages down but also restricted technological upgrading. The consumer electronics segment of electronics manufacturing continued to decline as firms began to relocate operations to China, Philippines, Indonesia, and Viet Nam.

The government extended the provision of R\&D grants to foreign electronics firms only from 2005, which helped attract the high value-added stages of wafer fabrication (e.g., Infineon, Onn Semiconductor, Osram); IC design (Intel, AMD, Freescale, Hitachi); and R\&D (e.g., Intel, AMD, Hitachi, Motorola, Alterra, Avago). Hence, the IMP3 appears more successful than IMP2 only because the government offered capital grants to foreign firms to stimulate functional upgrading. Thus, the components segment (mainly semiconductors) of the electronics industry has managed to grow again to overtake electrical-electronics equipment and parts as the leading sector in the industry since 2005 (see Figure 7.4).

However, serious shortages in the supply of human capital, including quality graduates in the fields of science and technology in related electronics specializations, and the lack of frontier research on semiconductors has restricted firms' participation in R\&D operations. As a corollary, science parks (for incubation) and research universities (for basic R\&D) have not evolved adequately to support firms' participation in high technology activities. In addition, the government's largely facilitative rather than developmental role has restricted technological upgrading in the industry. Even the provision of grants by the government has not been accompanied by upgrading milestones. Existing initiatives by a handful of MNCs in such activities are largely propelled from their parent and subsidiary sites abroad.

\subsection{Technological Catch-Up}

As discussed in Sections 7.3 and 7.4, the dynamic pillar of industrial policy constitutes the capacity to stimulate firms' upgrading from low to high valueadded stages or in technological terms, firms' catch up to the technology frontier and eventually to leapfrog competitors. We focus here on the semiconductor industry to undertake a profound assessment of technological upgrading in the most sophisticated component of the electronics industry. 
Since industrial policy in Malaysia did not seek technological upgrading over the period 1971-86, markets were left to shape firm-level technologies. Nevertheless, intense competition in electronics required that firms regardless of their location introduced best practices. Hence, especially in semiconductors, non-Japanese firms began introducing automation and just-in-time (JIT) practices from the late 1970 s and mid-1980s respectively. The active use of learning and innovation strategies through kaizen (continuous improvement) practices that included small group activities, quality control circles, integrated materials resource planning, and statistical process control, proliferated into all semiconductor firms in Malaysia (Rasiah 2010).

Since the 1980s, the introduction of cutting-edge process control technologies increased incremental engineering practices, as cutthroat competition forced a shakeout in the industry. The rising demand for statistical and cognitive skills led to poaching as their supply became scarce in Malaysia following the second major wave of electronics firms since 1988. Most semiconductor firms had already moved to levels 3 and 4 in the technological capability ladder by the 1990s (Rasiah 2010). The floating of the currencies of these countries following the Plaza Accord of 1985 and the termination of the GSP from Taiwan, Korea, and Singapore in February 1988 triggered this relocation to most of Southeast Asia (Rasiah 1987). The collaborative initiatives that were launched to solve infrastructure problems, such as security, customs coordination, power and water supply, and transport and housing for workers, became a key channel to the founding of the Penang Skills Development Centre in 1989. The Penang state, the anchor in solving collective action problems, responded to firms' requests and offered a large building at a nominal cost for their use in order to stimulate training for the industry.

Firm-level horizontal technological upgrading can be classified as developments largely driven by firm strategies conditioned by competition with the government playing a minimal role as facilitator. Suppliers began to expand in the 1980s and early 1990s when the use of JIT practices and rapid technological obsolescence stimulated proximate sourcing (Rasiah 1994). Much of these upgrades arose from the absorption of best practices with automation and statistical skills control dominating production operations of electronics firms.

Table 7.2 shows the extent of upgrading enjoyed by semiconductor firms by taxonomy and trajectory in 2014 from a sample of twenty-five semiconductor firms in Malaysia. The three lead firms in the semiconductor industry (i.e., Intel in microprocessors, Samsung in memory, and TSMC in logic chips) do not have their frontier operations in Malaysia. In 2014, seven foreign firms enjoyed mature R\&D competencies and capabilities.

It can be seen in Table 7.2 that none of the firms are at the frontier of all three embodied technological pillars (i.e., HR competencies, and process and 
Table 7.2. Technological competency and capability, semiconductor firms, Malaysia, 2015

\begin{tabular}{|c|c|c|c|c|c|c|c|}
\hline \multirow[t]{2}{*}{ Level } & \multirow[t]{2}{*}{ Type } & \multicolumn{2}{|l|}{$\mathrm{HR}$} & \multicolumn{2}{|l|}{ Process } & \multicolumn{2}{|l|}{ Product } \\
\hline & & National & Foreign & National & Foreign & National & Foreign \\
\hline 4 & Engineering & 4 & 21 & 4 & 21 & 4 & 21 \\
\hline 5 & Early R\&D & 1 & 20 & 1 & 20 & 1 & 20 \\
\hline 6 & Mature R\&D & 0 & 7 & 0 & 7 & 0 & 7 \\
\hline \multirow[t]{2}{*}{7} & Lead technology & 0 & 0 & 0 & 0 & 0 & 0 \\
\hline & $\mathrm{N}$ & 4 & 21 & 4 & 21 & 4 & 21 \\
\hline
\end{tabular}

Source: Rasiah (forthcoming).

product capabilities). Indeed, neither do any of the firms undertake frontier research in-house nor engage frontier research facilities in universities in Malaysia. All seven firms that reported having mature R\&D competencies and capabilities are foreign owned (i.e., five American, one Japanese, and one German). All foreign and national firms enjoyed at least engineeringintensive operations. Whereas twenty of the twenty-one foreign firms were engaged in at least the early stages of $R \& D$, only one of the four national firms reported undertaking such activities. Early stage supportive R\&D in foreign firms had already started in the 1990s. However, their progression to substantial $R \& D$ activities only took place after the provision of grants, and the approval of permits to import foreign $R \& D$ personnel. The seven foreign firms with mature $R \& D$ capabilities reported that Malaysia lacked the requisite human capital, as well as, frontier research capabilities in the country to attract frontier R\&D operations (level 7).

The efforts of the provincial government of Penang to start the Penang Skills Development Centre (PSDC) was instrumental in the federal government responding by launching a more institutionalized framework at the national level to support training through the enactment of the HR Development Act in 1992, which required that manufacturing firms with employment size of fifty or more contribute 2 per cent of their payroll to the HR Development Council. Firms can then claim from their contributions approved training expenses. The government had introduced a double deduction on taxable income scheme in 1988, which has continued among firms with employment size below fifty employees since 1993. In addition, the government introduced grants following the launch of the APITD in 1991 but its implementation was restricted until 2005. Only Silterra and 1st Silicon, both governmentowned wafer fabrication firms were awarded grants until then.

The government's efforts to launch the venture capital organization, Malaysian Technology Development Corporation (MTDC), and to corporatize MIMOS in 1993 did not yield significant results in the semiconductor industry. Arguably, the main effort of MIMOS has been the setting up of Silterra and 
1st Silicon. The former is still far from the technology frontier, while the latter has been acquired by the foreign firm, X-Fab. The introduction of the Multimedia Super Corridor in 1995 offered broad-brand infrastructure to stimulate firms' participation in design but they have largely been confined to service activities.

While significant technological deepening has taken place among semiconductor firms, functional upgrading only began to rise from 2005 with the integration of more knowledge-intensive stages, such as chip design, wafer fabrication, and chip implant activities. Semiconductor firms began to introduce the early aspects of $R \& D$, with a focus on the development of machinery and equipment prototypes, modifications, and production and organizational restructuring in the 1990s. Firms that considered upgrading, such as Hewlett Packard and Intel, into wafer fabrication and chip design respectively in the late 1980s, did not do so because of lack of capital grants upfront from the government (Rasiah 1996). Hence, by confining government support to financial incentives (tax breaks), security, and basic infrastructure, the government managed to attract foreign semiconductor MNCs into Malaysia into labourintensive activities. However, by not introducing the dynamic elements of industrial transformation, such as capital grants, to stimulate the introduction of chip design, wafer fabrication, and $R \& D$, the industry enjoyed little functional upgrading until 2005. In addition, Malaysia lacked the human capital and related research universities to support firms' participation in frontier technologies, such as the introduction of new generation technologies that can spur new cycles of innovation.

The risks associated with investing in massive fixed assets involving wafer fabrication and $\mathrm{R} \& \mathrm{D}$ discouraged firms from extending into these activities until 2005. Chip design is a complementary activity that thrives on proximity to wafer fabrication, and hence, the lack of the latter discouraged participation in the former. Nevertheless, software activities in chip design can be undertaken from locations far from wafer fabrication as is seen in Bangalore, India, and Haifa, Israel. The short supply of human capital in general and information technology (IT) specialists in particular has hampered the expansion of chip design in Malaysia.

Since 2000, Silterra and 1st Silicon enjoyed grants from the federal government to set up wafer fabrication in Malaysia, but both firms are engaged in old generation technologies. Nevertheless, the extension of R\&D grants after 2005 attracted functional upgrading. Hence, the number of semiconductor firms that upgraded into chip design and wafer fabrication production rose from none until 1999 to eleven in 2014. There were four foreign firms in chip design, one national, and five foreign firms in wafer fabrication. Although no semiconductor firm in Malaysia is shaping the globe's technology frontier, the integration of the high value-added activities of wafer fabrication and chip 


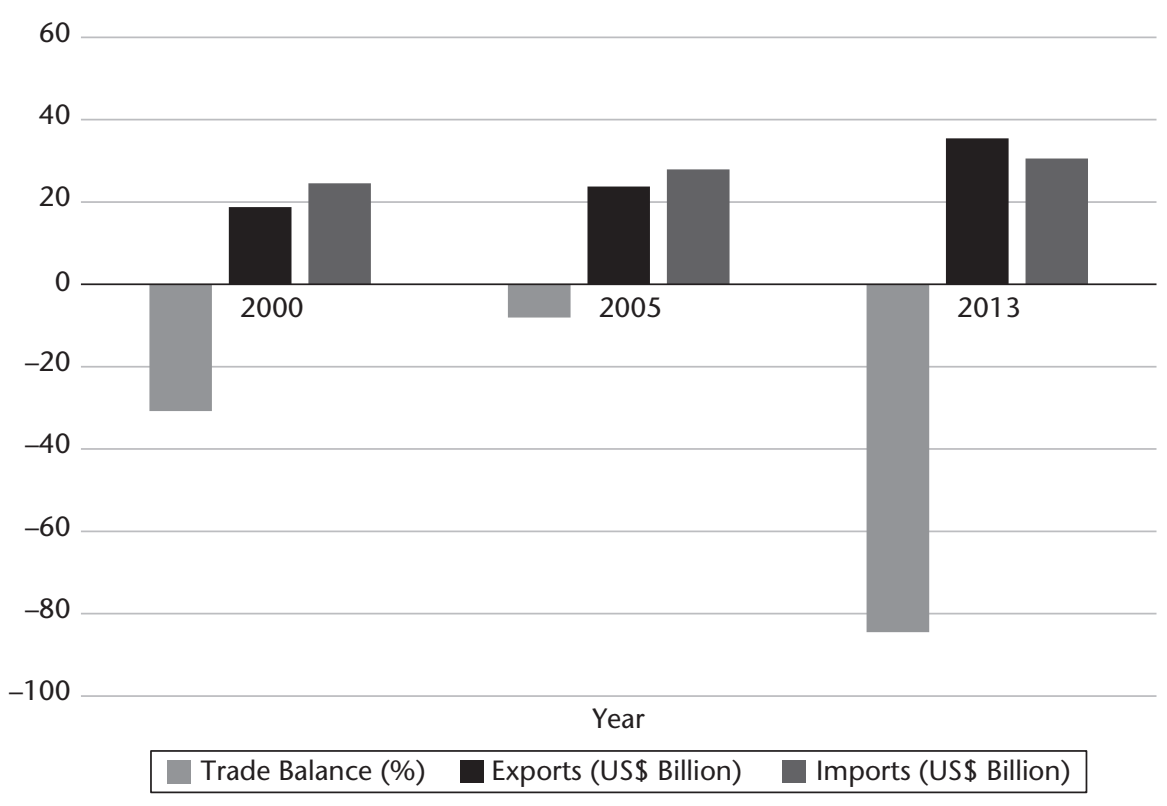

Figure 7.5. Trade, electrical electronics, Malaysia, 2000-13

Note: Trade balance estimated using the formula: $(\mathrm{X}-\mathrm{M}) /(\mathrm{X}+\mathrm{M}) \times 100$ where $\mathrm{X}$ and $\mathrm{M}$ refer to exports and imports.

Sources: Compiled from WTO $(2005,2014)$.

design has helped turn the negative trade balance in the integrated industry to a positive one (see Figure 7.5). While chip design typically does not require grants, its expansion in Malaysia required grants to train nationals and approval of imported IT engineers from abroad. Hence, the number of patents registered by semiconductor firms from Malaysia in the United States rose from 7 over the period 1980-2005 to 309 in 2006-11 (Rasiah, Yap, and Yap 2015: 65).

While a number of semiconductor firms have ventured into functional upgrading since 2005, none participate in R\&D activities associated with miniaturization and the enlargement of wafer diameter. In addition, none of the wafer fabrication plants in Malaysia are at the frontier. The flag bearers of such activity are Intel in microprocessors, Samsung in memory, and TSMC in logic chips. Despite the possibility of accessing R\&D grants, the short supply of engineers and R\&D scientists, and the lack of frontier research at Malaysian universities were reported by two CEOs of semiconductor firms to be the prime reasons for its absence in Malaysia. The lack of human capital endowed with tacit linkages with frontier R\&D centres (including universities), buyer supplier firms, and the vision to anticipate next generation technologies (e.g., Maurice Chang of TSMC) has reduced meso-organizations, such as MTDC and 
MIMOS, and universities to truncated silos with little interaction with industry. The absence of such leadership restricted the capacity of national firms to enter and catch up technologically in the electronics industry like South Korea and Taiwan. Also, the lack of frontier research centres-either at universities or at science parks-discouraged the development of R\&D and wafer fabrication activities in Malaysia. In addition, the lack of effective monitoring and appraisal restricted the capacity of the government to reduce the dissipation of rents offered through grants.

It can be seen that levels 5 and 6 technological activities have evolved in Malaysia, albeit in a few semiconductor firms. While the IMP2 provided some support for clustering activities, including the promotion of supplier networks, and recommended the provision of grants to promote $R \& D$ and wafer fabrication activities, there was little success. A combination of a lack of interest in providing foreign firms grants restricted its provision to Silterra and 1st Silicon until 2005. Venture capital through government agencies, such as MTDC supported only a selected number of proven firms, such as Unico but generated little university-industry linkages. The provision of grants upfront to foreign firms since 2005 has encouraged functional upgrading into chip design and wafer fabrication, and encouraged development in supportive R\&D activities. However, these developments have not been subjected to strong governance to ensure technological catch up to frontier activities of $R \& D$ and wafer fabrication because of the lack of frontier research centres in semiconductor engineering (either at universities or public laboratories), and a critical mass of human capital. Hence, neither foreign nor national firms are engaged in level 7 HR competencies, process, and product capabilities in Malaysia.

\subsection{Conclusions}

Malaysia's electronics industry provides a mixed experience where the industry emerged largely with little intervention by the government other than the provision of financial incentives, security, and subsidized infrastructure at FTZs. The only developmental role the state played over the period 1971-90 was to approach actively foreign MNCs to relocate in Malaysia. Such liberal instruments managed to attract FDI inflows to generate employment and exports. Competition between firms and the specificity of the industry also saw significant horizontal technological development in the industry by the 1980s as firms introduced rapidly cutting edge process and production technologies Malaysia's small domestic market and the specificity of electronics specialization in semiconductors made export orientation the only option to 
stimulate FDI inflows and rapid expansion. Import substitution was never a workable option in this industry.

Nevertheless, uncoordinated policies did not offer the institutional change required to spur significant functional upgrading vertically from low into higher value-added activities. There was a lack of high-technology organizations to solve collective action problems associated with public goods. Sensing such a shortcoming, the government introduced the APITD in 1991. However, while major meso-organizations; they failed to lead functional technological upgrading in the electrical-electronics industry. The provision of grants since 2005 has stimulated functional upgrading in the industry. However, the lack of research universities and laboratories undertaking frontier $R \& D$ in the electronics industry, and short supply of engineers and scientists were major weaknesses that have continued to discourage functional upgrades towards the technology frontier in the country.

Overall, the Malaysian experience with electronics in general and the semiconductor industry in particular shows that a minimalist role by the government that largely follows the direction of markets and, supplemented by good basic infrastructure and bureaucratic coordination when executed well can attract FDI inflows seeking low-wage labour. However, as labour reserves deplete it is not sufficient to sustain the technological upgrading required to support rising wages. Moreover, such policies are inadequate to stimulate technological development into $R \& D$ activities. While grants helped attract old-generation wafer fabrication into Malaysia, they were inadequate to attract cutting-edge $R \& D$ and wafer fabrication activities. Universities undertaking related research at the frontier, and a critical mass of related human capital are essential to attract frontier semiconductor manufacturing activities. There was a serious lack of focus on capability building in national firms in the technology transfer agreements like Japan, South Korea, and Taiwan. The political economy of ethnicity appears as a major constraint that has prevented the state from pursuing dynamic technological catch-up strategies in the country.

\section{References}

Abramowitz, M. (1956). 'Resource and Output Trends in the United States since 1870'. American Economic Review, 46(2): 5-23.

Amsden, A., and W. W. Chu (2003). Beyond Late Development: Taiwan's Upgrading Policies. Cambridge, MA: The MIT Press.

Amsden, A. O. (1989). Asia's Next Giants: South Korea and Late Industrialization. New York: Oxford University Press. 
Ariffin, N., and P. N. Figueiredo (2004). 'Internationalization of Innovative Activities: Counter-Evidence from the Electronics Industry in Malaysia and Brazil'. Oxford Development Studies, 32(4): 559-83.

Chenery, H., S. Robinson, and M. Syrquin (1986). Industrialization and Growth: A Comparative Study. Washington, DC: World Bank and Oxford University Press.

Cheong, K. C., V. Selvaratnam, and K. L. Goh (2011). 'Education and Human Capital Formation'. In R. Rasiah (ed.), Malaysian Economy: Unfolding Growth and Social Change. Kuala Lumpur: Oxford University Press.

Dahlman C. J. (1984). Foreign Technology and Indigenous Technological Capability in Brazil. London: Macmillan.

Figueiredo, P. N. (2001). Technological Learning and Competitive Performance. Cheltenham: Edward Elgar.

Gerschenkron, A. (1952). 'Economic Backwardness in Historical Perspective'. In M. Granovetter and R. Swedberg (eds), The Sociology of Economic Life. Boulder, CO: Westview Press.

Johnson, C. (1982). MITI and the Japanese Miracle. Stanford, CA: Stanford University Press.

Jomo, K. S. (1990). Growth and Structural Change in the Malaysian Economy. Basingstoke: Macmillan.

Kaldor, N. (1967). Strategic Factors in Economic Growth. Ithaca, NY: Cornell University Press.

Lall, S. (1992). 'Technological Capabilities and Industrialization'. World Development, 20(2): 165-86.

Lim, L. Y. C. (1978). 'Multinational Firms and Manufacturing for Export in LessDeveloped Countries: The Case of Electronics Industry in Malaysia and Singapore'. PhD dissertation, University of Michigan.

Malaysia (1971). The Second Malaysia Plan 1971-1976. Kuala Lumpur: Government Printers.

Malaysia (1986). The Industrial Master Plan. Kuala Lumpur: Government Printers.

Malaysia (1991a). Action Plan for Industrial Technology Development. Kuala Lumpur: Ministry of Science Technology and Environment.

Malaysia (1991b). The Way Forward. Kuala Lumpur: Government Printers.

Malaysia (1991c). The Sixth Malaysia Plan 1991-1995. Kuala Lumpur: Government Printers.

Malaysia (1996). The Second Industrial Master Plan 1996-2005. Kuala Lumpur: Government Printers.

Malaysia (2006). The Third Industrial Master Plan 2006-2015. Putra Jaya: Government Printers.

Marx, K. (1957). The Circuits of Capital, vol. 2. Moscow: Progress Publishers.

Nelson, R. R. (2008). 'What Enables Rapid Economic Progress: What are the Needed Institutions?'. Research Policy, 37(1): 1-11.

Rasiah, R. (1987). 'Production in Transition within the Semiconductor Industry and its Impact on Penang'. Kajian Malaysia, 6(1): 45-64.

Rasiah, R. (1988). 'The Semiconductor Industry in Penang: Implications for the New International Division of Labour Theories'. Journal of Contemporary Asia, 18(1): 24-46. 
Rasiah, R. (1994). 'Flexible Production Systems and Local Machine Tool Subcontracting: Electronics Component Transnationals in Malaysia'. Cambridge Journal of Economics, 18(3): 279-98.

Rasiah, R. (1996). 'Institutions and Innovations: Moving towards the Technology Frontier in the Electronics Industry in Malaysia'. Journal of Industry Studies, 3(2): 79-102.

Rasiah, R. (1999). 'Malaysia's National Innovation System'. In K. S. Jomo and G. Felker (eds), Technology, Competitiveness and the State. London: Routledge.

Rasiah, R. (2003). 'How Important is Process and Product Technology Capability in Malaysia and Thailand's FDI-driven Electronics Industry?'. Journal of Asian Economics, 14(5): 785-811.

Rasiah, R. (2004). 'Technological Capabilities in East and Southeast Asian Electronics Firms: Does Network Strength Matter?'. Oxford Development Studies, 32(3): 433-54.

Rasiah, R. (2010). 'Are Electronics Firms in Malaysia Catching Up in the Technology Ladder?'. Journal of Asia Pacific Economy, 15(3): 301-19.

Rasiah, R. (forthcoming). 'Interview: Survey, Semiconductor Firms'. Mimeo.

Rasiah, R., X. S. Yap, and V. G. R. Chandran (2014). 'Crisis Effects in the Electronics Industry in Southeast Asia'. Journal of Contemporary Asia, 44(4): 645-63.

Rasiah, R., X. S. Yap, and S. F. Yap (2015). 'Sticky Spots on Slippery Spaces: The Development of the Integrated Circuits Industry in Emerging East Asia'. Institutions and Economies, 7(1): 52-79.

Rosenberg, N. (1976). Perspectives on Technology. Cambridge, MA: Cambridge University Press.

Rosenberg, N. (1982). Inside the Black Box. Cambridge, MA: Cambridge University Press.

Schumpeter, J. A. (1943). Capitalism, Socialism and Democracy. Cambridge, MA: Harvard University Press.

Schumpeter, J. A. ([1943] 1961). The Theory of Economic Development. Cambridge, MA: Harvard University Press.

Scibberas, E. (1977). Multinational Electronic Companies and National Economic Policies. Greenwich, CT: JAI Press.

Veblen, T. (1915). Imperial Germany and the Industrial Revolution. New York: Macmillan. Wade, R. (1990). Governing the Market. Princeton, NJ: Princeton University Press.

WTO (World Trade Organization) (2005). International Trade Statistics. Geneva: World Trade Organization.

WTO (World Trade Organization) (2014). International Trade Statistics. Geneva: World Trade Organization.

Young, A. A. (1928). 'Increasing Returns and Economic Progress'. Economic Journal, 38 (152): 527-42. 


\title{
8
}

\section{Case Studies of Decentralized Coordination in China}

\author{
Hinh T. Dinh
}

\subsection{Introduction}

This chapter draws on both successful and failing cases of industrialization in China to analyse the nature of cooperation between business and government at the subnational level and to draw policy implications for African countries. The case studies were conducted during a number of field visits to China in 2010 and 2012 and cover the five most common light manufacturing sectors: agribusiness, wood products, leather products, apparel (including apparel accessories), and metal products. ${ }^{1}$

China's spectacular economic performance began in 1978 when Deng Xiaoping put forward the concept of 'letting some people get rich first'. The gradual relaxation of the government's institutional hostility towards the private sector followed quickly. In 1978, the government began issuing permits to allow individual businesses (ge-ti-hu) to hire up to seven employees. Subsequent reforms encouraged the growth of larger 'private' firms (with eight or more workers), which started to grow rapidly. Then, private enterprises-including sole proprietorships, partnerships, and limited liability companies-were permitted to set up joint ventures with foreign corporations, thus providing additional opportunities for ambitious entrepreneurs. At the same time, China adopted an export-oriented strategy that encouraged private and overseas investment in labour-intensive manufacturing. The private sector grew at an unprecedented rate beginning in the early 1990s as the government enacted a series of policy changes and legal steps that gradually enhanced the legitimacy of private business. By 2010, China had more than

1 Data for this chapter refer to 2009-10. See Dinh et al. (2012) for details. 
8.4 million registered private enterprises that employed more than 180 million people (Dinh et al. 2013).

A number of favourable circumstances have contributed to this success. At the global level, steeply rising costs had eroded the cost advantage of earlier global export leaders, creating an opening for Chinese exporters. China possessed an abundance of well-educated workers eager to trade diligent effort for low wages. When this workforce was combined with capital, commercial expertise, and knowledge of technologies and markets from ethnic Chinese entrepreneurs overseas, the result was ripe conditions for light manufactures. Domestic economic conditions also played a role. China's plan system viewed consumer products as costs rather than benefits and therefore channelled resources away from light manufacturing. As a consequence, there was pentup demand for clothing, shoes, and a wide array of other household and personal items, particularly among households in more prosperous urban areas. The immediate success of China's agrarian reforms enhanced the prospects of light manufacturing by boosting rural incomes and, thus, the demand for consumer products, as well as by expanding the supply of raw materials and non-farm labour. Finally, the main competition for private sector entrants in this growing market for consumer goods was represented by lumbering state-owned firms with little experience in market dealings.

Section 8.2 reviews briefly the major constraints that have held back the growth of light manufacturing in Africa and how China has been able to overcome similar constraints over the last thirty years. Section 8.3 provides an in-depth analysis of the role of the central government and subnational governments in China in cooperating with enterprises and the private sector, particularly in the development of clusters. This is followed by a detailed account of various types of enterprise support supplied by local governments in China, including the concept of backing winners. The chapter concludes with a general discussion on the lessons of the Chinese experience for Africa.

\subsection{How China Overcame the Binding Constraints on Light Manufacturing}

In a previous book, Light Manufacturing in Africa: Targeted Policies to Enhance Private Investment and Create Jobs, we show that, to grow the light manufacturing sector, policy makers in Africa need first to identify, prioritize, and remove the most binding constraints in each sector (Dinh et al. 2012). These constraints vary by country, sector, and firm size. The decentralized coordination approach used in China can actually go a long way in identifying and 
relaxing these constraints. Six binding constraints on African competitiveness in light manufacturing are identified, as follows:

- availability, cost, and quality of inputs;

- access to industrial land;

- access to finance;

- trade logistics;

- entrepreneurial capabilities, both technical and managerial;

- worker skills.

\subsubsection{Availability, Cost, and Quality of Inputs}

In the African countries we have studied, large and small firms alike identify input supply_including availability, quality, and cost-as a leading obstacle to the development of competitive light manufacturing (Dinh et al. 2012).

On average across the five subsectors, inputs were more than 25 per cent more expensive in Africa than in China, representing a 20 per cent production cost penalty because inputs account for more than 70 per cent of total production costs. In most cases, higher input costs wipe out Africa's cheaper labour cost advantage. The main input policy issues are import tariffs, price controls and export bans on agricultural products, barriers to the import and distribution of high-yield seeds, and disease control in the livestock sector.

China faced similar difficulties at the start of its accelerated entry into global markets for labour-intensive manufactured goods. It responded by pursuing a two-track strategy to facilitate access to inputs. First, it developed good trade logistics early on to support imports of the inputs that could not be competitively sourced domestically. Second, it reformed and provided support to key input industries so that these could become competitive. It also transferred large numbers of government-owned enterprises to partial or full private ownership, instituted reforms aimed at commercializing the remaining state enterprises, dismantled many official controls over prices and resource allocation, encouraged foreign direct investment (FDI) for key inputs (such as in machine manufacturers), and developed sustainably managed wood plantations and competitive agricultural sectors. National and, especially, local governments supported the creation of input and output markets through the provision of land and financing (such as in the Yiwu market in Zhejiang Province, which was developed with the initiative and support of local officials) and supplied coordination along value chains. China exempted exporters from taxes and duties on imported materials. It also offered information and technical assistance on inputs, technology, and suppliers to small and medium-sized enterprises (SMEs). 


\subsubsection{Access to Industrial Land}

It is ironic that land is a constraint on most manufacturing firms in landabundant sub-Saharan Africa (SSA). Because all manufacturing firms need industrial land equipped with utilities and transport links to markets, SSA's huge deficit in industrial land puts land policy at the core of its industrial development agenda. Problems with land acquisition often prevent firms in SSA with four or five employees from growing into businesses with more than ten to fifteen employees. To do so, they would need a larger workspace connected to affordable and reliable utilities and reliable transport links to the markets for inputs and outputs. Most small firms are located in the homes of the owners or in small workshops. Connecting to utilities requires large fixed investments that are typically beyond the means of small informal operators. The savings and retained earnings of small business owners are usually insufficient to purchase industrial land to expand the business. If the government attempts to provide factory shells outside cities, the transport costs for hauling raw materials and products are an additional constraint.

China's successful industrial parks provide enterprises with security, good basic infrastructure (roads, energy, water, sewers), streamlined government regulations (through government service centres), and above all, affordable industrial land. They also supply technical training, low-cost standardized factory shells that allow entrepreneurs to plug and play, and free and decent housing for workers next to the plants. By helping small Chinese enterprises grow into medium and large enterprises, the country has also avoided the shortage of medium firms - the missing middle-faced by most countries of SSA.

In recent years, Chinese industrial parks have been offering one-stop shops that allow firms located under their jurisdiction to simplify and speed up official registration and regulatory transactions. Western buyers have an appetite for large orders, and China's industrial parks allow the country's firms to scale up rapidly to meet the needs of buyers. Such arrangements reduce search and transactions costs and promote the ready availability of information for buyers and sellers.

\subsubsection{Access to Finance}

Access to credit has been identified as the most binding constraint on small companies in developing countries (Dinh, Mavridis, and Nguyen 2012). But our study of African and Chinese firms has found that the initial start-up investment among entrepreneurs has been sourced mainly from personal savings or financing supplied by informal networks of family, business colleagues, and friends. The savings are typically accumulated through migrant 
or other factory work, trading, or family workshops. In Jiangxi Province, local entrepreneurs built up savings through migrant work in nearby Guangdong and other coastal provinces during the 1990s, then returned home to set up garment, leather, and shoe-making enterprises. We found few instances of bank credit or of FDI in the start-up phase.

Financial institutions, however, are central in the growth from small to medium firms. In China, once the enterprise has achieved considerable success, start-ups may obtain bank loans to expand production facilities, build new factories, buy machinery or land, or acquire the working capital needed to execute large orders. The most common reason firms fail to gain access to bank loans at an earlier stage of their growth is the lack of collateral. If firms are able to take out loans, factory premises or land can be used as collateral, sometimes combined with a loan guarantee from a friend or from special companies established for this explicit purpose.

The clear implication of China's light manufacturing experience for other developing countries is that help from a financial intermediary is not a necessary precondition for starting an enterprise. However, entry into formal credit markets can make a big difference for businesses that have achieved initial success and aim to enlarge the scale of operations, upgrade equipment and production processes, or both.

\subsubsection{Trade Logistics}

Poor trade logistics penalize firms that rely on imported inputs and doubly affect exporters, mostly large and medium firms in Africa. On average, they add roughly a 10 per cent production cost penalty across the five subsectors in the three African countries we have studied. Poor trade logistics also cause long and uncertain delays, unacceptable to most global buyers, especially in the time-sensitive apparel industry. As a result, production in most African countries is typically confined to small market niches. The small orders mean higher input costs, lower capacity use, and higher overheads. ${ }^{2}$

Similar to the enterprises in Africa, reliable transport services and streamlined customs clearance are critical for manufacturing firms in Ganzhou, Jiangxi Province. Although located in a landlocked area, Ganzhou has developed an administrative system for dealing with overseas trade, including

\footnotetext{
2 Ethiopia exports small volumes of low-value products. The free-on-board (f.o.b.) price of an Ethiopian polo shirt is around US\$3.20, much lower than the US\$5.50 price of an equivalent shirt produced in China. The higher Chinese f.o.b. price results from higher-quality shirts and the premium global buyers put on China's capacity to offer greater choice, bigger volumes, and quicker and more certain deliveries. Tanzania exports polo shirts at an f.o.b. price similar to China's, but these are small-volume specialty products garnering orders of as low as 1,000 pieces per style, not the fairly standard orders of 15,000-60,000 pieces.
} 
customs and inspection, foreign exchange, trade facilitation, and port clearance. Goods can be exported directly to foreign markets through integrated railway-sea and truck-sea transport services. The Longnan customs office in Ganzhou collaborates with peers in Guangdong Province to expedite the commodity transfer and customs clearance services between Guangdong, Hong Kong, Jiangxi, and Macao. An agreement with Guangdong customs officials allows enterprises in Ganzhou, located across the provincial border in Jiangxi, to submit customs declarations at the local office, while containers are inspected at coastal customs checkpoints. This means an exporter needs to go through only one declaration and inspection process instead of two (in the place of origin and at the departure port), thereby reducing customs clearance for a cargo vehicle from Ganzhou from ten to four hours (Dinh et al. 2013). Customs clearance costs also plunged from $¥ 300$ (US\$44.00) per vehicle to about $¥ 2$ (US\$0.30).

\subsubsection{Entrepreneurial Skills}

There is considerable heterogeneity in firm performance in Africa, partly reflecting the entrepreneurial and management skills and partly the lack of competitive pressure in many countries. Inefficient firms are not driven from the market, and entrepreneurs find entry difficult. Large productivity variations within narrowly defined industries arise from multiple factors: the limited dispersion of entrepreneurial and technical skills, market segmentation arising from policy interventions (for example, tariffs or entry restrictions) or geography (for example, poor roads), and limited competitive pressure.

The first generation of Chinese entrepreneurs in the post-reform era generally established new businesses without the benefit of formal training in business management. They acquired entrepreneurial skills through imitation and by learning from failures. Entrepreneurs in the light manufacturing sector in Jiangxi and Zhejiang provinces do not choose their industries and products randomly. They acquire knowledge and skills from three sources: (1) prior work experience in the production of specific production items, as well as interactions with friends and relatives involved in this production; (2) trading the products that they eventually manufacture; and (3) networks and contacts established through former jobs in state-owned enterprises in the same manufacturing sector.

Many Chinese firms have been able to gain the managerial skills required for expansion by forming partnerships with companies in Hong Kong or Taiwan or with overseas Chinese in other Southeast Asian countries. These investors provide capital and access to new technologies and managerial and technical skills. It is the central government that creates the environment conducive to these investors, while local governments provide the incentives that attract them. 


\subsubsection{Worker Skills}

While worker skills are often mentioned as a constraint on manufacturing growth in Africa, our study indicates that, with the exception of the manufacture of wood products, the efficiency of African workers overlaps the range observed in China in simple labour-intensive products. The numbers suggest that low-level skills are sufficient for jobs in, for instance, computer management technology operations in the apparel industry. Africa's potential can also be inferred by the significant positive impact that targeted technical assistance programmes have had on both efficiency and quality (as in Ethiopia's footwear industry discussed in Section 8.5). So, SSA can be competitive in light industries that do not require semiskilled workers because there is a plentiful supply of trainable unskilled workers.

To graduate to more complex production such as the manufacture of dress shirts or trousers in the apparel industry, manual or artisanal skills are important. If SSA wants to upgrade its industries to more complex products, there is no shortcut to a more vocationally trained labour force. Our qualitative interviews and factory visits in China show that assembly line operations involving weaving machines for the production of sweaters, sports shoes, and toys or even for labelling and packaging require more technical skills and literate workers. Comparative advantage is dynamic: mastering the production of the simplest light manufactures such as Tshirts can open the door to a comparative advantage in more sophisticated light manufactures, but not without a corresponding upgrade in industry skills. Because skills upgrading is a public good, there is a clear role for government policy.

Local governments in China pay attention to the labour needs of enterprises, particularly in the light of rising labour costs. Thus, in the case of the Dieshiqiao Home Textiles Market in Jiangsu Province, the local government helped Dieshiqiao firms obtain unskilled and skilled workers by establishing a labour market through which enterprises could recruit workers. The local labour authority has partnered with Anhui and Henan-provinces that provide about 70 per cent of the incoming domestic migrants-to recruit more workers. Similarly, in the case of Yongkang's hardware cluster, the local government has set up thirty-six recruitment centres in ten cities and provinces to reach migrant workers in other regions. To meet the need for skilled workers, the municipal government has built twenty-eight training centres for local villagers. In cooperation with local vocational schools, these centres have processed nearly 90,000 trainees, of whom 36,000 passed the training exams and obtained employment in local hardware firms. 


\subsection{The Government Role in Identifying and Relaxing Enterprise-Binding Constraints}

At any point in time, the constraints to enterprise growth vary by country, by sector, and by firm size. Even for the same firm, the constraints to growth vary over time. Thus, for a start-up firm, searching for clients may be the most important issue while for a growing firm, finance maybe the most binding constraint as the firm needs money to buy equipment for expansion. Intimate knowledge of the enterprises and the obstacles they are facing therefore are critical to the success of policy intervention. So is the ability to formulate and carry out effective policy implementation. Identifying and relaxing enterprise binding constraints therefore remain a challenge for most policy makers in the world, but particularly so for African countries with limited resources.

Local governments, by their nature and location, have more intimate and up-to-date knowledge of the enterprise constraints than the central government. As discussed in this section, the Chinese system maximizes this local knowledge to the benefit of enterprises. There are areas where local knowledge is simply critical such as land, finance, and labour training. On the other hand, there are policy areas such as tariffs and quotas (which affect the cost and availability of inputs), infrastructure (which affects inputs and logistics), or migration, which are not under local government control. The central government role in relaxing these constraints is crucial also. This decentralized coordination works not only at the policy level, but also at the knowledge exchange level. Whether by design or by accident, the system of decentralized coordination in China as described in this section has helped identify and solve the problems faced by manufacturing firms across the sector over the past decades.

\subsubsection{The Nature of Government-Private Partnership in China}

In China, the public sector has overcome its initial hostility at the beginning of the reform process, and, despite remaining obstacles associated with property rights, access to finance, rule of law, and so on, it has demonstrated a growing capacity to support and cooperate with private business, especially at the local level and in sectors such as light industry that do not occupy a prominent position in official development plans.

In Africa, by contrast, there is often an adversarial relationship between the public and private sectors. Public entities view private firms as a source of rents or as vicious, corrupt profit-seekers bent on exploiting the nation's resources. Private firms see the public sector as a source of rent-seeking or trouble-making. Bridging this gap will take time. 
Government support in China includes policies across all levels of government, and these policies may vary from region to region and from locality to locality. In the early years of industrial development, the Chinese government built a reasonable track record in providing macroeconomic stability and gradually dismantled elements of the former planned economy that had prevented the establishment of openly private enterprises and hampered the expansion of SMEs in the public sector as well.

The remainder of this section traces out the respective roles of the central government and of subnational governments and their coordination in the development of economic activities in clusters. A cluster strategy can help overcome the constraints on the access to inputs, industrial land, finance, trade logistics, entrepreneurial skills, and worker skills that affect business and industrial development in low-income economies. Once a few firms in a specific industry have formed a cluster in a local community, the entry costs for followers are lower because of positive external economies (Marshall 1920; Fujita, Krugman, and Mori 1999). The agglomeration of similar firms creates a critical level of demand for specialized inputs and services. Clusters mature with the formation of upstream suppliers and downstream service providers in the local community. The deep division of labour among firms in the local community enables cluster firms to respond flexibly to market changes at low cost. Because local suppliers are available, cluster firms can subcontract urgent orders to other local firms without previous additional investment for expansion. One potential drawback is that the enormous convenience of doing business in clusters makes some firms reluctant to relocate, despite increasing labour and land costs.

Consistent with the fiscal literature on China, we discuss China's government at five levels: (1) the central government; (2) provinces; (3) prefectures; (4) counties; and (5) townships. In practice, there is also another level, villages, which are under townships. Because the size of provinces is large, we will make a distinction between the central government, provincial governments, and the remaining government levels, which we designate simply as local governments.

\subsubsection{The Central Government's Role}

The strong commitment of the central government to a market economy was critical to the formation of the first generation of private firms in China, while the fiscal reforms beginning in 1994 created strong incentives for local governments to foster clusters.

To incentivize local governments to promote clusters and stem growing fiscal deficits, the central government negotiated a tax-sharing system that 
split the tax revenue from enterprise income: 60 per cent now went to the central government, and 40 per cent to local governments. Local governments could thus benefit directly from the development of nearby industrial clusters. Before 1994, all taxes had been channelled to the central government, and local government expenditures had been the responsibility of the central government. By establishing a tax-sharing system, the 1994 reform introduced a hard budget constraint on local governments in that they were now financially responsible to provide most public services within their jurisdictions. However, the reform also provided a legitimate means for local governments to raise revenue by promoting local industries, which had to pay land and income taxes, and local governments thus began aggressively championing local businesses. The fiscal reform, by encouraging such growth, also led to a substantial increase in central government revenue.

To encourage local governments to promote cluster development, the central government gradually implemented a new performance evaluation system for local government officials that was consistent with the country's transition to a market economy. Besides political loyalty, local gross domestic product (GDP) is a decisive component of the system. Promotions among local government officials are greatly dependent on whether regional economic growth can catch up with or outpace the economic development of other areas in China. ${ }^{3}$ The central government established this performance evaluation system to enhance its political legitimacy through economic growth.

\subsubsection{Provincial Governments}

Compared with the central government, provincial governments play a more active and specific role in regional cluster development. They affect the formation and upgrading of clusters in two main ways: land allocation and cluster development planning.

Because China has little cultivable land relative to the large size of the population, the central government strictly controls the conversion of land from agricultural to industrial use. Each province is notified of an annual quota of industrially convertible land that it may allocate among various industries. In the highly industrialized coastal areas, such as Guangdong and Zhejiang provinces, land is the scarcest production factor because there is almost no idle land for industrial use. In recent years, there has been fierce competition for land among industries. Low-technology industries and industries that generate fewer jobs are at a disadvantage in this competition, and the land allocation

\footnotetext{
3 This system has also been criticized for promoting environmental degradation and income inequality.
} 
decisions of provincial governments have become tools of an industrial policy that tends to favour high-end clusters over less competitive ones.

Provincial governments use their market information and networks to identify exemplary clusters and design and implement cluster upgrading and development plans to support them. In Guangdong and Zhejiang, the provincial governments have established departments dedicated to such upgrading. Both governments have initiated projects to identify innovative clusters and provide financial support. They have also designed cluster development plans to promote collaboration and mutual learning among clusters, to facilitate the construction of joint research centres by universities and cluster firms, and to encourage cluster firms to explore international markets. In 2010, the Guangdong provincial government initiated a large planning project called 'one specialized town cluster, one upgrading strategy' to encourage each cluster, whatever its stage of development, to plan for structural transformation after the recent global economic crisis (Dinh et al. 2013).

\subsubsection{Local Governments}

China's fiscal reform of 1994 and the performance evaluation system based on growth in GDP gave local governments a strong incentive to promote local industries. These incentives encouraged local governments to become more involved in the development of clusters. Thus, while all levels of government now benefit from the growth of clusters, no single level of government totally controls cluster development. The Chinese style of federalism has created a political basis for the success of cluster-based economic development (Montinola, Qian, and Weingast 1995).

China's experience also illustrates the potential of local governments to support and contribute actively to industrial development. In some countries, the central government plans and develops strategic industries by mobilizing and allocating resources. These efforts to pick winners often fail. Local governments have fewer options. They cannot change the macroeconomic environment or build national monopolies, and they lack many of the resources available to the central administration for building industries. As a result, local governments have generally supported profitable firms that are already in business in local communities.

China's experience in the development of clusters substantiates the argument that the government's role is to nurture and support existing cluster firms rather than trying to create clusters from scratch. Local governments (prefectures, counties, townships, and villages) are directly connected to clusters, which generally account for most of the economic activity in a village or town. By focusing on individual clusters and communicating frequently with local 
entrepreneurs, local governments can devise policies clearly targeting specific industries. They can take several measures to foster cluster development.

\subsubsection{NURTURING CLUSTERS FROM AN EXISTING INDUSTRIAL BASE} Successful clusters are rarely built from scratch (Braunerhjelm and Feldman 2006). In China, entrepreneurs build clusters; governments nurture them, supporting the most profitable local industries. This industrial base can consist of private firms or state enterprises, such as the Chengdu footwear industry (Section 8.4.5). Potential entrepreneurs learn from these enterprises and form spin-offs. Local government officials in Haining explained how and why they picked the warp knitting industry to support as a strategic industry:

At the beginning, we here had several small warp knitting firms. After some analysis, we felt these products had a good market potential. ... We had four or five firms. From this, we discussed with these entrepreneurs and decided to develop [the industry].... Among the four or five firms, there is one called Zhejiang Jinda Materials Co., Ltd., which trained a lot of professionals in the local warp knitting industry, from front-line workers to technicians to middle-level managers. After acquiring some skills, these professionals started their own businesses. (2012 interview)

With the support of local government, the Haining industry developed into the world's largest warp knitting centre, with 360 firms and 2009 sales revenue of $¥ 15$ billion (US $\$ 2.2$ billion).

Some local governments have encouraged trading or sales agents to move into manufacturing to develop clusters. For example, the Nanhai metal cluster evolved from a group of scrap metal recycling and trading businesspeople in Guangzhou, Guangdong Province.

\subsubsection{BUILDING INDUSTRIAL PARKS}

Since most clusters develop organically, cluster firms are usually scattered across many villages or small towns. Rural areas are a good place for start-ups because the cost of land is low, but they are not such a good place to grow because there is no industrial infrastructure. In China, if local governments target a specific industry, they build industrial parks with good infrastructure and concentrate firms within the parks. Firms in these parks benefit from favourable policies on land acquisition, taxes, and duty drawbacks. Local governments may not be selective in the early stages of industrial parks, but, as more firms relocate into the industrial parks, local governments become more selective, and many parks are gradually dominated by firms in specific industries, thus becoming clusters. 
8.3.4.3 CREATING SPECIAL PLATFORMS FOR SPECIFIC INDUSTRIES

As firms develop from family workshops to modern factories, they need not only hard infrastructure, but also soft infrastructure such as new systems of organizational management, technological research and development (R\&D), and market exploration. Local governments often set up special platforms for specific industries. There are many examples of creative collaboration between the public and private sectors in this endeavour. In the Haining warp knitting cluster, the local government created professional platforms in science and technology, social services, cultural promotion, international communications, training, trading, finance, and business consulting. Thus, the park cooperates with Shanghai Jiao Tong University to provide high-level management courses for local professional executives, and has also built an experimental factory to offer training programmes for front-line workers and technicians. Some platform services are provided by professional companies set up by local governments. In Haining, the administrative committee of the Warp Knitting Industrial Park established a firm specializing in financial guarantees (danbao) to help firms obtain bank loans.

\subsection{Tailoring Government Support to the Business Life Cycle and Backing Winners}

Local government policies towards enterprises are dynamic and tailored to the needs that arise at the various stages of the life cycles of firms, from startup to growth and maturity. A successful cluster policy focuses less on bringing firms together and more on helping firms overcome barriers to growth. In the beginning, local governments tend to provide start-up funding and technology for local enterprises. As enterprises grow, cluster policies focus on developing supply chains in the local communities, and the governments offer loan guarantee services to help firms obtain loans for expansion. As enterprises enter a steady state of growth, local governments supply overthe-counter services. Finally, when firms reach a mature stage, local governments encourage cluster firms to go public, build their own brands, and transfer labour-intensive manufacturing activities elsewhere. In this mature stage, it may be possible to create new clusters in other developing areas or in other developing countries. While government support has been wide-ranging, including fiscal incentives, infrastructure development, and advisory support on upgrading, assistance has not always involved heavy spending. 


\subsubsection{Start-Up Phase}

In light manufacturing, government support for domestic start-ups is typically small and may amount to little more than providing infrastructure in the same way other countries have done. Among joint enterprises receiving FDI, official support takes the form of across-the-board policy measures established by the central government such as rebates on customs duties, undervalued exchange rates, income tax exemptions, and so on. In this respect, government support in China hardly differs from that of many other developing countries. What seems unusual is the way in which China's policy structures provide both central government officials and local officials with strong progrowth incentives that make them eager to see businesses succeed because private sector success may elevate their own financial prospects and career trajectories. In many other developing countries, government officials consider the private sector an opportunity to share the wealth of the community, while the private sector looks at government officials as robbers.

\subsubsection{Growth Phase}

In the growth phase and the maturity phase (Section 8.4.2), government support in China is substantial and provides clear evidence that the government's industrial strategy is designed not so much to pick winners as to back winners. This is a crucial difference with the strategy typically adopted in other countries. The range of enterprise support is wide and is best illustrated by the footwear example in Chengdu (Section 8.4.5).

Other areas of intervention during the growth phase include the following: (1) creating knowledge spillovers through the establishment of enterprise associations and chambers of commerce to strengthen local communication among enterprises and identify shortcomings in zone administration, (2) improving managerial and worker skills, (3) reducing the bureaucratic burden, (4) expediting payments, (5) reinforcing market signals, and (6) providing services such as quality control.

\subsubsection{Maturity Phase}

Government support during the maturity phase tends to be geared towards $\mathrm{R} \& \mathrm{D}$, networking, marketing, assistance through trading companies, and completing the value chain through investment in upstream and downstream activities. Chinese officials, acting as matchmakers, connect firms with research agencies and consultants, thereby reducing the costs of access to information. 
In matching producers with research facilities, the government creates cooperative relationships that strengthen both sides. Bringing actors together reduces transaction costs, resolves key constraints, and saves firms time and money. Researchers thus gain inside access to information on how firms operate. In another kind of match-making, industrial park authorities in the Dieshiqiao home textile cluster in Jiangsu Province links firms with banks to improve the access of firms to finance.

\subsubsection{Failure}

Along with instances of successful official intervention, we find episodes of failure. The automobile project in the Yinchuan economic development zone in Ningxia Province failed mainly because local governments tried to develop a sophisticated industry for which they do not have any comparative advantage. The result demonstrates that a viable cluster cannot be built from above, but must rest on private initiatives that can stand up to market discipline. This reinforces our recommendation that government industrial policy should not aim at picking winners, but rather at backing winners, a lesson that also emerges from the failure of many state-owned enterprises in Africa (Dinh et al. 2013). Policies that provide preferential treatment for certain investors without taking account of comparative advantage may encourage moral hazard and damage the local economy. This illustrates the downside of policies linking the advancement of local administrators to growth in local GDP and inflows of investment: if there is no regard for the market or for local comparative advantage, such a policy may not represent an incentive to succeed, but a temptation to take risks.

\subsubsection{An Illustration of Government Support in China}

Up to this point, our discussion on the decentralization of government support in China has been carried out on an analytical basis, breaking down this support-first, at the level of constraints to firms and, then, at different levels of government in the development of clusters. While this approach is useful in understanding the distinct effects of government support, it does not reveal the full richness of local government support in each locality. We thus discuss a complete menu of government support for footwear in Wuhou District, downtown Chengdu, Sichuan Province. While the enterprise support supplied by local governments in China is varied, it can be classified into three broad categories: (1) facilitating production factors, including land subsidies, credit, and training programmes to develop worker skills; (2) creating externalities through industrial parks or cluster development; and (3) helping to establish upstream and downstream activities to complete the value chain of enterprises. 
Home to one of China's largest footwear clusters, the Wuhou District invested $¥ 400$ million (US\$53 million) in 2007 to establish the Chengdu Wuhou Industrial Park Investment and Development Company Ltd, which functions as a large corporatized financing platform. Through fiscal funding and bank loans, the company raised $¥ 2.3$ billion (US\$302 million) in its first year, securing the funds for future development. The park's management committee promotes investment, supervises investment projects, and collects taxes. It also raises funds, manages land, and builds infrastructure. To speed up government approval, the park administration has established a one-stop shop that brings together all the individual departments to decide on an investment application on the spot. The park administration offers preferential taxing, financing, and screening for enterprises moving into the zone. Large investments have been made in infrastructure, thereby helping many family workshops modernize.

In 2005, to cultivate local brands, Wuhou District launched the construction of the Brand Enterprises Base of the Western Shoe Center of China Industrial Park to establish an industrial platform for footwear materials selection, shoe buying and trade, R\&D, and international logistics for women's shoes. The Brand Enterprises Base attracts top brands and cultivates local brand-name enterprises. At 4,200 square metres, the international trade centre is one of the largest in China for footwear products. The centre provides the services of purchasing agents and commission agents and offers assistance in international logistics, as well as training programmes for professional and management personnel. All these functions enable face-to-face contact between merchants and manufacturers, lowering costs and maximizing profits.

The government has helped develop Chengdu into an industrial park through establishment of a complete supply chain that spans backward and forward links, from upstream shoe-making machinery and spare parts, leather and fabric, heels, soles, accessories, and other auxiliary materials to the downstream manufacturing and distribution of footwear, as well as design and R\&D, logistics, and other services. Chengdu also has a raw materials market, as well as 160 logistics corporations, 10 shoe-making apprentice training schools, around 300 registered shoe trademarks, and nearly 100,000 employees. Chengdu's footwear firms have a staggering production capacity: 100 million pairs of shoes a year, which are sold in 120 countries and account for 10 per cent of China's footwear industry and 7 per cent of the world industry.

\subsection{Applying the Chinese Decentralization Model to Africa}

Compared to China, countries in Africa are of much smaller size, local government administrative capacity weaker, and the political system much 
different. The success of Chinese industrialization has also come in part at the expense of farmers. The system whereby all land belongs to the state and can be taken to generate resources for the local governments only exists in a few countries. So, how far can the Chinese decentralized coordination model apply to African countries?

It should be noted that decentralization has already proceeded in Africa regardless what model was adopted. Since the mid-1980s, most African countries have started the transfer of power, resources and responsibilities to their subnational governments. Progress to date, however, has been uneven, with some countries already on a highly decentralized path (South Africa, Nigeria, Ethiopia) while there is hardly any progress in many others, particularly in the francophone countries. Obviously, the final decentralization model in each country will ultimately result from historical, cultural, and institutional factors and no one model can fit the specific circumstances of a country.

However, some key aspects of the Chinese decentralized coordination model discussed in this chapter are useful to Africa. First, there is a need for both the central and local governments in Africa to realize that private sector growth is beneficial to poverty alleviation and all governments have a common purpose of assisting enterprises to grow. Second, since local governments are more familiar with the specific conditions of enterprises, they should have an important role in the promotion and facilitation of business growth. The division of power and responsibilities among different government levels would have to depend on each country's specific situation and would need to be clearly delineated. Third, the incentive framework for local governments should be realigned so that resource availability is linked directly to the enterprise performance. In the absence of land sale, local resources could be provided through grants and transfers that tie business growth to the size of the transfers. The criteria for allocation of these transfers should, however, be transparent and equitable. Fourth, communication channels between different levels of government have to be kept open and constantly reviewed. Finally, to make the local government system work, there must be efforts to build up the necessary managerial, organizational, and technical capabilities over time.

It is often said that one of the most serious constraints on Africa's industrialization is the lack of entrepreneurship. Could it be that at the time of its takeoff, China was endowed with abundant entrepreneurial skills which are lacking in Africa today? In our study, we find that if entrepreneurial skills are meant to denote the ability to sense profit and take advantage of it, a definition that Elkan (1988), used three decades ago, then Africa does have plenty of these talents, as seen in the large informal sector.

But entrepreneurial skills encompass more than the ability to sense profit and take advantage of it. Indeed, there are other critical aspects of the 
entrepreneurial skills that are lacking in Africa when compared to China, and it is those areas where public policy can have an important role to play. Thus, obtaining advice and finance at start-up may be a channel for good entrepreneurship to come to fruition. Fafchamps and Quinn (2012) found that firms in SSA are less able to take advantage of links to globally competitive suppliers, customers, and competitors than their Chinese counterparts. Given the same individual skill set of an entrepreneur in China and one in Zambia, the one in China has the advantage of proximity to a competitive local manufacturing sector. One entrepreneur does not have to know everything, but in Africa's manufacturing there is far less opportunity than in China for entrepreneurs to offset shortcomings arising from missing skills by accessing the established networks and institutions of a well-developed manufacturing sector.

As the Chinese decentralized coordination model shows, effective government assistance for industrialization does not necessarily involve spending money. There are many different ways a government can help entrepreneurs to grow in Africa, for instance, through technical assistance. An example is the Ramsay Shoe Factory in Ethiopia (Dinh et al. 2012). In 2009-10, the Ethiopian Ministry of Industry helped the Ethiopian Leather and Leather Products Technology Institute select the Indian Footwear Design and Development Institute to provide technical assistance for seven footwear factories in design, technical upgrading, quality assurance, productivity enhancement, and testing. As a result of this technical assistance, cutting at Ramsay Shoe Factory rose from 2,000 pairs a day to 2,400, and defect rates dropped from 3 per cent to 1 per cent. In July 2010 Ramsay signed a deal with Geox, an Italian shoe and apparel manufacturer, to produce 60,000 pairs a month to be sold in Geox's outlets in Italy, carrying the label 'Made in Ethiopia by Ramsay'. Clearly, the right technical assistance to owner-managers can make a big impact on factory performance.

Another area that entrepreneurs can benefit from good government policy, again without heavy government spending, is the acquisition of standard business practices such as book and inventory record keeping, because these are generally not implemented by the small, micro enterprises. African governments, both central and local governments, should seek opportunities to invest in programmes that can improve managerial and technical skills, especially among small-scale operators already working in high-potential subsectors. Governments should also support domestic firms to adopt and adapt existing technologies by providing targeted technical support and advice to owners and entrepreneurs. This support should encompass not only informal firms, but formal, large enterprises as well. Accordingly, policy interventions targeted at addressing this information asymmetry and providing public resources for awareness and skill-development may be appropriate in supporting manufacturing competitiveness in SSA. 
FDI offers another way to expand the domestic stock of entrepreneurial skill. Chinese firms benefited first from the knowledge provided by overseas Chinese entrepreneurs and foreign managers at multinational branch plants. Firms then benefited from the transfer of know-how associated with FDI, which contributed to a new generation of domestic entrepreneurs. Both the central and local governments play an important role in attracting FDI to specific industries and localities.

The discovery that African manufacturing entrepreneurs often lack access to sources of information that are widely available elsewhere, particularly in China, and may fail to appreciate the benefits linked to information that is available, provides a rationale for governments to go beyond the universally beneficial policy of expanding access to basic education. While fostering full and fair competition, central and local governments should create, fund, and promote programmes that are specifically designed to improve the managerial and technical skills of actual and potential entrepreneurs, starting with the high-potential subsectors, including the informal sector.

There are two reasons why market forces alone will not allocate optimal resources to create and introduce knowledge that entrepreneurs need in the informal sector. First, information spillovers and imitation are widespread, with the proximity of products of rival enterprises and the poaching of inputs and technical information from neighbours. Second, entrepreneurs may not know the value of training. As a result, the social return to creating and introducing new knowledge, both technical and managerial, exceeds the private return, resulting in socially suboptimal investment in new innovative knowledge.

Finally, the government can facilitate the entry of first movers to foster competition and establish new industry. First movers in late-mover countries typically face higher costs and risks-especially in Africa, which has limited infrastructure and high regulatory and governance risks. But strategic first movers can catalyse the growth of competitive new industries, as Ethiopia's first rose farm clearly shows. First movers can provide many benefits, including demonstration effects for other potential entrepreneurs and their financiers, specialized infrastructure that can be shared, skill development, policy reforms, supplier industries, and improvements in the country's reputation. The first producer of corrugated tin roof in Zambia attracted a dozen followers, largely replacing imports.

In the past, Africa's experience with government intervention had been disastrous and had resulted in a complete reversal of development policy from pervasive state intervention to laissez faire. An important lesson from the decentralized coordination approach in China is how local governments should minimize its risks through backing the winners rather than picking the winners. This backing-the-winners approach combines market forces with 
policy interventions to minimize the risk to public resources, all the while maximizing the potential for private success.

The concept of backing winners is not new in Africa. In the successful cases of industrialization in Africa, we found a wide presence of this approach (Dinh et al. 2013). However, in most cases, the approach was taken in an ad hoc manner and on a piecemeal basis, and was never put together as a strategy for industrialization. With the help of the government, Ethiopia's first rose farm, Golden Roses, was created in 2000 by an immigrant named Ryaz. In 2002, based on the farm's success, the prime minister agreed to support the industry by facilitating access to land and providing tax incentives, duty-free imports, and long-term financing for up to 70 per cent of initial investment. With this support and the demonstration effect of Ryaz's farm, investors poured in, enabling the government to meet its goal of developing 800 hectares of rose farms by 2007. Since the government announced its support, more than seventy-five firms have entered the rose industry. By 2010, this sector accounted for 45 per cent of all manufacturing exports and more than 6 per cent of total exports. It employs more than 50,000 workers and earns more than US\$200 million a year in foreign exchange.

The Ethiopian government has helped the cut flower industry emerge in several ways. It has provided land and eliminated many bureaucratic impediments to starting a flower business. It created a welcoming environment for FDI. A foreign investor can invest alone or jointly with domestic investors. The investment law guarantees capital repatriation and the remittance of dividends. The government has provided institutional support by establishing trade associations, such as the Ethiopian Horticulture Development Agency, which oversees the sector and provides facilitation services to individual firms, including skill development and marketing support. The government has offered a generous incentives package to investors, including access to lowcost land and to credit (up to 70 per cent of the total capital needs) at below market rates of 7 per cent, with a three-year grace period and ten years for repayment. A three-year loss carry-forward privilege is also offered, though it might not be necessary because most cut flower start-ups turn a profit from the beginning. Inputs, including packaging materials, are imported duty-free. The government also facilitates customs clearance and transport services.

In Kenya, too, cut flowers have become increasingly important, rising from 2.1 per cent of manufacturing exports and 0.6 per cent of total exports in 1980 to 16 and almost 8 per cent, respectively, in 2010. The Kenyan government has sought to facilitate the cut flower industry rather than directly intervene. A supportive trade and fiscal regime has alleviated some of the financing constraints of firms and has eased licensing and other regulatory constraints with the aim of allowing the private sector to flourish. Firms in the export processing zone receive a ten-year tax holiday on domestic taxes and on 
withholding taxes on repatriated dividends, plus exemption from the valueadded tax. The government also allows cut flower exporters to import plant machinery, equipment, and raw materials free of tax. Investors are able to obtain allowances on capital investments, including wear-and-tear allowances on items such as vans, tractors, other motor vehicles, aircraft, computer hardware, copiers, and plant machinery; industrial building allowances cover all industrial buildings; and farm work allowances cover all structures necessary for a farm to function properly. Kenyan exporters have gained from a favourable exchange rate.

The excellent performance of Mauritius's textile and apparel sector can be attributed to the launch by the government of an export processing zone in 1970. Starting with almost nothing in the 1970s, the industry has risen to international prominence. By the 1980s, textiles and apparel had become the leading industrial sector in the country, accounting for more than 60 per cent of gross export earnings and a third of employment. The export processing zone ensured smooth access to inputs and land in a favourable location between producers of raw cotton and end-users. Incentives such as the suspension of import duties on raw materials and equipment and a well-managed exchange rate kept input costs low, a boon to export companies in early development. Moreover, underemployed women were trained, thereby providing a steady source of labour for production. Openness to foreign investment was a key to success, and the investments helped alleviate domestic financing constraints.

These examples show that policy interventions of the right kind did work well in Africa. What is needed now is a conscious effort to systematize this backing-the-winner approach into a strategy, tailoring the approach to fit specific circumstances of individual countries. The next step is for both the central and local governments in Africa to focus their scarce resources on identifying the binding constraints, taking policy actions to remove these constraints, and proactively developing competitive value chains and clusters in those industries where they have a comparative advantage in resourcebased, labour-intensive light manufacturing.

\section{Acknowledgements}

The chapter is based on results of a World Bank project, Light Manufacturing in Africa, led by the author. I would like to thank many World Bank staff, especially Vandana Chandra, Vincent Palmade, and Ali Zafar; Deborah Bräutigam of Johns Hopkins University; John Page of the Brookings Institution, Thomas Rawski of the University of Pittsburgh, Finn Tarp of UNU-WIDER, and participants of the UNU-WIDER conference Institutional Reforms for Transformation, Inclusion, and Sustainability in Hanoi, Viet Nam, in June 2014 for valuable comments and support. All errors are mine. 


\section{References}

Braunerhjelm, P., and M. P. Feldman (eds) (2006). Cluster Genesis: Technology-Based Industrial Development. New York: Oxford University Press.

Dinh, H. T., D. A. Mavridis, and H. B. Nguyen (2012). 'The Binding Constraint on Growth of Firms in Developing Countries'. In H. T. Dinh and G. R. G. Clarke (eds), Performance of Manufacturing Firms in Africa: An Empirical Analysis, Directions in Development Series. Washington, DC: World Bank.

Dinh, H. T., V. Palmade, V. Chandra, and F. Cossar (2012). Light Manufacturing in Africa: Targeted Policies to Enhance Private Investment and Create Jobs. Washington, DC: World Bank. Available at: <http://go.worldbank.org/ASG0J44350> (accessed 15 September 2016).

Dinh, H. T., T. G. Rawski, A. Zafar, L. Wang, and E. Mavroeidi (2013). Tales from the Development Frontier: How China and Other Countries Harness Light Manufacturing to Create Jobs and Prosperity. Washington, DC: World Bank.

Elkan, W. (1988). 'Entrepreneurs and Entrepreneurship in Africa'. World Bank Research Observer, 3(2): 171-88.

Fafchamps, M., and S. Quinn (2012). 'Results of Sample Surveys of Firms'. In H. T. Dinh and G. R. G. Clarke (eds), Performance of Manufacturing Firms in Africa: An Empirical Analysis, Directions in Development Series. Washington, DC: World Bank.

Fujita, M., P. Krugman, and T. Mori (1999). 'On the Evolution of Hierarchical Urban Systems'. European Economic Review, 43(2): 209-51.

Marshall, A. (1920). Principles of Economics. London: Macmillan.

Montinola, G., Y. Qian, and B. R. Weingast (1995). 'Federalism, Chinese Style: The Political Basis for Economic Success in China'. World Politics, 48(1): 50-81. 


\title{
9
}

\section{The Political Economy of Industrial Development in Viet Nam}

\author{
Impact of State-Business Relationships on Industrial \\ Performance, 1986-2013
}

Tu-Anh Vu-Thanh

\subsection{Introduction}

Since Doi Moi (economic renovation), Viet Nam has experienced an impressive industrial growth (Figure 9.1). Between 1986 and 2013, in spite of serious economic downturns caused by the collapse of the Soviet Bloc, the Asian financial crisis, and the recent global financial crisis, industrial value-added grew at an average annual rate of 8.3 per cent, or an 8.6 fold increase over that period. ${ }^{1}$ This rapid industrial development has induced structural changes in the economy. Between 1986 and 2012, the share of agricultural workers in the labour force decreased from 78.2 per cent to 47.4 per cent. The competitiveness of the manufacturing industry has significantly improved, and its structure has diversified. Until the late 1990s, rice, oil, and food still accounted for more than half of the country's export basket, and there were absolutely no high-tech exports. By 2012, the share of these three commodities decreased to about one-quarter, while the share of manufactured goods accounted for nearly 70 per cent, of which 15 per cent are classified as high-tech products.

However, after nearly three decades of extensive development, Viet Nam's industry now seems to have reached a 'glass ceiling'. The rate at which labour

\footnotetext{
1 This rate is, however, still lower than the extraordinarily high growth rate of industrial value added (including construction) in China of 11.3 per cent per year, over the twenty-seven years between 1978 and 2005 (China National Bureau of Statistics 2006: 60).
} 


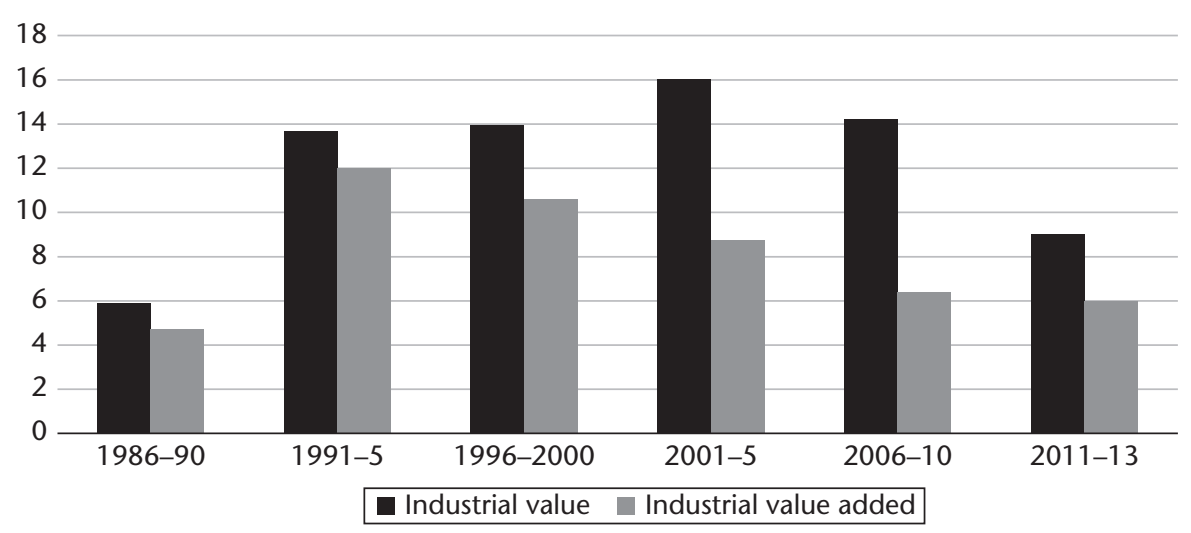

Figure 9.1. Average rate of industrial growth in Viet Nam since Doi Moi (\%)

Source: Author's calculation based on Viet Nam's Statistical Yearbooks (1986 to 2013) and data published by World Bank's World Development Indicators (WDI).

moved out of agriculture during the period 2006-12 was less than a third of the rate during 2000-6. In the last five years, the manufacturing value-added (MVA) growth rate has significantly declined to 7.5 per cent from 12.2 per cent in the previous period. In 2012, MVA accounted for only 17.4 per cent in the gross industrial value compared with 36 per cent in the early 2000s. The proximate causes of this stagnation are that Viet Nam has been caught in the 'low value-added trap' with shallow integration into the global value chain and declining productivity (Perkins and Vu-Thanh 2011; Dinh et al. 2014).

This chapter provides a political economy account of Viet Nam's industrial growth since Doi Moi. It will show that the improving relationship and coordination between the public and business sectors has been a key factor contributing to the success of Viet Nam's industry for the first two decades since Doi Moi. This chapter will also show that the clientelistic state-business relations (SBRs) emerged in the last decade have created significant structural obstacles for Viet Nam's continued development in the future.

This chapter is organized as follows. Section 9.2 will analyse the status of the three ownership sectors, namely state-owned enterprises (SOEs), domesticprivate enterprises (DPEs), and foreign-invested enterprises (FIEs), in the political and economic strategy of the Vietnamese Communist Party (VCP). In a oneparty authoritarian regime with communist ideology like Viet Nam, the political status of the business sector in the eyes and minds of the politicians largely determines the SBR, and therefore the coordination between the two sectors. Sections 9.3, 9.4, and 9.5 will analyse the dynamics of SBRs and coordination as reflected through the design and implementation of three generations of the law on private enterprises and their impacts on the country's industrial performance. Section 9.6 will conclude and draw some policy implications. 


\subsection{Political Ideology, Economic Legitimacy, and Tripartite Industrial Structure}

\subsubsection{Political Ideology, Economic Legitimacy, and Industrial Policy in Viet Nam}

Viet Nam's independence from the French in 1945 and reunification in 1975 after the Viet Nam War were both achieved under the leadership of the VCP. Until recently, the merits of liberating and unifying the country have been the greatest assets underlying the legitimacy of the VCP. However, this source of legitimacy has been depreciating and, over time, replaced by economic performance. One of the biggest challenges facing the VCP is how to maintain a balance between political ideology and economic legitimacy, or how to boost economic development while keeping its absolute power and comprehensive leadership. An understanding of how this dilemma has unfolded is critical for explaining the directions of economic policies of the Vietnamese party-state since Doi Moi.

Partly due to the communist ideology, partly because of the symbiotic relationship between the Vietnamese party-state and the SOE sector, SOEsespecially the larger ones-have always been regarded as the backbone of the economy, despite the fact that it is inefficient and, therefore, a heavy burden on the economy (Perkins and Vu-Thanh 2011). It follows that the private sector is fettered, discriminated, and, as we shall see in Sections 9.3 and 9.4, usually only taken seriously in crisis situations.

There exists discrimination even within the private sector: most FIEs and a handful of crony DPEs are treated much more favourably compared to the remaining majority of small and medium-sized enterprises (SMEs). The official rationale for giving favourable treatment to FIEs is that incentives for foreign direct investment (FDI) have to be more generous in order to compete with neighbouring countries and that on average FIEs are more capable and much larger than DPEs, and thus contribute far more to the economy in terms of capital, technology, industrial production, and employment. But the deeper cause is that, unlike the domestic-private businesses, FIEs do not present immediate and internal political threats to the communist regime. ${ }^{2}$

The difference in the status of the three ownership sectors in the political vision and strategy of the VCP has been systematically translated into differentiated economic institutions and policies for each ownership sector. Despite the establishment of the Unified Enterprise Law (2005) and the Common Investment Law (2005) under the pressure of the World Trade Organization

\footnotetext{
2 According to a senior politician, in the 1980s, and even until the early 2000s, a significant number of politicians still shared the view that if private enterprises have economic power, they will become independent and eventually challenge the political power of the VCP.
} 
(WTO), the discrimination against domestic-private SMEs still persists (Vu 2008; Malesky 2014).

Viet Nam's industrial policy today is a mix of policies. The policies that have had the largest impact on the country's industrial development are those that have provided an overall framework of incentives for individual enterprises irrespective of ownership. Many industrial policies, however, have been targeted at specific ownership sectors rather than at industry or businesses as a whole. Most notable in this category are the policies that provide special favours to SOEs. According to the Report on Economic Concentration of the Ministry of Industry and Trade (MITI) (2012), the state economic groups (SEGs) occupy a dominant position in most key industries and sectors, namely oil and gas, coal and minerals, infrastructure, transportation, aviation, rail, and electricity. In addition, the SOEs are given favoured access to critical resources such as land, credit, natural resources, and lucrative opportunities such as public investment and government procurement. Moreover, the SOEs are also entitled to many other privileges vis-à-vis private enterprises. Until very recently, SOEs were allowed to use state capital without paying dividends. ${ }^{3}$ They are generally not subject to hard budget constraints and virtually never face bankruptcy. ${ }^{4}$ The SOEs were designated to disburse the majority of official development assistance (ODA) capital. ${ }^{5}$ In many cases, they are also granted state-owned land for free, or if they must lease land then the rent is substantially subsidized. Moreover, they then can use the leased land as collateral for bank loans, while private businesses do not have such an option. SOEs, backed by the state, used to be given priority access to scarce foreign exchange for less than the market rates. Since 2005, the formation of large SEGs with near monopoly control over key industrial sectors is a form of government support that is only provided to SOEs. Although the degree to which the government can favour the state-owned sector over the others has been reduced by the 1999 and 2005 enterprise laws and the WTO membership, but it has by no means been eliminated.

The other set of industrial policies that is directed at a single ownership sector are those laws and regulations that deal with FIEs. At the outset of the reform period, Viet Nam opened up its economy to direct investment by foreign firms, and since the early reform years has steadily refined the rules governing FIEs. Ever since, foreign investors have in fact been favoured over domestic-private investors. In this respect, Viet Nam's experience is much like

\footnotetext{
3 See Decree 204/NĐ-CP/2013, dated 5 December 2013.

4 The number of SOEs totally owned by the state declined from about 6,000 in 1994, that is, when the Law on Bankruptcy was promulgated, to about 3,000 by mid-2000s. In about 3,000 SOEs that were subject to reform measures, only 17 were forced to go bankrupt (Vu-Thanh 2014a).

5 According to $\mathrm{Vu}$ (2008), the SOEs' share in ODA capital disbursement in 2006 was about 70 per cent.
} 
China's. In both countries domestic-private investors have had to struggle to get access to capital, have had to pay higher taxes for similar activities, and have had less help in cutting through government red tape. FIEs, especially in the early years, regularly develop joint ventures with SOEs to take advantage of these state firms' easier access to land among other things. Ironically one effect of joining the WTO may be to begin to level the playing field for domesticprivate investors vis-à-vis their foreign competitors (Vu-Thanh 2014b). Overall, however, the domestic-private industrial sector in Viet Nam still labours under some form of discrimination and the WTO rules will not end them all.

Although receiving many preferential treatments and playing an important role in improving economic legitimacy for the VCP, there has been so far no discernible evidence that FIEs, as a sector, receive special access to decision makers. The main reasons are that FIEs are quite diverse in terms of country of origin and that they share the need of improving the overall business environment, but compete otherwise. It is worth emphasizing that some particular groups of FIEs, most notably the American Chamber of Commerce (AmCham), European Chamber of Commerce (EuroCham), and Japanese Business Association (JBA), have better access to decision makers and are more active in policy lobbying efforts thanks to their relative significance. However, even some of these groups with particular access to policy-making face difficulty in their business operations in Viet Nam. In a recent report presented at the Viet Nam Business Forum (VBF) 2014, the chairman of AmCham asserts that 'doing business in accordance with the law is very hard to succeed in Viet Nam'. ${ }^{6}$ In his view, the business environment in Viet Nam is not competitive, administrative procedures are complicated, laws are not implemented fairly, and, in many cases, businesses do not compete based on their own capabilities in the access to capital, space, and opportunities.

\subsubsection{Viet Nam's Tripartite Industrial Structure and Performance}

Viet Nam's industry features a tripartite structure. There are the SOEs (both central and local), the FIEs, and the DPEs. ${ }^{7}$ In this and the next three sections (Sections 9.3 to 9.5), we will analyse performance of each of these sectors and, with that as background, show how SBRs and coordination help explain the pattern of industrial performance that we have observed. We will pay special attention to the regulatory environment, particularly the three generations of the law on private enterprises.

\footnotetext{
6 Source: <http://vneconomy.vn/doanh-nhan/amcham-lam-an-dung-luat-tai-viet-nam-kho-thanhcong-2014120111574856.htm?mobile=true>, accessed 20 December 2014.

7 There are also collective firms and household industrial firms, but the share of these latter groups is small and generally growing slowly, if at all.
} 


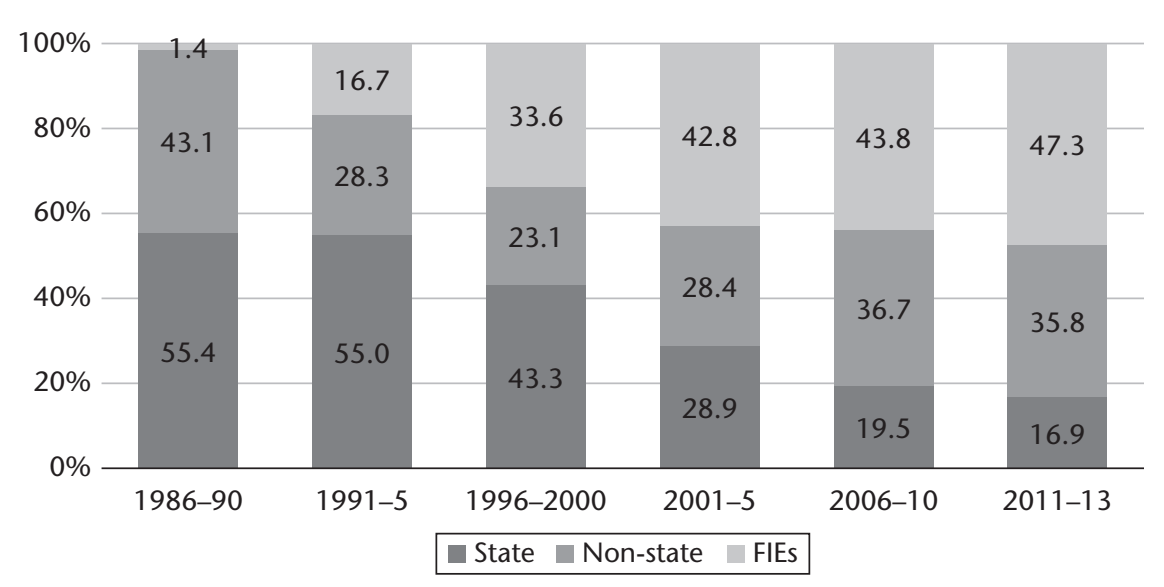

Figure 9.2. Industrial output share by ownership, 1986-2013

Source: Author's calculation based on Viet Nam's Statistical Yearbooks (1986 to 2013) and data published by World Bank's WDI.

The major theme of what follows is that there are substantial differences in performance between the three ownership sectors and that government policy discriminates in favour of the sector that has performed least well. It follows that elimination of the discriminatory policies that remain is critical to achieving an overall improvement in industrial performance.

Two significant structural changes occurred in the first decade of reform. Firstly, starting from a base line of almost zero, the growth of the FIE sector sky-rocketed. Since the first FIE came to Viet Nam in 1988, it took less than a decade for the FIE sector to account for a third of Viet Nam's industrial production (Figure 9.2). As a result, since 1996 the private sector (both domestic and foreign) replaced the public sector as the largest contributor in the nation's industrial production. Since then, this trend has continued and as of 2013, SOEs contributed less than 17 per cent of the total industrial production.

Secondly, since early 1990s, high industrial output growth rate has been sustained mainly by FIEs, and since the 2000 s by DPEs. The FIE sector was undeniably the industrial champion in the 1990s. By the end of 1990s-that is, after a decade of presence in Viet Nam-with an average growth rate of nearly 23 per cent, twice as high as the other two sectors, the FIE sector had become the biggest contributor to industrial growth in Viet Nam. In the following decade, with an average growth rate of about 20 per cent, compared to 16.7 per cent of the FIE sector and 8.8 per cent of the SOE sector, the DPEs had almost caught up with the FIE sector in terms of contribution to industrial growth.

During the period 2011 to 2013, the rate of industrial growth of both FIE and DPE sectors has declined, partly reflecting the fact that growth in these 
sectors in recent years has been from a much higher base, but most importantly, due to the impact of serious domestic macroeconomic turbulence since 2007 and global financial crisis since 2008.

The declining SOE sector's share in Viet Nam has occurred despite the fact that this sector received a unproportional share of investment vis-à-vis the non-state sector (Perkins and Vu-Thanh 2011). The state share of investment was consistently at or above 50 per cent of total investment until mid-2000s. Much of this investment was ploughed into industry, first through the government budget and later through state-owned commercial bank loans. Private SMEs had no access to the first source and little access to the second source for funding their fixed assets.

A large and rising share of exports is coming from FIEs. In 2013, the FIEs sector contributed two-thirds of Viet Nam's total exports. In effect, the FIEs are able to meet international competition whereas the state sector and substantial parts of the domestic-private sector are less able to do so.

An empirical puzzle that emerged from this discussion is that given the top priority the VCP has attached to SOEs' industrial performance and bias against the private sector, how has the private sector-the FIE sector in the 1990s and then the domestic-private sector in the 2000s-side-lined the SOE sector to become the main industrial player in Viet Nam?

At first glance, Figure 9.3(A) seems to suggest that the changing order in terms of investment share of the SOE vis-à-vis the private sector is the main reason behind the decline of the former and the rise of the latter. However, an additional look reveals that it is not investment but productivity that is the key determinant of private sector's rapid industrial growth. While the investment structure of the three sectors over the period 1991-5 and 2006-10 is almost identical (Figure 9.3(A)), the industrial structure was fully reversed (Figure 9.3(B)), implying a much higher efficiency of the private sector. The empirical question then now becomes: which political and policy changes between 1990 and 2010 help explain improvement in the rates of investment and the efficiency in the Vietnamese private sector vis-à-vis the state sector? We now turn to this puzzle in the next three sections (Sections 9.3 to 9.5).

\subsection{Economic Crisis in the 1980s and the Emergence of Private Sector in the 1990s}

In the first half of the 1980s, Viet Nam experienced what even the VCP has to admit as a 'comprehensive social and economic crisis'. ${ }^{8}$ A series of policies

\footnotetext{
${ }^{8}$ See the Strategy for Socio-Economic Stabilization and Development to 2000 (the 7th Party Congress, 1991).
} 
(a)

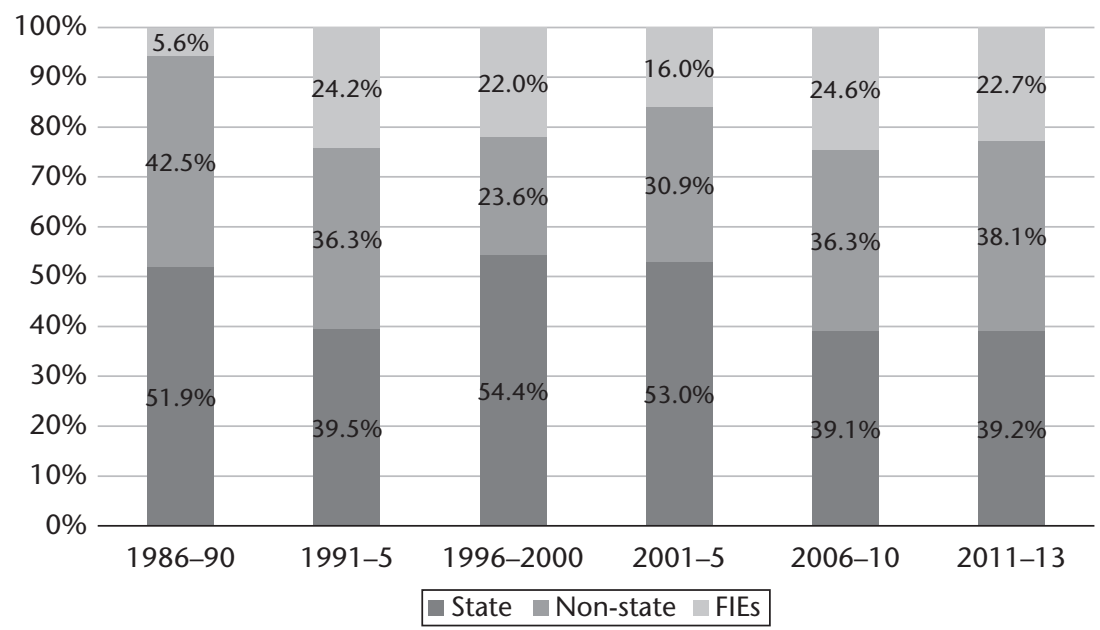

(b)

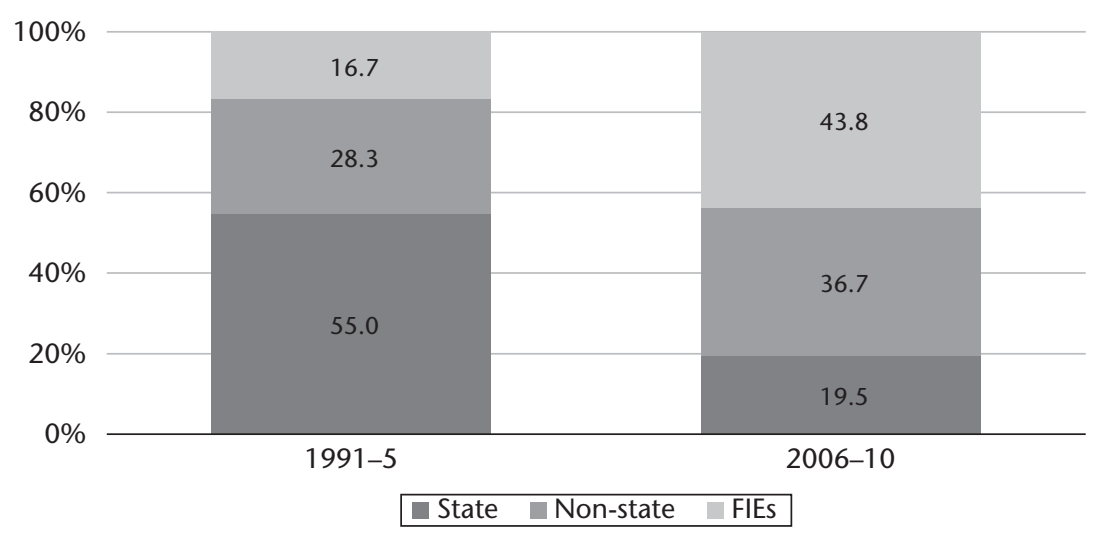

Figure 9.3. Share of investment and industrial output by ownership

Sources: Author's calculation based on Viet Nam's Statistical Yearbooks, 1986-2013.

intended to eradicate private property and put an end to the free market-such as commercial and industrial 'socialist rehabilitation', agricultural collectivization, and prohibition of inter-provincial circulation of goods-pushed the economy to the brink of crisis. Serious failures of the 'price-wage-money' package in 1985 was the final blow to the fragile economy. Not only exhausted internally, Viet Nam in the mid-1980s found itself completely isolated, both economically and politically, from the world. Aid from the Council for Mutual Economic Assistance (COMECON) was cut completely due to the political crisis within the socialist bloc. Viet Nam's involvement in Cambodia was not only extremely costly, but also shut down any window 
of opportunity for economic normalization with the USA and, therefore, trade with the West. In sum, the economy was pushed against a wall.

Truong Chinh-the then acting general secretary of the VCP-adopted market-oriented reforms; which were completely uncharted waters. He led a group of reformers within the VCP, in just five months (from July to December 1986), to rewrite the Political Report of the Central Communist Party in the direction of market-oriented reform with the hope of restoring economic growth and, thereby, the legitimacy for the VCP's leadership. Under his leadership, the party-state conducted Doi Moi in 1986, accepting the co-existence of different economic (or more precisely, ownership) sectors in the so-called 'commodity economy' and began to open up international trade and economic relations.

It must be emphasized that although sharing the goal of restoring legitimacy with the reformers, for the orthodox communists, Doi Moi were only viewed as a 'temporary setback'. To accept the existence of both the nonstate sector and market relations in the economy was considered a 'strategic step backward' in the transitional path to socialism. Similarly, the opening up of economic and trade relations with non-socialist countries was considered by many as the 'lesser of two evils' because traditional relationships with the COMECON had declined sharply in the late 1970s, almost collapsed in the mid-1980s, and were in danger of being terminated entirely at any time.

The Law on Foreign Investment - the first market-oriented law in Viet Namwas enacted in 1987. Then the Law on Private Enterprise and the Company Law-the first two laws on the DPEs-were issued in 1990. Results of this 'normalization' between state and private businesses were immediate and astonishing. Since the arrival of the first FIE in 1988, both the number of FDI projects and their registered capital on average increased about 36 per cent per year over the next decade (Figure 9.4(A)). Similarly, since their first appearance in 1990, the number of private enterprises increased at exponential speed, average 112 per cent per year over the period 1991-9 (Figure 9.4(B)). ${ }^{9}$ The private sector's investment growth increased more slowly, averaging only 17.2 per cent in the same period, reflecting its much smaller size as well as limited capacity to mobilize capital compared with the FIE sector.

While the advent of the Law on Private Enterprise and the Company Law in 1990 plays an important role in shaping the formal domestic-private sector, it is worth noting that these two laws were not sufficient to strengthen the position of the domestic-private sector. In fact, the share of this sector in total investment decreased continuously from 42.5 per cent in the period 1986-90 to 36.3 per cent in 1991-5 and 23.6 per cent 1996-2000 (Figure 9.3(A)).

\footnotetext{
9 Family businesses also increased rapidly from 0.84 million households in 1990 to 2.2 million households in 1996 (Pham 2008: 191).
} 
(a)

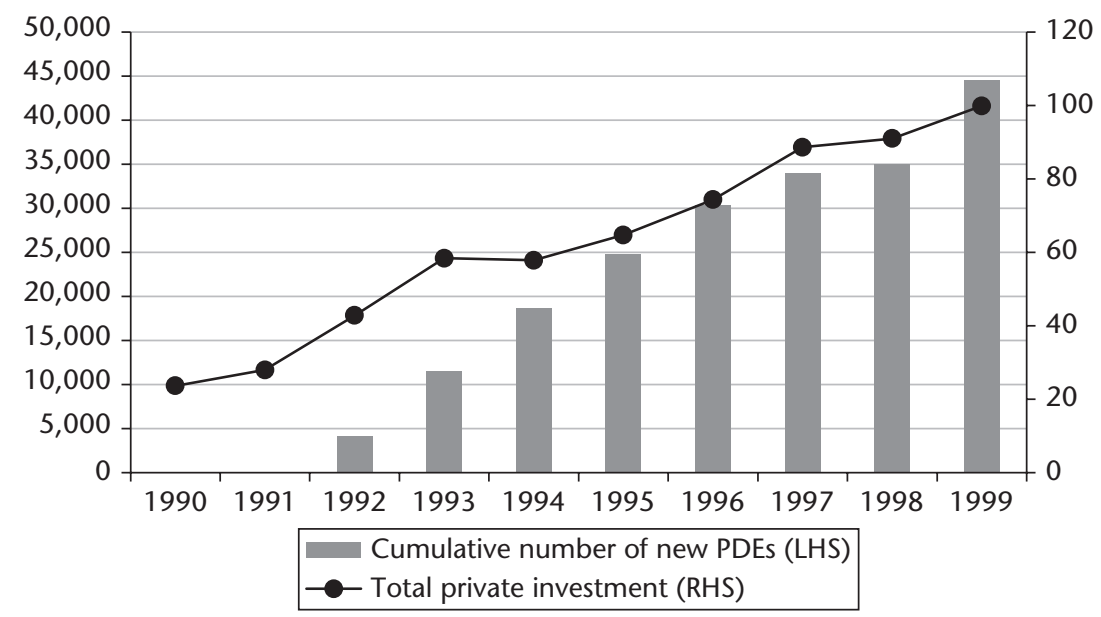

(b)

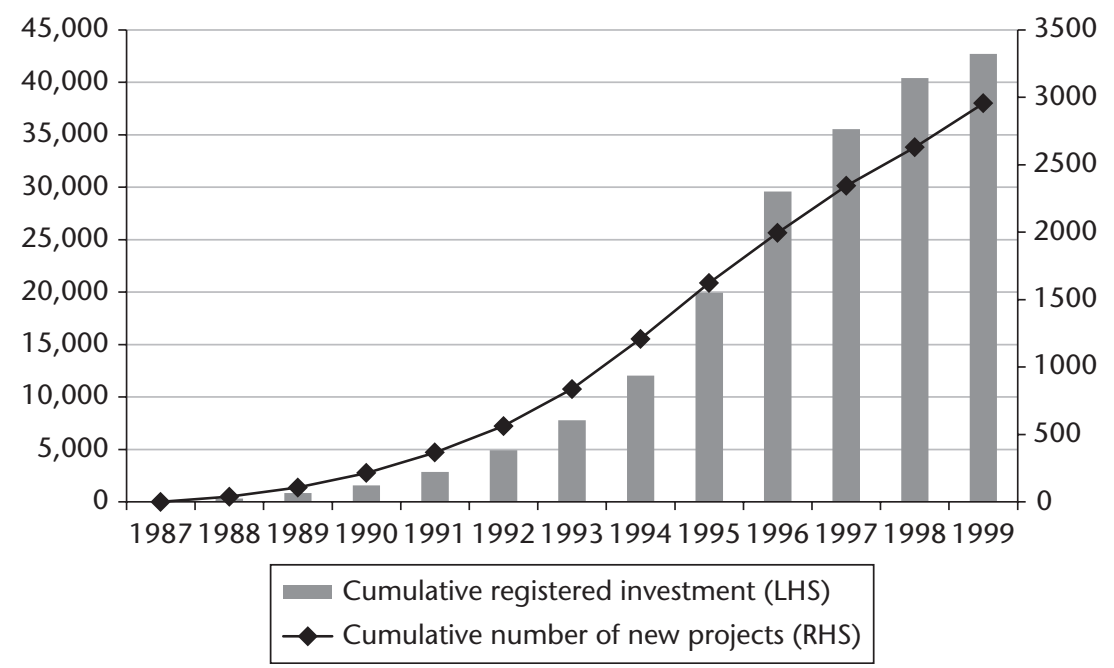

Figure 9.4. Newly registered FIEs and DPEs in Viet Nam, 1987-99

Source: Author's calculation based on data published by the MPI.

Thus, in the 1990s, industrial growth rate of the domestic-private sector was only 9.9 per cent, lower than that of the SOE sector and only about a third of the FIE sector. As a result, the share in industrial production of this sector fell sharply from 43.1 per cent in the period 1986-90 to 28.3 per cent in the period 1991-6 and to only 23.1 per cent in the period 1996-2000. As will be shown in Section 9.4, this declining trend was dramatically reversed only in the 2000s, after the passage of the 1999 Law on Enterprise. 


\subsection{Economic Slowdown in the Late 1990s and the Revival of the Domestic-Private Sector}

Due to heavy reliance on FDI and exports, the Vietnamese economy was significantly affected by the Asian financial crisis in 1997. From a peak of US $\$ 9.6$ billion in 1996, annual registered FDI plummeted to US\$6.0 billion in 1997 and to US\$2.3 billion in 1999. Moreover, many investors stopped investment or even withdrew licensed projects. Export growth, which was about 30 per cent per year, dropped to less than 2 per cent in 1998. Gross domestic product (GDP) growth fell from more than 9 per cent in the mid1990s to a nadir of only 4.8 per cent in 1999. Against this backdrop, the partystate decided to adjust the path of economic development, in which the internal forces were considered the backbone of the economy and, therefore, brought to the fore. It is in this context that the 1999 Law on Enterprise was introduced. Just like the Law on Private Enterprise and the Company Law in 1990, once again, only the combination of serious internal difficulties and external crisis was sufficient to force the party-state conservatives to accept the 'lesser evil', thereby paving the way for private sector development.

If the 1990 Law on Private Enterprise and the 1990 Company Law established the DPEs as a sector in the economy, then the 1999 Law on Enterprises (together with the US-Viet Nam Bilateral Trade Agreement (BTA)) has a crucial role in helping this sector flourish. Within two years of its implementation, more than 35,000 DPEs were established, nearly as many as the number of enterprises established in the previous ten years combined. During the period 2000-5, a total of approximately 160,000 DPEs were established with the total investment of VND 323 trillion (or about 1.5 times the total investment of the FIE sector), creating 3 million new jobs (Pham 2008). In term of industrial performance, during the period 2001-10, the private sector's average growth rate surged to 20.5 per cent, significantly higher than that of the FIE sector (16.7 per cent) and 2.5 times higher than that of the SOE sector (8.8 per cent). With this remarkable growth, the private sector's contribution to industrial growth in the period 2006-10 amounted to 42.2 per cent, far exceeding the contribution of the SOE sector (12.3 per cent) and quite close to the contribution of the FIE sector (45.5 per cent).

What really caused the huge difference between the two generations of law on private enterprises? There are, of course, many factors involved, but the most crucial one is a fundamental shift in the status of the domestic-private sector as regarded by the Vietnamese party-state. ${ }^{10}$ The remainder of this section will briefly present the difficult journey to reach this decisive change,

10 Another, very important factor was the BTA between Viet Nam and the USA (2001), which almost coincided with the time of the Law on Enterprise, and therefore strongly complemented it. 
and thereby demonstrate the critical importance of SBRs and coordination for the success of the 1999 Law on Enterprise.

\subsubsection{Designing and Lobbying for the New Law on Enterprise (1999)}

Although Doi Moi was officially launched in 1986, and although the first two laws on DPEs were enacted in 1990, not until the enactment of the 1992 Constitution were ownership rights and the freedom to do business officially recognized for the very first time. However, private enterprises in Viet Nam had to wait for another seven years to see these 'abstract' rights to be institutionalized in the 1999 Law on Enterprise, and then implemented in reality. ${ }^{11}$ Two years later, the Ninth Party Congress (April 2001) confirmed the new direction of 'widely encouraging the development of the private capitalist sector in the production and business areas which are not prohibited by law. ${ }^{12}$ Then, in the 5th Meeting of the Central Committee of the Ninth Party Congress (March 2002), the status of the private sector was firmly established as 'an important component of the national economy. Developing the private sector is a matter of long-term strategy in the socialist-oriented multi-sectoral economic development', and this strategy demanded that 'favourable institutional and social environment for the development of the private sector should be created' ${ }^{13}$

It is important to remember that during the process of designing and implementing the Law on Private Enterprise and Company Law in 1990, private enterprises were still considered the subject of 'socialist rehabilitation' and only allowed to do business in areas stipulated by law. With the advent of 1999 Law on Enterprise, they have become an important part of the national economy and could do business in any areas not prohibited by law. As will be discussed in Sections 9.4.2 and 9.4.3 designing a Law on Enterprise that truly respects the people's freedom to do business and can be effectively implemented requires coordination within the state system as well as between the state and businesses. ${ }^{14}$

The PMRC and a very small group of highly dedicated technocrats in the CIEM were the brain of the whole process, from initial idea to drafting and implementation of the 1999 Law on Enterprise. In 1996, realizing serious inadequacies in the 1990 Law on Private Enterprise and the Company Law, the PMRC proposed to Prime Minister Phan Van Khai that these two laws should be modified in line with the spirit of the 1992 Constitution. Shortly thereafter, a steering committee charged with drafting the new law (hereafter

${ }^{11}$ For further discussion, see Pham (2008), Tran (2008), and Vu (2008).

12 VCP (2001: 98). $\quad{ }^{13}$ VCP (2002: 58-9).

14 This section is based on Pham (2008) and interviews by the author with several key members of the Prime Minister's Research Commission (PMRC), the Steering Committee, the Central Institute of Economic Management (CIEM), and Viet Nam's Chamber of Commerce and Industry (VCCI). 
Box 9.1. THE PMRC

The predecessor of the PMRC was the Advisory Group on Economic and Public Administration Reforms, established in 1993 by the late Prime Minister Vo Van Kiet. By 1996, this group was reorganized into the Research Group for Socio-Economic and Public Administration Renovation, which was finally upgraded by Prime Minister Phan Van Khai to the PMRC, with greater autonomy in personnel, funding, and collaboration with domestic and international research organizations and experts.

PMRC was a very small organization, never having more than fifteen members, including supporting staff. At the heart of the PMRC was a core group of a dozen advisors, all sharing strong aspirations for change, under the direct supervision of the prime minister. Before joining PMRC, most advisors had served as senior experts or researchers in the party-state system. Nevertheless, they did not hold any executive posts in the administration, and many had already retired. ${ }^{15}$ Since PMRC members neither had official power nor sought it, and, moreover, since they refrained from any business activities and vested interests themselves, they were able to maintain a very high level of autonomy, both in relation to the government and businesses. Members of the PMRC, if they wished, could report and sent recommendations directly to the prime minister. In addition, they had the right to reserve their opinions if these differed from those of the chairman and other members.

The prime minister worked regularly with the PMRC chairman and attended regular meetings with the whole PMRC to listen to their comments and suggestions about the work of the government. Until Prime Minister Nguyen Tan Dung dissolved the PMRC in July 2006 (i.e., immediately after taking office), the organization was assigned the task of being the lead editor of the prime minister or deputy prime ministers' reports presented to the National Assembly, the prime minister's reports submitted to the Party Central Committee, the Politburo, and the National Assembly. Such documents in included the Socio-Economic Development Strategy 2001-10 and the Five-Year Plans, as well as other documents of the Central Committee's meetings on economic, administrative, and local political system reforms.

A top priority of the PMRC was to observe the economy and society closely through daily interactions with various institutions, businesses, and practitioners, as well as through field trips at the local level. At the same time, the PMRC also built an information and documentation centre for research, and tried to learn from international experience by conducting well-designed surveys overseas.

Source: Based on Tran (2008) and interviews by the author with Tran Duc Nguyen and Tran Viet Phuong during 2011 and 2012.

Steering Committee) was established, headed by Mr. Tran Xuan Gia, by then the minister of Ministry of Planning and Investment (MPI), with members including representatives of CIEM (the principal drafter of the law), deputy minister-level representatives from the National Assembly and relevant ministries. For the very first time, a representative of the business community-the VCCI-was invited to participate in the drafting process.

15 In addition to retirement pension, the retired members of PMRC received a modest monthly allowance of VND500,000 (equivalent to about US\$32), which was, in 2005, increased to VND1,000,000 (equivalent to about US\$63). 
Box 9.2. IMPORTANT REFORMS INITIATED BY THE 1999 LAW ON ENTERPRISE

(1) Merge the Law on Private Enterprises and the Company Law into a unified Law on Enterprise;

(2) Introduce the principle of 'enterprises can do anything that is not prohibited by law', and stipulate clearly the kinds of business which are prohibited or subject to specific conditions;

(3) Replace licensing system with business registration;

(4) Apply post-audit instead of pre-audit;

(5) Institutionalize the autonomy of enterprises in selecting business areas, locations, forms of business and organization;

(6) Clarify internal decision-making mechanisms within private enterprises, protect the rights of investors, particularly minority shareholders and creditors.

Source: Author's compilation.

For three years, after countless heated debates within as well as between the Steering Committee with relevant state agencies, particularly those agencies whose authority was narrowed down by the Law on Enterprise, the 23rd, and also the final version of the Law on Enterprise was passed by the National Assembly in May 1999. During this process, under the initiative proposed by CIEM and VCCI, the 5th, the 9th, and the 14th draft were discussed with the business community around the country, particularly where the private business community is strongest such as Ho Chi Minh, Ha Noi, Da Nang, and Can Tho. These consultations attracted very large and enthusiastic participation of the private business community, as this was the first time they were invited to comment directly and formally on a legislation draft which was of most immediate concern to them. With the initiative of the PMRC and the dedication of the Steering Committee, backed by the support of the business community, the 1999 Law on Enterprise was more successful in institutionalizing several fundamental reforms (Box 9.2) compared with the 1990 Law on Private Enterprise and the Company Law.

\subsubsection{The Task Force for the Implementation of the 1999 Law on Enterprises}

Anticipating the risk that the Enterprise Law would be distorted during the implementation process, the PMRC proposed to Prime Minister Phan Van Khai to establish a 'special task force' to help various government organizations implement the Law on Enterprise. In December 1999-right before the Law on Enterprise came into effect-the prime minister established the Law on Enterprise Implementation Task Force (hereafter Task Force), again led by Tran Xuan Gia, who previously chaired the Steering Committee. The Task Force also includes some of the most dedicated reformers who previously 
served in the Steering Committee and the Drafting Committee. The Task Force was entrusted with the task to draft decrees guiding the implementation of the Law on Enterprise and check the current business licensing system. Equally important, the Task Force enjoyed autonomy vis-à-vis the government, that is, it reported directly and was accountable only to the prime minister.

In February 2000-which was only two months after the Task Force was founded-Decree 02/2000/NĐ-CP drafted by the Task Force was enacted, thereby significantly reducing administrative procedures for business and administrative burden for the state apparatus. Also in the beginning of February 2000, following the recommendation of the Task Force, the Prime Minister issued Decision 19/2000/QĐ-TTg revoking eighty-four licences deemed contrary to the Law on Enterprise. In August 2000, Decree 30/2000/NĐ-CP abolished twenty-seven additional licences and moved thirty-four licences to business conditions. In total, under recommendation of the Task Force, 286 licences have been revoked.

\subsubsection{Direct Dialogue between the Prime Minister and the Business Community}

Unlike his predecessors, Prime Minister Phan Van Khai neither had substantial revolutionary credentials nor was he particularly politically adept. Being a dedicated technocrat, Phan Van Khai soon realized the vital importance of adopting a market economy and fostering private businesses. In 1989, when he was made chairman of the State Planning Committee (which then became MPI) and assigned to lead the team in charge of drafting the Strategy for SocioEconomic Stabilization and Development to the Year 2000 (hereafter Strategy 1991-2000), he managed to put together a group of the most ardent reformers in his drafting team. A number of people in this team later became core members of the PMRC. He and the drafting team advanced the idea that '[o]n the road to doi moi, the central character for revitalizing the country's economy is the businessmen of various calibers, from household business owners intrinsically linked to the market to investors and managers of large enterprises' (Tran 2008: 94-5).

In 1997, just several months after taking office, Prime Minister Phan Van Khai-again following the advice of the PMRC-held the first meeting with the business community, marking a fundamental shift in the SBR. ${ }^{16}$ This is also the very first time that private enterprise owners in the country were officially recognized by the state not as 'rehabilitation subjects' or

\footnotetext{
16 Also in 1997, the VBF was established as one of the first public-private dialogue (PPD) mechanisms that provides regular channels of communications between foreign and domestic companies with the Vietnamese government.
} 
'management objects' but as 'policy interlocutors'. Since then, meetings like this have been held every year and officially become the policy dialogue between the Prime Minister and the business community. These meetings appealed mostly to domestic-private SMEs, who are virtually voiceless and otherwise never have the opportunity to dialogue directly with the top leaders of the government.

Following this precedent, many ministries, agencies, and local governments also held regular meetings with the business community. In these policy dialogues, the most-discussed topics always concerned the laws and regulations on taxation, customs, import and export, land, credit, investment, and administrative procedures, and from 2000 onwards an additional thread on the implementation of the Law on Enterprise. Through direct dialogue with the business community that the head of the government, ministries, and agencies better understood the obstacles to the operation and development of the business, thereby adjusting the laws and legislation to create a better environment for businesses. Equally important, this sincere action on the part of the government helped build trust in the government among the private businesses, who are traditionally underrepresented. The business community started to have a sense of government's sympathy towards them, which encourages them to invest, start up and expand their business (see Vu-Thanh 2014a: figure 6). This is a key factor contributing to the very high rate of industrial growth of 25 per cent in the mid-2000s.

\subsection{The Relative Failure of the 2005 Unified Enterprise Law}

After several years of implementing the 1999 Law on Enterprise, the earlier advantages were eaten away, partly because of the lack of internal pressures for reform, and partly because the initial 'low-hanging fruit' had already been exhausted. The later implementation of the Law on Enterprise increasingly clashed with even more powerful vested interests groups.

Understandably, the strongest opposition came from government agencies whose licences risked being revoked by the Implementation Task Force. According to Pham (2008: 213, emphasis added),

[m]any times, the Implementation Task Force had to work directly with the most senior leaders of the licensing agencies to explain and persuade, nevertheless there are cases in which the agency insisted not to revoke their licenses, and their main rationale was the need to keep the 'state management' with regards to these business activities, and in order to manage them, it was necessary to keep the licensing mechanism. When the Implementation Task Force submitted the proposal to revoke licenses to the government, these agencies also found ways to 
prove and lobby for the opposite, leading to the government's hesitance and indetermination.

With no executive power in the context of declining political will for reform and opposed by increasingly powerful interest groups, the Task Force ceased to be effective. Moreover, some ministries and agencies also lobbied to recover many previously revoked licences. Worse still, these organizations found ways to add new licences by building them right into the new laws or amendments of existing ones. As a result, the number of licences gradually increased, and the mentality of 'if it's not manageable, then prohibit it' started to spread out among state agencies. The conflicting views about the government's role and its relationship with business sectors resurfaced. In these debates, the real motives of self-interested economic power and interests were often disguised under the umbrella of political and ideological correctness.

Meanwhile, the discrimination among ownership sectors is still very strong, with the same pecking order as before: the SOEs come first, followed by the FIEs, and the DPEs come last. This discrimination exists both de facto and de jure. Until 2005, in the Vietnamese legal system, the Law on [Private] Enterprise co-existed with the Law on State-Owned Enterprise; and the Law on Domestic Investment Promotion existed alongside the Law on Foreign Investment. The reformers realized an increasingly urgent need to create a level playing field for all types of businesses regardless of their ownership, which was also a critical requirement of WTO accession. With this motivation in mind, the PMRC and the Task Force recommended to Prime Minister Phan Van Khai to merge the two existing enterprise laws into the unified Law on Enterprise and the two investment laws into the common Investment Law, both were enacted in late 2005 and became effective in mid-2006.

While the first two generations of law on private enterprise in 1990 and 1999 were drafted and enacted during crisis and therefore considered an 'emergency exit' for the economy, on the contrary, the 2005 Law on Enterprise came out when the economy was at its peak and vested interest groups began to take root and spread. Moreover, for some senior party-state leaders, the two new laws were merely a necessary means to achieve the objective of joining the WTO. Together, these are the main reasons that prevented the 2005 Law on Enterprise from creating necessary breakthroughs compared with the 1990 and 1999 enterprise laws. Moreover, the 'breakthroughs' that made their way through legislation have generally been disabled during the implementation process. For instance, lawmakers have succeeded in forcing the SOEs to 'sit at the same table' with the other economic players in the unified Law on Enterprise, and this opened the hope for ensuring equal footing for all types of businesses, especially for private SMEs. But in reality, 
the discrimination has still been persistent and serious, and is even becoming more sophisticated (Pham 2008), especially given the emergence of powerful SEGs since 2005 (Vu-Thanh 2014b).

In summary, the 2006 Law on Enterprise has not brought about the significant changes as expected. It follows that the limited success in terms of domestic-private sector development and industrial growth during the 2006-10 period has more to do with the lingering effects of the 1999 Law on Enterprise and other factors rather than with the 2005 Law on Enterprise itself. In terms of SBR, from the mid-2000s onwards, the cooperative relationship and trust between the state and business sectors built during Phan Van Khai's terms (i.e., 1997-2006) have been degrading. After a period of macroeconomic instability and economic slowdown, DPE confidence in the state has seriously declined. Meanwhile, quid pro quo relationship between the state and big businesses-mostly SEGs and a very small group of big DPEs-in search of political support or privileged benefits has become increasingly widespread. It is no surprise that the annual meetings between the Prime Minister and the business community have ended since $2007 .{ }^{17}$ The acceleration of this situation, as will be seen in Section 9.6, resulted from major changes in the party-state leadership and in the internal structure of the state system.

\subsection{Conclusion and Policy Implications}

Viet Nam's industrial development since Doi Moi is a success, but only a partial one. There are obviously many factors behind this performance, but the key determinant is the relationship between the party-state and the private sector. Adhering to the Communist ideology, the party-state's distrust of, and therefore, discrimination against the private sector is inescapable. However, the level of distrust and discrimination has depended on the degree of the trade-off between the political ideology and economic legitimacy, on the internal structure of the state, and on the quality of leadership.

This study offers several implications. First, Viet Nam's experience has been consistent with the statist literature (e.g., Johnson 1987; Amsden 1989; Evans 1995; Kohli 2004) in suggesting that a prerequisite for rapid industrial growth in the late-late-late industrializers is that the leaders commit to economic growth and put national interests above political, ideological and personal interests. These are preconditions for the ruling elites to form a close alliance with the most productive forces, build strong reform coalitions, and create a

\footnotetext{
17 The prime minister's first meetings with the business sector were with the SOEs, then commercial banks, and the FIEs.
} 
meritocratic bureaucracy-all of which are the 'usual suspects' behind the success of Japan, South Korea, and Taiwan.

In the Vietnamese case, because the alliance with the most dynamic and efficient sectors was viewed by many as a temporary concession rather than a coherent strategy, the success was only partial. More fundamentally, because of the orthodox ideology at the beginning of reforms and later on due to a symbiotic economic relationship with the SOEs, the Vietnamese party-state has chosen to rely on the SOEs, which are persistently the least efficient sector in the economy. Additionally, the fragmentation of power and inherent lack of effectiveness render the state incapable of imposing hard budget constraints on the SOEs or sanctions them for underperformance. Without effective 'sticks', and an overreliance on 'carrots' for political support rather than development goals-the SBRs run the risk of being degraded into clientelism and corruption.

Second, the relationship between the state and business will influence the institutions and the quality of coordination between them. In Viet Nam before 1986, when private businesses were deemed to be subjects of 'socialist rehabilitation', there could hardly be any possibility of coordination between the state and the private sector. True coordination first requires a certain degree of equality between the parties involved, and therefore never exists when the state assumes the dominant role and the private sector is merely subservient. This implies that, for non-capitalist countries, before discussions about the optimal institutions for effective state-business coordination (see, for instance Schneider 2013), it is necessary to analyse the role of the business sector in the vision and strategy of the ruling elites.

Third, the statist literature has emphasized that industrial development requires effective coordination between the public sector and businesses. This coordination, in turn, requires effective coordination within the state system itself as well as within the business sector. In Viet Nam, the coordination within the business sector is inefficient, partly because of the clear hierarchical structure dominated by SOEs, and partly because business associations are often designed as extended arms of the party-state rather than representatives of business community. In addition, as analysed in Ketels and colleagues (2010: 68 ), 'inter-ministerial coordination on policy substance as well as implementation details is poor primarily because mechanisms are lacking to encourage different ministries to work together'. Under these conditions, the consolidation of state-business coordination authority can be necessary. Although Viet Nam has never had any institutions even close to the Economic Planning Board (EPB) in South Korea or the Council for Economic Planning and Development in Taiwan, the 'embedded autonomy' of and the coordination by the PMRC and the Implementation Task Force led to the impressive success of the 1999 Law on Enterprise. In contrast, with the concentration of controlling power 
over SEGs and the disbandment of the PMRC right after taking office, Prime Minister Nguyen Tan Dung has, on the one hand, created 'socialist cronyism' and, on the other hand, destroyed the very little 'corporate coherence' and 'embedded autonomy' that existed in the bureaucracy.

Fourth, the greatest effect on industrial development does not necessarily come from narrowly defined industrial policy per se, or even from purely economic policy. As evidenced in the case of Viet Nam, political compromises about the role of the private sector are the foundation in which economic and industrial policies are shaped. This also implies that industrial development runs the risk of being reversed because of changes in leadership or political coalition.

\section{Acknowledgements}

I am grateful to Phạm Chi Lan, Đào Xuân Sâm, Trần Việt Phương, Trần Đức Nguyên, Trần Xuân Giá, Nguyễn Đình Cung, David O. Dapice, and Atul Kohli for their insightful discussions. I would also like to thank Eric Thun and participants at the OxfordPrinceton Global Leaders Fellow Colloquium for their helpful comments. Any remaining errors are mine.

\section{References}

Amsden, A. (1989). Asia's Next Giant: South Korea and Late Industrialization. Oxford: Oxford University Press.

China National Bureau of Statistics (2006). China Statistical Yearbook 2006. Beijing: China Statistics Press.

Dinh, H. T., Mishra, D, L. D. Binh, P. D. Minh, and P. T. T. Hang (2014). Light Manufacturing in Vietnam: Creating Jobs and Prosperity in a Middle-Income Economy: Directions in Development; Private Sector Development. Washington, DC: World Bank.

Evans, P. (1995). Embedded Autonomy: States and Industrial Transformation. Princeton, NJ: Princeton University Press.

Johnson, C. (1987). 'Political Institutions and Economic Performance'. In F. Deyo (ed.), The Political Economy of the New Asian Industrialism. Ithaca, NY: Cornell University Press.

Ketels, C., D. C. Nguyen, N. T. Tue Anh, and H. H. Do (2010). Vietnam Competitiveness Report. Hanoi: Central Institute for Economic Management and Asia Competitiveness Institute.

Kohli, A. (2004). State-Directed Development: Political Power and Industrialization in the Global Periphery. Cambridge: Cambridge University Press.

Malesky E. (2014). The Vietnam Provincial Competitiveness Index: Measuring Economic Governance for Private Sector Development. 2013 Final Report, PCI Report 
\#9. Ha Noi: Vietnam Chamber of Commerce and Industry and United States Agency for International Development.

MITI (Ministry of Industry and Trade) (2012). 'Báo cáo Tập trung Kinh tế Việt Nam' (Report on Economic Concentration in Vietnam). Hanoi: Ministry of Industry and Trade Publication.

Perkins, D. H., and T.-A. Vu-Thanh (2011). 'Industrial Policy in Vietnam: From Industrial Policy to Industrial Development'. Background Paper for 'Vietnam's Ten-Year Socio-Economic Strategy', Development Strategy Institute, Ministry of Planning and Investment.

Pham, C. L. (2008). 'Development of Legal Environment for Businesses in Vietnam: The Memorable Paths'. In D. Xuan Sam and V. Q. Tuan (eds), Renovation in Vietnam: Recollection and Contemplation. Hanoi: Tri Thuc Publishing House.

Schneider, B. R. (2013). 'Institutions for Effective of Business-Government Collaboration: Micro Mechanisms and Macro Politics in Latin America'. Inter-American Development Bank Working Paper Series No. IDB-WP-418.

Tran, D. N. (2008). 'The 1991-2000 Strategy: A Breakthrough in Development Viewpoint'. In D. Xuan Sam and V. Q. Tuan (eds), Renovation in Vietnam: Recollection and Contemplation. Hanoi: Tri Thuc Publishing House.

VCP (Vietnamese Communist Party) (2001). Documents of the 9th Party Congress. Hanoi: National Political Publishing House.

VCP (Vietnamese Communist Party) (2002). Documents of the 5th Plenum of the 9th Party Congress. Hanoi: National Political Publishing House.

Vu, Q. T. (2008). 'Enterprises Development: Reflection on a Process'. In D. Xuan Sam and V. Q. Tuan (eds), Renovation in Vietnam: Recollection and Contemplation. Hanoi: Tri Thuc Publishing House.

Vu-Thanh, T.-A. (2014a). The Political Economy of Industrial Development in Vietnam: Impact of State-Business Relationship on Industrial Performance, 1986-2012, WIDER Working Paper 2014/158. Helsinki: UNU-WIDER.

Vu-Thanh, T.-A. (2014b). WTO Accession and the Political Economy of State-Owned Enterprise Reform in Vietnam, The Global Economic Governance Program Working Paper 2014/92. Oxford: Oxford University Press. 



\section{Part III}

Building Coordination in Africa 



\title{
10
}

\section{A Natural Experiment of Industrial Policy}

\author{
Floriculture and the Metal and Engineering \\ Industries in Ethiopia
}

Mulu Gebreeyesus

\subsection{Introduction}

Industrial policy is back on the development agenda (for example, Hausmann and Rodrik 2003, 2006; Khan and Blankenburg 2009; Cimoli, Dosi, and Stiglitz 2010) and several countries in Africa and the rest of the developing world have already started to re-introduce industrial policy. African governments have also collectively taken initiatives to promote industrialization in Africa under the theme 'Industrialization of Africa' at their January 2008 summit (UNECA and AU 2013).

Learning from past experiences is an inevitable process of policy-making. And yet the focus of learning has been on the successful industrialization of East Asian countries. Industrial policy-making in Africa needs to take account of the specific character of the continent. In this regard, the continent should critically evaluate its own experience and learn from its success and failure.

This chapter aims to contribute towards this by providing evidence of success and failure of industry cases from Ethiopia. The country represents an excellent case study as it is among the leading countries in Africa of the recent wave of reintroducing industrial policy. The focus of this study is on two sectors, floriculture and metal and engineering, both of which are among the priority sectors for promotion by the government but performed differently despite similar policy environment. Understanding why one intervention worked and the other failed in the same political context provides valuable lessons. 
The main critic against industrial policy has been the inability of state bureaucrats to pick winners and the high probability that they promote rent-seekers instead (for example, Krueger 1974; Pack and Saggi 2006). As a result, the state-business relation (SBR) and particularly the rent management has taken centre stage in industrial policy debate (for example, Hausmann and Rodrik 2003, 2006; Khan 2008; Khan and Blankenburg 2009; Schmitz, Johnson, and Altenburg 2013). Schmitz, Johnson, and Altenburg (2013) defines rent management as government intervention for raising (lowering) profitability in selected sectors and thus making private investment in these selected sectors more (less) attractive. They argue that success of industrial policy depends on how we deal with the following four categories of risks of rent management.

(i) political capture by private investors and allied policy makers;

(ii) choice of wrong instruments;

(iii) targeting the wrong sector/technologies; and

(iv) doing too little.

This chapter adopts these critical success factors for rent management as analytical framework to understand the success or failure of industrial policy in the two sectors under consideration. Some more specific questions we would like to address in our quest for lessons from the rent management practice in the two sectors in Ethiopia are:

- How were the sectors selected and what are the instruments used by the government to create incentives (rents) in each sectors?

- How are results defined and monitored and what are the sanctions instituted?

- What are the institutional arrangements and particularly how does the government manage the tension between coordination and capture?

- How is the private sector organized in its dealing with the government and each other?

- How did these sectors perform and what are the key drivers of success or failure?

Many of these questions are about institutional linkages and coordination, thus, cannot be answered quantitatively. The analysis is, therefore, mainly qualitative and descriptive. A number of available databases (for example, Central Statistics Agency (CSA), Ethiopian Revenue and Customs Authority (ERCA), and surveys conducted by Ethiopian Development Research Institute (EDRI) on floriculture and metal industries) have been used to highlight each sector's structure and relative performance. Moreover, secondary sources (published and unpublished documents from academia and policy circles) 
and additional interviews with key players in each sector (associations and government agencies) have also been used in the analysis.

The rest of the chapter is organized as follows. Section 10.2 highlights the current debate concerning the implantation of industrial policy. Section 10.3 provides a general background of industrial policy in Ethiopia. Sections 10.4 and 10.5 respectively discuss the implementation and performance of industrial policy in the floriculture and metal and engineering industries. Section 10.6 tries to draw lessons from the two cases.

\subsection{Principles of Successful Industrial Policy: Brief Review of the Literature}

There seems little dispute on the theoretical arguments justifying industrial policy. The objection towards industrial policy often revolves around implementation and management. For example, the rent-seeking literature (for example, Krueger 1974; Tullock 2005; Pack and Saggi 2006) provides at least two main reasons as to why industrial policy is doomed to fail. The first is related to the fact that governments have no sufficient information to make the right choice, that is, to pick the winners. The second is that industrial policy is an invitation to corruption and rent-seeking, referred to as political capture. They, therefore, argue that rents should be avoided or minimized.

Khan (2008) and Khan and Blankenburg (2009), on the other hand, emphasize the advantage of looking at industrial policy through the lens of rent management. They argue that catching up with advanced countries requires rapid and sustained productivity growth which in turn depends on the creation (or learning) of new technologies. Building up technological capabilities can create a very high return in the future but the private sector will not play a big role particularly at the early stage because of the 'risk' involved. Governments should, therefore, create rents to attract investment in the selected sectors through different instruments. According to them, the challenge is then not to avoid rents but to manage them.

There are different perspectives on how to ensure good governance and avoid political capture in implementing industrial policy. One view is to create arm's-length relationships between the government and private sector implying the need for autonomy of bureaucracy from the pressure and lobby group. The criticism against this view is that it implicitly assumes an omniscient government (i.e., the principal has already needed information), thus, limiting the importance of flow of information from below.

An alternative and widely held view is the concept of 'embedded autonomy', which highlights the need for dense links between government and the private sector. According to Evans (1995: 12), the government should be 'embedded in 
a concrete set of social ties that binds the state to society and provides institutionalized channels for the continual negotiation and re-negotiation of goals and policies'. Rodrik (2013) emphasizes on three key principles regarding the state business relation: embeddedness, discipline, and accountability.

The presence of strong private sector association is regarded as helpful for effective SBRs. According to Schmitz, Johnson, and Altenburg (2013) high organizational capacity of the private sector and broad-based membership of its association increases the likelihood of an alliance becoming effective and legitimate. Hausmann and Rodrik (2006) also argue that the trade associations might be a cooperative solution not only to the free-rider problem among private participants but also to improve the transparency and legitimacy of the relation between the private and public sectors. According to them the association should be left free to organize by itself at the level of what it deems is necessary. Forcing groups to organize according to some predetermined criteria, for example, by sector classification, may create groups that have few specific needs in common.

The rent management literature seems to implicitly assume that the potential sector is correctly identified and instruments are readily available. But the debate on how to choose potential sectors is far from settled. One dimension of this debate is whether the choice of the sectors should follow or defy existing comparative advantage (Lin and Chang 2009). Another strand of the debate is whether the factor endowment model that predicts broad structure of comparative advantage (for example labour-intensive, natural resource-based products, etc.) can give any practical guide to the choice of potential activities (Hausmann and Rodrik 2003). Hausmann and Rodrik (2006) argue that the new activities that become successful cannot be known with certainty ex ante. It is an 'ongoing learning' process, which requires entrepreneurial experimentation of the private sector. According to them it is, therefore, important whenever possible for the government not to predetermine whom it will deal with in terms of sectors or activities but making choices endogenous to an open process. However, this should not preclude setting a priority sector by the government ex ante. Rather, policy makers should be open to adjust their list to include new ones and/or exclude from an existing list upon information.

Similar arguments arise in relation to the required instruments and institutions for successful industrial policy (for example, Khan 2008). There are no bullet-proof instruments and institutional configurations that can work in every circumstance. The choice of instruments is also a matter of experimentation and compatibility with the organization and structure of a political poser in that society. Choosing wrong sectors and instruments is an inevitable but the most important thing is to put in place a mechanism to learn from mistakes. Industrial policy should, therefore, be seen as experimental process of trial and error. And again, an effective SBR can help reduce the risk of uncertainties in the choice of sectors and instruments. 


\subsection{The Evolution of Industrial Policy in Ethiopia: Some Background}

The Ethiopian People's Revolutionary Democratic Front (EPRDF)-led incumbent government adopted a Structural Adjustment Programme (SAP) in 1992/ 3 , a year after it seized power. A series of reforms were then introduced to replace the command economic system by a market-oriented one. An export promotion strategy was adopted in 1998 as a reaction to the lack of progress in export diversification. A comprehensive industrial development strategy (IDS), that gave impetus to the export promotion, was then formulated in $2002 / 3$. The IDS which is based on the government's broader development vision-Agricultural Development-Led Industrialization (ADLI)—states some key principles such as: (i) strengthening the linkage between industry and agriculture, (ii) export-oriented sectors as a leader of the industrialization process, and (iii) due emphasis on labour-intensive industries. ${ }^{1}$

The strategy also recognizes the private sector as an engine in the industrialization process and at the same time explicitly states the need for a strong state role not only as facilitator but also as a leader. It made a distinction between 'rent-seeking' and 'developmental' capitalists and the need to curtail the former and promote the latter. The strategy cited two important mechanisms in which the government could engage and promote the private sector; creating conducive environment for investment and direct support for priority sectors. The sectors that were declared as priorities include textile and garment; meat, leather, and leather products; other agro-processing industries; construction; and micro and small enterprises (MSEs). The priority list has been adjusted through time. For example, the flower industry starting from the Plan of Action for Sustainable Development and Eradication of Poverty (PASDEP) covering 2005/6-2009/10 and import-substituting industries (ISI) such as metal and engineering and chemical industries with the launch of Growth and Transformation Plan (GTP) I (for the period 2010/11-2014/15) were officially rendered as priority sectors.

\subsection{The Ethiopian Flower Industry}

\subsubsection{The Emergence of the Flower Industry in Ethiopia at a Glance}

Ethiopia's attempt to export summer flowers, produced under the state farms, to Europe in the early 1980s did not last long. The private sector-led flower industry began to emerge in the mid-1990s in the aftermath of the extensive

\footnotetext{
1 Gebreeyesus (2013), on which this section is heavily dependent, gives extensive review of the history of Ethiopian industrial policy.
} 
Table 10.1. The entry process and export patterns of the Ethiopian flower industry

\begin{tabular}{lllllll}
\hline & \multicolumn{7}{c}{ Year } \\
\cline { 2 - 7 } & 2000 & 2003 & 2004 & 2006 & 2008 & 2010 \\
\hline Ownership type of the farm & & & & & 24 & 22 \\
Domestic & 2 & 3 & 4 & 20 & 28 & 43 \\
$\begin{array}{l}\text { Fully foreign } \\
\text { Joint venture }\end{array}$ & 1 & 2 & 4 & 18 & 15 & 12 \\
Total number & 3 & 5 & 10 & 53 & 67 & $77^{2}$ \\
Total exports (million US\$) & 0.56 & 5.07 & 6.78 & 42.33 & 133.48 & 189.88 \\
\hline
\end{tabular}

Source: Author's compilations. The export figures are taken from the UN-COM TRADE database, while the number of firms from the author's own surveys (for more on this see Gebreeyesus 2013).

reform programmes to transform the command economy to a marketoriented one. Table 10.1 gives the number of firms and the pattern of export values of the Ethiopian flower industry. The entry process at the early stage was slow and there were only five flower firms exporting no more than US\$5 million worth of cut flowers until 2003. But things started to change drastically after 2003 with the beginning of active government support to the sector. The number of flower firms doubled in only one year (2003-4) and reached sixty-seven by 2008. The sector was estimated to generate direct employment for about 50,000 people out of which above 70 per cent are women. In 2008, the industry became one of the five top export commodities for the country with more than US\$133 million foreign exchange earnings. With an export value of nearly a quarter billion US\$ in 2012, Ethiopia ranked as the secondlargest floriculture products exporter from Africa (Gebreeyesus 2014).

\subsubsection{Some Factors behind the Success of Ethiopia's Flower Industry}

How did the Ethiopian flower sector become visible and successful in such a short period of time? The following subsections try to examine the main factors behind this extraordinary performance with a focus on the policy management.

\subsubsection{PRIVATE ENTREPRENEURIAL EXPERIMENTATION THAT REVEALED ETHIOPIA'S COMPARATIVE ADVANTAGE IN FLORICULTURE}

Ethiopia is endowed with the conditions required for a successful flower industry especially suited to the production of high-quality roses. The country also has comparative advantage due to its geographical proximity to the world's largest flower market, the European Union (EU), which is the primary destination of flower exports from sub-Saharan Africa (SSA). However,

\footnotetext{
2 Note that the total number of firms at this time was about eighty-one, which means four firms were missing from the 2010 survey.
} 
this latent comparative advantage was not realized until the mid-1990s when two domestic entrepreneurs (namely Meskel Flowers Plc. and Ethio-Flora) started production of flowers with the aim of exporting them directly to Europe.

In 1999, Golden Rose Agrofarms Ltd, a foreign-owned UK-based business started its production after thoroughly examining the performance of the two early entrants as part of its feasibility study. Unlike the two early entrants, Golden Rose located its farm in a highland area (about 2,060 metres above sea level) to enable the production of high-value roses, and introduced modern steel-structure greenhouses. While the first two movers ceased their flower production in the course of the time, between 2001 and 2003 four other rose farms joined the industry following the success of Golden Rose.

The early entrants had faced various uncertainties and incurred substantial searching costs. The first source of uncertainty was the choice of appropriate technology. Despite Ethiopia's comparative advantage lying in the production of large budded highland rose varieties, the two early entrants started production in lowlands which is only suitable for small budded roses and summer flowers. It was Golden Rose that pioneered the production of highland roses in modern steel structure greenhouses in 1999. The early entrants had also encountered marketing problems. All had started exporting through the Dutch auction but later on at least two of them forced to change their route through direct sales in Germany as a result of low price and unexpected service charges at the Dutch auction. Shortage of skilled personnel was also another acute problem, whereby the firms opted for recruiting expatriates and initiating on the job training.

\subsubsection{LATELY AWARE BUT 'PRO-ACTIVE' GOVERNMENT}

Besides technology and marketing knowledge the early entrants had also other challenges such as transport, land, and finance. In order to seek support from the government the few existing entrepreneurs (only five) at the time organized themselves and formed an association called Ethiopian Horticulture Producers and Exporters Association (EHPEA). ${ }^{3}$ The government was not aware of the potential of the flower industry in Ethiopia until the end of 2002 when it was approached by private entrepreneurs. Upon realization of the big opportunity the government decided to actively support the sector development not only as a facilitator but also assuming its coordination role. The government prepared a five-year action plan for the sector development with the participation of representatives from the association.

Accordingly, targets were set up to put 1,000 hectares under flower production by the end of five years (2003-8). To scale-up from the low base (covering no more than thirty hectares in 2002), government came in with a

3 The association now consists of about eighty-five members. 
multifaceted support focusing on: access to land, access to long-term credit, infrastructure, and air transport coordination. Starting from 2003, land held by the government was made available at a very cheap price within the vicinity of the airport in Addis Ababa, leading to the creation of flower enterprise clusters. Long-term credit was also made available through the state bank (Development Bank of Ethiopia) on very generous terms. Lending was undertaken against a project plan with no collateral requirements. The government has also played an important role to solve the transport problem by initiating close cooperation between the exporters and the state-owned Ethiopian Airlines. In an effort to support the booming flower industry Ethiopian Airlines purchased extra cargo planes as well as relocating its flight destinations.

\subsubsection{FDI AS A CATALYST IN THE SECTOR DEVELOPMENT}

The government's announcement of its engagement with the flower industry sent a positive signal on the prospect of the flower industry. As a result the sector witnessed speedy flow of domestic and foreign investors leading to the industry takes-off beginning 2004. Since then the foreign-owned firms started to dominate the flower industry (see Table 10.1), a significant number of them coming from neighbouring countries including Kenya, Uganda, and Zimbabwe. The large flow of foreign investors had helped not only scaling up the industry but also in the diversification of activities into summer flowers and production of cuttings as well as other types of roses.

\subsubsection{MANAGING THE POLITICAL CAPTURE AND COORDINATION}

How did the government organize itself and manage the rents it provided to the private sector in the flower industry? What were the monitoring mechanisms of performance and sanctions instituted in case of failing to meet expectations? The remaining part of this section provides some highlights on this focusing on the SBR.

The relation between the government and the private sector was exemplary from the commencement. Meles Zenawi, the late prime minister, was personally involved in the promotion of the flower sector, holding regular meetings with investors to get up-to-date information and seeking immediate solutions to the business constraints faced. See Box 10.1 for further elaboration on the involvement of Meles Zenawi. The minister of Ministry of Trade and Industry (MOTI) was also personally involved making regular visits to the farms to get first-hand information. The Horticulture Development team that was formed within the MOTI around 2002 as a window of interaction with the private sector was upgraded to agency in 2008 and named the Ethiopian Horticulture Development Agency (EHDA). The agency was set up to act as a one-stop shop 


\section{Box 10.1. MELES ZENAWI'S PERSONAL PROMOTION OF THE ETHIOPIAN FLOWER INDUSTRY}

The late prime minister, Meles Zenawi, came to know about the flower companies in Ethiopia through the meeting he used to hold with exporters on a regular basis. In 1997, the flower exporters were invited to join the trade delegation to Dubai, which was led by the prime minister himself. Meles talked with every individual in the trade delegation, including those from the flower sector.

In 1998, the flower producers invited the prime minister to visit the flower farms. Unable to personally visit due to the Ethio-Eritrea War, he assembled a delegation of thirteen senior officials led by the chief economic advisor, who held the rank of deputy prime minister. The team was impressed by the prospect of the flower industry and pledged to address all the nine questions the flower exporters raised, including land, credit, agro-chemical inputs, and transport. The government then took necessary measures.

In 1999, Meles encouraged the flower companies to form an association to help them organize and handle the demand. In 2001, Meles met with the Minister of UK Development Cooperation and was briefed about the success of the flower industry in Kenya, and Ethiopia's potential in this regard. Subsequently, they both agreed to start promoting the flower industry in Ethiopia. The UK's Department for International Development (DFID) pledged to support this initiative, and a senior advisor to MOTI was tasked to coordinate these efforts.

Meles continued to show personal interest and used to open his office to the flower producers. The Ethio-Horti Share Company that handles inputs imports and forwarding of exports was established on Meles' recommendation-as a way to coordinate flower transport with the Ethiopian airlines.

About six months before his death (i.e., 2012) Meles discussed the lack of progress in entering the Russian flower market with the association members. In an effort to push the issue further, he promised to talk with Putin at the following G8 meeting. Accordingly, both leaders agreed to organize Ethiopian flower week in Moscow in September 2012. Mr Hailemariam Desalegn (the deputy prime minister and foreign minister at the time) was tasked to lead the Ethiopia delegation, while Ethiopian Airlines was to cover the transport cost. Unfortunately, Meles died in August 2012 and the deputy prime minister was not able to attend the workshop.

Source: Author's interview with flower association leaders.

for services required by investors including capacity building, investment support, and market promotion.

The industry association, EHPEA, was the conduit for the successful collaboration between the private sector and the state in the sector building. The potential of the flower industry was revealed by the private sector lobbying process and not by individual firms but through association. The association was self-organized and focused on its activities. More importantly, the association was not merely involved in extracting rents from the government but also active in mobilizing its members and other stakeholders to resolve the coordination problems. It acted as a developmental partner involved in a 
range of activities aiming to promote the sector. For example, in 2004 the association established a subsidiary named Ethio-Horti Share Company, which handles both input supply and export handling and forwarding services. In 2006, responding to the mounting pressure for standards compliance the association in collaboration of other actors initiated the national scheme of good agricultural practice (GAP) known as EHPEA Code of Practice for Sustainable Flower Production which is in alignment of international standards. To implement the GAP it provided a series of training programmes to its members towards certification.

The association has also developed a very strong connection with the international community which enabled to mobilize additional resources. It is also engaged in market diversification efforts through visits to potential market countries and invitation of potential buyers. It continues to organize international trade fairs in Addis Ababa on a two-year basis attracting hundreds of floriculture companies from abroad. These all give evidence that the emergence of the self-organized industry association was instrumental in managing the rents created to the sector.

The relationship between the government and the private sector was not only rosy. Some tensions have appeared which are worth stressing here to in the context of the rent management practice in the sector development. One such issue was the repatriation of foreign exchange of flower exports. As a reaction to the under reporting of export sales by many exporters the National Bank issued a directive in 2006 to monitor the export of flowers, foreign exchange repatriation, and trading prices.

The second tension arises in relation to bank loans. As shown in Section 10.4.2.2, the government, through the Development Bank, was the main source of long-term investment loan for the sector. Due to mismanagement or misconduct, some firms were not able to profitably run their flower business and put the Development Bank of Ethiopia (DBE) under dilemma whether to foreclose or reschedule the loan. The financial crisis in 2008-9 had aggravated the problem of servicing debt of many exporters and led to an industry level request of debt rescheduling. According to officials at the EHDA, thirty-nine out of the forty-two investors who had borrowed from DBE tabled such a request. Based on the request of the National Export Promotion Committee, a team comprised of staff members from different government agencies, was established to evaluate each farm individually and produce recommendations with the aim of preventing foreclosure. Based on the recommendations of the team DBE implemented a number of measures including rescheduling of loan repayments, additional credit for some farms and even direct management intervention in the most heavily affected farms. These measures have not only saved the sector from collapse but also the bank itself. 
Another emerging area of rent management concerns profit tax. Investors in this sector have been granted up to five year profit tax holiday. This privilege has, however, started to expire for most of the firms as the time passes. We have learned from the EHDA officials that some firms have already requested for an extension of the years of tax holiday on different grounds. This shows that tax have become an area of rent management. Profit tax is practically handled by the revenue authority. Yet we have no sufficient information whether these requests are genuine and on the response of the authorities.

Land provision has been one component of the incentive packages for investment in the flower sector. The government through the regional governments has made available thousands of hectares of land at a very cheap price primarily in the vicinity of Addis Ababa for interested investors. But not all investors have actually developed the land they acquired. We learned that the government is in the mood to reclaim the land from investors that are not able to develop for an extended period of time following its repeated calls to the private sector to rectify that.

\subsection{The Basic Metal and Engineering Industry}

\subsubsection{The Five-Year Metal and Engineering Industry Development Plan and Actions}

The focus of the industry promotion of the incumbent government in Ethiopia has been the export sectors. However, beginning 2006 the authorities entertained the idea of adding some import-substituting sectors in to the priority list as a reaction to the growing import dependence of the country. Consequently, the five-year GTP covering the period 2009/10 to 2014/15 identified the basic metal and engineering industry (hereafter, BMEI) as primary industries for import-substitution based industrial development. The BMEI was then declared to be included in the list of priority industries for promotion. ${ }^{4}$

In 2010, the BMEI sector strategy was designed with the objective and targets taken from the five-year GTP. The objective of the BMEI development strategy is not only to substitute the BMEI imports but also to strengthen other sectors including the export industries by developing local capacity of design and manufacturing and facilitating technology transfer. Accordingly, targets were set for the sector to be achieved by the end of the GTP period (2014/15). ${ }^{5}$

\footnotetext{
4 The chemical industry was also similarly declared among the priority sectors for importsubstitution-based industrial development.

${ }^{5}$ See Gebreeyesus (2014) for the detailed targets.
} 
The government has taken various measures to implement the sector strategy and meet the targets. First, similar to the other priority sectors, the BMEI has been granted economic incentives such as provision of land at a reasonable price, generous credit schemes (for example, 70:30 credit/equity), free duty on imported investment capital goods and raw materials, and up to five years' tax holidays on profits.

Second, the responsible government entity coordinating the sector development was upgraded to institute level. Accordingly, the Metal Industry Development Institute (MIDI) was established in 2010 under the Ministry of Industry by ministries regulation number 182/2010 (Council of Ministers Regulation 2010) to lead the development of the sector.

MIDI has been actively engaged in the support of the sector development since its inception. It has produced a number of potential project profiles to attract domestic and foreign investment and provides continuous support to ongoing projects. It also supports the private sector capacity development such as investment capability (e.g., project development and acquisition of capital) and monitoring performance including quality and productivity improvement through the introduction of Kaizen. Towards this it has created a database for fifty-two medium and large (M\&L) firms and eight ongoing projects, and allocated one engineer for fifteen companies to provide support and monitor performance of the private sector.

The Institute has also established close relation with the private sector through the industry association. It provides office for the association free of rent in its premises and also holds monthly meetings of the joint committee of the industry association and MIDI often identify the challenges and discuss on solutions. MIDI also facilitates dialogues between the private sector and the responsible government organs such as banks, revenue and customs authorities, and regional administrations in an effort of smooth implementation of the incentive schemes provided to the sector.

Third, in addition to the efforts to strengthen the private sector the government has also sought state direct investment to play a catalytic role in the sector development. Accordingly, in 2010 the government reorganized fifteen state-owned enterprises operating in the metal and engineering sector, most of which were part of the Defence Industry aimed to satisfy the military needs, and form a large corporation, namely the Metal and Engineering Corporation (METEC). The objective of the corporation is to help realize the GTP by accelerating technological transfer and capacity in the sector.

\subsubsection{The Structure and Performance of BMEI in Ethiopia}

In this part we examine the structure and performance of the BMEI in relation to other industries and against the targets set in the five-year development 
Table 10.2. The structure of Ethiopia's BMEl, 2012-13

\begin{tabular}{|c|c|c|c|c|}
\hline & $\begin{array}{l}\text { Number } \\
\text { of Firms }\end{array}$ & $\begin{array}{l}\text { Share } \\
(\%)\end{array}$ & $\begin{array}{l}\text { Gross Production } \\
\text { Value (Billion } \\
\text { Birr) }\end{array}$ & $\begin{array}{l}\text { Share } \\
(\%)\end{array}$ \\
\hline Manufacture of basic iron and steel & 38 & 15.6 & 3.70 & 18.8 \\
\hline Manufacture of fabricated metal products & 182 & 74.9 & 10.37 & 52.6 \\
\hline $\begin{array}{l}\text { Manufacture of machinery and equipment (not } \\
\text { elsewhere classified) }\end{array}$ & 12 & 4.9 & 0.18 & 0.9 \\
\hline $\begin{array}{l}\text { Manufacture of motor vehicles, trailers, and } \\
\text { semi-trailers }\end{array}$ & 11 & 4.5 & 5.46 & 27.7 \\
\hline Total BMEI & 243 & 100 & 19.72 & 100 \\
\hline
\end{tabular}

Source: Author's calculations based on CSA survey report (2012/13).

plan. Table 10.2 presents the current structure of the BMEI in Ethiopia based on recent survey report of the CSA on M\&L manufacturing sector consisting firms with ten and above employees. According to the survey report, in 2012/ 13 there were $243 \mathrm{M} \& \mathrm{~L}$ firms operating in the BMEI producing in sum about Birr 19.7 billion value of production. This is below 10 per cent of the total number of firms and 18 per cent of the value of production of the whole manufacturing sector.

The BMEI is customarily classified into two broad categories the basic metal and the engineering sub-sectors. The engineering sub-sector is larger in size but dominated by the manufacture of fabricated metal producing hand tools, spare parts, and cutleries, which are characterized by low technology activity. The manufacture of fabricated metal alone account respectively for 75 per cent and 53 per cent of total BMEI number of firms and gross value of production. The engineering industry also consists of about eleven vehicle assembly plants and twelve machinery and equipment manufacture plants, both of which are characterized by low value added activity.

The manufacture of basic metal industry in Ethiopia is small in size accounting for only 15.6 per cent and 18.8 per cent of the BMEI's total number of firms and production, respectively. It is concentrated in producing basic construction materials such as reinforced bars, hollow sections and corrugated sheets as well as billets. Moreover, this sub-sector is heavily dependent on imported raw materials and locally available scraps rather than domestic iron making.

Next we assess the performance of the BMEI sector against the targets set under GTP. Table 10.3 gives performance of the sector against the targets for the first four years of GTP-period (2010/11 to 2013/14). The figures are taken from MIDI recent reports, which in turn are based on information from CSA for the domestic production and ERCA for imports. The domestic production covers only the production of M\&L manufacturing firms with ten and above employment size. Based on the M\&L sector statistics we can show that the 
Table 10.3. Performance of the BMEl against the target set under GTP

\begin{tabular}{|c|c|c|c|c|c|c|c|c|c|}
\hline & \multicolumn{3}{|c|}{ Domestic Production } & \multicolumn{3}{|c|}{ Capacity Utilization } & \multicolumn{3}{|c|}{ Per Capita Consumption in $\mathrm{Kg}$} \\
\hline & $\begin{array}{l}\text { Target } \\
\text { (billion Birr) }\end{array}$ & $\begin{array}{l}\text { Actual } \\
\text { (billion Birr) }\end{array}$ & $\begin{array}{l}\text { Achievement against } \\
\text { target (\%) }\end{array}$ & $\begin{array}{l}\text { Target } \\
(\%)\end{array}$ & $\begin{array}{l}\text { Actual } \\
(\%)\end{array}$ & $\begin{array}{l}\text { Achievement against } \\
\text { target (\%) }\end{array}$ & $\begin{array}{l}\text { Target } \\
(\%)\end{array}$ & $\begin{array}{l}\text { Actual } \\
(\%)\end{array}$ & $\begin{array}{l}\text { Achievement against } \\
\text { target (\%) }\end{array}$ \\
\hline 2010/11 & 20 & 6.65 & 33.3 & 75 & 53 & 70 & 14.23 & 9.73 & 68.4 \\
\hline 2011/12 & 26 & 12.0 & 46.2 & 80 & 61 & 76 & 17.78 & 14.6 & 82.1 \\
\hline $2012 / 13$ & 33.8 & 19.02 & 56.3 & 85 & 62 & 73 & 22.23 & 17.75 & 79.9 \\
\hline $2013 / 14^{*}$ & 50.7 & 30.14 & 59.45 & 90 & 54 & 60 & 27.75 & 20.36 & 73.4 \\
\hline 2014/15 & 101.4 & & & 95 & & & 34.75 & & \\
\hline
\end{tabular}

*Note: The performance of $2013 / 14$ is based on assessment of MIDI in its communication with the private sector.

Source: Author's calculation based on MIDI (2014) internal report. 
domestic production of BMEI products grew more than four times in the first four years of the GTP period. This achievement is, however, only 59 per cent when compared with the target set. The capacity utilization also shows very weak performance. Despite the targets to reach above 90 per cent, the BMEI average capacity utilization remained below 62 per cent of the installed capacity over the period under consideration.

According to the MIDI report annual per capita metal consumption of the country has doubled in the first four years registering better performance (73.4 per cent) even against the target. The rise in demand for metal and engineering products is driven by the fast economic growth in the country and particularly booming construction sector. Unfortunately, this demand is still largely satisfied by the growing imports. For example, in 2013 (the recent available data) the total demand for metal and engineering products was about 116.3 billion Birr, out of which 83 per cent were met by imports. ${ }^{6}$ The imports share in this sector shows no sign of decline in the last fifteen years, suggesting failure in terms of imports substitution.

\subsubsection{Main Challenges Facing the Ethiopian BMEI}

\subsubsection{PERCEPTIONS OF THE STAKEHOLDERS}

There exists some common understanding among the stakeholders (the government and private sector) on the BMEI underperformance. For example, a study committee was established constituting experts from different government organs such as the parliament, Ministry of Industry, and MIDI in an effort to understand and resolve the challenges facing the sector. The study report which was placed for discussion among the stakeholders on the 1 March 2014 identified a number of bottlenecks deterring the sector development some of which are listed:

- Unfavourable tariff/tax structure: the existing tariff/tax structure encourages imports rather than domestic production and does not identify low and high value-added activities.

- Lack of market and unfavourable government procurement system: the government is the main buyer of BMEI products but most government organizations prefer imports and have less interest in domestic products. And at the same time the government procurement system favours bulk purchases, which can only be met by imports.

- Shortage of finance: the financial system favours importers over producers as well as short-term over long-term loans.

- Poor-quality infrastructure: This includes frequent power cuts, low-quality telecom services, and shortage of land.

\footnotetext{
${ }^{6}$ See figure 2 in Gebreeyesus (2014).
} 


\subsubsection{ABSENCE OF DISTINCT INSTRUMENTS}

The author's recent discussions with the association and MIDI representatives confirmed that there is a shared view among the private sector and government regarding the challenges identified, most of which imply the absence of sufficient protection of the selected industries from imports. As shown in Section 10.3, the industries selected for import substituting including the BMEI and the chemical industries were granted the same package of incentives that have been given to the export sectors such as credit, land, free duty on imported capital and inputs, and tax holidays. The programmes that aim to enhance the capacity of the private sector have also equally applied in the export-oriented as well as the import-substituting selected industries. As far as our review, there was no revision of the tariff structure of competing imported products in favour of the domestic metal and other ISIs following the decision to promote them. The package of incentives that works for the export industry might be irrelevant or less sufficient for the promotion of ISIs. In sum, the promotion of the ISI needs to have distinct instruments particularly designed to address the bottlenecks facing the sectors and trade policy is one of them.

\subsubsection{CHOICE OF THE SECTOR AND THE ABSENCE OF CHAMPION PRODUCTS}

Even if the development of the import-substitution industries requires some form of protection, in the present globalized world it is difficult to completely shield the industry from foreign competition. It is, therefore, crucial to identify the sectors whereby the country has some comparative advantage to kickoff the industrialization whether through the promotion of export-oriented or import-subtitling industries. In theory, there is no inherent conflict between the export-oriented industrialization (EOI) and ISI strategies. In fact the development strategies in the successful Asian countries (e.g., South Korea, Taiwan, and China) have always been a combination of ISI and EOI strategies. The most important issue is then in which sectors do you start the promotion. Taiwan and South Korea start implementing not only the EOI but also the ISI strategy with consumer goods such as textile, food, and other labour-intensive industries. In both countries, the heavy and chemical industry drive for import substitution only came lately in the 1970s following the success in the labour-intensive industries through EOI as well as ISI strategies.

Unfortunately, despite the comparative advantage of the country lies on labour-intensive industries, the sectors that have been selected to kick-off the ISI-based promotion in Ethiopia, the basic metal and engineering and chemical industries, are by nature capital- and technology-intensive sectors. The ISI strategy lacks the analysis of existing and future comparative (dis)advantage rather it relies on the need to tackle the growing import dependence and the possible role of BMEI and the chemical industries in import-substitution. 
The absence of careful analysis of opportunities and gaps has also resulted in the identification of a sector that is too broad to make effective action plans as a single industry. The BMEI is a highly diversified sector constituting resourceintensive industries (e.g., metal making), technology intensive industries (e.g., office, accounting and computing machinery, radio, TV and communication materials, machinery and equipment, vehicles and transport equipment), and low-tech or labour-intensive activities (e.g., fabricated metal, consumer electronics). As a result, no champion product has emerged yet in this process.

\subsubsection{WEAK AND LESS-MOTIVATED PRIVATE SECTOR}

In subsection 10.5.1 we have shown the government's extensive efforts to promote the BMEI and engage the private sector in the development course. However, there lies some weaknesses in the organization and motivation of the private sector. First, the industry association was formed by the recommendation of the government in a consultation assembly held in April 2007. Four months later (i.e., September 2007) the association was established with ten members and named as the Ethiopian Association of Basic Metal and Engineering Industries (EABMEI). Immediately, the EABMEI has successfully gained affiliation with MOTI. In the beginning the private sector was largely reluctant. Thus, the association continued to have few members, for example no more than thirty-two members until 2010. In recent years, the number has grown relatively faster and currently reached about eighty following the realization of some benefits from the close consultation with the government through their association. But still this number is only about half the number of operating companies suggesting the continued lack of interest among many.

A second weakness is that the organization of the association is too broad amalgamating various industries, which might be one cause of the lack of interest in the association. This is also a reflection of the fact that the initiative of forming private associations was driven from the government side. This is not consistent with the emerging literature that suggests that associations need to be organized at sub-sector level to address specific industry constraints and motivate members (for example, Hausmann and Rodrik 2006).

Third, the activities of the association have been limited to facilitating government and private sector consultations and particularly lobbying the government for the provision of improved services and other supports. So far, it has made very limited efforts to mobilize the private sector itself and other stakeholders (except the government) in the sector building. The contributions for members of the association are very small (about US\$150 per annum) and unable to undertake extra activities. The association needs to be a developmental partner in the sense that it is not only a forum of government lobbying but also discharges its own fare share. 


\subsection{Lessons to be Learned}

The aim of this chapter was to provide some insights from the success and failure cases of present industrial policy experiment in Ethiopia. We selected two sectors, the floriculture and the metal and engineering industry which are considered to represent respectively the success and failure cases. The two sectors are different in the context that the former is export oriented while the latter is importsubstituting. Moreover, unlikely to the floriculture the BMEI industry promotion has started relatively lately, thus, it might be too early to evaluate the full outcome in this sector. One can, however, draw some useful lessons from the undergoing experiments, which is what we have tried to do in this study. The main lessons to be learned from the case studies can be summarized as follows.

First, the selection of a potential industry for promotion has long been a source of controversy in industrial policy debate. The analysis of comparative advantage (actual or latent) can be an instant aid in this regard. Our case study shows that Ethiopia has a clear comparative advantage of high-value cut flower production over other competitors. This opportunity was identified by the private entrepreneurs through their costly experimentation. In contrast, the import-substituting strategy declares the capital- and technologyintensive sectors such as the BMEI as a priority despite the country's advantage lies over labour-intensive industries such as textile, leather, or food. The import-substituting experience of successful Asian countries, however, suggest otherwise. The heavy and chemical industries were promoted at a later stage following the success in the labour-intensive industries through EOI as well as ISI strategies. The current performance of the BMEI as well as the experience elsewhere leads to the question that whether the selection of BMEI (but not other labour-intensive industries) for import substitution in Ethiopia at this early stage of development was proper.

Second, the emerging literature shows that a sector promotion had to focus on a specific activity with clear analysis of opportunities and challenges. The two sectors are very different in this regard which might have an impact on their relative success. The floriculture is a specific activity, while the BMEI which consists of highly diversified industries was broadly defined to make any effective industry action plan. The implication is that the future development plan of the BMEI sector ought to be based on a specific activity level.

Third, the specific activity-level promotion has also great implications to the choice of policy instruments and the nature of the engagement with the private sector. The successful discovery of the flower industry in Ethiopia was a result of private entrepreneurs' experimentation. These enlightened entrepreneurs demonstrated that Ethiopia has great potential for the flower industry. In their effort to seek support they organized themselves and convinced the government to take this opportunity seriously. A warm relationship 
was established between the private sector and the state since then. This relationship not only enabled the government to pick the floriculture as a priority sector but also facilitated the design of appropriate policy instruments addressing emerging bottlenecks. Identifying the binding bottlenecks and designing appropriate policy tools requires careful understanding of the dynamics of the system at local and global levels. This was not possible without the emergence of a vibrant industry association, the EHPEA, which facilitated among others sharing emerging concerns, disseminating the available knowledge and consensus building among relevant stakeholders. This is consistent with the view (Rodrik 2007) that a strategic collaboration between the private sector and the government is needed to uncover where the most significant obstacles to restructuring lie and what type of interventions are more likely to remove them.

Unlike the floriculture, the establishment of the private sector association in the BMEI was initiated by the government on a predetermined criterion. As a result, the EABMEI consists of diversified sectors that have few specific needs in common and the less motivated private sector. The association activities mainly focus in lobbying the government support but lack any significant initiative to mobilize private sector and other stakeholders towards the sector development. The presence of diverse sectors under this organization might have also hindered the design of appropriate instruments addressing sectorspecific binding constraints. More importantly, there is a lack of distinct instruments addressing the special needs of the ISIs such as the BMEI, rather the authorities apply a more or less similar set of incentives and support programmes designed for the export sectors.

Lastly, the analysis shows that the management of rents that are provided to the private sector was crucial in the success of the flower industry. The SBR in this sector was exemplary but not necessarily always smooth. Over the course we have seen some sources of tensions between the public and private sector, for example, repatriation of foreign exchange, debt rescheduling and termination of tax holidays. The responsible government institutions have learned from their experiences. They began to strengthen their internal capacity and have developed a mechanism to monitor the performance and properly manage the rents. In contrast, no clear pattern has emerged yet in the BMEI sector in this regard.

\section{References}

Cimoli, M., G. Dosi, and J. Stiglitz (2010). Industrial Policy and Development: Political Economy of Capabilities, Accumulation. Oxford and New York: Oxford University Press. Council of Ministers Regulation (2010). 'Establishment of the Metals Industry Development Institute', Regulation Number 182/2010, Federal Democratic Republic of Ethiopia, Addis Ababa. 
CSA (Central Statistics Agency) (2012/13). 'Report on Small Scale Manufacturing Industries Survey'. Addis Ababa: CSA.

Evans, P. (1995). Embedded Autonomy: States and Industrial Transformation. Princeton, NJ: Princeton University Press.

Gebreeyesus, M. (2013). Industrial Policy and Development in Ethiopia: Evolution and Present Experimentation, WIDER Working Paper 2013/125. Helsinki: UNU-WIDER.

Gebreeyesus, M. (2014). A Natural Experiment of Industrial Policy: Floriculture and the Metal and Engineering Industries in Ethiopia, WIDER Working Paper 2014/163. Helsinki: UNU-WIDER.

Hausmann, R., and D. Rodrik (2003). 'Economic Development as Self-Discovery'. Journal of Development Economics, 72: 603-33.

Hausmann, R., and D. Rodrik (2006). Doomed to Choose: Industrial Policy as Predicament. Cambridge, MA: Harvard University Press.

Khan, M. (2008). 'Governance and Development: The Perspective of GrowthEnhancing Governance'. In GRIPS Development Forum (ed.), Diversity and Complementarity in Development Aid: East Asian Lessons for African Growth. Tokyo: National Graduate Institute for Policy Studies.

Khan, M., and S. Blankenburg (2009). 'The Political Economy of Industrial Policy in Asia and Latin America'. In M. Cimoli, G. Dosi, and J. E. Stiglitz (eds), Industrial Policy and Development: The Political Economy of Capabilities Accumulation. Oxford: Oxford University Press.

Krueger, A. O. (1974). 'The Political Economy of the Rent-Seeking Society'. American Economic Review, 64: 291-303.

Lin, J. Y., and H. Chang (2009). 'DPR Debate: Should Industrial Policy in Developing Countries Conform to Comparative Advantage or Defy It?' Development Policy Review, 27(5): 483-502.

MIDI (Metal Industry Development Institute) (2014) 'Metal and Engineering Industry Plan for the Second Growth and Transformation Plan Period (2015-20)', draft mimeo.

Pack, H., and S. Saggi (2006). 'Is there a Case for Industrial Policy? A Critical Survey'. World Bank Research Observer, 21(2): 267-97.

Rodrik, D. (2007). 'Industrial Policy for the Twenty-First Century'. In D. Rodrik (ed.), One Economics-Many Recipes: Globalization, Institutions and Economic Growth. Princeton, NJ: Princeton University Press.

Rodrik, D. (2013). 'Unconditional Convergence in Manufacturing'. Quarterly Journal of Economics, 128(1): 165-204.

Schmitz, H., O. Johnson, and T. Altenburg (2013). Rent Management: The Heart of Green Industrial Policy, IDS Working Paper, 418. Brighton: Institute of Development Studies. Tullock, G. (2005). The Rent Seeking Society. Indianapolis, IN: Liberty Fund.

UNECA and AU (United Nations Economic Commission for Africa and African Union) (2013). 'Industrialization for an Emerging Africa'. Paper presented at 6th Joint Annual Meetings of the ECA and AU Conference of African Ministers of Finance, Planning and Economic Development, Abidjan, Côte d'Ivoire 25-26 March. Available at: <http://www.uneca.org/sites/default/files/uploaded-documents/ $\mathrm{CoM} / \mathrm{cfm} 2013 /$ industrialization-for-an-emerging-africa-issuespaper.pdf $>$ (accessed 16 September 2016). 


\section{1}

\section{Policy Coordination and Growth Traps in a Middle-Income Country Setting}

\section{The Case of South Africa}

Haroon Bhorat, Aalia Cassim, and Alan Hirsch

\subsection{Background}

On a number of indicators and measures, South Africa's post-apartheid performance has been both a significant improvement on the past, as well as representing a noticeable Pareto improvement in the welfare of its citizens. The economy witnessed the longest period of positive uninterrupted growth in real gross domestic product (GDP) since the 1960s. Welfare gains are apparent in access to social services, housing and infrastructure services, and in a significant reduction to extreme poverty.

Compared with many of its emerging market peers however, economic growth has been pedestrian. In terms of poverty, inequality, and unemployment the numbers are not encouraging. Using the national poverty line of US $\$ 43$ per month (in current prices), 47 per cent of South Africans remain poor. In 1994, this figure was 45.6 per cent. More jarring, South Africa's unemployment rate is an eye-watering 25 per cent, whilst the Gini coefficient at 0.69 renders the country one of the most unequal in the world (Bhorat and Tseng 2014).

Industrial policy was on the agenda of the African National Congress (the ruling party after 1994) and its allies before and during the transition to democracy, through the well-conceived Industrial Strategy Project for example (Joffe et al. 1995). However, the successful implementation of industrial policy is the exception rather than the rule in democratic South Africa. Apartheid South Africa built several industries, such as steel, automotive 
assembly, and petrochemicals, through decisive interventions, and left the legacy of a well-endowed Industrial Development Corporation-a targeted development bank. Several factors have undermined the effectiveness of contemporary industrial policy initiatives; including poor coordination within government, and fractious relationships between government and the key social partners, business, and labour.

Persistently high levels of inequality are due, in part, to a number of policy coordination failures that have entrenched the deeply unequal structures of the pre-democracy era. Low levels of diversification in productive sectors, inadequate human capital accumulation, and inefficient state-run utilities have not promoted inclusive economic growth. In addition, an unintended consequence of the development of the South African economy has been to facilitate rent-seeking between key players in the economy. The structure of the economy has led to the outcomes observed today. This chapter examines South Africa's economic trajectory and key policy decisions that have facilitated the country's low growth trap.

\subsection{South African Economic Overview}

The South African economy grew at 3.2 per cent a year on average from 1994 to 2012. Potential growth is currently thought to be around 3.5 per cent, though it was estimated at around 4.5 per cent during the four-year period from 2004 to 2007, when growth averaged around 5.5 per cent. Economic growth however, has mainly been driven by domestic demand and financed through a persistent current account deficit. The current account balance was close to zero around 2003 but has subsequently increased, and regularly hovered at around 6 per cent of GDP.

\subsubsection{The Structure of the Economy and Employment Growth}

In post-apartheid South Africa, economic growth has been uneven: in contrast to the relatively dynamic sectors, ${ }^{1}$ such as financial services, transport, and communication, which grew annually at around 5 per cent between 2001 and 2012, sectors such as agriculture and manufacturing tended to grow slowly at around 2 per cent annually in the same period. In real terms, agricultural gross

\footnotetext{
${ }^{1}$ In this chapter, shortened names are used; the sectors' full names are as follows: Agriculture, Hunting, Forestry and Fishing; Mining and Quarrying; Manufacturing; Electricity, Gas and Water Supply; Construction; Wholesale and Retail Trade; Transport, Storage and Communication; Financial Intermediation, Insurance, Real Estate and Business Services; Community, Social and Personal Services; and Private Households, Exterritorial Organizations, Representatives of Foreign Governments and other Activities not adequately defined.
} 
value added rose by 1.4 per cent a year from 1994 to 2012, manufacturing by 2.7 per, and general government services by 1.9 per cent a year. As a result, the financial sector's contribution to GDP was 5 percentage points higher than manufacturing in 2012. Furthermore, whilst primary sectors and manufacturing saw a decline in their GDP contribution in 2012, trade and transport were amongst the sectors that increased their share compared to $1994 .^{2}$

Figure 11.1 explores the interaction between GDP and employment growth by sector between 2001 and 2012. Each of the bubbles represents a sector, while the size of the bubbles indicates the relative size of employment in that sector in the base year: 2001. The coordinates for the centre of each bubble are the relevant sector's employment and gross value-added growth for the period. The 45-degree line divides the figure into two sections: bubbles below the line show sectors in which employment growth was lower than gross value-added growth, while those above the line show sectors in which employment growth exceeded output growth.

Figure 11.1 shows that primary sectors faired particularly badly in the period: output growth was negative for mining ( -0.3 per cent) and lowest among positive growth sectors for agriculture (2.2 per cent). Furthermore, these are the only two sectors that experienced a contraction in employment in the period, with employment growth in agriculture and mining falling by 5.1 per cent and 4.1 per cent, respectively. The discrepancy between output and employment was the highest in the two primary sectors.

The tertiary sectors achieved relatively high output growth. Specifically, gross value-added growth for the finance and community services sectors stood at 5.4 and 3.1 per cent for the period, while employment growth was 5.3 and 3.0 per cent, respectively. These two tertiary sectors thus experienced labour-neutral growth, while all other sectors saw output growth that was faster than employment growth.

Among the secondary sectors, output growth in construction was high at 7.2 per cent, but employment growth in this sector was much lower, at 4.7 per cent. The construction boom can be attributed to, among other factors, infrastructure projects related to the 2010 FIFA World Cup, construction of the Gautrain rapid-rail system, and several other public and private sector investment initiatives including those undertaken by Eskom and Transnet (Hanival and Maia 2008). In contrast, neither the manufacturing nor utilities sectors saw a significant increase in employment over the period.

Post-apartheid South Africa has delivered an economy characterized by an eroding primary sector and an un-dynamic and un-diverse manufacturing sector. Yet the modest growth levels since 1994 have been marked by a rise

\footnotetext{
2 See figure 1 in Bhorat, Cassim, and Hirsch (2014), available at: <http://www.wider.unu.edu/ publications/working-papers/2014/en_GB/wp2014-155/> (accessed January 2015).
} 


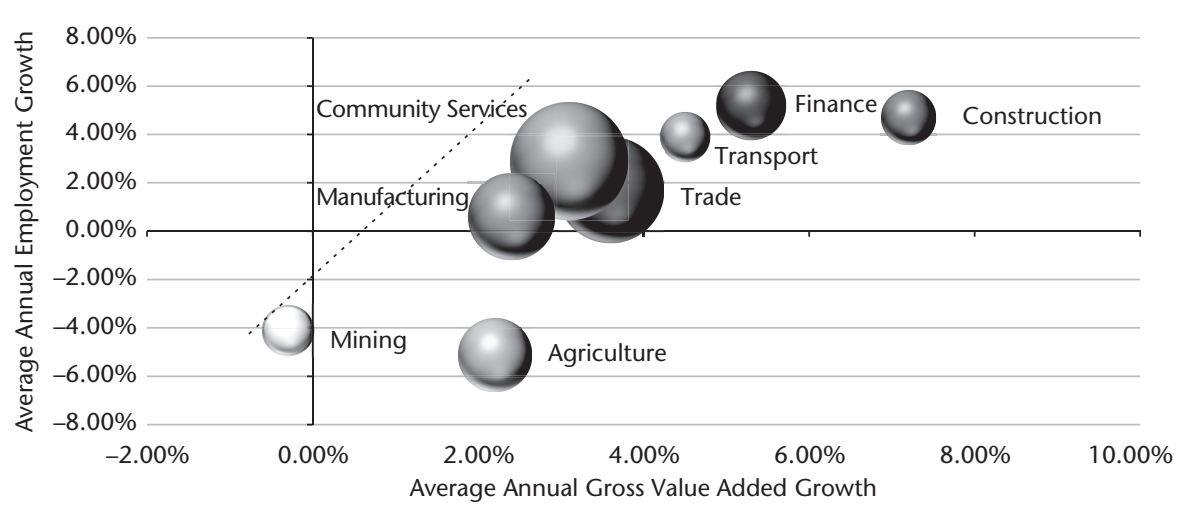

Figure 11.1. Gross value added and employment growth, by sector, 2001-12

Source: South African Reserve Bank (2014) and StatsSA (LFS 2001 and QLFS 2012), authors' calculations.

in financial and business services, and wholesale and retail trade. In short, this post-apartheid growth path has been built around South Africa's sophisticated and globally competitive financial sector and its consumer-driven domestic aggregate demand. The weakness of mining, agriculture, and in particular manufacturing, endangers the longer-term ability of the South African economy to grow, generate employment, and improve living standards (Rodrik 2013). In Section 11.2.2, we assess whether the outcomes of the structure of the economy are unique to South Africa, or are a broader middle-income country experience.

\subsubsection{Middle-Income Country Growth Traps: The Case of South Africa}

Freed of the laws of apartheid for over twenty years, the new South Africa has existed in a global era dominated by fast-growing emerging markets such as China and India. These economies have regularly recorded growth rates in excess of 6 per cent over a sustained number of years. South Africa, despite its membership of the G20 and the BRICS (Brazil, Russia, India, China, and South Africa) group of economies, remains mired in a cycle of low, single-digit GDP growth. This experience can be located within a broader phenomenon first described by Gill and Kharas (2008) and Kharas and Kohli (2011), as representative of a middle-income country growth trap. ${ }^{3}$

So why, when South Africa shares so much in common with rapidly growing emerging markets, and has one of the largest and most diversified sub-

\footnotetext{
${ }^{3}$ See figure 3 in Bhorat, Cassim, and Hirsch (2014).
} 
Saharan African economies, has the country failed to converge (Bhorat and Hirsch 2014)?

\subsubsection{The Anatomy of a Growth Trap: A Cross-Country Comparison}

Historically, a common trend for middle-income countries is that, as imported technology is employed, labour is switched from low productivity to high productivity sectors, increasing growth gains resulting in a rise in per capita GDP. The technologies are usually employed in labour-intensive sectors, absorbing the pool of underemployed or unemployed labour. Productivity growth from technological catch-up is then exhausted, wages rise, and labourintensive exports become more expensive and less competitive in international markets. At this point growth no longer occurs from shifting workers from a low productivity sector to a high productivity sector, such as from agriculture to manufacturing, and thus the gains for importing foreign technology diminish (Eichengreen, Donghyun, and Kwanho 2011; World Bank 2011; Agénor, Canuto, and Jelenic 2012). Higher levels of growth then require exploitation of economies of scale through specialization and innovation, allowing a country to move up the value chain and integrate into international trade of goods, money, and ideas (Gill and Kharas 2008).

The middle-income country 'growth trap' is often illustrated by a crosscountry comparison of GDP per capita over time. Many low income countries have moved up to middle-income country status by exploiting low labour costs. However, at some point, surplus labour is exhausted and wages start to increase (OECD 2014). Regulation, politics, and firm structure are amongst the factors that essentially block innovations required to sustain economic growth or to develop a better-skilled labour force that can produce higher value-added products, taking labour on to a better wage (OECD 2014). China is a key example of an innovator that managed to sustain high levels of growth and productivity, and as a result GDP per capita increased by 8 per cent annually between 1990 and 2013. Whilst not as high, India and Malaysia yielded annual GDP per capita growth of 5 and 4 per cent respectively, during the same period. On the lower end, Turkey, Brazil, and the Philippines yielded around 2 per cent annual increases of GDP per capita, whilst South Africa held the lowest increase in per capita GDP with a mere 1 per cent annual increase during the period. ${ }^{4}$

South Africa, Brazil, the Philippines, and Turkey would be viewed tentatively as representing the sample of emerging markets, which, over a period of thirteen years, have been unable to significantly increase per capita growth

\footnotetext{
${ }^{4}$ See figure 4 in Bhorat, Cassim, and Hirsch (2014).
} 
rates. This may represent the underpinnings of a growth trap in these emerging economies. The lower growth path depicted for South Africa, can in part, be explained by policies of the past. The apartheid government attempted to exploit cheap labour for mining and agriculture for far longer than it actually served as a productive engine of growth. The model failed since the 1960s when the growth in agriculture and mining slowed (Levy, Hirsch, and Woolard 2014). The vast mass of the labour force was not moved to more productive sectors where they could be up-skilled. The entrenched racial politics of the time blocked the adjustment the economy needed for a better-educated and trained workforce, in the pursuit of higher growth levels.

Economic growth outside of the declining mining and agricultural sectors was insufficient to absorb the wave of new entrants into the labour market since the mid-1990s, and those who lost jobs in mining and agriculture. This resulted in unemployment rates persistently above 20 per cent. ${ }^{5}$ Structurally, the economy has grown in sectors such as the financial and services sector, demanding high skilled labour-not in primary sector employment, generally geared towards lower skilled workers. Low-skilled work seekers, however, make up the vast majority of the unemployed.

From the sample of upper middle-income countries mentioned, South Africa's unemployment rate is extraordinarily high. This is even true amongst those economies that have experienced similarly low levels of growth and investment, such as Brazil and Turkey. Unlike these countries however, South Africa's informal sector is unusually small and unable to absorb low-skilled workers, further exacerbating unemployment levels.

\subsubsection{INVESTMENT, SAVINGS, AND ECONOMIC GROWTH}

Fixed investment and savings rates in South Africa are well below those of many other emerging markets. Between 1990 and 2012, countries experiencing consistently low levels of growth such as the Philippines, Brazil, and Turkey, had levels of investment and savings similar to South Africa. On the other hand, savings and investment in China, Malaysia, India, and Indonesia have experienced average investment levels at least 1.5 times greater than South Africa. ${ }^{6}$

Low investment rates are usually a result of low real returns to investment, but evidence suggests that real returns to capital in South Africa are highly favourable (World Bank 2011). Real returns averaged around 15 per cent between the 1994 and 2008 period, whilst nominal returns were 22 per cent in the 2005-8 period-which was the same as China, albeit over a longer period. Returns have been substantially higher than the prime lending rate,

\footnotetext{
5 See figure 5 in Bhorat, Cassim, and Hirsch (2014).

${ }^{6}$ See figure 6 in Bhorat, Cassim, and Hirsch (2014).
} 
which is particularly surprising given the modest growth experienced by the South African economy. However, investment does not respond to returns in the expected way. Domestic and foreign investors in South Africa seem inelastic with respect to the return on capital, but partially elastic to other factors such as perceived political risks, structural impediments, and low national savings rates. Structural barriers include low levels of industrial competition because of concentrated industries with high barriers to entry; and volatile labour relations that are essentially a tax on investment and the scarcity of skills.

Government and public enterprise expenditure tends to be fairly low, and even in the World Cup boom period did not reach levels comparable with public investment in the boom of the 1960s and 1970s. Private investment has made up between 65 and 75 per cent of total investment, and has been facilitated through large-scale capital expenditure projects in mining, platinum, automotive, chemical manufacturing, retail, real estate, and tourism. Industries that attracted investment were invariably capital-intensive in nature, so reinforcing the economy's growth trajectory. ${ }^{7}$ Overall gross fixed investment in recent years has been very low at around 19 per cent of GDP, though it is slightly better than during a long period between the 1980s and the mid-2000s when it hovered around 15 per cent.

The low savings rate, relative to comparator countries, has meant that financing investment has necessitated a fairly large current account deficit. Financing of the deficit has largely been dependent on portfolio investment rather than foreign direct investment (FDI), the latter being the less volatile capital flow option for emerging markets.

The dependence on short- to medium-term capital inflows tends to perpetuate dependence on the resource sector, processers of resources, and powerful, publically quoted oligopolies in the services sector. The market power of these companies produces the generous margins that portfolio investors seek (Bhorat et al. 2014).

\subsubsection{IS SOUTH AFRICA COMPETING IN A GLOBAL VALUE CHAIN?}

South African export performance has been poor, even in a period of relatively high commodity prices. Exports grew by just 3.5 per cent per annum over the period 1990-2012, less than half the rate of Malaysia, which reflects not only its poor response to the commodity boom due to regulatory and infrastructure complexities and deficiencies, but also the poor degree of integration of South Africa into global value chains. ${ }^{8}$

\footnotetext{
7 See figure 7 in Bhorat, Cassim, and Hirsch (2014).

${ }^{8}$ See figure 9 in Bhorat, Cassim, and Hirsch (2014).
} 
Extensions to trade theory hold that international competitiveness is a function of micro-level innovations in technology and increasing technological sophistication (Dosi and Soete 1983). This suggests that the method of production and the basket of exported goods are critical to growth, development and international competitiveness (Gallagher, Moreno-Brid, and Porzecanski 2008).

A number of East Asian countries performed well in this respect, taking advantage of lower transport costs as well as international trade barriers (Agénor, Canuto, and Jelenic 2012). The Asian region also benefits from regional integration that had been established to a lesser extent in Latin America and Africa. China, for example, is currently one of the single largest high technology exporters in the world, with average annual growth of 7 per cent between 1993 and 2012, as well as growing exports in high skilled services. Malaysia and the Philippines have, however, seen a decline in high technology exports as China becomes more competitive. Amongst its middle-income peers, South Africa relies relatively more than others on exports of ores and metals, insurance, and financial services, but falls short in innovative or value-added exports. ${ }^{9}$

After the advent of democracy in 1994, South Africa re-entered the global economy through a rapid process of trade liberalization. While imports and exports increased relatively sharply, South Africa lagged behind its emerging market peers who had better production methods and a more diversified basket of goods. Though sanctions had encouraged domestic diversification of production in South Africa, management, skill, and technology levels were not comparable to developing country peers. In addition, liberalization led to greater import penetration than export diversification, though in the earlier years of liberalization it appeared that South African producers were able to respond to opportunities. South African competitiveness was also hampered most notably by labour market constraints and the volatile exchange rate. In addition, investment has been biased towards processing and heavy manufacturing as opposed to light manufacturing industries. As a result, the composition of exports is still made up of a large share of commodity type exports (ores and metal exports). Furthermore, manufactured exports still rely heavily on primary commodity inputs. As such, South Africa's export profile continues to be capital-intensive in nature and driven by natural resources (Bhorat et al. 2014). The only evident and significant diversification in exports other than the heavily subsidized automobile sector is through insurance and financial services ( 4 per cent average annual growth), and tourism.

\footnotetext{
${ }^{9}$ See table 2 in Bhorat, Cassim, and Hirsch (2014).
} 


\subsubsection{Human Capital Accumulation}

It is well known that human capital accumulation will raise earnings levels, both in terms of private and social returns. This suggests that educational attainment has a key role to play in reducing income inequality through improved labour market opportunities. The literature on what differentiates high growth economies from stagnating ones notes that it is often the accumulation of technical knowledge through high-quality education, thus allowing a society to assimilate foreign technology and improve levels of productivity (Nelson and Phelps 1966; Abramovitz 1986; Engelbrecht 1997; Gill and Kharas 2008).

An outcome of the apartheid government's policy was first a highly unequal schooling system, and second, a tertiary education system that was not accessible to those with poor levels of schooling. Data on school scores in 2012 suggest that firstly, in every grade and for every subject other than Grade 3 Language, pupils in the South Africa schooling are, on average, failing standardized tests (Presidency 2012). Second, a pupil's progress through the schooling system falls, as shown by declining average pass rates. ${ }^{10}$

Unsurprisingly then, when examining cross-country results for standardized mathematics and reading scores, South Africa falls below a number of African countries including Tanzania, Swaziland, Kenya, Botswana, and Zimbabwe, as well as below the global average scores, in both subjects. ${ }^{11}$

Using a standard Cobb-Douglas production function approach, we find that amongst all education cohorts (schooling, schooling with matric, vocational training, and university) a statistically significant impact on economic growth returns is only derived for the employed with university degrees (Bhorat, Cassim, and Tseng 2014). Whilst the number of enrolments into tertiary institutions has more than doubled since 1994, the proportion of graduates from the population of high school leavers varies between 15 and 17 per cent. Of those enrolled, only between 4 and 6 per cent graduated with a Science, Engineering, and Technology degree. ${ }^{12}$ Whilst Brazil had a similar proportion of engineering graduates to South Africa, Turkey had just over double the proportion of graduates, but Malaysia had just under five times the proportion of graduates in this field. In comparison, 40 per cent of the students in China are enrolled in mathematics, science, and engineering fields, constituting around 6.7 times the proportion of graduates that South Africa has in this field. Needless to say, significant investment in technical human capital accumulation is essential for developing a domestic absorption capability of global knowledge (Yao et al. 2008).

10 See table 3 in Bhorat, Cassim, and Hirsch (2014).

11 See figure 10 in Bhorat, Cassim, and Hirsch (2014).

12 See figure 11 in Bhorat, Cassim, and Hirsch (2014). 
This lack of technical knowledge accumulation has, in part, prevented the diversification of exports and the absorption of the labour in the pursuit of a more diversified growth path. Ultimately though, the quantity and quality of human capital held by individuals remains poorly matched to meet the conditions required for this more diversified growth path. This structural mismatch may be a key constraint in the economy's attempt to break out of its current low growth trap.

The data presented thus far clearly illustrates that South Africa falls below peer emerging economies in terms of key economic variables such as investment, savings, trade volume and diversification, and human capital accumulation. In Section 11.3 we consider the interaction between policy coordination and key economic players that has led to certain industrial biases that may have inhibited inclusive economic growth and perpetuated unemployment.

\subsection{Policy Coordination and Economic Growth Traps in South Africa}

In the early 1990s, before and during the transition to democracy, engagement between business, labour and the old and new governments was extraordinary in its depth and breadth. The last minister of finance in the old regime was also briefly the first minister of finance in the democratic government, and in 1992, he sanctioned the establishment of a National Economic Forum where the three social partners gathered, informed by high quality research by the Industrial Development Corporation and other government agencies (Hirsch 2005).

One of the first laws to pass through the democratic parliament led to the establishment of a tripartite National Economic Development and Labour Council of South Africa (NEDLAC), designed to negotiate labour laws and to coordinate potentially binding agreements on social and economic policies. Labour, business, and government met, considered challenges, jointly commissioned policy research, and agreed to recommendations on the basis of the findings. This generally led to good faith action by government and the other social partners.

Nevertheless, signs of poor economic policy coordination emerged as early as 1996, two years after democracy, when three different and conflicting economic policy frameworks were developed and published by different parts of government: the Reconstruction and Development Planning (RDP) office in the Presidency produced the National Growth Path Framework; the Labour Department's Presidential Labour Market Commission produced an approach 
towards a social plan; and the Treasury produced the influential Growth, Employment and Redistribution (GEAR) strategy.

GEAR included a commitment to the National Treasury offering to convene a process of economic policy coordination within government. However, coordination hosted by Treasury lasted a few months before it was abandoned. From this uncertain point of departure, economic coordination proceeded on an erratic downward path.

While the World Trade Organization (WTO)-linked trade liberalization programme forged steadily ahead on the principle of reducing oligopoly power to encourage new investment, the policy around network industries seemed to move in the opposite direction. Electricity provision remained a monopoly of Eskom - the very large state-owned corporation-and while the national legacy fixed-line telecommunications provider Telkom was partially privatized, its monopoly over fixed line provision was extended by the state to a five-year period and beyond, in the misguided belief that it would follow through on its commitment to the extension of services to unserved customers in poor rural areas, as well as to raise the privatization sale value of the company. And while the export strategy of GEAR rested explicitly on a competitive exchange rate resting on an accommodative monetary policy, the Reserve Bank followed its own course and raised interest rates sharply in two volatile episodes.

\subsubsection{Industrial Policy}

In the area of industrial policy, the Department of Trade and Industry (DTI) pushed a sector, or cluster-based, development strategy which would combine various incentives. But the National Treasury opposed what it called 'picking winners', and blocked programme implementation, weakening the already shaky relationship between domestic producers and the government.

When a targeted tax holiday to encourage investment was introduced following the adoption of the GEAR policy in 1996, its design was compromised by the inability of its architects to fend off entrenched interests in the labour and business communities. This rendered it difficult for anyone to benefit from the tax holiday, and it was soon withdrawn.

Historically, industrial policy incentives introduced under apartheid, such as the Regional Industrial Development Plan (RIDP) in 1960 and the Simplified Regional Industrial Development Plan (SRIDP) in 1993, were essentially spatial tools to create industrial zones away from city centres, to restrict migration of black people into urban areas. RIDP support was biased in favour of labour-intensive sectors and evidence suggests that increased investment incentives in the 1990s and early 2000s led to increased employment (Kaplan 2003). However, given the priorities of the incentives, there was little impact on skills development, technology upgrades, or attracting foreign investment. 
The Small and Medium Manufacturing Development Programme (SMMDP) was introduced in 1998 and was biased towards capital intensive industry, despite the fact that the SMMDP was designed 'to encourage new investments in small and medium sized manufacturing companies ...' (Kaplan 2003). The Spatial Development Initiative was also introduced, targeting smaller projects that would be managed within a unit of the DTI.

Several studies have shown that although the subsidies tended to favour the formal sector and some had a bias towards capital investment, the industrial incentives introduced by the DTI in the post-1994 period were reasonably well targeted and appeared to have some impact (Rustomjee 2006; World Bank 2006). However, the 1994-2005/6 period certainly saw a decline in the overall value of the budget for DTI programmes (Rustomjee and Hanival 2008). What the same studies tend to point to though, was the lack of coordination between DTI programmes and the orientation of other influential government departments. For example, incentives for small businesses were rendered relatively impotent by the very slow movement towards improving the regulatory environment for small businesses. Indeed, a series of reports prepared for the Presidency in 2005 showed how municipal laws and labour laws, amongst others, stood in the way of the expansion of the small business sector.

\subsubsection{THE MINERAL-ENERGY COMPLEX}

What Fine and Rustomjee (1996) named 'the mineral-energy complex' (MEC), elicits significant government support and attention. In most cases government has sought, in the words of one senior DTI official, 'quick wins' — such as the Maputo Corridor and other large projects. These projects invariably serve to support the mining industry and are capital-intensive.

Historically, economic policy interests were aligned to the MEC. In recent decades, macroeconomic stability was biased towards ensuring suitable exchange rates for commodities exports such as gold and minerals; and state-owned enterprises (SOEs)-largely the minerals and energy complex (Fine and Rustomjee 1996; Takala-Greenish 2008). Capital within the MEC was also highly concentrated and strongly linked to the financial sector, which maintained control and economic power, and MEC owners and managers had a huge influence on policy.

\subsection{Big Business, Big Government, and Big Unions: A Policy Coordination Paradigm in South Africa?}

An unintended consequence of the structural development of the South African economy has not only been to perpetuate low levels of growth, but 
also to facilitate rent-seeking between key players in the economy. Empirical evidence suggests a link between rent-seeking, poor economic performance, and high levels of income inequality (Olson 1971; Chakraborty and Norris 2005). Rent-seeking activities are often driven by the relatively elite or wealthy in a society through social pacts, who choose rent-seeking over engaging in productive activities. In this section we assess the role of the political economy, policy coordination, institutional factors, and market structure, in reinforcing rent-seeking and poor economic performance.

After the establishment of NEDLAC in 1994, it seemed that the foundations were being put down for a system of social pacts that would overcome the divisions within South Africa's economic society. Policy coordination would ostensibly be pursued through this tripartite structure-much in the spirit of the country's political negotiations which shaped the peaceful transition to democracy. However, cooperation and trust between the three social partners weakened after the GEAR was adopted in mid-1996, and lost further credibility with the failure of a Jobs Summit in October 1998.

One consequence of the weakening of NEDLAC has been that the corporate sector and trade unions settled in an uneasy, but stable, political economy equilibrium defined by high margins, or rents, distributed between organized labour and big business. In particular, for sectors where the cost of not complying with big government and big labour was high, big business' growth and development trajectory has been invariably shaped by the implicit contract between these three actors. Recent labour market disputes in the mining industry are strongly indicative of this growth narrative. It is also within this environment of a strong alliance with the union movement that the ruling party, whilst publically pushing for employment-friendly labour market policies, has found it difficult to materially counter trade union interests in terms of labour market reform.

The wage premia associated with militant trade unions have, to some extent, worked as a disincentive to employment creation. Overall mean monthly earnings, and specifically in agriculture, mining, manufacturing and for private households, grew at a faster rate than employment between 1997 and 2012. ${ }^{13}$ In manufacturing and mining in particular, employment declined steadily. What this suggests is that the distribution of rents for organized labour may have been counter to employment-generating policies.

Mahajan (2012) describes the firm owners, government, and organized labour as 'locked in a continual, rambunctious public tussle over the distribution of the high rents being generated under the system'. This triad is constrained by the bounds of labour regulation, competition policy, tax policy

13 See figure 12 in Bhorat, Cassim, and Hirsch (2014). 
and equity considerations. These constraints have not always been productivity enhancing. This process has created a barrier to entry for new firms that could create a more competitive environment and normalize returns. Within this, the unemployed are left out, as are those who would like to see rents being transferred into higher productivity, higher investment, growth-enhancing actions. The outcome is an economy that performs below its potential. Some form of modification of this unintended agency triumvirate then, it is argued, may be essential for placing South Africa on a more inclusive growth path. ${ }^{14}$

Perhaps the overriding characteristic of government in South Africa today is fragmentation, particularly in economic policy formulation and implementation. So, while the DTI steadily drives forward the fifth iteration of its Industrial Policy Action Plan with nine cross-cutting interventions and over thirty sectoral strategies, this is generally not seen, or acted on, as if it were a strategy followed by all arms of government. Although political support for industrial policy is stronger than before, at the level of policy, the ability of government to implement and monitor programmes systematically is limited.

Government, despite its initiatives towards developmental partnerships, has not proved strong or effective enough to lead a process of breaking free from the path dependent pattern of low value-added exports, and oligopolistic market structures with high margins. Such a strong, efficient state is also essential for managing a change from a growth path financed by short-term capital flows and dependent on domestic consumption levels.

\subsection{Testing the Paradigm}

We hope here, to describe representative examples of policy outcomes or sectoral growth experiences which have in effect excluded the unemployed and those in the informal sector-thus generating this ongoing problem of a low-level growth trap for South Africa.

\subsubsection{Capital Investment Has Not Favoured Labour-Intensive Sectors}

The notion of investment bias towards MEC subsectors can be clearly seen when annual growth in capital is measured at a subsectoral level. There was an annual decline, between 1990 and 2012, of capital investment into labourintensive sectors such as clothing ( -4.9 per cent); electrical machinery and apparatus ( -4.4 per cent); and textiles ( -3.9 per cent) amongst others. ${ }^{15}$

14 See figure 13 in Bhorat, Cassim, and Hirsch (2014).
15 See figure 14 in Bhorat, Cassim, and Hirsch (2014). 


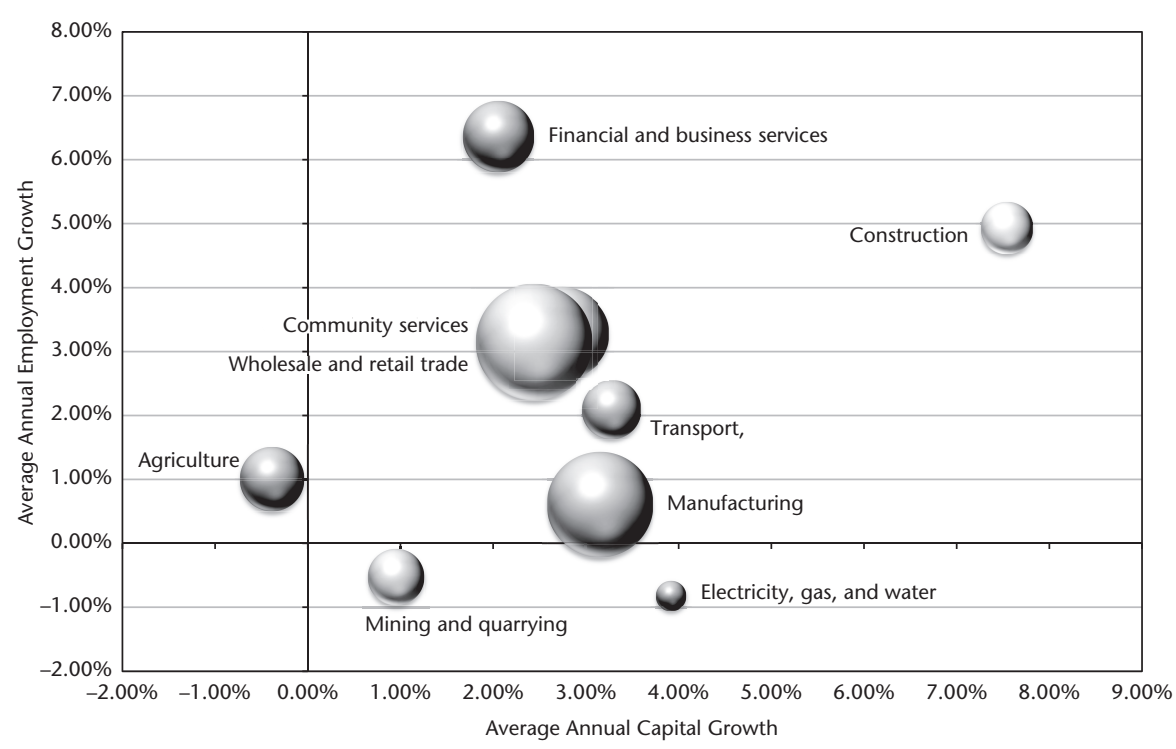

Figure 11.2. Growth of employment and capital by sector, 1997-2012

Source: LFS and QLFS sources from Statistics South Africa (2014a, 2014b), Quantec (2014), and author's calculations.

Those sub-sectors that have seen increasing annual capital investment within the period include medical and dental services ( 8.5 per cent); civil engineering and construction (6.5 per cent); coal mining (5.1 per cent); and motor vehicles (4.1 per cent). At an industry level, annual growth in capital investment in community services as well as finance and business services has in fact out-weighed investment growth in manufacturing, and particularly light manufacturing.

Figure 11.2 examines the interaction between capital and labour at an aggregate sectoral level between 1997 and 2012. The horizontal axis measures annual growth in capital intensity whilst the vertical access measures annual growth in employment. ${ }^{16}$ The interaction of capital intensity and employment first speaks to whether mechanization through capital deepening has been used to displace labour, and, second, the level of investment in capital formation associated with increasing labour in a particular sector.

Rodrik (2006) found that between 1980 and 2005 capital deepening resulted in a higher demand for skilled as opposed to low-skilled workers, which is amongst the reasons for the wage push in skill-intensive occupations. Sectors

\footnotetext{
16 Annual employment growth differs in Figures 11.1 and 11.2 as the versions of the Labour Force Surveys (LFS) and Quarterly Labour Force Surveys (QLFS) used were not the same; as such, different quarters or annuals were used and may yield different growth rates.
} 
such as construction, manufacturing, mining, and electricity have increased capital intensity at a rate greater than employment. Whilst mining increased capital intensity by just under 1 per cent per annum, gross value added declined for the sector. Construction increased annual capital formation by 7.54 per cent at a rate greater than employment (4.84 per cent) and gross value-added growth (7.2 per cent), indicating that generating both employment and value added in construction came with a cost of high levels of investment in capital deepening.

Manufacturing has seen higher levels of capital formation than growth in employment, hence reinforcing a capital intensive growth trajectory. Annual capital formation was around 3.15 per cent whilst employment growth was less than 1 per cent. This indicates increasing mechanization in sectors that may have previously been more labour-intensive, as well as increased investment in heavy manufacturing.

Where employment has grown it has followed a high-skilled labour demand trajectory such as that found in the finance and business and community services sector (Bhorat, Goga, and Stanwix 2013). Employment has exceeded growth in capital in finance (6.36 compared to 2.05 per cent), community services (3.15 compared to 2.44 per cent) and wholesale and retail (3.28 compared to 2.74 per cent). These sectors have therefore had lower levels of investment in the form of gross capital formation, yet increased employment suggesting that the cost of creating employment was lower. Driving these trends in wholesale and retail for example, was in part an increase in informal sector employment. The apparent labour intensity in finance and business services was driven by the rapid rise of temporary employment service providers - a relatively new phenomenon in South Africa.

Sectors that yield the lowest levels of capital accumulation, such as agriculture, increased employment by 1 per cent annually. This sector could have had the potential to absorb low-skilled labour yet is stagnating; in part because of poor levels of investment, and the imposition of the minimum wage (Bhorat, Kanbur, and Stanwix 2014).

Ultimately, capital investment in a number of South African main sectors has not yielded high growth returns for employment. Sectors which have gained employment on the back of capital investment have either been in the public sector CSP (Community, Social, and Public Services), reinforced the consumption-based growth trajectory of the economy (wholesale and retail trade), or indeed have been labour outsourcing sectors. In particular, in the growth engine of many fast-growing emerging markets in the world-manufacturing-investment is low and it remains unable to convert capital expenditure into sufficiently high levels of employment generation. 


\subsubsection{Transport Tariffs Have Not Facilitated Trade}

The bulk of South African export and import trade is through its seaports, ${ }^{17}$ yet tariffs have been inhibitive of trade in certain sectors, whilst favouring others. An SOE, Transnet, owns all South African ports through the Transnet National Ports Authority (TNPA) and controls the bulk of operations through the Transnet Ports Terminal. Monopoly state ownership means that there is little room for competition between or within ports and therefore little incentive to improve efficiency or productivity levels, which could reduce costs by generating economies of scale.

An outcome of limited competition was that the South African marine tariff structure (port costs to shipping lines) was recognized to be amongst the highest amongst emerging markets (Ports Regulator South Africa 2012). A comparison of terminal handling charges (THC) suggests that Durban-South Africa's major port-has very high THCs compared to the benchmarked ports. ${ }^{18}$ In 2012 , charges in Durban were found to be in line with European ports, which have higher labour costs than South Africa does. Behind these charges is the differential pricing that operates for bulk and container transport. The Ports Regulator South Africa (2012) roughly estimated that a Durban cargo owner faced between 364 per cent to in excess of over 800 per cent higher charges than the global average for containers. Not all industries are subject to uncompetitive tariffs and bulk commodities (e.g., coal and iron, mild steel, raw timber, etc.) are charged much lower total port costs than the global averages. ${ }^{19}$

The relatively lower charges for low value add and larger firms reinforce biased policy coordination in favour of particular industries to the detriment of other economic activities. Indeed, this underpins South Africa's pattern of low economic growth, shaped by large, capital intensive firms within the mineral energy complex. An outcome of the MEC in particular, has been to offer support to various industries through incentives, and of particular interest here, lower transport costs. It is clear that these tariff structures serve to reinforce a growth trajectory favouring large, capital-intensive, and resourcebased firms and sectors. In so doing the economy's port tariff regime is indirectly a constraint on labour-intensive growth.

\subsubsection{Regulation in the Communications Sector Has Perpetuated Anti-Competitive Conduct}

A number of East Asian countries managed to escape potential growth traps through developing advanced infrastructure in the form of high-speed

\footnotetext{
17 Ninety-six per cent of export volumes are estimated to be transported by the sea (TIPS 2014).

18 See figure 17 in Bhorat, Cassim, and Hirsch (2014).

19 A few examples of the disparity in pricing are worthy of noting: see section 6.2 in Bhorat, Cassim, and Hirsch (2014: 24).
} 
communications networks and broadband technology (Gill and Kharas 2008). Information and communication technology (ICT) manufacturing and implementation was formally embedded in the national development strategy of Korea and the result was a far more developed ICT system than a number of other emerging markets, manifest in part in an internet usage rate in excess of eighty users per hundred people. ${ }^{20}$

South Africa's ICT sector in 2000 lagged significantly behind comparator countries: in 2009, there were only nine internet users per hundred people. However, in the past five years internet access has increased significantly, with forty-one users per hundred people in 2012. Access to mobile phones has been central to this shift. Pricing, however, remains a barrier to access and usage of both fixed-line and mobile phone services. In particular, the cost of equipment such as internet-enabled mobile phones and personal computers is high-as is the cost of accessing services, which has limited growth in the uptake of data services. Growth and development gains that could potentially be achieved through this sector have only recently been realized.

Historically, the telecommunications market in South Africa has been highly concentrated and dominated by the incumbent state-owned operator Telkom: 67 per cent government owned, 30 per cent held by strategic equity partners. For much of the last twenty years, Telkom has had a monopoly over local and long-distance calls, backbone infrastructure for internet provision, international services, and public pay phones (Hodge 1999). The Telecommunications Act (Act 103 of 1996) allowed Telkom exclusivity, while it met its obligation to roll out 2.81 million new lines. After its period of exclusivity, a second network operator was to be licensed in 2003. However, this was severely delayed due to legal and regulatory bottlenecks and the second operator only became operational in 2007. Telkom has been charged by the competition regulators for anticompetitive behaviour-notably in terms of pricing-which has had an overall impact on service providers and ultimately consumer access.

The evidence is thus of another majority state-owned entity where regulation has been used to distort markets to extract rents in favour of certain stakeholders. This has perpetuated a poor quality, inefficient system that has hampered knowledge transfers and increased the cost of doing business in South Africa that, essentially, lowers the potential levels of output and economic growth.

\subsubsection{Black Economic Empowerment for the Minority}

The premise of Black Economic Empowerment (BEE) was to redress inequalities of the past through a redistribution of ownership rights to those who

${ }^{20}$ See figure 18 in Bhorat, Cassim, and Hirsch (2014). 
were previously economically disadvantaged. Essentially, BEE was introduced (in 2001) as a tool to support greater economic equality, as it was unlikely that this would be a natural market outcome of the then new political environment (Acemoglu, Gelb, and Robinson 2007).

BEE in practice focused on transferring ownership and control to the politically networked elite. This meant BEE had limited impact and largely excluded low-skilled labour, the unemployed, and those in the informal sector. As a tool for redistribution, the policy has been a failure. Instead it has become, apparently unintentionally, a tool for redistributing rents amongst the elites of the society-so reproducing the pattern of highly unequal economic growth. As Manning (2014) suggests, it has created clusters of rent-seeking behaviour by elites and thus has had a limited impact in empowering the broad majority of black South Africans.

Acemoglu, Gelb, and Robinson (2007) presented evidence of the prevalence of narrow-based BEE. Information was collected on board members of companies listed on the Johannesburg Stock Exchange (JSE), as well as the African National Conference (ANC) executives and elected officials since $1994 .^{21}$ Names of the Board members and ANC members were then matched up. Fifty-six ANC politicians were found to be on the board of directors of JSE-listed firms. The result essentially reinforced the strong interrelationship between political power and large corporates. ${ }^{22}$ In particular, it is suggested that previously white-owned firms have been trying to match politically connected people to secure their property rights, or to influence government policy.

The demographic distribution of economic assets through the process of BEE was skewed, and redistribution benefits are ostensibly shared by a small section of the previously disadvantaged. Black ownership on the Johannesburg Stock Exchange is estimated to be about 15 per cent, up from about 4 per cent in the mid-1990s (National Planning Commission 2011). Whilst firms are actively responding to BEE and in its newer guise-Broad-Based Black Economic Empowerment (BBBEE) - it is suggested that this is done in a static structural context where firms look to established networks for participation in the economy, limiting the number of beneficiaries of BEE (Andrews 2008).

Ultimately this suggests that BEE and BBBEE, have served as instruments of political and policy access for large corporate South Africa, reinforcing existing economic structures with the consequence of neither redistributing wealth nor serving as an engine for a more dynamic inclusive growth path for South Africa.

21 The ANC has been the dominant political party since 1994.

22 See figure 19 in Bhorat, Cassim, and Hirsch (2014). 


\subsection{Conclusions}

We have described South Africa's economic development trajectory as being starkly representative of a low level economic growth trap. An undiversified export profile, a low-quality schooling system, and insufficient savings and investment levels, all serve to perpetuate this growth malaise. Our analysis points to incoherence in policy coordination and a lack of clear politically supported industrial policy framework. In turn, the default social contract between big business, government and labour is readily evident in key areas of the economy ranging from port tariffs to telecommunications. We argue that those instances of a sewn-up social contract serve to perpetuate a growth path which favours: capital intensity over labour intensity; the currently endowed to the marginalized; oligopoly to competition; importation ahead of innovation; and heavy manufacturing over light manufacturing. These are the ingredients we identify, for a low growth performance and the perpetuation of a growth path unable to engender strong redistributive outcomes and employment gains.

Arguably, the pattern and level of economic growth lies at the core of persistently high levels of inequality, which has ensured that a minority of high-end, well-educated households at the top of the distribution have gained relative to those at the bottom. This lack of pro-poor growth in South Africa is a direct manifestation of a path dependency in growth which consistently favours modes of economic activity which inhibit innovation and diversification, reproduce patterns of inequality, and marginalize employment creation.

\section{References}

Abramovitz, M. (1986). 'Catching Up, Forging Ahead, and Falling Behind'. Journal of Economic History, 46(2): 385-406.

Acemoglu, D., S. Gelb, and J. Robinson (2007). 'Black Economic Empowerment and Economic Performance in South Africa'. Non-Technical Policy Brief, Harvard University Center for International Development, Cambridge, MA.

Agénor, P., O. Canuto, and M. Jelenic (2012). Avoiding Middle Income Growth Traps. Washington, DC: World Bank.

Andrews, M. (2008). Is Black Economic Empowerment South Africa's Growth Catalyst? A Study of the Policy's Impact on Relational Structures in the Economy, Working Paper RWP08-033. Cambridge, MA: Harvard University Center for International Development.

Bhorat, H., and Hirsch, A. (2014). 'South Africa: Perspectives on Divergence and Convergence'. Paper presented at Think Tank 20, Growth Convergence, and Income Distribution: The Road from the Brisbane G-20 Summit, Brookings, November. 
Bhorat, H., and D. Tseng (2014). Poverty and Inequality in South Africa: A Consideration of Trends: 2005-2010. Cape Town: University of Cape Town.

Bhorat, H., A. Cassim, and A. Hirsch (2014). Policy Co-ordination and Growth Traps in a Middle-Income Country Setting: The Case of South Africa, WIDER Working Paper WP2014/ 155. Helsinki: UNU-WIDER. Available at: <https://www.wider.unu.edu/publication/pol icy-co-ordination-and-growth-traps-middle-income-country-setting $>$ (accessed 28 April 2016).

Bhorat, H., A. Cassim, and D. Tseng (2014). 'Higher Education, Employment and Economic Growth: Exploring the Interaction'. LMIP Report 5, Human Sciences Research Council, Pretoria.

Bhorat, H., S. Goga, and B. Stanwix (2013). 'Occupational Shifts and Shortages: Skills Challenges Facing the South African Economy'. LMIP Report 1, Human Sciences Research Council, Pretoria.

Bhorat, H., R. Kanbur, and B. Stanwix (2014). 'Estimating the Impact of Minimum Wages on Employment, Wages, and Non-Wage Benefits: The Case of Agriculture in South Africa'. American Journal of Agricultural Economics, 96(5): 1402-19.

Bhorat, H., A. Hirsch, R. Kanbur, and M. Ncube (2014). 'Economic Policy in South Africa Past, Present, and Future'. In H. Bhorat., A. Hirsch, R. Kanbur, and M. Ncube (eds), The Oxford Companion to the Economics of South Africa. New York: Oxford University Press.

Chakraborty, S., and E. Norris (2005). Rent Seeking, IMF Working Paper WP/05/43. Washington, DC: IMF.

Dosi, G., and L. Soete (1983). 'Technology and Cost-Based Adjustments: Some Explorations on the Determinants of International Competitiveness'. Metroeconomica, 35 (3): 197-222.

Eichengreen, B., P. Donghyun, and S. Kwanho (2011). When Fast Economies Slow Down: International Evidence and Implications on China, Working Paper 16919. Cambridge, MA: National Bureau of Economic Research.

Engelbrecht, H. J. (1997). 'International R\&D Spillovers, Human Capital and Productivity in OECD Economies: An Empirical Investigation'. European Economic Review, 41 (8): 1479-88.

Fine, B., and Z. Rustomjee (1996). The Political Economy of South Africa: From MineralsEnergy Complex to Industrialisation. London: Hurst, and Wits University Press.

Gallagher, K. P., J. C. Moreno-Brid, and R. Porzecanski (2008). 'The Dynamism of Mexican Exports: Lost in (Chinese) Translation?' World Development, 36(8): 1365-80.

Gill, I., and H. Kharas (2008). An East Asian Renaissance: Ideas for Economic Growth. Washington, DC: World Bank.

Hanival, S., and J. Maia (2008). An Overview of the Performance of the South African Economy since 1994. Pretoria: The Presidency, Government of South Africa.

Hirsch, A. (2005). Season of Hope: Economic Reform under Mandela and Mbeki. Pietermaritzburg: University of KwaZulu-Natal Press and IDRC.

Hodge, J. (1999). Liberalising Communications Services in South Africa. Washington, DC: World Bank.

Joffe, A., D. Kaplan, R. Kaplinsky and D. Lewis (1995). Improving Manufacturing Performance in South Africa: Report of the Industrial Strategy Project. Cape Town: UCT Press, IDRC. 
Kaplan, D. (2003). 'Impact of Government Programmes using Administrative Data Sets, Investment Incentives'. Project 6.2 of the Ten-Year Review Research Programme, Interim draft.

Kharas, H., and H. Kohli (2011). 'What is the Middle Income Country Trap, Why Do Countries Fall into It and How Can It Be Avoided?' Global Journal of Emerging Market Economies, 3(3): 281-9.

Levy, B., A. Hirsch, and I. Woolard (2014). South Africa's Evolving Political Settlement in Comparative Perspective. Cape Town: SALDRU.

Mahajan, S. (2012). When are Macroeconomic Stability and Exceptionally High Returns Not Enough for Private Investors?. Washington, DC: World Bank.

Manning, C. (2014). 'Origins, Trends, and Debates in Black Economic Empowerment: The Rationale for Black Economic Empowerment'. In H. Bhorat, A. Hirsch, R. Kanbur, and M. Ncube (eds), The Oxford Companion to Economics of South Africa. New York: Oxford University Press.

National Planning Commission (2011). Economic Diagnostic (June). Pretoria: Government of South Africa.

Nelson, R. R., and E. S. Phelps (1966). 'Investment in Humans, Technological Diffusion, and Economic Growth'. American Economic Review, 56(1/2): 69-75.

OECD (Organisation for Economic Co-operation and Development) (2014). Perspectives on Global Development 2014: Boosting Productivity to Meet the Middle-Income Challenge. Paris: OECD Development Centre.

Olson, M. (1971). The Logic of Collective Action; Public Goods and the Theory of Groups. Cambridge, MA: Harvard University Press.

Presidency (2012). Development Indicators. Pretoria: Government of South Africa.

Ports Regulator South Africa (2012). Global Port Pricing Comparator Study: 01/04/2012 Research Summary. Durban: Ports Regulator South Africa.

Quantec (2014). Capital Intensity dataset (various years). Pretoria: Quantec.

Rodrik, D. (2006). 'Understanding South Africa's Economic Puzzles'. CEPR Discussion Paper No. 5907, CEPR Discussion Papers.

Rodrik, D. (2013). The Past, Present and Future of Economic Growth, Working Paper 1. London: Global Citizen Foundation.

Rustomjee, Z. (2006). 'DTI Incentives Review Process Phase 1 Incentives Policy Framework, Final Report', 16 November. A study commissioned by the Department of Trade and Industry, Pretoria.

Rustomjee, Z., and S. Hanival (2008). A Review of Industry Policy, Instruments and Support Programmes 1994-2008. Pretoria: TIPS.

Statistics South Africa (2014a). 'Labour Force Survey (LFS) (various years)', Statistics South Africa, Pretoria.

Statistics South Africa (2014b). 'Quarterly Labour Force Surveys (QLFS) (various years)', Statistics South Africa, Pretoria.

Takala-Greenish, H. L. (2008). 'The Role of Industrial Policy and the Minerals-Energy Complex in the Decline of South African Textiles and Clothing'. TIPS Annual Forum Paper: mimeograph. Available at: <http://www.tips.org.za/research-archive/annualforum-papers/2008/item/1580-the-role-of-industrial-policy-and-the-minerals-energy- 
complex-in-the-decline-of-south-african-textiles-and-clothing > (accessed 15 September 2016).

Trade \& Industrial Policy Strategies (TIPS) (2014). Review of Regulation in the Ports Sector. Pretoria: TIPS.

World Bank (2006). Enhancing the Effectiveness of Government in Promoting Micro, Small and Medium Enterprise, AFTPS Consultants. Washington, DC: World Bank.

World Bank (2011). South Africa Economic Updates, issue 1. Washington, DC: World Bank.

Yao L., J. Whalley, S. Zhang, and X. Zhao (2008). The Higher Educational Transformation of China and its Global Implications, NBER Working Paper 13849. Cambridge, MA: National Bureau of Economic Research. 


\title{
12
}

\section{Special Economic Zones in Africa}

\section{Political Economy Challenges and Solutions}

\author{
Thomas Farole and Lotta Moberg
}

\subsection{Introduction}

Much has been made of the role of special economic zones (SEZs) in contributing to East Asia's economic success. This has led to a rush of countries seeking to replicate this model of export-led growth and structural transformation by launching SEZ programmes of their own. The wave of SEZ projects in sub-Saharan Africa (SSA) is a case in point. The scale of their expansion in recent years has been remarkable, and more zones may be developed over the next decade than during the three preceding decades combined. This recent crop of SEZs should be expected to benefit from the experience of SEZ policymaking and implementation over recent decades. Yet the majority of SEZ projects continue to fall well below expectations, with the experience in SSA being particularly disappointing.

This chapter argues that often-cited problems with SEZs can largely be attributed to the political economy surrounding them. Because political economy issues are context-specific, the avenues to replicate 'best practice' for SEZ development and management are limited. We apply a 'robust political economy' framework, which divides political economy problems into those of inadequate knowledge and distorted incentives. The framework helps us examine the nature of the political economy problems that different countries seem to encounter, as well as to suggest some possible solutions to these problems. As we argue, governments should consider political economy concerns when setting the initial strategic objectives and carrying out strategic planning of zones. 
Section 12.2 provides a brief introduction to SEZs, their objectives, and international experience in their use. Section 12.3 discusses the experience of SSA countries with SEZs and traces some of the usual explanations for their failure back to their root causes of political economy. In Section 12.4, we introduce the political economy framework, which we apply to SEZs in Section 12.5, and illustrate with examples from the African experience. Section 12.6 concludes by outlining how political economy considerations can be understood and mitigated in the planning and implementation stages of SEZ programmes.

\subsection{Special Economic Zones: Theory and Experience}

SEZs are demarcated geographical areas within a country's national boundaries. In these zones, rules of business are different, and often more liberal, from those that prevail in the national territory. Typically, these zones offer advantages to investors in terms of infrastructure, special customs regimes such as duty free import and export, special regulatory regimes, and a range of fiscal incentives. Export-processing zones (EPZs), free-trade zones (FTZ), and free ports are all different forms of SEZs. We will use 'SEZ' as a generic term, encompassing a broad range of such regime types.

SEZs have a long-established role in international trade. However, it was only in the 1970s and 1980s, starting with East Asia and Latin America, that zones became a cornerstone of trade and investment policy. In 1986, the International Labour Organization (ILO) reported 176 zones in 47 countries. By 2006, this had risen to 3,500 zones in 130 countries (Boyenge 2007).

SEZs have played a catalytic role in supporting structural transformation. This includes East Asia's 'tiger economies' such as China, which used SEZs as platforms to support the development of export-oriented manufacturing. In Latin America, countries such as the Dominican Republic, El Salvador, and Honduras used EPZs to take advantage of preferential access to the US market. These zones generated large-scale manufacturing sectors in economies previously dependent on agricultural commodities. In the Middle East and North Africa, SEZs played an important role in promoting diversification in the Arab Republic of Egypt, Morocco, and the United Arab Emirates, among others.

SEZs are designed as instruments of trade, investment, and spatial industrial policy. They are generally established with a few specific, but by no means exclusive, policy goals, with export promotion and foreign direct investment (FDI) attraction central to almost all zones (FIAS 2008). They also unlock agglomeration economies by concentrating economic infrastructure and public 
goods in one geographic area, allowing industries to overcome minimum size thresholds and begin to leverage scale economies (Collier and Page 2009).

In addition, zones have played an important role within the political economy of reform. In many countries, they have supported partial exposure to global markets while maintaining protective barriers in a 'stepwise' approach to reform. SEZs have helped piloting experimental new policies before rolling them out to the broader economy; and in the absence of political will to undertake reforms, acted as 'second best environments' and 'pressure valves' to absorb excess labour.

Despite the theoretical advantages of SEZs and high-profile success stories like China, SEZs have a decidedly mixed record. Investments in zone infrastructure have in many cases resulted in 'white elephants', which cost more to maintain than the benefits that they bring. SEZs can become zones where investors take advantage of tax breaks without delivering substantial employment or export earnings. Many traditional EPZs have been successful in attracting investment and creating employment in the short term, yet failed to sustain competitiveness in the face of rising wages or eroding trade preferences. Empirical research shows that many SEZs have been successful in generating exports and employment, and come out marginally positive in cost-benefit assessments (Warr 1989; Chen 1993; Jayanthakumaran 2003; Arce-Alpazer, Monge-González, and J. Rosales-Tijerino 2005; Wang 2013). However, as they give preferences to specific firms and distort markets, economists view zones as a second-best solution to policies promoting competitiveness more generally (Hamada 1974; World Bank 1992; Madani 1999). Another concern is that zones, by and large, have failed to extend benefits outside their enclaves or to contribute to upgrading of the domestic skills and the production base (Kaplinsky 1993). The SEZs in Africa are by no means shielded from these problems.

\subsection{SEZs in Africa}

Several African countries, including Liberia, Mauritius, and Senegal, launched SEZ programmes in the early 1970s. However, most African countries did not operationalize their programmes until the 1990s or 2000s. As of 2014, the majority of countries in SSA have active SEZ programmes, most of these being traditional EPZs and industrial parks.

The African experience with SEZs over the past two decades has been less than spectacular. With the exception of Mauritius and the partial initial success of Kenya, Madagascar, and Lesotho, ${ }^{1}$ most African zones have failed

\footnotetext{
1 Lesotho does not have a zone programme per se, but combines the same policy instruments as SEZ regimes (Farole 2011).
} 
to attract significant investment, promote exports, and create sustainable employment (Farole 2011). No country except Mauritius has managed to use SEZs to support a successful process of structural transformation. Even where SEZs have had some initial success, the quality of investment and employment has often been poor, undermining their sustainability. For example, Madagascar lost tens of thousands of jobs in SEZs following recent political turmoil and the country's subsequent suspension from African Growth and Opportunity Act (AGOA) (Staritz and Morris 2013).

One reason for the failure of African SEZs may simply be poor timing. East Asia's success was driven in part by an unprecedented era of globalization, underpinned by the emergence of global manufacturing production networks. Because most African countries launched their zones later, they faced a more established global competition. However, this is only a small part of the explanation. Most blame for the failed African SEZ schemes lies with zone planning and implementation, rather than with the global environment. While African zones in most cases established physical and regulatory environments that were more attractive than their national markets, these improvements were far from sufficient to attract footloose international investors. Other African zones have failed due to a lack of physical or social infrastructure, regulatory uncertainty, policy instability, weak implementation capacity, or lack of institutional coordination (Farole 2011).

These observations suggest that the real problems with African SEZs may lie in a lack of sustained political will or strategic planning, if not simply poor choice of location. However, it is still unclear why such problems emerged and persisted. There is no lack of research on the planning and implementation on SEZs in other countries. Legions of international consultants and development agencies have spent time and money on the matter. Asian countries with successful SEZs also provide technical expertise and financial support for African SEZ development as part of their bilateral development assistance (Bräutigam and Xiaoyang 2011).

Despite all this global experience and expertise, failures persist. We suggest that while most issues with SEZs, such as location, planning, regulatory frameworks, customs, administrative capacity, and management are technical in nature, their application and coordination rely on a solid political economy. A country's politics and public institutions shape both the strategic thinking as well as the planning and implementation of SEZs, and are therefore crucial for SEZ success.

In Section 12.4 we outline the robust political economy framework, which we use to analyse the challenge of SEZs. We then apply the framework to the African experience, to show how political economy factors explain the difference between success and failure. 


\subsection{The Political Economy Framework and Its Application to SEZs}

Economics usually treats governments as a 'black box', where the policies that set the rules by which economic agents act are exogenous (Basu 2000: 5). Such a framework assumes that policymakers have access to all relevant data and information to forecast the outcomes of different policies, and that the interest of policy makers and other government officials are the same as the stated objectives of the government. In standard macroeconomic models, there is no room for transaction costs of policy execution, and governments function by automation and based on perfect information.

Political economy models, by contrast, treat governments and the people within them as having their own goals and information asymmetries, and focus on the interaction between market and government actors. The School of Public Choice is a strand of political economy that applies the principles of incentives of economic agents to non-market actors, and explores the actions of people in politics or political institutions. Public choice extends the fundamental logic of standard microeconomic models, of rational actors who maximize personal utility, to the individuals within public institutions. It helps explain collective decision-making, such as policy adoption and implementation, by allowing for policies to emerge from the interplay among actors in political institutions (DiLorenzo 1988; Buchanan 2003; Wagner 2007).

Buchanan and Tullock (1962) suggest treating government officials as rational and utility maximizing, just as economists treat businesses and households, albeit with very different pursuits. Politicians seek to be re-elected, civil servants may seek larger offices and more staff, and bureaucrats seek more leisure time (Niskanen 1971; Tullock 1987). As a result, the self-interest of policy makers and policy executives often conflict with their assumed goal of maximizing social welfare. While assumptions of rational self-interest may produce optimal policies in the market place, in politics, they can lead to corruption and other forms of rent-seeking. Officials may, for instance, use trade policy for personal gains by selling import or export quotas (Krueger 1974) or by adjusting tariff rates to please interest groups (Grossman and Helpman 1994). Political elites may use foreign aid that they receive for their personal advantage, rather than distributing it effectively (Friedman 1958; Bauer 1971). They can even gain by depressing economic development (Easterly 2007). Officials may thus use policies to enrich themselves both financially and politically at the expense of the economy as a whole.

Another line of political economy studies starts with the assumption that the government is not perfectly informed. Even if a government has the right incentives and tries honestly to improve economic conditions, it lacks the knowledge and understanding of market fluctuations and possibilities that it 
would need in order to improve on an economy's resource allocation (Lavoie 1985; Horwitz 1996; Boettke 1998).

Much insight about the limited knowledge emerges from the 'calculation debate' over the feasibility of government planning in the Soviet Union (Horwitz 1998). As Hayek (1935: 157) explains, even if a central authority could calculate all prevailing prices, it would be unable to perform the multiple small adjustments in prices that constantly take place in a market regime. Not only are market participants more familiar with the details about local market conditions. They also constantly obtain and digest feedback on their performance through their profits, which allows for regular improvement and updates. This logic applies well to industrial policy, which relies on the premise that government can mitigate consequences of market failures (see, e.g., Harrison and Rodriguez-Clare 2009: 4). Industrial policy often fails because government is at an inherent disadvantage to market participants when it comes to knowing what development projects are actually worthwhile (Keck 1988).

A robust political economy analysis accounts for the absence of both government benevolence and of government omniscience. It considers problems caused by distorted incentives in the absence of benevolence as well as the limited knowledge of policy makers. This forms a reality-based, positive theory of policy-making, where policies are not exogenous and not automatically in the interest of the public.

Arguing that people in government are fallible is not to say that policymakers always get things wrong. Policy makers may well act for the benefit of social welfare and governments are sometimes successful in improving welfare through productive public investments. The goal with a robust political economy analysis is to identify policies and institutions that safeguard against policy makers exploiting their positions of power or wasting public resources. In the absence of alignment between incentives and beneficial policies and between knowledge and power, policy-making will often work against the common good. The right institutional environment can align the self-interest of public officials while still benefiting the citizenry and allowing market actors to allocate resources when they possess the superior knowledge to do so. This institutional environment constitutes a robust political economy (Leeson and Subrick 2006; Pennington 2011) (see Figure 12.1).

In the SEZ context, a robust political economy enhances the chances of zones improving market conditions and spurring economic development. Obstacles to getting SEZs right, such as providing a sufficient quantity and quality of infrastructure, can thus be overcome by introducing the right institutions. SEZs can only be successful when they benefit an economy despite the limitations of distorted incentives and inadequate knowledge. The more prominent the 


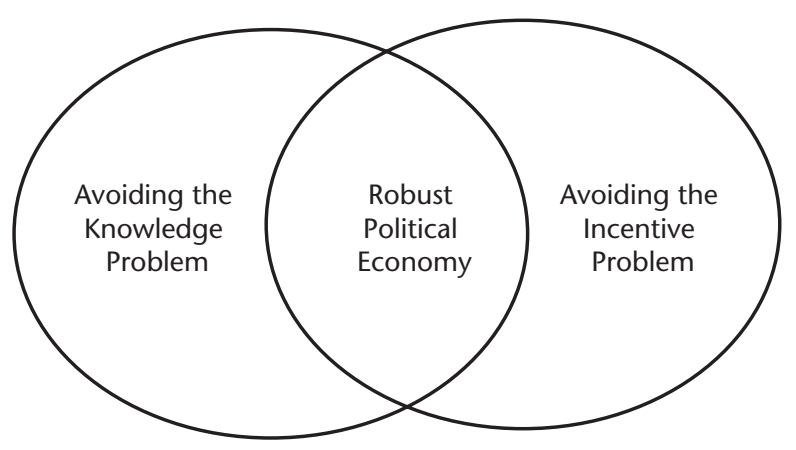

Figure 12.1. Framework for robust political economy Source: Authors' illustration.

political economy problems, the more careful a government must be when setting up the policies and institutions regulating SEZs.

In Section 12.5 we discuss the main political economy problems with SEZs, with a focus on the African context. The analysis deals with the two main political economy problems, namely distorted incentives and inadequate knowledge. If the incentives are not aligned with a successful outcome, the knowledge of proper SEZ policies and location will be irrelevant, as policy makers will not choose to act on them. In the presence of problems stemming from inadequate knowledge, any amount of political will and coherent motivation of an administration will be insufficient to get an SEZ scheme right.

\subsection{The Political Economy of African SEZs}

Many African SEZ programmes have suffered from both distorted incentives and imperfect information. In this section, we discuss how such political economy factors have manifested themselves and contributed to underperformance of African SEZs.

\subsubsection{Problems of Distorted Incentives}

African SEZ investments are often hampered by weak SEZ governance, inefficient bureaucracies, and poorly designed legal frameworks. Such problems may appear to stem from inadequate funding or weak capacity. However, at their root, they result from a lack of incentives of policy makers and other officials to improve on SEZ governance, policies, and laws.

The most blatant example of rent-seeking is when politicians use the privileges that SEZs confer, including access to cheap land and fiscal incentives, for 
self-enrichment. SEZs around the world are rife with examples of corrupt land deals involving government officials. There have also been many instances where board members of an SEZ regulator pursue their own political and business interests in the SEZs by influencing SEZ regulations in ways that do not benefit the programme as a whole (Farole 2011: 182; Levien 2011).

However, corruption is not likely to be the main part of the African story. Distorted incentives primarily cause more subtle and legitimate forms of rent-seeking. In particular, politicians motivated by electoral gains have the incentive to use SEZs as an instrument to show visible progress and results. Given the short-term nature of the election cycles, the emphasis tends to be on immediate gains, which is usually at odds with the long-term nature of SEZs. Politicians also have the incentive to use SEZs as an instrument to confer privileges on various domestic constituencies, and therefore to quell potential internal political dissent. We will discuss these problems in turn.

\subsubsection{THE APPEAL OF VISIBLE AND SHORT-TERM RESULTS}

The visible and marketable nature of SEZs gives politicians an incentive to adopt them even though simpler, quicker, and less expensive ways to promote job creation and growth may exist. SEZs can actually delay the process of getting the right policies in place, since it takes both time and money to develop and implement laws, regulations, and infrastructure projects.

It also becomes politically attractive to concentrate government efforts on the 'hardware' of SEZs, such as infrastructure, which is easy to measure and to display to the public as signs of progress. The 'software' of an SEZ, such as a good business climate, a proper legal framework, and the professional and effective execution of it, generates much less political capital. These SEZ features cannot be measured as easily or showcased visibly with groundbreaking ceremonies and modern entry gates. The emphasis on outward appearance of SEZs has often resulted in zones that fail to address the fundamental investment constraints that should have been their raison d'être. Senegal, for example, long faced problems of policy distortions and an unfriendly and unpredictable investment environment. Yet, its legal framework for SEZs has changed many times since its inception in the 1970s, often reinforcing rather than overturning the country's investment climate weaknesses (Baissac 2011). South Africa has by far the best industrial infrastructure in Africa, yet its industrial development zones programme included significant provision of infrastructure. Meanwhile its regulatory regime, which was most in need of change, saw virtually no improvements (CDE 2012).

Because capital-intensive investments in industrial parks are attractive showcases for progress, policy makers also have the incentive to dismiss the value of other forms of production and usage of land. Agriculture in particular 
has frequently been held in low esteem in comparison to manufacturingoriented SEZs, despite most African countries having a comparative advantage in agriculture. Moreover, the very designation of a piece of land as an SEZ can raise its value substantially, which has often resulted in questionable deals to convert agricultural land into SEZs, without appropriate compensation to those previously using or occupying it. Widespread land grabbing was observed following India's 2005 SEZ Act, resulting in the 'conversion of the fertile land into cement structures' (Khan 2008: 14; Mitra 2008: 13; Levien 2012). Viet Nam has seen around 100,000 rural villagers displaced to make way for industrial zones and complexes-a 2005 report asserted that more than a third of them were inadequately compensated (Action Aid Vietnam 2005). Nigeria has also faced protests from local communities over land compensation and resettlement around the SEZ of Lekki. These clashes inevitably cause delays in SEZ projects. They may also contribute to suboptimal use of land.

The political appeal of SEZ growth is also an incentive to attract more businesses to SEZs, regardless of whether they have the potential to be competitive or to fulfil their targets for investments and exports. The government may lower its standards for SEZ licences to attract a larger quantity of firms, many of which are not competitive enough to bring a positive contribution to the zone. If SEZ authorities have quantitative goals, they have the incentive to offer zone licences cheaply. One of the visible manifestations of this in African SEZs is the failure of many allegedly committed investors to actually set up operations on the ground.

In trying to expand their SEZ schemes, policy makers tend to cause inefficient fragmentation of resources. They often allocate investment to peripheral regions that are poorly positioned to attract investment with or without a zone. Several countries have SEZ programmes designed to establish one zone in each region, province, or state. In 2009, for instance, Tanzania announced plans to establish twenty-five to thirty zones, spread out around the country, before its first SEZ was even operational. Such expansion has serious fiscal implications in most countries. In the case of Tanzania's zones, government committed itself to securing the land and carrying out feasibility studies for all twenty-five to thirty zones. South Africa is launching a new SEZ programme with thirteen identified zones, including at least one zone per province, with government commitment to finance feasibility studies and finance infrastructure in each zone location. Lesotho faced serious financial constraints preventing investments to expand successful industrial estates in and around the capital. The government nevertheless invested scarce resources in developing zones in remote regions. Not surprisingly, these zones went unoccupied while supply constraints in core areas worsened. 


\subsubsection{CONFLICTING INTERESTS BETWEEN BUREAUCRACIES}

Many African SEZs have seen poor performance because of conflicting interests across official institutions. This complicates the work of building the authority, capacity, and communications between people that an SEZ scheme needs, thus hindering coordination across government bureaucracies.

Coordination failure among institutions can sometimes result in the creation of multiple, overlapping SEZ regimes. Tanzania, for example, launched an EPZ programme in 2002, led by its National Development Corporation. Four years later, when the EPZ programme was still not operational, the government passed a law setting up an SEZ regime under the purview of the Ministry of Planning, Economy, and Empowerment. The multiple regimes not only created internal policy confusion and competing interests, but also diluted already limited financial resources and sent conflicting signals to the investment community.

Another example is the EPZ Authority in Nigeria. Four years after its launch in 1992, before the first zone was established, the government created the Oil $\&$ Gas Free Zone Authority. The two organizations were in conflict for many years over which had the authority over a number of important activities. The Attorney General was ultimately forced to mediate.

The most common bureaucratic coordination problems occur not in the planning but in the implementation of SEZs. Several zone projects have failed because of misaligned incentives between groups promoting exports and investment and those responsible for fiscal matters, such as ministries of finance or customs. In Nigeria, the government has disputed with the customs officials for some twenty years, as they refuse to implement certain key SEZ incentives. The Tinapa SEZ, in the south-east of Nigeria, represents an extreme case of the consequences of conflicting interest. Announced in the mid-2000s, the zone was to become a 'duty-free shopping' destination. However, while the plan on which the investment was made called for a duty exemption of $\$ 5,000$ per person, in the end, customs allowed only an exemption of $\$ 330$ per person. This fatally undermined the business case for the zone after hundreds of millions of dollars were already invested, leaving it struggling for survival (CNN 2010; Daily Champion 2012).

So-called 'one-stop shops' are intended to showcase the potential of SEZs to deliver streamlined, efficient services. Ironically, when they fail to align the incentives and practices across agencies with highly disparate institutional objectives, one-stop shops vividly exemplify the challenge of coordination. Civil servants administering the work permits at a one-stop shop may for instance adopt the same protectionist and security-focused approach that dominates the immigration agencies in the rest of the country. There are in fact few African countries where central SEZ authorities have had decisionmaking power over the regulatory activities in the one-stop shop. 
When Lesotho introduced a one-stop shop for investors in 2007, the physical co-location of agencies did little to resolve the problems of facilitation because officers still reported to individual ministries (Farole 2011: 216). The head of the one-stop shop thus had no authority to ensure that the officers worked efficiently and provided quality service. The Dakar EPZ in Senegal was similarly plagued by an excessive bureaucracy and long delays in customs and agencies granting permits. Such defects are by no means limited to African SEZs. A 2005 study of Indian SEZs found that companies often needed to pass through fifteen different authorities before they could invest in the zones (Aggarwal 2005: 26).

Investment promotion activities supporting SEZs pose another common coordination challenge of agencies' incentives. Relatively small countries such as Ireland, Sri Lanka, and Uganda often manage SEZs through their Investment Promotion Agency. However, most countries establish a separate SEZ Authority for promotion and regulatory oversight of the SEZs. This separation is sensible considering the different nature of the roles of the agencies. But separation also causes operational disconnect between the agencies, with little coordination between marketing, planning, and execution, and no formal process for handoff or cross-support of investor aftercare between the agencies. In many cases in SSA, including Tanzania, Nigeria, and Kenya, the lack of formal institutional link between the agencies, such as sitting on each other's boards or even forming joint committees, contributes to operational disconnect.

Misaligned incentives between SEZs and local governments also lead to coordination problems in SEZ policy execution. In Ghana, the development plans for the Tema zone assumed that provision of water would be provided by the local municipality responsible for water provision in the area. Municipal officials, however, had no incentive to invest in delivering water to the zone. Because they did not receive any share of revenues from, or even political recognition for, the success of the zone, they prioritized delivering water to their municipal residents and businesses. Zone investors, with highly water-intensive activities like cocoa processing, were therefore forced to bring in water by tanker truck, at great cost.

In Nigeria, institutional competition and bureaucratic coordination failures led to a situation where the country's flagship zone in Calabar was ultimately unconnected to the Calabar port, which established its own free zone. For many years, national institutions also failed to agree to dredge the port, and goods shipped to and from Calabar therefore had to go by road via Lagos instead.

Finally, misaligned incentives between public and private sector actors can in many cases cause coordination failure. Design and construction of SEZs requires coordination between off-site, typically public, infrastructure and onsite, often private, development, to ensure that they are seamlessly connected. 
Time lags or discrepancies in the infrastructure delivered can result in destructive disagreements and mistrust between public and private parties. Governments often have the incentive to link their offsite investments to other political programmes, which may affect timing and alter approaches from initial plans. They may also want to secure private commitment before implementing public investments. Private zone investors, on the other hand, are reluctant to invest before the government commits to delivering infrastructure. In Ghana's initial development of the Tema zone, misalignments in the expectations of the private developers and government led to a stalemate that stalled zone development for almost seven years (Farole 2010). Similar problems contributed to delays in the development in the Eastern zone in Ethiopia.

\subsubsection{AVOIDING REFORMS}

Finally, SEZs are sometimes used for political, rather than an economic, purposes. This may not be a problem if the zones allow for better policies than would have been feasible in their absence. In the case of Mauritius, for example, the SEZ programme was the result of a process of political compromise that opened the door for a substantial political experimentation and reform. However, too often, officials use SEZs as a tool to appease regional interests, often with the aim of alleviating unemployment and spurring growth in lagging parts of the country. As such, SEZs can be a way for policy makers to avoid broader reforms that may mitigate these problems in the long term.

\subsubsection{The Problem of Inadequate Knowledge}

Even with the best of intentions and aligned incentives, the success of government policies is limited by the inadequate knowledge of policy makers. When it comes to SEZs, government officials face knowledge gaps on several crucial features, including their optimal location, appropriate industry focus, and the best combination of features that will attract investors. SEZs are often meant to open up new frontiers for a country, such as giving new life to an underutilized port or establishing new lines of production. However, the novelty that SEZs bring to an economy also makes it inherently difficult for the government to know the right combination of factors that will make a zone work.

\subsubsection{MISGUIDED INFRASTRUCTURE SPENDING AND INDUSTRY CONCENTRATION}

Government miscalculations can lead to costly mistakes, not least in the form of misguided infrastructure projects. One example of this is the Bataan EPZ in the Philippines. In the 1970s and 1980s, the central government invested 
almost \$200 million in upgrading the port and built road, bridges, and other zone facilities, but this was still not enough to attract investors to its remote location. As a result, the performance of the zone was dismal. Even sixteen years after its founding, the failure of the Bataan zone was so discouraging that it had the international community questioning the zone model of development entirely (Warr 1987; Moran 2011: 16). Bataan shows that while poor infrastructure is a commonly cited reason for SEZ failure, more infrastructure investment is not a solution if the SEZ is poorly located. In Africa, the unused infrastructure in the Calabar zone in Nigeria provides a parallel story, as does the case of the Coega Industrial Development Zone in South Africa, where more than $\$ 300$ million of infrastructure investment generated less than 3,000 operational jobs in its first decade (CDE 2012).

Some governments set specific goals for the type of production that an SEZ should host. SEZs are often meant to develop a country by opening up new lines of manufacturing and linking them with global supply chains. Therefore, one cannot simply mimic the production that is already taken place in a country. Governments must instead make qualified guesses about the country's potential comparative advantages.

Due to the knowledge problem, however, SEZ policies often end up targeting the wrong industries. They may thus exclude crucial investors in industries that have growth potential in the country (Farole 2011: 161). India's new SEZ act exempts information technology (IT) zones from minimum size requirements, which has spurred their proliferation compared to zones with other industries. The Indian SEZ scheme has underperformed, and the heavy reliance on IT-only zones is seen as a burden rather than a benefit (Govardan and Srivastav 2012; Mishra 2013).

\subsubsection{PICKING THE RIGHT INVESTORS AND INCENTIVES}

Regardless of the efforts made to vet potential investors, the logic of the knowledge problem implies that policy makers can never fully predict the success of SEZ developers. Indeed, many SEZs in SSA suffered from poor quality private investment. An early example of this was the investment in Ghana's Tema zone by the Malaysian investor Business Focus in the early 1990s. The company did not live up to its promised investments, and later abandoned the project (Farole 2010). Several investors that have come as part of China's high-level 'Trade and Co-operation zones', have turned out to be inexperienced in zone development and lacking in financial capabilities.

The problem of inadequate knowledge is also expressed in the design and implementation of fiscal incentive regimes for SEZs. SEZ designers cannot know the real value of the projects' costs and benefits. Unable to assess whether these investments would have come about without the incentives, they seem to overlook the full cost of tax expenditures. In African zones, 
this neglect frequently leads to sunset clauses on tax breaks being renewed, or firms shutting down and reopening under a new name, so that governments never succeed in realizing the tax revenues originally expected.

\subsubsection{THE MISTAKE OF SEZ REPLICATION}

A common mistake is to believe that a model that worked in one country will do so in another. Governments often refer to previous SEZ successes elsewhere, and assume that those models are replicable.

China's SEZ success is most often cited to motivate the development of new SEZ programmes. The whole country developed at a time when its SEZs could serve both as centres for growth and as showcases for economic reform. However, China in the 1980s enjoyed some particular circumstances that have not been and are not likely to be replicated elsewhere. One of many important differences between China and contemporary SEZ schemes is that most countries introducing SEZs today have already taken steps to open up to FDI, liberalize trade, and in other ways promote a free market economy. SEZs in African economies can therefore not be expected to have similar transformational effects. This significantly narrows the margin for error for African SEZ programmes.

\subsubsection{Political Economy Implications for SEZ policy}

To understand how SEZs become successful, governments often look at the symptoms of SEZ success rather than its causes. The political economy insights imply that what is commonly described as the reasons for SEZ success, such as infrastructure, beneficial location, and a good business environment, are in fact symptoms of institutions that align incentives and enhance decision making. The political economy analysis also implies that it is futile to try to replicate successful SEZs by matching their level of infrastructure investments, strategic positioning, or regulatory regimes. Here, we will discuss the political economy factors that determine the final outcomes of SEZ schemes, by shaping the gap between the de jure and de facto SEZ environment.

In approaching the design and implementation of SEZs, governments must aim at creating a robust political economy, in which SEZs are successful despite the inevitable and natural flaws of both government and civil servants. Policy makers need to acknowledge these flaws, and understand the obstacles to SEZ success that they cause. Only then can remedies be found that target the root causes of SEZ failure. We conclude this chapter by discussing some potential solutions to the specific political economy problems with SEZ that we have discussed. 


\subsection{Conclusion: Addressing the Political Economy Challenges}

Acknowledging the political economy challenges with SEZs opens up the possibility to mitigate their deleterious effects. The incentive problem implies that institutions and policies need to align the incentives of policy makers and bureaucrats with promoting long-run social welfare. The very nature of the incentive problem may make many existing stakeholders reluctant to establish such institutions and policies, but this in no way makes the task of proposing political economy improvements futile. People with an interest in beneficial long-run societal outcomes can still try to influence policy makers by any means that their political system allows. The knowledge problem implies that policy makers need to realize that while information gathering may help, they can never fully predict the outcomes of different SEZ policies. Therefore, a careful and conservative approach should be taken when embarking on large, costly, and long-term projects like SEZs.

Our suggested solutions are by no means an exhaustive list of plausible measures to take. Solutions to political economy problems are context specific, and will inevitably vary with the political and economic circumstances of different countries at different times. We therefore focus on the types of approaches that have been effective so far at managing or at least alleviating the political economy problems that SEZs face.

A starting point is to ensure transparency in the deliberation process where the decision to adopt SEZs and the nature of the SEZ regime to be implemented is made. Such deliberation should involve all stakeholders, including domestic business, local communities, and the media. Governments that engage in open and public debate over an SEZ programme are less prone both to the incentive problem and the knowledge problem. Public debates can reveal adverse incentives that may ultimately undermine SEZ programmes, whether related to land, the industries and activities that are being promoted, or the nature of decision-making.

Public debates also alleviate knowledge problems. Through detailed debates regarding all aspects of planned SEZs, issues emerge that might not otherwise have been considered. In South Africa, following the relative failure of their industrial development zones, a long and intense public debate ran parallel to the process of restructuring the regime into a more inclusive SEZ programme. This public discourse was instrumental in ensuring greater flexibility to meet local needs and limiting the extent to which an SEZ regime targeting FDI may bias against local investors.

Feasibility studies are commonly seen as a procedural activity that must be 'ticked off' before a government can introduce an SEZ. However, by making these studies open to public review, they are an important part in a transparent SEZ process. Feasibility studies can help detect occasions of distorted 
incentives. Due diligence analyses are also important for determining which private developers and key anchor tenants should receive special government benefits. It is not only important to avoid developers that lack sufficient technical or financial capacity, but also developers that are selected on the basis of their personal and/or political connections. Due diligence should at a minimum apply to legal, business operations, and financial matters.

A high level of transparency in the institutional design of an SEZ programme is also important, but is rarely pursued by the board of the SEZ authority. This is likely because such boards have traditionally been composed mainly of government ministries and agencies. Broader representation, including from the private sector, community groups, and labour, provides a better check against distorted incentives through conflicts of interests. This can also help mitigate the knowledge problem on an ongoing basis, as these groups have more insights into businesses on the ground and the condition of workers and communities affected by the SEZs. An increasingly common approach is to ensure that half or more of board members come from outside the government, and that these members are elected or appointed by their community, rather than being appointed by the government.

The private sector plays a fundamental role in addressing both the knowledge problem and the incentive problem. While some of the biggest SEZ success stories are run by governments or state-owned enterprises, including in China, Singapore, the United Arab Emirates, and Malaysia, SEZs that rely on public resources often fail to benefit the economy at large, as they are channelled into SEZs that could be used more productively elsewhere. Private SEZ developers can be an effective antidote. Private businesses have better knowledge about commercial realities, and can bring technical and managerial expertise. Their willingness to commit funding to an SEZ project is also an important market signal of its feasibility. As such, it serves as a check against projects with little chance of commercial success. Private companies also have the incentive to carefully avoid risky or unpromising investments, and are not constrained by short-term political considerations (Moberg 2015). International experience from countries such as the Dominican Republic, Colombia, and the Philippines shows that the private sector brings credibility and a network of potential investors to locate in an industrial park. Privately developed parks therefore tend to command higher prices from end users and attract higher value-added activities.

A flexible legal regime for SEZs allows for continuous adaptation, which addresses both types of political economy problems. The knowledge problem stems from the impossibility of predicting what circumstances that the SEZ regime will need to cope with in the future. When the mistake in a legal regime become clear, it is therefore important that policy makers can adjust them. As we have seen in this chapter, countries with rigid initial legal regimes have later been 
forced to introduce new ones that are better adapted to current economic conditions. Establishing a flexible legal framework from the start avoids the problems that such parallel regimes may cause. It also avoids the incentive of different ministries to introduce their own regimes as a form of 'empire-building'. In the Panamá Pacífico SEZ, a former air force base with a focus on logistics, the legal regime granted special fiscal incentives for civil aviation sector 'maintenance and repair operations'. As it later became clear that the SEZ could attract investment in call centres, the SEZ law was sufficiently flexible to incorporate working hour flexibility. This attracted a large investment by Dell. Similarly, Jordan's Aqaba SEZ legislative framework was flexible enough to enable subsequent regulations addressing the needs of the area's tourism sector. This ultimately became Aqaba SEZ's key investment sector. ${ }^{2}$

The right power structure can mitigate an SEZ programme's internal coordination challenges. International experience of failed and successful SEZs suggests that an SEZ regime should be regulated by an autonomous, powerful government authority, possibly linked to the head of state or of the government. An autonomous agency helps relieve the SEZ programme of day-to-day political considerations that may distort its incentives. Linking such an agency to a central authority facilitates coordination across various government ministries and agencies. By contrast, if the SEZ authority is the responsibility of a particular ministry such as the ministry of trade and industry, other ministries often have little incentive to coordinate their activities to support its aims.

The successful zones regimes of Jordan and Dubai both rely on a strong, centralized authority. In Jordan, once King Abdullah had decided to proceed with the $375 \mathrm{~km}^{2}$ Aqaba SEZ project, a series of feasibility studies were commissioned, including organizational audits of existing government bodies. The clear objective was to merge the various bodies into a single, overarching authority, the Aqaba SEZ Authority, which is run by six commissioners who wield ministerial powers and report directly to the prime minister (Farole, Baissac, and Gauthier 2013).

Other countries have succeeded with very different structures of power, which suggests that the best set-up is context specific. For example, in the Panamá Pacífico zone, Aqaba-style 'true one-stop shop' was not feasible for political reasons. The regime designers therefore granted the overall administrative and financial coordination to a new, permanent agency. An effective 'hybrid model' SEZ one-stop shop was developed, with physical coordination and service delivery done centrally, but with decisions about SEZ licences taken by separate authorities.

\footnotetext{
2 Examples in this section are gathered from Farole, Baissac, and Gauthier (2013).
} 
There are other proven mechanisms to overcome institutional coordination challenges of SEZs. Too often, inter-agency memoranda of understanding and service-level agreements break down when the political incentive for coordination is weak. A way to avoid gridlock is the use of a 'silence is consent' provision in the SEZ law. This provision, used in Senegal among other places, grants authorization by default if an applicant does not receive a response to its application for a licence or a work permit within a specific period of time.

Finally, the fiscal proceeds sharing arrangements for SEZ institutions are critical. The revenue from SEZs must be correctly assigned between local and national authorities to avoid coordination challenges and institutional conflicts. In its early years, the China-Singapore Suzhou SEZ, a joint venture between the governments of China and Singapore, suffered from misaligned incentives between the authorities running the zone and the local government of Suzhou. The SEZ authorities pursued returns on its investment while the local government was concerned about wider socioeconomic outcomes and tax revenues. Local governments in China are responsible for the provision of most public goods and services, and their main source of revenue is the value-added tax paid by industrial firms. As the SEZ was allowed to keep all tax revenues collected, the local government had no incentive to support the project. Instead, it invested in competing industrial zone projects. The conflict was finally resolved by realigning the incentives of all stakeholders. National authorities rearranged the tax-sharing formula for SEZs, striking a balance between national and local government as well as the SEZ authorities. This gave the local municipality the incentive to invest in key social and economic infrastructure linked to the zone and to support its development more generally.

These are just some of the legal, institutional, and procedural approaches that can address the political economy challenges of SEZs. By no means do they guarantee success, as they alleviate, rather than eliminate, political economy problems. The complexity and context specificity of SEZs means that there is no 'best practice' that guarantees success. Recognizing this reality is, however, a starting point for a successful SEZ regime. We hope that the principles outlined in this section, of transparency, broad participation, technical expertise, and leveraging the incentives for coordination, may help policy makers trying to steer through the muddy waters of the political economy challenges of SEZs.

\section{References}

Action Aid Vietnam (2005). Migrant Workers in Vietnam: A Summary Research Report. Hanoi: Action Aid International Vietnam.

Aggarwal, A. (2005). Performance of Export Processing Zones: A Comparative Analysis of India, Sri Lanka, and Bangladesh, Indian Council for Research on International 
Economic Relations (ICRIER) Working Paper 155. Available at: <http://icrier.org/pdf/ wp155.pdf $>$ (accessed 13 November 2014).

Arce-Alpazar, G., R. Monge-González, and J. Rosales-Tijerino (2005). Cost-Benefit Analysis of the Free Trade Zone System: The Impact of Foreign Direct Investment in Costa Rica, OAS Trade, Growth, and Competitiveness Studies (January). Washington DC: Organisation of American States.

Baissac, C. (2011). 'Senegal's Special Economic Zones Program: Historical Performance, Contribution to Reform, and Prospects', Draft, World Bank, Washington, DC, October.

Basu, K. (2000). Prelude to Political Economy: A Study of the Social and Political Foundations of Economics. Oxford: Oxford University Press.

Bauer, P. T. (1971). 'Economic History as Theory'. Economica, 38: 163-79.

Boettke, P. J. (1998). 'Economic Calculation: The Austrian Contribution to Political Economy'. Advances in Austrian Economics, 5: 131-58.

Boyenge, J. P. S. (2007). ILO Database on Export Processing Zones, Revised. Geneva: International Labour Organization.

Bräutigam, D., and T. Xiaoyang (2011). 'African Shenzhen: China's Special Economic Zones in Africa'. Journal of Modern African Studies, 49(1): 27-54.

Buchanan, J. M. (2003). 'Public Choice Politics without Romance'. In J. M. Buchanan, The Logical Foundations of Constitutional Liberty, The Collected Works of James M. Buchanan, vol. 1. Indianapolis, IN: Liberty Fund, Inc.

Buchanan, J. M, and G. Tullock (1962). The Calculus of Consent: Logical Foundations of Constitutional Democracy. Ann Arbor, MI: University of Michigan Press.

CDE (Centre for Development and Enterprise) (2012). Special Economic Zones: Lessons for South Africa from International Evidence and Local Experience. Johannesburg: Centre for Development and Enterprise.

Chen, J. (1993). 'Social Cost-Benefit Analysis of China's Shenzhen Special Economic Zone'. Development Policy Review, 11(3): 261-71.

CNN (2010). 'Tinapa Failing?'. 22 April. Available at: <https://www.youtube.com/ watch?v=kkzCiTQfQ k> (accessed 13 November 2014).

Collier, P., and J. Page (2009). Industrial Development Report 2009. Vienna: UN Industrial Development Organization (UNIDO).

Daily Champion (2012). 'Can FG's Deal with Imoke Save Tinapa?'. 21 February. Available at: <http://allafrica.com/stories/201202230363.html> (accessed 13 November 2014).

DiLorenzo, T. J. (1988). 'Competition and Political Entrepreneurship: Austrian Insights into Public-Choice Theory'. Review of Austrian Economics, 2(1): 59-71.

Easterly, W. (2007). 'Was Development Assistance a Mistake?' American Economic Review, 97(2): 328-32.

Farole, T. (2010). Case Studies of Special Economic Zones: Ghana. Washington, DC: World Bank.

Farole, T. (2011). Special Economic Zones in Africa: Comparing Performance and Learning from Global Experience. Washington, DC: World Bank.

Farole, T., C. Baissac, and J.-P. Gauthier (2013). 'Special Economic Zones: A Guidance Framework for Policy-Making', Draft, World Bank, Washington DC. 
FIAS (The World Bank's Facility for Investment Climate Advisory Services) (2008). Special Economic Zones: Performance, Lessons Learned, and Implications for Zone Development. Washington, DC: World Bank.

Friedman, M. (1958). 'Foreign Economic Aid: Means and Objectives'. In G. Ranis (ed.), The United States and the Development Economies. New York: Norton.

Govardan, D., and V. Srivastav (2012). 'What SEZ?' Financial Chronicle, 23 November. Available at: <http://wwa.mydigitalfc.com/news/what-sez-535> (accessed 14 September 2016).

Grossman, G. M., and E. Helpman (1994). 'Protection for Sale'. American Economic Review, 84(4): 833-50.

Hamada, K. (1974). 'An Economic Analysis of Duty-free Zone'. Journal of International Economics, 4(3): 225-41.

Harrison, A., and A. Rodríguez-Clare (2009). Trade, Foreign Investment, and Industrial Policy for Developing Countries, Working Paper 15261. Cambridge, MA: National Bureau of Economic Research.

Hayek, F. A. (1935). 'Socialist Calculation II: The State of the Debate'. In F. A. Hayek, Individualism and Economic Order. Chicago: University of Chicago Press.

Horwitz, S. (1996). 'Money, Money Prices, and the Socialist Calculation Debate'. Advances in Austrian Economics, 3: 59-77.

Horwitz, S. (1998). 'Monetary Calculation and Mises's Critique of Planning'. History of Political Economy, 30(3): 427-50.

Jayanthakumaran, K. (2003). 'Benefit-Cost Appraisals of Export Processing Zones: A Survey of the Literature'. Development Policy Review, 21(1): 51-65.

Kaplinsky, R. (1993). 'Export Processing Zones in the Dominican Republic: Transforming Manufactures into Commodities'. World Development, 21(11): 1851-65.

Keck, O. (1988). 'A Theory of White Elephants: Asymmetric Information in Government Support for Technology'. Research Policy, 17(4): 187-201.

Khan, S. (2008). 'India's SEZ: Business Zones Development: Economic Performance, Social/Environmental Impacts'. SSRN. Available at: <http://ssrn.com/abstract= 1292195> (accessed 14 September 2016).

Krueger, A. O. (1974). 'The Political Economy of the Rent-Seeking Society'. American Economic Review, 64(3): 291-303.

Lavoie, D. (1985). National Economic Planning: What is Left? Washington, DC: Cato Institute.

Leeson, P. T., and J. R. Subrick (2006). 'Robust Political Economy'. Review of Austrian Economics, 19: 107-11.

Levien, M. (2011). 'Special Economic Zones and Accumulation by Dispossession in India'. Journal of Agrarian Change, 11(4): 454-83.

Levien, M. (2012). 'The Land Question: Special Economic Zones and the Political Economy of Dispossession in India'. Journal of Peasant Studies, 39(3-4): 933-69.

Madani, D. (1999). A Review of the Role and Impact of Export Processing Zones, Working Paper, No. 2238. Available at: <http://siteresources.worldbank.org/INTRANETTRADE/ Resources/MadaniEPZ.pdf> (accessed 26 May 2014).

Mishra, A. R. (2013). 'Study Lists Why India's Special Economic Zones Policy Didn't Work'. Live Mint. Available at: <http://www.livemint.com/Politics/pZ1V1BKitKNV1tzWqII 
ShL/Study-lists-why-Indias-special-economic-zones-policy-didnt.html> (accessed 13 November 2014).

Mitra, S. (2008). 'Special Economic Zones in India: White Elephants or Race Horses'. Available at: <http://ssrn.com/abstract=969274> (accessed 13 November 2014).

Moberg, L. (2015). 'The Political Economy of Special Economic Zones'. Journal of Institutional Economics, 11(1): 167-90.

Moran, T. H. (2011). 'International Experience with Special Economic Zones (SEZs): Using SEZs to Drive Development in Countries around the World'. Report Commissioned by Center for Development and Enterprise. Available at: <http://www.pmg. org.za/files/130522annexure_b1.doc> (accessed 13 November 2014).

Niskanen Jr, W. A. (1971). Bureaucracy and Representative Government. Chicago: Aldine, Atherton.

Pennington, M. (2011). Robust Political Economy: Classical Liberalism and the Future of Public Policy. Cheltenham and Northampton, MA: Edward Elgar.

Staritz, C., and M. Morris (2013). 'Local Embeddedness and Economic and Social Upgrading in Madagascar's Export Apparel Industry'. Working Paper, Austrian Foundation for Development Research (ÖFSE), Vienna.

Tullock, G. (1987). The Politics of Bureaucracy. Lanham, MD, New York, and London: Public Affairs Press.

Wagner, R. E. (2007). Fiscal Sociology and the Theory of Public Finance: An Exploratory Essay. Cheltenham: Edward Elgar.

Wang, J. (2013). 'The Economic Impact of Special Economic Zones: Evidence from Chinese Municipalities'. Journal of Development Economics, 101: 133-47.

Warr, P. G. (1987). 'Export Promotion via Industrial Enclaves: The Philippines' Bataan Export Processing Zone'. Journal of Development Studies, 23(2): 220-41.

Warr, P. G. (1989). 'Export Processing Zones: The Economics of Enclave Manufacturing'. World Bank Research Observer, 4(1): 65-88.

World Bank (1992). Export Processing Zones, Policy and Research Series, 20. Washington, DC: World Bank. 


\title{
13
}

\section{Ghana's Experiments with Business-Government Coordination}

\author{
Ernest Aryeetey and Nkechi S. Owoo
}

\subsection{Introduction}

In Ghana, business-government collaboration has tended to be dependent on the political ideologies of the reigning political regime in addition to state institutions and organizations such as the Constitution, existing laws, ministries, departments, and agencies (Ackah et al. 2010).These state institutions are responsible for the formulation and implementation of policies that are aimed at regulating the activities of the private sector. The private sector in Ghana typically refers to institutions and organizations such as the informal sector, privately owned local and foreign businesses, business associations, and financial institutions.

The nature of business-government coordination may be expected to be an important component of a country's economic growth. Indeed, effective coordination mechanisms that exist between the state and private businesses could contribute significantly to the growth and development of a country for a number of reasons. An effective state-business relationship (SBR) is characterized by a high level of trust between the government and the private sector. This implies that entrepreneurs and business people should have significant confidence in the government and its policy directives, especially when these are directed at addressing market failures in the economy and enhancing private sector performance. The presence of mutual trust also implies that there are positive reactions from the private sector in response to policies set up by the government to assist the former. For example, where government sets up a fund to encourage research and development or export activities, firms respond by taking advantage of these opportunities to enhance their own output. There should also be a high degree of transparency in the operations 
of the state and the private sector, and an appropriate and effective channel of information flow between these two parties.

Sen and te Velde (2009) state that there are four ways to measure the effectiveness of SBRs. First, the degree of private sector participation is a crucial determinant of the state of state-business cooperation. In Ghana, the presence of strong private sector participation is a necessary condition for effective business-state collaboration. Where a large number of firms is involved in the dialogue and collaborative mechanisms between businesses and the state, it is more likely to lead to mutually beneficial outcomes. This is because firms are able to channel accurate information to government about their positions on relevant issues and the challenges they face and be involved in formulation policies to address these issues. Where there is adequate buy-in, firms are also crucial in the implementation of formulated policies and are also able to provide useful feedback to government on the success, or otherwise, of the enacted policies.

The second approach suggested by Sen and te Velde (2009) is the manner in which the state organizes itself in its interaction with the private sector, particularly with respect to the presence of an investment promotion agency and a governing unit for the private sector. The Ghana Investment Promotion Centre (GIPC) was established in 1994, and has been in existence for over twenty years to encourage investment in the country. With respect to a governing unit for the private sector, the Exporter's Forum, established in 2001, which organizes forums twice a year, where the private sector has the opportunity to interact with government. Other opportunities for public-private dialogue (PPD) have been advanced by various governments and the private sector over time in the country. Third, there should be effective mechanisms for PPD that encourages continuous and transparent communication between the state and the private sector. Finally, there should be mechanisms to prevent rent-seeking and harmful collusive behaviour between the state and some special-interest groups of the private sector.

In the following sections, we will critically examine the nature of statebusiness collaborations, with particular emphasis on the mechanisms created over time to foster an effective relationship between the state and the private sector. Based on the criteria developed by Sen and te Velde (2009), Ghana appears to satisfy some of the criteria for effective SBRs as pertains to the participation of the private sector in the decision-making process, and the degree of dialogue between the government and the business community. Nonetheless, issues of corruption and general rent-seeking activities remain prevalent. Additionally, although there are pieces of legislation aimed at regulating competitive behaviour, such as the Public Utilities Regulatory Commission Act 1997 (Act 538) and the Protection 
against Unfair Competition Act 2000 (Act 589), there are currently no comprehensive competitive laws to monitor general competition in the economy and address the incidence of malpractice that affects the competitive process. The presence of competitive laws to protect the interests of consumers and producers is crucial. In Section 13.2, an attempt will be made to establish some correlations between the evolving state-business mechanisms that exist in various points of Ghana's history and various macroeconomic indicators, with specific focus on industry and the manufacturing sector.

\subsection{A Review of the Historical Nature of Business-Government Coordination in Ghana}

The relationship between the state and the private sector has varied over the years, and over different political regimes. There is a prevailing perception that businesses have tended to benefit more in terms of relations under civilian governments compared to military rule. In the former, the interests of the private sector have been better recognized and accepted, and the state has demonstrated greater concern for the integration of the private sector as the main driver of economic growth.

The establishment of a number of business associations such as the Association of Ghana Industries (AGI), the Ghana Employers' Association (GEA), Ghana National Chamber of Commerce and Industry (GNCCI), the Private Enterprise Federation (PEF), among others, has also transformed the nature of SBRs in the country, and has led to increased dialogue and engagement between the state and business community over time. The role of international influences in response to macroeconomic pressures experienced by the country is another significant contributor to the degree of businessgovernment collaboration in Ghana.

This section of the chapter reviews the defining moments of businessgovernment coordination mechanisms in Ghana, from independence to the present period. The analysis focuses on three periods in the economic history of SBRs in Ghana: (1) the immediate post-independence period and the adoption of a statist approach to development where the state was the main engine for development; (2) the period of military rule that was characterized by some semblance of civility in the relations between the state and the private sector; and (3) the post-military regime, where positive relationships with the private sector were deliberately developed and cultivated and the private sector was declared as the main engine of growth for Ghana's development. 


\subsubsection{The Immediate Post-Independence Era and the Pursuit of Statism as a Development Approach}

The immediate post-independence era from 1957 to 1966 emphasized a period of dominance of the state in economic activities in the country. There are diverging reasons attributed to the lower involvement of the private sector around this period. One school of thought states that private businesses were less involved in the development process due to a general distrust of private entrepreneurs by the ruling government. Proponents of this theory assert that there was some concern by the state that the emergence and success of a capitalist class that was independent of government might be politically threatening (Opoku 2014). According to Weber (1978), in the interest of continued supremacy therefore, the state tended to oppose the economic independence of the bourgeoisie. The thriving private businesses at the time were those with close ties to the government, who could contribute towards the fortunes of the government and would not pose a threat to state control.

A second school of thought, however, proposes that the lack of a welldefined private sector and the greater participation of the state in economic activities was a result of the lower capacity of the private sector to provide the necessary impetus to spearhead rapid economic growth in the country, despite the efforts of the state to build capacity in the sector. Initially, the private sector was deemed crucial to the success of the import substitution policy at the time of independence and therefore, local entrepreneurs were frequently sent abroad to be trained in the areas of shoe-making, laundry services, and other relevant productive activities, so that they could return and contribute towards the development of the Ghanaian economy. Unfortunately, a number of these entrepreneurs did not return to Ghana but remained in the developed countries to which they had been sent. ${ }^{1}$ Identifying the importance of credit to the development of private businesses, the state also established institutions, such as the Industrial Development Organization, to provide access to credit to businessmen. Indeed, according to macroeconomic indicators, domestic credit to the private sector as a percentage of gross domestic product (GDP) increased during the period from 1960 (see Aryeetey and Owoo, 2015: figure 1).

Additionally, legislations such as the Industrial Relations Act of 1958 (to harmonize relations between employers and employees); the Companies Code of 1960 (to regulate profit and non-profit companies); and the Capital Investment Act of 1963 (to provide guidance on the allocations of concessions to investors) were introduced to further regulate the conditions of businesses in the country. Despite the state's attempts, however, the pace

\footnotetext{
${ }^{1}$ Interview with K. B. Asante in December 2008.
} 
of development was deemed too slow, and efforts at a private sector-led growth were therefore abandoned in favour of a more socialist approach to economic development.

Ghana's development path immediately after independence was characterized by statism, where the government played a dominant role with respect to economic activity within the economy. Although there were some attempts by the state to encourage participation by the private sector, the pace of growth by this sector was slower than anticipated as investments made in raising the capacity of indigenous businessmen did not appear to yield the anticipated results. This resulted in the state taking up the core mandate of development, with the private sector playing a less-pronounced role within the economy. Therefore, in the post-independence period, the largest stateowned enterprises (SOEs) were created, including cocoa marketing and mining enterprises. The number of SOEs increased from four in 1957 to about fifty-three a few years after independence (Appiah-Kubi 2001). Additionally, employment levels also rose from 11,052 in 1957 to 115,826 in 1966 (Adda 1996). According to Appiah-Kubi (2001), the public sector accounted for about 86 per cent of total employment during the Nkrumah regime. Although increases in growth rates were observed between 1960 and 1963, economic growth however began to fall after 1963 and reached a low of -4.3 per cent in 1966, the year of overthrow of the Nkrumah regime (see Aryeetey and Owoo 2015: figure 2).

There appears to have been very little participation by the business community in decision-making processes in the early post-independence era. Additionally, there were no structured avenues for continued and structured dialogue between the state and the private sector, all of which led to a lessvibrant private sector. The state led the development process and the businesses that flourished were those that were closely affiliated with the state.

\subsubsection{State-Business Coordination under Military Regimes}

Statism was not pursued during the various military regimes, and indeed there were concerted efforts to erase the effects of statism in earlier military regimes. According to Ackah and colleagues (2010), the National Liberation Council (NLC) and National Redemption Council (NRC) regimes (and later, the Progress Party) undid the socialist machinery of the state and attempted to forge a new relationship between the state and the private business community. For instance, a number of boards were set up to review the nature of SBRs in the country, and some of these were responsible for the privatization of many of the SOEs that had been set up in the immediate pre-independence era. A reason for the unpopularity of statism was that it was generally considered to have failed and there was some attempt by subsequent governments to 
distance themselves from this ideology. For example, the NLC, between 1966 and 1969, deliberately privatized a number of SOEs that had been established under the statism development programme. Additionally, given the lower attention given to business people (particularly non-party affiliates) ${ }^{2}$ during the era of statism, earlier military regimes were eager to forge a new relationship with the private sector which gave more prominence to the business community. It is important to note, however, that these business people were often individuals who had close political ties to the ruling government.

The NLC therefore instituted a number of liberal market reforms in order to achieve this goal of closer SBRs. For example, the Ghana Business Act was established in 1969 to encourage local business start-ups, with restrictions set on foreign nationals to prevent them from engaging in certain sectors of the economy. The import licensing regime was also modified to better favour local business people. Additionally, in order to better underscore the importance of the private sector, business people were often consulted in major policy decisions. This nature of dialogue was further encouraged with the emergence of a number of business groups such as the Association of Ghanaian Businessmen, the Crusade for the Protection of Ghanaian Enterprises, the Indigenous Ghana Manufacturers' Association, among others. A number of prominent business people were also appointed to lead major public ventures (Esseks 1975). There was also the introduction of the policy of Economic Ghanaianization through the Ghanaian Enterprises Decree (GED) of 1968, which reserved particular enterprises for Ghanaians in areas of retail, wholesale, transport, and extractive businesses, among others. Interestingly, however, despite the attempts by early military regimes to distance themselves from Nkrumah's ideologies, this policy of Economic Ghanaianization that was initiated by the NLC was among Nkrumah's chief policy objectives that were aimed at attaining greater economic independence and control of the economy by indigenous Ghanaians (Killick 2010).

The policy of Ghanaianization was continued by the NRC between 1972 and $1979 .^{3}$ There were deliberate attempts by the state to instil some semblance of law and order in the execution of economic activities in the economy. For instance, in 1973, the NRC set up the Regional Development Corporation in all regions of the country to spearhead development in these regions, based on their unique resource endowments and the needs of the regions. Development

\footnotetext{
2 It is argued that this preferential treatment of party affiliated businesses was also present during the NLC regime, and indeed characterized the operations of the various political regimes, both civilian and military.

${ }^{3}$ Although the period between these military regimes was characterized by civilian rule, the civilian government did not stay long enough in power to effect significant changes on the nature of business-government coordination. Additionally, the Organization of the Petroleum Exporting Countries (OPEC) oil crisis of the 1970s also presented macroeconomic challenges around this period that the state struggled to bring under control.
} 
in the regions was to be accelerated through the promotion of agriculture, industry, and commercial businesses. The main economic policy that was adopted under this regime was one of Indigenization, which encouraged the participation of the private sector in economic activity. To achieve these goals, entrepreneurial skills of indigenous business people were developed and decrees, such as the Investment Policy Decree of 1975 and Ghana Enterprises Development Decree of 1975, were enacted to encourage investment activities by the private sector. Similar to the activities undertaken by its predecessor, the NRC engaged in dialogue with business leaders and attended inauguration ceremonies of new businesses in order to further promote the activities of the private sector (Opoku 2014). From 1972 to 1974, the economy recovered somewhat from the worldwide economic stagnation that had been caused by the oil crisis of 1973, with growth rates rising from -2.5 per cent in 1972 to 6.85 per cent by 1974 (see Aryeetey and Owoo 2015: figure 2). More significantly, the growth of the industry sector and manufacturing sub-sector (as a proportion of GDP) increased from 19.9 per cent and 12.18 per cent respectively in 1972, to 23.4 per cent and 15.5 per cent by 1975 .

Despite the positive macroeconomic developments, closer relations with the state inadvertently contributed to higher incidences of rent-seeking and corruption. For instance, indigenous businessmen felt that foreigners were being given preferential treatment in the allocation of import licences. Foreign businesses were also concerned with certain unfavourable actions undertaken by the government. For example, a number of foreign-owned firms, such as the Ashanti Goldfields Corporation, were nationalized against the will of foreign owners. Additionally, the government refused to settle external debts that it considered to be dubious (Ackah et al. 2010). Net foreign direct investment (FDI) (per cent of GDP) into the country therefore declined to an all-time low of -0.66 per cent by 1976 (see Aryeetey and Owoo 2015: figure 3), and growth in the manufacturing sector fell. Furthermore, despite its initial impressive trend, economic growth rates plummeted from 6.85 per cent in 1974 to an all-time low of -12.43 per cent in 1975 , to -2.5 per cent by the end of the NRC regime.

Although the earlier military regimes of the NLC and NRC made some attempts to include the private sector in investment initiatives, they were not always successful as the process of selection for private sectors was not transparent and or guided by any clear policies. There was perceived to be a high incidence of corruption in the relationship between the state and the private sector, particularly with respect to the securing of import licences and other rent sources. This was believed to have prompted the more radical and ideologically minded military interventions of 1981 and 1992 of the Armed Forces Revolutionary Council and the Provisional National Defence Council (PNDC), respectively. The private sector had been identified as the root of all 
things corrupt; it was generally felt that the activities of corrupt and selfseeking businessmen were largely to blame for the hardships that the country had experienced in the 1970s. The subsequent policies that were adopted and the manner in which these policies were implemented resulted in several actions that had devastating effects on business people in the country. For example, prominent business people were continually questioned by the state under its belief that corruption was endemic in the business community. Under the PNDC, the private sector was initially excluded from major policyand decision-making processes-a deviation from policies practiced in the earlier military rule regimes. The state did not engage in dialogue and discussion with long-standing business organizations, such as the AGI and the Ghana National Chamber of Commerce (GNCC), which had been formed under earlier military regimes, thereby weakening their advocacy functions. This was because the ruling government believed that these institutions themselves may have been part of the culture of corruption that was endemic to the country. The general strategy of business people around this period was therefore to maintain a low profile for fear of being investigated, tried for offences in a court of law, or have their businesses confiscated.

The initial limited contact under the PNDC regime with the private sector between 1981 and 1983 saw industry grow at a negative rate of -12.5 per cent and the manufacturing sub-sector grow at -15.6 per cent. Manufacturing exports as a percentage of total exports was about 5.65 per cent between 1980 and 1984. The turning point in the SBRs between the PNDC government and the private sector came later in the 1980s, with the adoption of the economic reforms, including privatization and trade liberalization. There was some speculation by the international community that the market reforms, in response to the debilitating state of the economy, were not yielding much success due to the limited response and commitment on the part of the private sector. This led to pressures on the state by international donors including the World Bank and the International Monetary Fund (IMF), to open discussions with the private sector in order to increase the acceptance and success rate of these reforms. In response to these pressures for increased dialogue with private businesses, the first consultative body, the Private Sector Consultative Committee (PSCC), was established in 1988, but it collapsed a year later without any significant impact due to continuing distrust between PNDC officials and business leaders (Hart 1996). In 1991, a second consultative body, the Private Sector Advisory Group (PSAG), was formed, but it also collapsed after a year due to frustrations in the business community that their opinions were not being taken into consideration by the government.

The state continued to tentatively dialogue with members of the private sector with continued encouragement from international donors. Macroeconomic indicators show some improvement in the performance of the economy 
with the adoption of the economic recovery packages from the IMF. For example, gross investment had increased steadily from 3.75 per cent in 1983 to 15.88 per cent in 1991 (see Aryeetey and Owoo 2015: figure 4).

Inflation had also fallen from an all-time high of 123.06 per cent in 1983 to 11.15 per cent by 1992 (see Aryeetey and Owoo 2015: figure 5). With respect to the industry sector, the sector experienced positive growth rates of 9.7 per cent between 1984 and 1989, with the manufacturing sub-sector growing at about 10.6 per cent. Within the period, manufacturing exports as a percentage of total exports rose from 5.65 per cent to 8.77 per cent (see Aryeetey and Owoo 2015: figure 6).

The adoption of liberal market policies also steadily increased exports from 5.6 per cent in 1993 to 17.2 per cent by 1992 , and to 48.8 per cent by 2000 . And, finally, economic growth rates rose from -6.2 per cent in 1982 to 5.3 per cent by 1991 .

\subsubsection{State-Business Coordination Mechanisms in Post-Military Regimes}

Post-military regimes have tended to be more engaging and accommodating of the private sector. This is most evident particularly from 2000 to 2008, where a 'golden age of business' was declared by the state and the private sector was affirmed as the engine for growth and development of the economy. This was not so much the case in the earlier civilian regime from 1992 to 2000 , where the state was, at best, tolerant of the private sector. The conversion of the military regime of the PNDC to a civilian one in 1992 did not do much to dampen the government's perception of the private sector as corrupt and the source of the nation's slow growth. Between 1992 and 2000, although more effort was made by the state to collaborate with the private sector, this was under continued pressure from the international community such as the World Bank.

Although relations with big businesses remained strained, better relations existed between the state and small-scale entrepreneurs as the state perceived these smaller groups to be less corrupt (Opoku 2014). For example, the Council of Indigenous Business Associations (CIBA) was established in 1993, which was consisted of small and medium-sized enterprises (SMEs). Although CIBA received a good amount of financial support for their activities, due to poor administration and inefficient personnel, it collapsed by 1996. Another consultative group, the Private Sector Roundtable (PSR), was also formed in 1993 for the aggregation and expression of private sector opinions about lingering impediments to private sector growth (Ayee, Lofchie, and Wieland 1999). The PSR made some recommendations on the conduct of policy, such as the need for reduced government borrowing in order to prevent crowding out of the private sector, instituting government-business consultation, among others. 
Although government endorsed these recommendations, it did not act on them (Opoku 2014), and the PSR eventually collapsed in 1995.

It is interesting to note that the newly formed civilian government seemed to engage the private sector primarily through the establishment of new business organizations, despite the presence of already-existing associations such as the AGI and GNCC. The state appeared to deliberately ignore these prior-existing organizations and excluded them from deliberations on relevant policies. In 1995, the Private Enterprise Foundation (now Private Enterprise Federation) (PEF), was founded under the initiative of the private sector and made up of a large representation from the private sector in order to increase dialogue and collaboration with government on development of the private sector. The organization carried out its mandate successfully for a period until it was determined to be too critical of government. Around the 1990s, there were continued efforts to open up channels of communication between the government and the general public with the setting up of a number of policy think tanks, such as the Institute of Economic Affairs (IEA), Centre for Democracy and Development (CDD), Third World Network (TWN), among others, with funding from international donors. Additionally, the introduction of several private television and radio services further widened the platform for discourse between the government and the private sector, and restructured the decision-making process in the country to a degree.

The GIPC was also established by an Act of Parliament in 1994 (Act 478) to encourage investments in the county. Despite its mandate for promoting investments in the country, there have not been impressive gains in this area. According to Aryeetey (1994), there was decreasing investment in the manufacturing sector so that by 1996, manufacturing accounted for only about 4.8 per cent of GDP, from 7 per cent in 1993. Foreign direct inflows (as a percentage of GDP) also decreased from 4.3 per cent in 1994 to 3.3 per cent by 2000. Reasons often given for this dismal performance included unfavourable macroeconomic conditions such as high inflation rates and exchange rate volatility (Gyebi, Owusu, and Etroo 2013), lack of reliable and up-to-date information on costs of investment and the investment opportunities within the country, due to the low capacity levels of the personnel and a lack of proper coordination between the GIPC and the Ministries, Departments, and Agencies (MDAs). Additionally, there were significant delays in the registration of local and foreign investment firms through the GIPC. In 2013, the GIPC Act was revised-a major component of this revision was to raise the capital requirements for investments within the country, in order to steer foreign investments to more capital-intensive and technologically advanced sectors. This amendment however had the unintended consequence of reducing domestic investments as local investors 
faced some difficulties in raising enough capital to meet the requirements stipulated by the new Act.

Although the establishment of the GIPC did not significantly improve investments in the economy, the greater effort at state-business coordination by the state, in general, was correlated with some positive macroeconomic indicators within the country. For example, between 1990 and 1996, industry grew at 4 per cent, with the manufacturing sub-sector growing at about 2.6 per cent. The electricity and water sub-sector experienced the greatest growth of 8.5 per cent within the period. Additionally, manufacturing exports as a share of total exports was approximately 18 per cent between 1990 and 1996. Value added by industry as a percentage of GDP increased from 17.5 per cent in 1992 to 28 per cent by 2000 , although there was little growth in the manufacturing sub-sector within the period.

\subsubsection{THE NEW PATRIOTIC PARTY AND A GOLDEN AGE OF BUSINESS}

The New Patriotic Party (NPP) assumed office in 2001 and given its probusiness orientation, there were high expectations of a radical transformation of the private sector and a corresponding marked improvement in economic performance. Indeed, in the first week of office, the NPP proclaimed a golden age of business and set up a Ministry for Private Sector Development to oversee and promote business development. Additionally, liberal market reforms continued to be pursued.

The main factor driving the NPP government's approach to SBRs was its ideology, which was largely pro-market. Many of the key actors in this new civilian regime and the business sector had endured a difficult relationship with government under Rawlings in both military and civilian regimes (Opoku 2014). President Kufuor was himself a businessman, as were indeed a large number of NPP supporters and affiliates. The private sector generally expected to do better under the NPP administration. It was therefore not surprising that the number of new business grew significantly in the period. Between 2004 and 2008, the number of new businesses emerging in the private sector more than doubled from about 5,989 to 14,485 (see Aryeetey and Owoo 2015: figure 8). Additionally, the growth in the industry sector was sustained from 2000 to 2006 at about 28 per cent, as percentage of GDP.

The main approach to defining the relationship between the state and the private sector under the NPP was the pursuit of an industrial policy embodied in what were described as Presidential Special Initiatives (PSIs). The PSIs were mainly centred on five pillars including the mobilization of private initiative, expansion of the industrial and export base, and a fruitful partnership between government and the private sector. The proposed policy had a number of similarities with models of development adopted by the East Asian countries. For example, the state pledged not only to protect local industries, 
but also to assist in identifying strategic opportunities and redirecting resources appropriately. Additionally, the attempt to foster closer relations between owners of capital and the state is also a feature of the East Asian model. The NPP expected that the adoption of a liberalized trade, investment, and industrial policy would attract both local and foreign investors and eventually lead to an expansion of the export industry (Arthur 2006). Indeed, net FDI flows as a percentage of GDP tripled from about 3 per cent in 1999 to about 9.5 per cent by 2008. Due to the rigorous adoption of liberal market reforms and pro-business inclinations, there were some positive changes in the economic growth of the country: between 1999 and 2008, the growth rate increased from about 4.4 per cent to about 8 per cent.

The PSIs were aimed at identifying and lending support to potential business opportunities in Ghana in the areas of salt, cassava, starch, textiles, and garments, where Ghana was considered to have a comparative and competitive advantage over other neighbouring countries. This was done in an effort to promote diversity and wealth creation in the productive sector of rural areas. Other priority areas included Cotton and Distance Learning initiatives. These initiatives were couched within the president's vision of creating a golden age of business that would place the private sector at the forefront of growth and development.

The PSIs were intended to identify new sources of growth through added value to non-traditional export and domestic commodities and through this channel increase job creation and rural incomes, thereby alleviating poverty. The PSIs were based on a public-private partnership (PPP) in which the state mobilized financial and technical resources. When the businesses became viable, the entrepreneurs had the option of full ownership, thereby empowering smallholder private businesses and farmers to organize production to raise investment and promote exports (Asante 2012). The collaboration between the state and private entrepreneurs should have been wholly successful, particularly because these were projects that were of particular significance to the president. Indeed, an entire Ministry (Ministry for Trade and Industry, Private Sector Development, and PSIs) was set up and dedicated to the management of the President's initiatives and private sector-led growth.

Asante (2012) has reported that despite the PSI projects carrying the President's special seal of approval, they collapsed soon after introduction for a number of reasons. First, planning of the PSIs was not done in continued consultation with local entrepreneurs and the industry. The government's strategy had been to select a few winning sectors of the economy and direct support to them. The choice of which sectors or sub-sectors to invest in, and what policies to adopt were decided by the President's Special Advisors and other party functionaries. Stakeholders were consulted only after the final drafts of the project details had been put together, for example as in the case 
of the Oil Palm PSI (Asante 2012). This led to disagreements between the industry participants and government on details of the implementation. For example, the Corporate Village Enterprise (COVE) model to expand and finance the industry was a major object of disagreement (Asante 2012). Nonetheless, this model was still included in the final project design, despite negative reactions from some industry participants. Second, these initiatives were based mostly in southern Ghana and would therefore not be expected to benefit the poor citizens of the country. Third, there was also a shortfall with respect to technical, financial, and material support for the initiatives, which led to their eventual collapse. This included requisite human capital and managerial competencies. Finally, it is also argued that political imperatives had a role to play in the eventual failure of the PSIs through the lack of consensus among a number of political elites on the objectives, management, and procedural legitimacy of the initiatives (Asante 2012).

Other areas of interest in the NPP administration followed a number of studies commissioned by public organizations including Bank of Ghana and the Ministry of Trade and Industry (MOTI). They often indicated that access to credit facilities was of prime concern to the private sector. This therefore culminated in the setting up of a number of financial interventions to increase credit access to private businesses. Indeed, with the setting up of a Venture Capital Fund and the Business Assistance Fund, domestic credit to the private sector increased from 12.56 per cent to 15.89 per cent between 1999 and 2008 . The Microfinance and Small Loans Centre (MASLOC) was also established in 2006 to implement the Government of Ghana's microfinance programmes targeted at reducing poverty, creating jobs and wealth. Among its functions included the disbursement of micro and small loans to low-capital entrepreneurs and the provision of business advisory services, training, and capacity building for SMEs. These were aimed at providing the required skills and knowledge for the efficient management of entrepreneurs' respective businesses. Some recent research indicates that the programme has produced some positive outcomes among loan beneficiaries such as expansion of business activities, increases in profit margins, and general increases in livelihoods (Quansah, Amankwah, and Aikins 2012). Despite its positive outcomes, a major challenge of the programme was the high loan default rates. Currently, MASLOC has a default rate of over 90 per cent, a situation which undermines the very purpose of the credit and loans scheme. A number of other financial support schemes were provided to businesses, for example, the Export Development and Investment Fund (EDIF) was established in 2001 to provide funds for the development and promotion of business activity and export in the country. There does not appear to have been significant effects on exports, however, as the exports to GDP ratio increased from about 32 per cent in 1999 to an all-time high of 48 per cent in 2000, but fell to 25.05 per cent by 2008 . 
Corporate tax cuts were also extended to businesses in the NPP era and the general costs of doing business in the country were reduced. For example, the costs of business start-up procedure as a percentage of gross national income (GNI) per capita reduced significantly from about 80.5 per cent in 2003 to about 30.6 per cent by 2008 (see Aryeetey and Owoo 2015: figure 9).

Increased dialogue with the private sector was encouraged and the government organized regular highly visible bi-annual meetings with business leaders such as the PEF, where opinions and feedback from the business community were solicited. The Ghana Investors Advisory Council (GIAC) ${ }^{4}$ was also founded by former President J. A. Kufuor in 2002 with encouragement from the IMF and World Bank. This was a public-private collaboration mechanism aimed at creating a platform for dialogue between the government and the business sector, where governments could have access to the opinions of matured business people. Additionally, such a forum would help to identify certain challenges faced by the business community and propose useful solutions for resolving these difficulties. Although the President of Ghana acted as the Chair of this council, the lack of commitment on the part of the members of this council dwindled and the Council collapsed. It may be surmised that the NPP era was one of the periods where considerable open attention was paid to the private sector and the state made attempts, not only to include them in the development process, but outlined the development strategy of the country with private businesses and entrepreneurs as the main engine of growth for the country.

It is important to note that even though the performance of the economy under the NPP government improved significantly, it would be difficult to attribute this to the policies on the private sector. GDP growth increased from 3.7 per cent in 2000 to 8.4 per cent by 2008; the level of FDI in the country also rose from 3.3 per cent to 9.5 per cent as a percentage of GDP within the period. There were several other things happening at the same time, including increased assistance as a result of a Heavily Indebted Poor Countries (HIPC) status, rising commodity prices, and a generally improved macroeconomic environment. There is the widely held view that the performance of the economy encouraged more private initiatives (ISSER 2008). While the private sector initiatives were generally seen to be positive, they are also assessed to have been inconsistent in their delivery and therefore limited in their impact.

\subsubsection{THE STATE AND ITS RELATIONS WITH BUSINESS AFTER 2008}

There was a change in government in 2008 after democratic elections. There was some intention on the part of the new NDC government to engage and

${ }^{4}$ No longer in existence. 
promote the activities of the private sector in a new period through, for example, the creation of a Private Sector Advisory Council (PSAC), and the promotion of PPP. The PSAC was inaugurated in 2012 and is made up of a nine-member council with the President as the Chairman, aimed at addressing strategic issues regarding private sector development, in an effort to accelerate the growth and transformation of the economy. In a recent PSAC meeting on February 2015, the Chairman re-emphasized a commitment to executing relevant private sector policy to develop a thriving, productive, and competitive private sector, in order to transform the sources of the country's growth and provide greater economic opportunity to all Ghanaians. It was noted that certain steps had been taken towards the achievement of this goal: direct financial support to certain segments of the private sector including the pharmaceutical industry, agri-business, and the non-traditional export sector. Concerns relating to the ensuing energy crisis were discussed, as part of the President's 2014 'agenda for transformation', which focuses on diversification and value-additions to primary products.

The National Policy on PPP was launched in 2011 and is intended to serve as a framework for carrying out PPP projects in the country. The aim of this policy is to address the infrastructure gap in the country through partnerships between businesses and the government, spanning projects from transport to health and business to community development. The PPP policy was developed with about US\$30 million in aid from the World Bank in the preparation of the legal framework, systems, and capacities of relevant institutions for the adoption of the policy. The policy was expected to increase economic growth and employment in the economy. Nonetheless, there have been concerns of low local entrepreneurs' capacity, resulting in a number of PPP projects being undertaken by some foreign firms-sometimes in partnership with some local firms - and the state. Additionally, the large capital investments required for these projects often discourage investments by the private sector as they are often unable to mobilize the required resources. These challenges have led to limited uptake of this policy as a whole from local entrepreneurs.

A major economic occurrence in the country around 2010 was the production of oil in the country after its discovery in 2007. The government took some steps to design policies that would be inclusive of both state and private interests. After a nationwide consultation process, a policy framework to address local content issues was put forward. Following further deliberation, the Local Content Petroleum Bill was passed in 2013.

Local content generally refers to a set of rules established by the Government of Ghana to ensure that local companies are active participants in ongoing petroleum operations in the country in order to ensure some transfer of knowledge from the foreign investors to the host country, build the capacity of local companies, create local jobs, and finally, accelerate the growth 
and development of the local economy. According to the policy objectives, 90 per cent local content and local participation in all petroleum activities was to be achieved by 2020. There are a number of concerns and challenges with this Bill, however. The delay in the establishment of the local content law has been identified as a major challenge to the achievement of the policy objectives by local non-governmental organization (NGO) Africa Centre for Energy Policy (ACEP). Although the local content law was passed in 2013, it had been in consideration since 2007, and oil production began around 2010. The delay in the passing of the Local Content Bill was met with a large degree of concern by policy think tanks and other concerned groups because first, delays would likely lead to a compromise in the transparency with which contracts would be awarded; and second, oil contracts that were negotiated before the bill was passed, for example between AGM Petroleum and the Republic of Ghana, provided only 2.5 per cent for the participating Ghanaian company, despite the draft regulations of 5 per cent equity for Ghanaians in every oil contract, representing a lost opportunity. Other contracts that do not involve any indigenous Ghanaians will also be hard to revoke when the law finally comes into force. Third, there were additional concerns that some recently discovered oil fields were sold in the absence of the local content bill, and did not confer any positive benefits on indigenous companies.

Additional concerns were raised by the indigenous business community and foreign investors as well after the passing of the law in 2013. First, despite the law stipulating that at least 5 per cent equity participation by Ghanaians, a sub-regulation of the bill gave wide discretionary powers to the Minister of Energy to determine the persons who qualify for this minimum equity, therefore creating room for subjective contract allocations and abuse of power. Another concern with the domestic content law was the low capacity of local companies that made it challenging to collaborate on petroleum operations with higher-capacity foreign companies. The low capacity and capability of the local entrepreneurs posed a challenge for the implementation and enforcement of the law. For example, the abrogation of the contract between a foreign company, Tullow Oil, and a local Ghanaian company, City Link, on the grounds of low standards, is a case in point. Therefore, the low competence of local entrepreneurs made it difficult to secure effective partnership between international and local enterprises. Furthermore, it was noted that there was some lack of communication between businesses and government on exploitable opportunities for local business growth. For example, despite the passing of the law on Local content, it appeared that there was not much awareness of contract opportunities by local entrepreneurs. These entrepreneurs often did not know where and how to access relevant information on upcoming tendering opportunities and even when they were able to obtain the information, 
the information was late and therefore entrepreneurs did not have adequate time to prepare and submit a tender.

The introduction of a financial tax on financial transactions in 2014, given the existing macroeconomic challenges, did not do much to foster favourable relations between state and the private sector. In July 2014, the Ghana Revenue Authority introduced a 17.5 per cent levy on financial services in the country in order to boost revenues. This was met with some resistance by the private sector. Despite the higher costs of business that entrepreneurs would have to incur with the implementation of this levy, it appears that insufficient stakeholder consultations were carried out before its intended introduction. Amid challenges with implementation, the policy was therefore suspended a short while after. The decision to suspend the policy was taken in consultation with relevant stakeholders after it was noted that greater public education would be necessary in order to implement the policy directive effectively. The suspension was supported by the AGI and other business organizations as it was deemed necessary to adapt and tailor the tax policy to be less harmful to the private sector. The tax policy was reintroduced in early 2015 , without immediately apparent considerations for the private sector.

One observes that even though both the NPP and NDC governments have maintained some interest in the role of the private sector in national development, the approaches have been strongly influenced by the exigencies of current politics. As a result there is the perception that although the state continued to maintain the private sector as the engine of growth between 2008 and 2014, there was not much commitment to the private sector with respect to its empowerment to lead the country's development agenda. This has been despite sustained pressures from international development partners such as the World Bank and bi-lateral development agencies. Business activity has been negatively affected, and the gains from earlier macroeconomic progress have not been sustained. For example, the export-GDP ratio raised from 25 per cent in 2008 to 48 per cent in 2012 but reduced to 42 per cent by 2013. Despite the production of oil in the country, economic growth fell from a high of 15 per cent in 2011 to 7.6 per cent by 2013 and about 5 per cent in 2014. Furthermore, the number of new businesses registered fell between 2008 and 2013, while a substantial number of companies went out of business owing to a number of challenges in the energy sector and an inadequate supply of electricity to businesses. With respect to the industry sector, the sector witnessed a large jump in growth from 20.8 per cent in 2006 to 25.6 per cent in 2011, although the manufacturing sector continued to experience decreases in growth rates. The increase in the industry sectors growth is a result of the production of oil in Ghana. 


\subsection{Conclusions}

Literature has tended to emphasize the strong linkages between SBRs and the economic growth of a country. Indeed effective business-state collaborations which are underscored by trust, transparency, credibility, and reciprocity between both parties can influence the performance of the private sector. This may be achieved through the design and implementation of good policies and institutions.

As we have highlighted, the nature and forms of business-state collaborations in Ghana have tended to change with changing political landscapes and regimes in the country. They have been underpinned by unclear and inconsistent ideologies at times. Business-government relationships have ranged from distrust and tension to modest cooperation and consensus building. Generally, it is observed that there are more cordial relations under civilian, than military, regimes. Despite its best attempts, however, the various political regimes do not appear to have fully addressed the key needs of the private sector, that is, strengthening the sector to become a key actor and independent. Its needs in relation to access to credit, skills, and entrepreneurial training, export promotion, technological development, among others, have been responded to with not very consistent and adequately designed programmes.

A number of challenges are noted in the continued sustainability of positive SBRs. First, it seems that there remains some distrust between the state and the business community with regards to favouritism and the award of contracts. This appears to be an unintended outcome of closer collaborations between the state and the private sector. There is some concern that the rent-seeking activities of party affiliates lead to non-equitable treatment by the government and a lack of transparency in the operations of the state and the private sector. Although there have been some attempts by the state to reduce the level of these rent-seeking and corrupt practices, they remain endemic in statebusiness operations within the country. Second, the efforts to formally institutionalize SBRs appear to be primarily driven by efforts by international organizations such as the World Bank. This raises questions and concerns of sustainability once the supporting structures from these donor organizations are removed. The presence of a long-term development plan with clearly stated functions of the state and the private sector in the development process, in addition to well-developed mechanisms for coordinating these relations, would be beneficial to both the state and the private sector. The absence of such a framework results in the varied experiences discussed in this chapter; where the private sector's engagement with the state tends to reflect the personal sentiments and political ideology of the ruling government. This 
contributes towards feelings of uncertainty on the part of the business community, and hampers developmental processes.

Third, there is the need to pay special attention to the building of local capacity so that the private sector may be able to take advantage of a number of pro-business policies put forward by the state.

\section{Acknowledgements}

An earlier version of this chapter was presented at the United Nations University World Institute for Development Economics Research (UNU-WIDER) authors' workshop on in Helsinki. We are grateful to the meeting participants for their feedback. John Page and Finn Tarp both provided comments, support, and direction, which contributed greatly towards this chapter. The usual caveats apply.

\section{References}

Ackah, C., E. Aryeetey, J. Ayee, and E. Clottey (2010). State-Business Relations and Economic Performance in Ghana, IPPG Discussion Paper Series 35. Manchester: IPPG.

Adda, W. A. (1996). 'Privatization in Ghana's Public Enterprise Reform Programme'. In O. Fadahunsi (ed.), Privatization in Africa: The Way Forward. Nairobi: AAPAM.

Appiah-Kubi, K. (2001). 'State-Owned Enterprises and Privatization in Ghana'. Journal of Modern African Studies, 39(2): 197-229.

Arthur, P. (2006). 'The State, Private Sector Development and Ghana's "Golden Age of Business"'. African Studies Review, 49(1): 31-50.

Aryeetey, E. (1994). 'Private Investment under Uncertainty in Ghana'. World Development, 22(8): 1211-21.

Aryeetey, E., and N. Owoo (2015). Ghana's Experiments with Business-Government Co-ordination, WIDER Working Paper 2015/99. Helsinki: UNU-WIDER.

Asante, E. A. (2012). The Case of Ghana's President's Special Initiative on Oil Palm (PSI-Oil Palm), DIIS Working Paper 2012:11. Copenhagen: DIIS.

Ayee, J., M. Lofchie, and C. Wieland (1999). 'Government-Business Relations in Ghana: The Experience with Consultative Mechanisms'. A Report for the World Bank, Private Sector Development Department, Fall.

Esseks, J. (1975). 'Economic Policies'. In D. Austin and R. Luckham (eds), Politicians and Soldiers in Ghana, 1966-1972. London: Frank CASS.

Gyebi, F., M. Owusu, and J. K. Etroo (2013). 'Foreign Direct Investment and Gross Domestic Product in Ghana'. International Journal of Academic Research in Accounting, Finance and Management Services, 3(3): 256-65.

Hart, E. (1996). 'Liberal Reforms in the Balance: The Private Sector and the State in Ghana, 1983-95'. PhD dissertation, Princeton University. 
ISSER (Institute of Statistical, Social and Economic Research) (2008). State of the Ghanaian Economy Report 2007. Accra: Institute of Statistical, Social and Economic Research, University of Ghana, Legon.

Killick, T. (2010). Development Economics in Action: A Study of Economic Policies in Ghana. London: Taylor \& Francis e-Library.

Opoku, D. K. (2014). The Politics of Government-Business Relations in Ghana, 1982-2008. New York: Palgrave Macmillan.

Quansah, P., E. Amankwah, and E. Aikins (2012). 'Influence of Microfinance and Small Loans Centre (MASLOC) on the Development of Small Scale Enterprises in the Wa Municipality'. European Journal of Business and Management, 4(1): 1-10.

Sen, K., and D. W. te Velde (2009). 'State-Business Relations and Economic Growth in Sub-Saharan Africa'. Journal of Development Studies, 45(8): 1-17.

Weber, M. (1978). Economy and Society: An Outline of Interpretive Sociology. Berkeley, CA: University of California Press. 


\title{
14
}

\section{Importing Coordination}

\section{Africa's Presidential Investors' Advisory Councils}

\author{
John Page
}

\subsection{Introduction}

When Horst Koehler, then Managing Director of the International Monetary Fund (IMF), and James Wolfensohn, then President of the World Bank, undertook their 'Odd Couple' joint tour of Africa in 2001, they urged the president of each country they visited to establish a Presidential Investors' Advisory Council (PIAC). The councils were an Asian import into Africa. Modelled on the deliberation councils widely used in East Asia, they were expected to enable the Presidents to hear the views of experienced and successful business leaders and to 'identify constraints to foreign and domestic investment, generate recommendations for concrete action and reinforce and accelerate policy reforms' (IMF 2003: 2).

PIACs were created by the Presidents of Ghana, Tanzania, and Senegal in 2002 and in Mali and Uganda in 2004. Subsequently, councils were set up in Mauritania and Benin. ${ }^{1}$ Ethiopia launched a Public-Private Consultative Forum (PPCF)-loosely modelled on the PIAC—in 2010. In the vision shared by the Bank and the Fund, business and government were jointly to define an agenda for action, agree on accountabilities, and monitor and evaluate implementation. Not surprisingly, the World Bank became the prime sponsor of the councils. World Bank management linked the councils to the Bank's private sector development and investment climate programmes. Whatever

\footnotetext{
1 The names of the PIACs have adapted to local circumstances. In the text that follows the term 'councils' will be used generically to describe the investors' advisory group that is chaired by the head of state or head of government.
} 
the original intent of Messieurs Koehler and Wolfensohn, the councils became one of Africa's first experiments with public-private coordination mechanisms.

Over more than a decade, the PIACs have been used with varying degrees of enthusiasm by African governments as a vehicle for public-private dialogue (PPD). This chapter examines their performance. It draws on case studies of PIACs in four countries-Ethiopia, Senegal, Tanzania, and Uganda-undertaken in 2012 by the African Development Bank (AfDB). ${ }^{2}$ Following this introduction, Section 14.2 summarizes early experience with the councils. Section 14.3 describes the current status of the PIACs in Ethiopia, Senegal, Tanzania, and Uganda. Section 14.4 sets out a framework to assess the performance of the councils, based on East Asian experience with business-government coordination mechanisms, and applies it to the African cases. Section 14.5 concludes with some lessons learned.

\subsection{Early Experience, 2002-8}

Rather than solicit suggestions from the countries involved regarding the appropriate membership and structure of the PIACs, the World Bank and the IMF provided a single blueprint. The councils were initially designed as a forum in which fifteen 'corporate champions'-experienced and successful international business leaders-five government representatives, and an international financial institution representative would meet with the head of state or government on a semi-annual basis. The breakdown for the fifteen was onethird local, one-third foreign, and one-third potential foreign investors. The private sector representatives were to be both local and foreign chief executives. Despite the marked tilt towards foreign investors, both small- and largescale domestic firms were expected to be represented.

The councils were intended to be a direct channel for dialogue between investors and political leaders at the highest possible level to 'identify obstacles to investment and focus on a limited number of issues to generate concrete recommendations for action and/or further analysis' (IMF 2003: 8). The business leaders in the council were to be supported by a small secretariat to assist in agenda setting and follow-up. At the World Bank's urging all of the secretariats were located in bodies closely aligned with the office of the President. ${ }^{3}$ The costs of the council and secretariat were funded by the World Bank through its operational budget.

\footnotetext{
2 No case study was done in Ghana because the PIAC there had been moribund for several years.

3 In Senegal and Uganda the secretariat was located in the Investment Promotion Agency. In Ghana it was situated in the Ministry of Private Sector Development in the President's Office, and in Tanzania it was made part of the National Business Council, a private sector body with links to the presidency.
} 
In addition to the council and secretariat, the Bank-Fund blueprint called for the creation of working groups consisting of both public and private sector stakeholders. These groups were intended to identify obstacles to investment and to recommend tangible policy reforms. Technical work leading to evidence-based policy recommendations was to be done by working group members, supported by consultants and World Bank operational staff. The views of small and medium-sized enterprises (SMEs) were to be conveyed to the working groups mainly through industry associations and Chamber of Commerce representatives.

Two reviews of the four original PIACs were conducted by the World Bank, the first in 2005 and the most recent in 2009. The 2005 World Bank review concluded that the councils were having a positive impact in terms of fasttracking previously identified reform proposals, primarily because they created an 'atmosphere of discipline and pressure for action in the face of government inertia' (World Bank 2005: 2). The evaluators went on to point out that some of the councils were more successful than others at initiating new reform proposals, but that all suffered from limited government implementation of council decisions, due to 'capacity constraints' in the public administration (World Bank 2005). In light of this the evaluators concluded that 'care needed to be taken to not overestimate or over promise what a council could do'(World Bank 2005: 3).

The review also identified a number of structural problems that were common to the councils. The most significant was that participation from the private sector was dominated by representatives of a fairly small number of large firms. The role and impact of local business associations-and therefore of smaller domestic enterprises-was unclear. The evidence base to support working group proposals and council decisions was found to be lacking, and the donors were criticized for failure to provide technical, research, and analytical support. The secretariats frequently lacked experienced and dynamic professionals who had a combination of economic, business, and management skills. The reviewers suggested that the councils could be made more effective by adapting their structure, composition, and processes to local circumstances (World Bank 2005).

By 2009 there was evidence of considerably more variation in performance. Ghana demonstrated what happened when a President lost interest. The Ghana PIAC had undertaken a number of initiatives up to 2006, mainly in the area regulatory reform, but from early 2006 to 2008-a period of over two and a half years-not a single council meeting was held, killing momentum and damaging relations with stakeholders. The council stopped meeting because the President was 'not available'. Frequent changes at the ministerial level left it without a champion in government and the private sector members, frustrated by lack of action, did not press strongly to reinstate the 
Table 14.1. Number of reforms attributed to PIACs

\begin{tabular}{lcc}
\hline Country & Year Established & Reforms through 2009 \\
\hline Uganda & 2004 & 35 \\
Ghana & 2002 & 18 \\
Senegal & 2002 & 10 \\
Tanzania & 2002 & 5 \\
\hline
\end{tabular}

Source: World Bank (2009).

consultative process (World Bank 2009). National elections in 2008 further eroded support for the council since it was an initiative of the outgoing government. The council disappeared.

Judged by the number of reforms that had been introduced on the recommendation of the council, Uganda had emerged as a clear leader and Tanzania as a clear laggard (Table 14.1). The success of the Uganda Presidential Investors' Roundtable (PIRT) was largely attributed to the care taken in designing its structure and processes and to a firm commitment from the President to take action on its recommendations. Representation of the private sector was extended beyond a small number of big business leaders to SMEs and business associations (World Bank 2009). The two leading business membership organizations in Uganda participated actively in council deliberations and engaged regularly with the secretariat. The council agenda was focused primarily on constraints to investment at the sector level and a Cabinet Implementation Committee, chaired by the prime minister, was tasked with ensuring implementation of recommendations.

The 2009 evaluation, drawing largely on the stark contrast between Ghana and Uganda, concluded that government commitment to reform and the sustained attention of the head of state were critical to success. It also pointed to the need for a sufficient number of champions in both the public and private sectors to make reform happen and adequate attention to follow-up by the public administration. Looking across the range of themes covered by the councils and their working groups (given in Table 14.2), the reviewers urged greater focus on sector-specific reforms. ${ }^{4}$ After the initial PIACs were established (and the two authors of the idea moved on), the attention and energy of the World Bank Group shifted to International Finance Corporation (IFC)-sponsored Public Private Dialogue (PPD) mechanisms, which are now present in ten additional African countries. ${ }^{5}$

\footnotetext{
4 Notably, no data were given for Tanzania.

5 The structure of the IFC-supported PPDs is strikingly similar to the councils, yet, despite the similarity, there has been no further systematic effort by the World Bank Group to learn lessons from the PIACs since 2009.
} 
Table 14.2. Themes of working groups of PIACs, 2009

\begin{tabular}{|c|c|c|}
\hline Predominantly Cross-Cutting & $\begin{array}{l}\text { Combination of Cross-Cutting and } \\
\text { Sector-Specific }\end{array}$ & Predominantly Sector-Specific \\
\hline Senegal & Ghana & Uganda \\
\hline Administrative procedures & Financial sector & $\mathrm{ICT}$ \\
\hline Finance and taxation & Labour & Agriculture \\
\hline \multirow[t]{2}{*}{ Infrastructure, land, production } & Civil service/customs & Education \\
\hline & Land & Infrastructure \\
\hline \multirow[t]{3}{*}{ Human resources } & Agriculture and agribusiness & Regulatory environment \\
\hline & & Tourism \\
\hline & & Mining \\
\hline
\end{tabular}

Source: World Bank (2009).

\subsection{Where Are the Councils Today?}

The councils in Senegal, Tanzania, and Uganda have evolved in different ways in terms of their structure, agenda, and impact. Ethiopia has only recently begun its experiment with a council. In all four countries, a number of common elements remain from the original blueprint set out in 2001. The councils meet infrequently-not more than twice per year-and the Head of State or Government chairs council meetings. Technical preparation for meetings is carried out by a secretariat with guidance from sector- or policy-specific working groups. Foreign and domestic investors are represented in the councils, but their proportions have shifted in every case away from the predominance of foreign investors initially recommended by the World Bank and IMF. Follow-up on decisions reached is the responsibility of the public administration.

The councils differ significantly in some important respects, however. The first is in the way in which issues are identified and brought to the attention of the council. The second is in the degree to which council recommendations are both actionable and acted upon. The third is in the extent to which the council is recognized as representative of the private sector. Finally, the councils differ markedly in the types of issues that they seek to address and in the impact that they have achieved.

\subsubsection{Ethiopia}

The council in Ethiopia-unlike the councils in Ghana, Senegal, Tanzania, and Uganda-evolved from a domestic dialogue between the government and the private sector: one that was at times filled with acrimony and mutual incomprehension. In 2002, at the government's initiative, a process of consultation between the private sector-represented by the Ethiopian Chambers 
of Commerce and Sector Associations (ECCSA)-and the governmentrepresented by the Ministry of Trade and Industry (MOTI)—was introduced. A 'Government and Business Community Joint Consultation Forum' was created and seven consultations were held between 2002 and 2004. This first attempt at business-government dialogue came to an abrupt end in 2005 , when lack of government support and political unrest led to the complete abandonment of the forum process.

In 2007 new leadership of the national Chamber of Commerce committed itself to restart the national public-private consultative process. An agreement, partly brokered by the IFC, established three types of bodies at the federal level: the National Business Consultative Forum, the Federal PPCF, and Sectoral PPCFs. The National Business Consultative Forum was scheduled to be held once a year, chaired by the Prime Minister. It was intended to be an opportunity for national level issues to be raised by the private sector and addressed by the government. The two public-private fora were, like working groups, intended to create a locus for joint analysis of problems and agreement on policy and institutional reforms. A dedicated secretariat was established and tasked with giving technical and managerial support to the consultation process and with following up on implementation.

The first federal PPCF-focused mainly on tax administration-took place in 2011. Several concrete action points emerged from the meeting, but they did not receive sufficient follow-up by the National Chamber and the Revenue and Customs Authority and were not implemented. A second federal PPCF was conducted in February 2012. The major objective was to come up with a topic that could secure an 'early win'. The ECCSA chose to make trade logistics - a broadly shared concern in landlocked Ethiopia-the central agenda item. Agreement on an action plan was reached and an initial positive reception by the government has given the consultative process some momentum (AfDB 2012d). So far, fifteen federal or sectoral dialogue forums have been held covering such topics as trade licensing and registration, government procurement, company formation and registration issues, tax appeal, and VAT refund issues.

Although the National Business Conference with the prime minster did not take place in 2012, one was held in June 2013. The second National Business Conference in 2014 brought together more than 1,000 members of the business community and the entire cabinet. No formal system is in place to follow up on agreed action points arising from the forum meetings, however, and few concrete results have come from the agreed action points of the meetings. On a more positive note, in 2013 the Council of Minsters rejected a draft customs procedures law primarily due to a concern that not enough consultations had taken place with the private sector. 


\subsubsection{Senegal}

In Senegal the Conseil Présidentiel de l'Investissement (CPI) meets once a year, chaired by the Head of State. It has held eleven meetings since 2002. Following a change of government in 2012, the new President and government signalled their commitment to continue the CPI process. The most recent meeting of the council took place in June 2015. As in previous meetings, members of the government, senior civil servants, CPI members, and selected guests from the private sector, public sector, and the donor community were present.

Following the Bank-Fund design, at inception CPI membership was divided into one-third domestic investors, one-third foreign investors, and one-third prospective foreign investors. As a result of the business associations' requests to allow better representation of domestic investors, today, the CPI consists of forty-six members, of whom eight are foreign investors. Over time the membership has evolved to include more local SMEs and business associations. The organization of the CPI and the roles of its subsidiary bodies are largely unchanged from the blueprint laid down by the IMF and World Bank in 2002. The Council has set up four working groups, chaired by the private sector (Table 14.3). Membership in the working groups is not restricted to members of the CPI. The working groups can request the secretariat to carry out analytical work to guide their recommendations.

The agenda of the CPI has been driven largely by the World Bank. A 1999 study Senegal Investor's Roadmap by the Foreign Investment Advisory Service (FIAS 1999) and the annual Doing Business surveys have been used to set the agenda on barriers to investment. ${ }^{6} \mathrm{CPI}$ activities have been funded under the World Bank's Private Investment Promotion Project (PIPP). ${ }^{7}$ Most of the reforms undertaken by the council are related to regulations and administrative procedures. Success in implementation of the reform agenda is benchmarked by the secretariat to the Doing Business report.

In spite of an apparently high-profile oversight and monitoring framework (at the presidential and ministerial levels), implementation of reforms has been weak. In a self-assessment conducted in 2011 the council found that: 'Reforms are moving slowly and Senegal is still behind its potential performance in terms of improvement of its business climate' (AfDB 2012a: 32). This was particularly true in such areas as tax reforms, access to land, and getting construction permits. The council blamed weaknesses in the civil service's capacity to implement reforms for its lack of success in achieving results.

\footnotetext{
${ }^{6}$ Doing Business is the World Bank's highly publicized annual survey of business regulations in more than 140 countries. It measures 'stroke of the pen' changes in nine regulatory areas.

7 FIAS is a part of the World Bank Group.
} 
Table 14.3. Working groups of PIACs, 2012

\begin{tabular}{|c|c|c|}
\hline Senegal & Tanzania & Uganda \\
\hline $\begin{array}{l}\text { (1) Administrative } \\
\text { procedures }\end{array}$ & (1) Agriculture & $\begin{array}{l}\text { (1) Agricultural production and value } \\
\text { addition (cotton, fish, food, and } \\
\text { leather) }\end{array}$ \\
\hline $\begin{array}{l}\text { (2) Cost and quality of } \\
\text { inputs, } \\
\text { human capital } \\
\text { finance, } \\
\text { access to utilities } \\
\text { and land }\end{array}$ & $\begin{array}{l}\text { (2) Empowerment, } \\
\text { entrepreneurship, and job } \\
\text { creation }\end{array}$ & $\begin{array}{l}\text { (2) Competitiveness and doing } \\
\text { business }\end{array}$ \\
\hline $\begin{array}{l}\text { (3) Communication } \\
\text { and coaching of civil } \\
\text { servants }\end{array}$ & $\begin{array}{l}\text { (3) Infrastructure, the financial } \\
\text { sector, tourism and image, } \\
\text { and energy }\end{array}$ & $\begin{array}{l}\text { (3) E-government and creative } \\
\text { industry }\end{array}$ \\
\hline $\begin{array}{l}\text { (4) High social impact } \\
\text { investments }\end{array}$ & $\begin{array}{l}\text { (4) TNBC consultative } \\
\text { mechanism and statistics } \\
\text { (5) Growth and business } \\
\text { environment } \\
\text { (6) Human capital development } \\
\text { (7) Commercial hubs and } \\
\text { manufacturing }\end{array}$ & $\begin{array}{l}\text { (4) Oil and gas (petroleum) } \\
\text { (5) Transport and logistics }\end{array}$ \\
\hline
\end{tabular}

Source: AfDB (2012a, 2012b, 2012c).

\subsubsection{Tanzania}

Founded in 2002, the Tanzania National Business Council (TNBC) is the umbrella organization that acts as Tanzania's Investors' Advisory Council. Its membership consists of representatives drawn equally from the business community and the public sector, under the chairmanship of the President. Discussion of proposed reforms is primarily undertaken by two subordinate bodies: a Local Investors' Round Table and an International Investors' Round Table, which meet both individually and jointly. The TNBC has met eight times since 2002 while the two investors' round tables have met eighty-four times. A majority (fifty-one) of the investors' round tables have been conducted jointly.

Initially, the TNBC created eight working groups, structured along sectoral lines: finance, agriculture, tourism, human capital development, technology, manufacturing, agro-processing, and infrastructure. At a later stage the working groups were reduced to four-public-private partnerships (PPP), private sector development, land, and the business environment-and restructured to reflect a sharper focus on the investment climate. The agendas of both the National Business Council and the investors' round tables have been structured mainly on thematic lines (Table 14.3). There is a mismatch between the council's recommendations and action plans and practice. Many of the proposed investments and policy changes at the sector level have been delayed or not undertaken. 
The council agenda in Tanzania derives from two sources. The main source has been the council's primary sponsor, the World Bank. A number of measures have been taken to improve Tanzania's scores on Doing Business. For example, measures to reduce the cost and time of business start-ups, improve processes to acquire construction permits, register property, improve access to credit, and protect investors were adopted with the specific objective of boosting Tanzania's ranking in the Doing Business report. Implementation of these 'stroke of the pen' reforms has lagged. In addition, elements of the national development agenda-as expressed in the National Vision Statement and the five-year plan-are placed before the round tables and the council for discussion and endorsement by the business community (United Republic of Tanzania 2011a, 2011b). This approach was used in discussions of Kilimo Kwanza ('Agriculture First') and information and communications technology (ICT), when the council endorsed government initiatives to reform land tenure and promote the development of agricultural value chains and to develop ICT backbone infrastructure.

\subsubsection{Uganda}

The PIRT in Uganda was established in 2004 with a mandate to advise the government on how to make Uganda a more competitive investment destination and to increase its share of international, regional and local investments. The council has worked in four cycles, and there have been sixteen PIRT meetings with the President. Council meetings are held approximately every six months, and are also attended by the prime minister, cabinet ministers, and permanent secretaries. The council had an initial membership of fifteen investors, divided into thirds among existing and potential foreign investors and domestic investors. By its third phase (2009-11) the PIRT had grown to twenty-five members, thirteen from Uganda's private sector and twelve from the international business community. Membership on the council is for a period of two years and has changed with each phase of implementation. SMEs are represented through industry associations.

The Uganda council has taken a sector-based approach in defining areas for analysis and public action. Recommendations are developed by technical working groups composed of PIRT members and invited participants. The number of working groups is determined by the number of priority sectors (Table 14.3). The council has attempted to address both policy and institutional constraints to performance-as well as infrastructure and skill needsat a detailed level in such sectors as agribusiness, ICT, business process outsourcing, and tourism (AfDB 2012b). It has devoted less time and attention than other councils to implementing the Doing Business list of reforms. 
In the course of its last two business cycles the council in Uganda has established working groups on infrastructure constraints, ICT and business process outsourcing, and tourism. The council is credited with a number of significant reforms at the sector level, such as eliminating export taxes on agribusiness, allowing duty-free imports of packaging materials for agroexport products, and the appointment of private sector representatives to public bodies in the agribusiness sector. In ICT the council supported the National Backbone Infrastructure project and the East African Submarine Cable System (EASSY) Protocol. At the council's recommendation, an Energy Equity Fund of USD100 million was created for the construction of the Bujagali power station (AfDB 2012b).

The PIRT has also experienced a number of setbacks. Despite calls for action, there has been slow progress in updating commercial laws, computerization of the land registry, pension reforms, and reform of the national identify card system. In the agribusiness sector land availability for large-scale commercial agriculture remains problematic. Slow progress made in implementing action plans arising from previous phases has been identified by some private sector observers as a major problem.

\subsection{An East Asian Perspective on PIACs}

The recent histories of the PIACs in Ethiopia, Ghana, Senegal, Tanzania, and Uganda paint a mixed picture of their relevance and impact. The bookends remain, as they were six years ago, Ghana and Uganda. Ghana has abandoned its council while the PIRT in Uganda continues to receive relatively high marks from both public officials and businessmen. Ethiopia, Senegal, and Tanzania fall between the two extremes. In general the councils have been best at accelerating previously identified reforms and have performed poorly at identifying specific new constraints to investment and the public actions to relieve them. Follow up by the civil service on council recommendations has been sporadic. With the possible exception of Uganda, the business community has expressed disappointment at the level of ambition of the councils and their impact.

The PIACs were an East Asian 'import' into Africa. The initial one-size-fits-all blueprint of the IMF and World Bank reads like it was lifted from a history of the practice of industrial policy in Korea during its rapid growth period and given a small facelift to reflect the prevailing fashions in PPD at the turn of the 21st century. An appropriate perspective from which to view their performance might, therefore, be to consider the extent to which the councils have been able to replicate some of the critical elements of success that characterized business-government coordination in East Asia. 
Writing on the implementation of industrial policy in Asia has emphasized four elements of effective coordination processes in rapidly growing Asian economies: commitment, focus, ownership and feedback (Amsden 1989; Wade 1990; World Bank 1993; Campos and Root 1996; Rodrik 2007; Harrison and Rodriguez-Claire 2010; Dinh 2013a, 2013b). To a large extent the substantial differences in performance of PIACs across Africa reflect differences in how the councils have dealt with these aspects of public-private coordination.

\subsubsection{Commitment}

In Asian economies, ranging from Japan to Viet Nam, senior members of the political and government elite were publicly committed to a high level of engagement with the private sector. In the cases of Indonesia, Korea, Malaysia, Singapore, and Taiwan the champion was the head of state or government (World Bank 1993). Indeed, the famous 'Blue House' meetings between President Park and Korea's powerful industrialists may well have been at the back of the minds of Messrs Koehler and Wolfensohn as they made their African tour. In China and Viet Nam, party and government officials at all levels ranging from the national to the municipal are actively engaged in the industrial development agenda and judged on results achieved (Dinh 2013a, 2013b).

As a signal of highest level commitment, the IMF and World Bank called for the councils to be chaired by the senior political leader in each countryeither the head of state or head of government. However, the extent to which each President or Prime Minister has demonstrated their commitment to the council process has varied widely. Ghana, of course, is the extreme case. Because President Kufuor could not find time in his schedule to conduct a meeting in more than two years, the council was abandoned and written off as a failure. To a lesser degree, the top political leadership in Ethiopia, Senegal, and Tanzania have shown tolerance of, but marked lack of enthusiasm for, the councils. At the most basic level this is demonstrated by the fact that no head of state or government in those countries has chosen to hold council meetings more frequently than once a year.

In the case of Ethiopia, the late Prime Minister Meles Zenawi sent strongly mixed signals by engaging with much greater enthusiasm directly with private investors at the sector or industry level. While the 2012 meeting of the newly designed council was not held, investors in priority sectors-such as cut flowers - and exporters had easy access to policy makers and a commitment from the Prime Minister to solve problems. Meetings with investors in these sectors were frequent and conducted on schedule. Deliberations on policy and regulatory matters were based on issues raised by the industry private 
sector organizations. Actions were agreed and followed up (Gebreeyesus and Iizuka 2010).

President Museveni of Uganda has shown the greatest sustained commitment to the council process. From the beginning, council meetings have been held on average twice per year. The President is actively involved in vetting proposed council members and has drawn several private sector council members into senior levels of government at the end of their council membership cycle, including as Minister of Finance, Planning and Economic Development and as the Chairman of the Uganda Investment Authority. The President not only attends PIRT meetings, he also has a track record of demanding progress reports on implementation of the decisions taken (AfDB 2012b).

The degree of commitment at the top is mirrored at lower levels of government in the extent of implementation of council decisions. A consistent theme running through the evaluations of the councils is the slow pace of implementation of council decisions. Most frequently this failure is ascribed to 'capacity constraints in the public administration' (World Bank 2005, 2009). But it also reflects a perception on the part of senior government officials and civil servants that they will not be held to account for lack of action. The most extreme case may be Ethiopia, where the council secretariat has struggled to implement the decisions reached at the national publicprivate investors' fora, even within the coordinating Ministry of Trade. At the same time, decisions reached in meetings with priority sectors or exporters were implemented with minimal delay (AfDB 2012d). In Senegal and Tanzania formal oversight mechanisms are in place, but a significant number of council decisions-some dating back several years-have not yet been implemented (AfDB 2012a, 2012c).

Follow-up has been most effective in Uganda. A Cabinet Implementation Committee, chaired by the Prime Minister was established, and the Prime Minister's Office is responsible for ensuring follow-through in implementing the council's recommendations. This provides a clear institutional structure and accountability mechanism linking recommendations by the PIRT with the regular business of the public sector. Yet, even in Uganda, private sector representatives complain that council decisions are not implemented quickly enough (AfDB 2012b).

\subsubsection{Focus}

In East Asia one way in which the flow of information between the public and private sectors was encouraged was by focusing policy decisions and actions on specific constraints to firm-level performance. They were in effect attempting to address failures of collective action. These types of industrial development problems proved to be best dealt with at the level of a specific sector or 
industry. The key elements of the process were agreement with major players in the private sector on the specific constraint and the proposed course of action. A timetable for resolution of the problem was announced, the public officials charged with the programme were sufficiently senior to make the decisions needed for implementation and progress was monitored and reported.

The work of the councils in Africa on the other hand has largely centred on an economy-wide agenda of 'investment climate' reforms drawn from the World Bank private sector development playbook. ${ }^{8}$ To a great extent this reflects the role played by the World Bank in setting up and funding the councils. Rather than focusing attention and resources on the diagnosis of sector specific constraints, the councils became captives of the World Bank's private sector development agenda and its Doing Business machine. This focus on a donor-driven agenda fundamentally contradicts the rationale for creating a public-private coordination mechanism in the first place. Doing Business was invented in Washington, not Dakar or Dar es Salaam, and it is unlikely to reflect the constraints actually faced by firms in Africa. ${ }^{9}$

Apart from regulatory reforms, the councils have attempted to address a wide range of issues; perhaps too wide a range. In Senegal a working group was created in 2011 to explore ways in which private investment could contribute to the welfare of vulnerable groups. The council is also attempting to set out an action agenda in such areas as access to health care and renewable energy. In Tanzania the council has set out reform objectives in fourteen areas ranging from agriculture to empowerment of an indigenous middle class. In Uganda the secretariat lists fifty-one actionable recommendations in sectors ranging from agri-business to petroleum. The councils in Tanzania and Uganda have been used to advise and endorse several broad development initiatives put forward by the government.

These agenda items fall more under the rubric of PPD than coordination. The focus has been mainly on exchange of information and building of mutual trust rather than on solving specific problems. While such engagements have been assessed as useful by the private sector participantsparticularly in building private sector consensus for such programs as Kilimo Kwanza in Tanzania and the ICT strategy in Uganda-they have not been regarded as highly productive. The contrast between the outcomes of the industry- and sector-specific coordination processes in Ethiopia and the national forum is particularly instructive. Because they do not regard the

\footnotetext{
8 This is despite the advice of the Bank's own Independent Evaluation Office in 2009 to shift the focus of Council deliberations towards sector issues and constraints.

${ }^{9}$ For an assessment of the relevance of Doing Business to industrial development in Africa see Page (2012).
} 
forum as an effective venue in which to pursue problem-solving with the relevant government bodies, investors in the priority sectors have largely operated their coordination mechanisms with the government separately.

\subsubsection{Ownership}

A key attribute of the East Asian deliberation councils was the extent to which the agenda of the councils and the policy initiatives adopted by them derived from a national process of PPD. Public actions were developed and the results-measured in terms of specific outcomes-were carefully observed. Policies that failed to achieve their objectives were often abandoned. Put in the jargon of 21st-century aid policy, the Asian coordination mechanisms 'owned' their policy reform agenda.

In Africa the work of the councils has more often than not reflected donor rather than national priorities. In Senegal and Tanzania the councils have explicitly benchmarked their performance to the World Bank's Doing Business indicators. Indeed, they have given themselves (or been given) improving the national ranking on Doing Business as an explicit objective (AfDB 2012a, 2012c). The council in Senegal in particular has chosen to focus on progress in Doing Business as its main measure of success. The councils in Ethiopia and Uganda have shown less inclination to use the Doing Business indicators to set their reform agenda, but both have been urged by the World Bank and other donors to focus on 'low-hanging fruit' in terms of the regulatory reform agenda.

Under the World Bank-IMF blueprint for the African councils, working groups were intended to be the engine of new, nationally owned ideas. In the working groups, members of the council were expected to engage with public officials and other relevant parties to identify, analyse, and recommend public actions to relax investment constraints. Over time, the working groups have evolved in different ways. In Ethiopia the national Public-Private Forum and the sectoral fora are intended to function in the place of the working groups. In Senegal there are four working groups covering very broad themes such as 'administrative procedures'. Initially the council in Tanzania created eight sector working groups. At a later stage the number was reduced to four and the focus shifted to thematic areas, more closely aligned to the World Bank driven private sector development agenda. In Uganda, working groups are established at the beginning of each two-year council cycle, based on government priorities, but it is unclear what the role the private sector has in setting out priorities for the new business cycle.

For the working groups to function as a source of ownership it is critical that they represent a broad spectrum of firms. The designers of the councils attempted to address the problem of representativeness by encouraging governments to 
include other national bodies of private investors in the working groups. Uganda has made an effort to include business associations representing SMEs in the working groups, although some private sector associations within the country continue to argue that the council process is not representative of the private sector as a whole (AfDB 2012b). In Senegal more local SMEs and business associations have been drawn into the working groups, and in Tanzania the breadth of representation of stakeholders has increased due to the creation of the regional and district business councils. In each country, however, local business groups, especially those representing SMEs, have argued that the large enterprise bias of the council membership limits their participation in meaningful dialogue with the government.

\subsubsection{Feedback}

Feedback was an essential element of the East Asian policy-making process. Often this was done by measurement of observable outcomes, for example the rate of growth of jobs or exports. It was also a central objective of the deliberation councils, themselves. Feedback is perhaps the least satisfactory aspect of council performance in all four economies. With the exception of the annual Doing Business reports, the councils in Senegal, Tanzania, and Uganda have not put in place systematic monitoring and evaluation frameworks. There are no examples of cases where councils have attempted to measure the impact of reforms on the cost of doing business or the decision to invest. ${ }^{10}$

In Tanzania the council uses the network of regional and district councils to collect information on the impact of its decisions, but evaluation studies have not been undertaken regularly. The Kilimo Kwanza programme, for example, has not been evaluated since its inception in 2009. Uganda has no formal mechanism for monitoring and evaluating the performance of its council. The government has argued that the PIRT is self-monitoring, but no monitoring framework is in place and the extent to which individual council members can follow up on initiatives is limited by the changing membership in each twoyear cycle. The council in Ethiopia is still sufficiently new that its experience with monitoring outcomes cannot be assessed, but the fact that the secretariat is having difficulty getting council decisions implemented at the ministry level does not augur well and contrasts sharply with the direct feedback provided by investors to senior government officials, including the Prime Minister, in priority sectors.

\footnotetext{
10 The World Bank's 2005 review noted that while it was possible to link specific individual reforms to actions by the councils, there was no evidence of a direct link between those actions and increases in private investment (World Bank 2005).
} 
Put bluntly, with the exception of the quantitative feedback provided by the Doing Business surveys, none of the councils have a systematic means of assessing the impact of their decisions on firm performance, investment, and growth. ${ }^{11}$ This lack of feedback is closely linked to the councils' lack of focus in agenda setting. Where the reform agenda has been pre-cookedusually by the donor community-the councils have proved moderately effective in accelerating implementation and have been able to measure progress. In other areas, whether at the sector level or in such cross-cutting areas as infrastructure and skills development, lack of feedback on prior council recommendations has limited the scope for understanding what works and what does not. This in turn has resulted in a 'shotgun' approach by councilsadvocating a wide range of reforms in the hope that some will have impact.

\subsection{Conclusions}

The PIACs were an unintended experiment in the conduct of industrial policy. Neither the IMF nor the World Bank was prepared in 2001 to allow the words 'industrial policy' to be uttered within its walls. The councils were surely seen by their creators as a place for dialogue between domestic and foreign investors and senior government officials, and as a tangible expression of the commitment of the head of state or government to the development of the private sector. Once the operational staff of the World Bank and the IMF linked the activities of the councils to the private sector development operations of the World Bank and to the policy agenda of the government, however, the councils became-at least in principle-policy-setting institutions. Business and government were to define jointly an agenda for action, agree on accountabilities, and monitor and evaluate implementation. In short, the councils morphed from 'chat shops' into coordination mechanisms.

Over slightly more than a decade, the councils have evolved in different ways, both in terms of their mandate and structure and in terms of their impact. Ghana's council disappeared, while Ethiopia, which had a history of deep distrust between business and government, felt the need to introduce a council in 2010. Uganda's council has been judged by external evaluators to have been the most successful; a judgement validated by the generally high marks given to the council by private investors in the country. The councils in

\footnotetext{
11 Unfortunately, Doing Business is very likely monitoring the wrong things. Studies using the Doing Business indicators to attempt to explain variations in investment and growth across countries yield ambiguous results and suffer from the same econometric woes as all other crosscountry growth regressions (World Bank 2008; Page 2012).
} 
Senegal and Tanzania have had some impact, but fall between Ghana at one extreme and Uganda at the other in terms of their performance.

Seen through the lens of public-private coordination in East Asia, the councils have a number of shortcomings. While the senior political leadership in each country has remained as the chair of the council, the actual level of high-level commitment varies quite substantially. Uganda is the only country in which the president has found time to hold more than one council meeting a year, and in which he has a reputation for following up on council deliberations. Ghana and Ethiopia represent the other extreme. In Ghana the president quickly lost interest and the council lost momentum. In Ethiopia the prime minister, who had a track record of close engagement with private investors at the sector and industry level, failed to call for a national meeting of the newly created council.

In general, the councils have been better at focusing attention and provoking action on a donor-driven agenda of previously identified reforms than they have been at setting their own agenda. Ethiopia is the only country in which the council has not used the World Bank regulatory reform menu as a basis for action. Most of the 'successes' of the councils in Senegal, Tanzania, and Uganda consist of accelerating regulatory reforms. Especially in Senegal and Tanzania, the regulatory reform agenda has been aligned to the nine Doing Business indicators, and impact has been judged by movements in the country's relative ranking. Before it collapsed, the reform agenda of the council in Ghana was similarly structured.

Outside of regulatory reform, councils have chosen to take a broad-based approach, rather than focusing on a limited number of specific constraints to firm performance and attempting to resolve them. In Senegal, Tanzania, and Uganda they have been used as sounding boards to test the reaction of the private sector to national development initiatives. This has led to multiple recommendations for action-often unsupported by analysis-that, for the most part, have failed to be taken up.

None of the councils have established a track record of strong ownership. This derives from two sources. The first is the agenda-setting role of the World Bank and the broader donor community. From the perspective of the donors, the councils are often seen as an implementation mechanism for their own policy reform agenda. The second limit to ownership comes from the restrictive membership of the councils. While in all cases membership has shifted to include more domestic investors, there is a still a distinctly large-scale bias. With the possible exception of Uganda, the working groups do not appear to have made sufficient efforts to include members with the knowledge and interest to suggest innovative solutions to problems.

One of the key reasons to develop coordination mechanisms is to provide feedback on the impact of prior public actions. Where these do not have their 
intended outcomes, mid-course corrections can be made or bad policies can be abandoned. The African councils have failed to put in place adequate feedback mechanisms. In the first instance, the secretariats have often lacked the capacity to follow up recommendations of the councils. This has led to delays in implementation or simply lack of action. The monitoring and evaluation capacity of the councils is similarly poor. No council has made a systematic effort to monitor and evaluate the impact of decisions taken.

To Horst Koehler and Jim Wolfensohn, getting leading private investors together with the president or prime minister must have seemed a commonsense approach to improving mutual understanding and signalling a commitment to private sector development. That the framework developed by their staffs to support the idea might become a policy setting institution-a coordination mechanism-would undoubtedly have come as a shock. Whether intended or not, the PIACs became an experiment in using Asian-style public-private coordination in Africa. They certainly provide a cautionary tale with respect to importing wholesale an institutional structure that worked successfully in one context into another. The councils also provide another cautionary tale: institutional capture is not unique to the private sector. In the case of the PIACs the coordination mechanism was captured by the donors.

\section{Acknowledgements}

An earlier version of this chapter was presented at the UNU-WIDER conference Learning to Compete: Industrial Development and Policy in Africa, Helsinki, 24-25 June 2013. The research was supported by the AfDB under its project Vision for Accelerating Growth and Structural Transformation in Africa.

\section{References}

AfDB (African Development Bank) (2012a). Assessing the Impact of Presidents Investors' Advisory Councils: Senegal. Tunis: African Development Bank.

AfDB (African Development Bank) (2012b). Assessing the Impact of the President's Investors Round Table (PIRT) in Tanzania. Tunis: African Development Bank.

AfDB (African Development Bank) (2012c). Presidential Investors' Advisory Councils in Tanzania. Tunis: African Development Bank.

AfDB (African Development Bank) (2012d). Report on the Performance of the Ethiopian Public-Private Consultative Forum. Tunis: African Development Bank.

Amsden, A. (1989). Asia's Next Giant: South Korea and Late Industrialization. New York: Oxford University Press. 
Campos, J. E., and H. Root (1996). The Key to the Asian Miracle: Making Shared Growth Credible. Washington, DC: Brookings Institution.

Dinh, H. (2013a). Light Manufacturing in Vietnam. Washington, DC: World Bank.

Dinh, H. (2013b). Tales from the Development Frontier: How China and Other Countries Resolve the Binding Constraints in Light Manufacturing to Create Jobs and Prosperity. Washington, DC: World Bank.

FIAS (Foreign Investment Advisory Service) (1999). Senegal Investor's Roadmap. Washington, DC: Foreign Investment Advisory Service.

Gebreeyesus, M., and M. Iizuka (2010). Discovery of the Flower Industry in Ethiopia: Experimentation and Coordination, Working Paper 2010-025. Maastricht: UNU-MERIT. Harrison, A., and A. Rodriguez-Claire (2010). 'Foreign Investment and Industrial Policy for Developing Countries'. In D. Rodrik and M. Rosenzweig (eds), Handbook of Development Economics, vol. 5. The Netherlands: North Holland.

IMF (International Monetary Fund) (2003). Africa PIAC Status Report. Washington, DC: International Monetary Fund.

Page, J. (2012). Aid, Structural Change and the Private Sector, WIDER Working Paper 2012/ 12. Helsinki: UNU-WIDER.

Rodrik, D. (2007). 'Normalizing Industrial Policy'. Paper prepared for the Commission on Growth and Development, World Bank, Washington, DC.

United Republic of Tanzania (2011a). Review of the Tanzanian Development Vision 2025, vol. 1: Main Report. Dar es Salaam: President's Office, Planning Commission.

United Republic of Tanzania (2011b). The Tanzania Five Year Development Plan 2011/ 12-2015/16: Unleashing Tanzania's Latent Growth Potentials. Dar es Salaam: President's Office, Planning Commission.

Wade, R. (1990). Governing the Market. Princeton, NJ: Princeton University Press.

World Bank (1993). The East Asian Miracle: Economic Growth and Public Policy. New York: Oxford University Press.

World Bank (2005). Presidential Investors Advisory Councils in Africa: Impact Assessment Study. Washington, DC: World Bank.

World Bank (2008). Doing Business: An Independent Evaluation. Washington, DC: Independent Evaluation Group, World Bank.

World Bank (2009). Review of World Bank Group Support to Structured Public Private Dialogue for Private and Financial Sector Development. Washington, DC: World Bank. 



\section{Index}

Abdullah, King 250

Abramowitz, M. 127

accountability 11, 67, 194

Acemoglu, D. 229

Ackah, C. 259

Africa

applying the Chinese model $160-5$

catch-up 44

communication channels 161

constraints on competitiveness 147

coordination efforts 11-14

decentralization 161

education 41, 58-9

entrepreneurship 161-3

first movers 163

government-private relationship 152

growth 42-3

health systems $58-9$

islands of success 81, 96

lessons from South Korea

120-1

local governments 161

population density 90

regional diversity 93

special economic zones (SEZs) 13, 236-7, 240-7

state capability 80-96

technical support 162

Africa Centre for Energy Policy

(ACEP) 270

agglomerations $3,65,153-7$

aid see official development assistance (ODA)

Altenburg, T. 194

American Chamber of Commerce 171

Amsden, A. H. 112, 127

Andrews, M. 90

Appiah-Kubi, K. 259

Ariffin, N. 128

Arinori, M. 54

Aryeetey, E. 12, 14-16, 264

Asante, E. A. 266

Asian financial crisis 177

aspiration $46-8$
Association of Southeast Asian Nations

(ASEAN) 46, 60, 74

Atkinson, A. 31

backing winners 5, 157-60, 163-4

Baeg Im, H. 91

benchmarking 55

Bhorat, H. 12-14

Black Economic Empowerment (BEE) 228-9

Blankenburg, S. 193

Bloom, N. 65

border fixity 90

Botswana 219

Brazil

bureaucracy 93

growth trap 215-16

grupo executivo 93

human capital 219

National Development Bank (BNDE) 93

Petrobrás 93

state capacity 96

Buchanan, J. M. 238

bureaucracy 92-3, 193, 243

business associations 67

business discipline 108

business-government relationship see statebusiness relations (SBRs)

Buur, L. 67, 71, 73

Cali, M. 69

Cambodia 44, 174

capital

human 41, 57-9, 219-20

and labour 225-6

markets $5,26-7$

capitalists, rent-seeking and developmental 195

capture 6, 9, 13, 66, 292

avoiding 24, 33

and coordination 6,13

political 198-201

state 92,94

Cassim, A. 12-14 
Chang, H.-J. 84-5
Chang Myon 106,

Chenery, H. 127

Cheong, K. C. 136

Chiang Kai-shek 104

China 44, 111, 131, 219

aspiration $47-8$

backing winners $5,157-60,163-4$

central government 153-4

cluster strategy 153-7

comparative advantage 26

credit access $148-9$

decentralized $13,145-65$

exports 145, 218

footwear industry 159-60

foreign direct investment (FDI)147

government-private partnership 152-3

growth 214-15

industrial parks 148, 156

input supply 147

international SBRs 73

investment 216

knowledge spill-overs 158

land policy $148,154-5$

light manufacturing 146-51

local governments $151-3,155-7$

National Development and Reform

Commission (NDRC) 7

policy failure 159

private sector $145-6$

provincial government $154-5$

skills $150-1$

special economic zones (SEZs) 235, 247, 251

state learning 56

trade logistics $147,149-50$

Choi Kyuha 115

Chu, W. W. 127

Chun Doo Hwan 115-18

Chung Ju-yung 115

Churchill, W. 104

climate change 29

cluster policies 153-7, 221

Cohen, W. M. 56

collaboration see cooperation

colonial institutions 90

commitment 9, 52-6

Presidential Investors' Advisory Councils (PIACs) 285-6

commodities 34

communications $52-3,227-8$

comparative advantage $6,26,31-2,246$

Africa 44-6, 48-9, 59-60

definition 31,45

Ethiopia 196-7, 206, 208-9

competence $52-3$

coordination 40-60, 67, 95 and capture 6,13

decentralized $145-65$

definition 53

Ethiopia 198-201

public-private $2-8$

and state capability $80-96$

within government 13

see also state-business relations (SBRs)

corruption 272

private sector 107,263

state $110-11,193,238,256,261-2$

Council for Mutual Economic Assistance (COMECON) 174-5

credibility 52-3

credit 148-9, 200-1

Daewoo 115

Dahlman, C. J. 127

de-industrialization $44-5$

deliberation councils $7,67,72$

Deng Xiaoping 47, 145

Department for International Development (DFID) 75

Desalegn, H. 199

development

and structural change 46-59

successes and failures $84-5$

see also growth

developmental state 91, 93-4, 120

democratic 117-18, 121

empirical foundations 127

and industrialization 104-7

limited 116-17

Dinh, H. 5, 9-10, 13

discipline 67,194

distorted incentives 234, 240-5, 248-9

Dominican Republic 235

Doner, R. 66

Dubai 250

East African Submarine Cable System (EASSY) Protocol 284

East Asia

export-led growth 25,27

market failure correction 26-7

political instability 90

strategic coordination 8-11

successful policies $40-1$

economic stability 36,116

social cost of instability 28

education $30,35,41,57-8,136$

see also human capital

Egypt 70, 235

El Salvador 235

Elkan, W. 161

embedded autonomy 6-7, 193-4

embeddedness 67 
employment 124-5, 132, 213-14

entrepreneurship 150, 161-3

Ethiopia 191-209

basic metal and engineering industry (BMEI) 16, 201-7

Chambers of Commerce and Sector Associations (ECCS) 279-80

comparative advantage 196-7, 206, 208-9

coordination 198-201

credit 198, 200-1

cut flower industry $5,14-15,164$, 195-201, 208

Development Bank of Ethiopia (DBE) 200

Ethio-Horti Share Company 200

Ethiopian Association of Basic Metal and Engineering Industries (EABMEI) 207

Ethiopian Horticulture Development Agency (EHDA) 198

Ethiopian Horticulture Producers and Exporters Association (EHPEA) 197, 199-200

Ethiopian People's Revolutionary Democratic Front (EPRDF) 195

exports 149, 195, 206

footwear industry 162

foreign direct investment (FDI) 198

foreign exchange 200

Government and Business Community Joint Consultation Forum 12

Growth and Transformation Plan (GTP) 195

import-substitution 195, 201, 206, 208-9

industrial policy $195,208-9$

Kaizen 202

land policy 201-2

leadership 198

Metal and Engineering Corporation (METEC) 202

Metal Industry Development Institute (MIDI) 202

Ministry of Trade and Industry (MOTI) 280

National Business Consultative Forum 280

political capture 198-201

Presidential Investors' Advisory Council (PIAC) 279-80, 284-92

profit tax 201-2

Public-Private Consultative Forum (PPCF) 280

state-owned enterprises (SOEs) 202

Structural Adjustment Programme (SAP) 195

trade barriers 206

transport 198

European Chamber of Commerce 171

European Union (EU) 196

Evans, P. B. 6, 67, 82-3, 85, 91-3, 96, 193 exchange rate policy 32,34

export orientation 10, 109-10, 112, 119, 131-6, 145, 206, 208

export-processing zones (EPZs) 235

see also free-trade zones (FTZs); special economic zones (SEZs)

externalities 28-9, 123, 131-3

Fafchamps, M. 162

Farole, T. 8-9, 13, 15, 17

Figueiredo, P. N. 128

financial crisis, global 126

financial market deregulation 24

Fine, B. 222

firms

capabilities 65

self-discovery 5

see also multinational corporations (MNCs); small and medium-sized enterprises

(SMEs); state-owned enterprises (SOEs)

Five-Year Economic Development Plans (FYEDPs) 6

foreign direct investment (FDI)

China 147

Ethiopia 198

Ghana 261, 264, 266

incentives 169

Malaysia 123-5, 131-3, 134

Viet Nam 169, 175, 177

fragile states see state weakness

free-trade zones (FTZs) 10, 235

see also export-processing zones (EPZs); special economic zones (SEZs)

Gebreeyesus, M. 5, 12, 14, 16

Gelb, S. 229

Gerschenkron, A. 127

Ghana 12, 244-5, 246

aid 264

Armed Forces Revolutionary Council 261

Association of Ghana Industries (AGI) 16, 257, 264

Association of Ghanaian Businessmen 260

Business Assistance Fund 267

Capital Investment Act 258

Centre for Democracy and Development (CDD) 264

Companies Code 258

comparative advantage 266

Corporate Village Enterprise (COVE) 267

Council of Indigenous Business Associations (CIBA) 263

Crusade for the Protection of Ghanaian Enterprises 260

Economic Ghanaianization 260

Export Development and Investment Fund (EDIF) 267 
Ghana (cont.)

Exporter's Forum 256

fiscal incentives 246-7

foreign direct investment (FDI) 261, 264,266

Ghana Business Act 260

Ghana Employers' Association (GEA) 257

Ghana Enterprises Development Decree 261

Ghana Investment Promotion Centre (GIPC) 256, 264-5

Ghana Investors Advisory Council (GIAC) 268

Ghana National Chamber of Commerce (GNCC) 262, 264

Ghana National Chamber of Commerce and Industry (GNCCI) 257

indigenization 260-1

Industrial Development Organization 258

Industrial Relations Act 258

Institute of Economic Affairs (IEA) 264

Investment Policy Decree 261

local capacity 273

local content 14, 269-70

micro-studies 69,74

Microfinance and Small Loans Centre (MASLOC) 267

Ministry for Private Sector Development 265

Ministry of Trade and Industry (MOTI) 267

National Liberation Council (NLC) 259-60

National Policy on Public-Private Partnership 269

National Redemption Council

(NRC) 259-61

nationalization 261

NDC 268, 271

New Patriotic Party (NPP) 265-8, 271

oil 269-70

post-independence $258-9$

post-military regimes $263-5$

Presidential Investors' Advisory Council (PIAC) 277-8, 284-5

Presidential Special Initiatives (PSIs) 265-6

Private Enterprise Federation (PEF) 16, 257, 264, 268

Private Sector Advisory Council (PSAC) 269

Private Sector Advisory Group (PSAG) 262-3

Private Sector Consultative Committee (PSCC) 262-3

Private Sector Roundtable (PSR) 263-4

Protection against Unfair Competition Act 256-7

Provisional National Defence Council (PNDC) 261-3

Public Utilities Regulatory Commission Act 256

Regional Development Corporation 260

state-business relationship (SBR) 5, 255-73 state-owned enterprises (SOEs) 259

taxation 268,271

under military regimes 259-63

Venture Capital Fund 267

Gill, I. 214

Gisselquist, R. M. 8, 13, 90

global value chains $3,5,217-18$

Goh, K. L. 136

Goh Keng Swee 55

government

as black box 238

coordination within 13

costly mistakes 245-6

definition 82

failure 66

officials' commitment 9

perfectly informed 238-9

role $23-4,153-4$

see also state

grabbing hand 66

Greenwald, B. 28

growth

and education 57-8

and employment 213-14

and investment 216-17

per capita 215-16

see also development

growth theory, endogenous 37

growth traps 214-20

Hausmann, R. 5, 64, 194

Hayek, F. A. 239

Heavily Indebted Poor Countries (HIPC) 268

Heilmann, S. 56

helping hand $4-5,17,66$

Herbst, J. 90

Hewlett Packard 132

Hirsch, A. 12-14

Hirschman, A. 24

Honduras 235

Hong Kong 73

human capital 41, 57-9, 219-20

see also education

Hyundai 115, 118-19

import-substitution 27-8, 132, 195, 201, 206, 208

incentives 18

distorted 234, 240-5, 248-9

fiscal 246-7

India 44

case-study evidence 71

growth 214-16

micro-studies 69-70

technology zones 246

Indonesia 7, 9, 216, 285 
industrial policy

analytic framework 128-30

brief history of $64-5$

definition $24,82,126-7$

effective 91

evaluation 24,49

experimentation 10, 191-209

feedback 11

focus $9-10$

implementation 50-3

literature 193-4

macroeconomics as 36

national control 15-16

and public-private coordination 2-8

risk taking in 25

state role in $82-5$

and structural transformation $1-2,27-8$

theories of $126-8$

and trade policy $31-4$

industrialization $104-7$

inequality $3,29,211$

of income 41, 219, 223

and rent-seeking 223-4

infant economy $24,31-3$

information 3, 5-6

information and communications technology (ICT) 41

intellectual property rights (IPR) 33-4

international competitiveness 218

International Finance Corporation (IFC) 278

International Monetary Fund (IMF) 29, 71, 262-3, 268, 275-92

investment

in education $57-8$

and growth $216-17$

in infrastructure 35

promotion 244

Ireland 244

Jackson, R. H. 90

Jansen, M. B. 54

Japan 9, 109, 113

catch-up 127

Charter Oath 46-7

colonialism 103-4, 111

Economic Planning Agency (EPA) 51

international SBRs 73

Ministry of Finance (MOF) 51

Ministry of Industry and Trade (MITI) 51, 72 state learning 54

Japanese Business Association (JBA) 171

Johnson, C. 127

Johnson, O. 194

Jordan 250

Kaldor, N. 127

Kenya 13, 198, 219, 244 cut flower industry 164-5

Special Economic Zone (SEZ) 236

Khan, M. 193

Kharas, H. 214

Kim, E. M. 6, 7-11, 13, 18

Kim Chong Pil 108

Kim Il-sung 105

Kingombe, C. 63

knowledge

acquisition $53-7$

inadequate $234,240,245-9$

spill-overs 158,162

Koehler, H. 275-6, 285, 292

Kohli, A. 82, 85, 91, 93-4

Kohli, H. 214

Korean War 103, 105

Kufuor, J. A. 15, 265, 268, 285

labour

and capital 225-6

imported 136

low-skill 29, 226

Lall, S. 127

land policy $148,201-2,242$

Latin America 27, 34, 64, 95, 111, 218, 235

Le Dang Doanh 7

leadership 46, 48

in Ethiopia 198

and growth 64

political 67

Presidential Investors' Advisory Councils

(PIACs) 278

strong 14-15

in Viet Nam 181-2

learning 3, 5, 23-37

by doing 25

and imperfect appropriability 28

and institution creation 24

institutional 11

instruments for 37

private sector $56-7$

society 29-31

spill-overs 28,31

state $53-6$

underinvestment in 27

Lee Byung-chull 111

Lee Kuan Yew 47, 55-6

Lemma, A. 4-5, 7, 12

Lesotho 236, 242, 244

Levithan, D. A. 56

liberalization 116, 266

Liberia 236

Lin, J. Y. 5-7, 11, 45, 64-5, 83-4, 94

Loh Kin Wah 135

Lucas, R. E. 42, 57 
Madagascar 236-7

Mahajan, S. 223

Mahathir 135

Malaysia 9, 51, 215-16, 285

Action Plan for Industrial Technology

Development (APITD) 124

catch-up 136-41

currency 134

education 136,140

electronic industries 123-42

employment 124-5, 132

exchange rate 124

exports 10, 131-6, 218

firm ownership 129

foreign direct investment (FDI) 123-5, 131-4

free-trade zones (FTZ) 123, 131-3

grants 124

import-substitution sector 132

imported labour 136

Industrial Master Plans (IMPs) 6, 125, 131, $133,135-6,141$

licensed manufacturing warehouse (LMW) 123, 131-3

Malaysian Institute of Microelectronics Systems (MIMOS) 134, 138, 141

Malaysian Technology Development Corporation (MTDC) 138, 140-1

New Economic Policy (NEP) 123

Penang Skills Development Centre (PSDC) 137-8

Performance Management and Delivery Unit 7

Pioneer Industry Ordinance (PIO) $130-1$

R\&D grants $136,139-41$

technological upgrading 135-41

VLSI technology 135

managerial skills 150

Mann, M. 90-1

Manning, C. 229

manufacturing 26, 145-51, 226

Marcos 109

markets 45

failure $3,5,66$

Marx, K. 127

Mauritius 69, 74-5, 165, 236, 245

Maxfield, S. 67

Mazzucato, M. 25

Mbeki, T. 12

Meles Zenawi 198-9, 285

Moberg, L. 8-9, 13, 15, 17

Mobutu Sese Seko 91-2

Morocco 70, 235

Morris Chang 135

multinational corporations (MNCs) 111, 123

Murray, D. 54

Museveni 15, 286

Myanmar 132 national control $15-16$

nationalization 107,261

neoclassical theory $82-3$

New Partnership for Africa's Development (NEPAD) 18

New Structural Economics (NSE) 45-6, $81,83-5$

Nguyen Tan Dung 179

Nigeria 13, 244, 246

land policy 242

neopatrimonial state 94

Oil \& Gas Free Zone Authority (OGFZA) 243

Nixon, R. 113

Nkrumah 259-60

North Korea 105, 113

official development assistance (ODA) capability trap 90

external control through 15-16

Ghana 264

South Korea 104, 107, 113

Viet Nam 170, 174

oil 269-70

openness 24

Organisation for Economic Co-operation and Development (OECD) 29

Development Assistance Committee (DAC) 103

PPD Handbook 75

Owoo, N. 12, 14-16

Page, J. 12, 15-17

Page, P. 65, 67

Park Chung Hee 9, 54-5, 106-9, 111-16, 285

Pham, C. L. 182

Phan Van Khai 178-81, 183

Philippines 109, 131

exports 218

growth 215-16

infrastructure projects $245-6$

picking winners 2, 5, 33, 155, 158, 193, 221

Polanyi, K. 82

political capture 198-201

political economy 32-3

of African Special Economic Zones

(SEZs) 240-7

of reform 236

robust framework 234, 239-40

poverty

elimination $103-4$

escape from 52

persistent 106, 211

reduction $35,41,59,85,120,161,266-7$

Presidential Investors' Advisory Councils

(PIACs) 15, 71-2, 275-92

blueprint $276-7$

East African perspective $284-90$ 
feedback 289-91

focus $286-8$

leadership 278

ownership 288-9, 291-2

reviews $277-8$

shortcomings 291

working groups 277, 279, 281-2, 284, 288-9

Pritchett, L. 90

private sector $33,35,46,59$

China 145-6, 152, 157-8, 161, 164

corruption 107, 263

Ethiopia 198-202, 205-10

Ghana 255-69, 271-3

and imports 275-92

learning 56-7

overview 1-4, 6-18

South Africa 211-13

South Korea 107, 115, 117

Special Economic Zones (SEZs) 244, 249

Viet Nam 48, 169, 172-3, 175-8, 184-6

weak 94-5

see also state-business relations

privatization 83, 221, 259-60, 262

production

for exports 65

stages 127

structure 34

productivity 2,215

total factor (TFP) 5

public choice 238

public debates 248

public-private dialogue (PPD) 276

public-private partnership (PPP) 266, 269

Quinn, S. 162

Qureshi, M. 69

Rasiah, R. 6, 128, 135

Rawlings, J. 12, 265

rent management 192-3, 200-1, 209

rent-seeking 14, 24, 195, 240-1, 272

by the state $238,256,261-2$

inequality 223-4

South Korea 229

resource fragmentation 242

rewards 13-14, 17

Rhee Syngman 105-6, 108-10, 114

risk $5,25,26-7$

Robinson, J. 229

Robinson, S. 127

Rodrik, D. 3, 5, 64, 67, 194, 225

Roosevelt, F. D. 104

Rosberg, C. G. 90

Rosenberg, N. 127

Rosenstein-Rodan, P. N. 82

rules 13, 16-17

Rustomjee, Z. 222
Sadun, R. 65

Samoa 70

Samsung 111, 118-19

savings 216-17

Schein, E. H. 52-3

Schmitz, H. 194

Schneider, B. R. 66-7, 95

Schumpeter, J. A. 37, 127

Selvaratnam, V. 136

Sen, K. 68, 71, 74, 256

Senegal 236, 241, 244, 251

Presidential Investors' Advisory Council (PIAC) 281, 284-92

short-termism 241-2

Singapore $6,9,132,285$

aspiration 47

Committee on the Future Economy (CFE) 50

Committee on Singapore's Competitiveness (CSC) 50

Economic Committee 50

Economic Development Board (EDB) 52-3, 55

Economic Review Committee (ERC) 50

Economic Strategies Committee (ESC) 50

productivity movement 56-7

Special Economic Zone (SEZ) 251

specialization 127

state learning 55

Strategic Economic Plan (SEP) 50

strategy formulation and review 49-50

small and medium-sized enterprises

(SMEs) 112, 119-20, 169-70

South Africa

African National Conference (ANC) 13, 211, 229

apartheid 211, 216, 219, 221

case-study evidence 70

clusters 221

communications sector 227-8

Department of Trade and Industry (DTI) 221-2, 224

diversification 35

exchange rate 218

exports 217-18

fragmentation 224

in a global value chain $217-18$

Growth Employment and Redistribution (GEAR) 221, 223

growth traps $211-30$

human capital 219-20

Industrial Development Corporation 212, 220

industrial policy 221-2

inequality 211, 223

informal sector 216

investment 224-6 
South Africa (cont.)

labour 218, 226

manufacturing 226

mineral-energy complex (MEC) 222, 224

National Economic Development and Labour Council (NEDLAC) 12, 70, 220, 223

National Economic Forum 220

policy coordination paradigm 222-9

poverty 211

Regional Industrial Development Plan

(RIDP) 221

rent-seeking 14, 229

Small and Medium Manufacturing

Development Programme (SMMDP) 222

Spatial Development Initiative 222

Special Economic Zone (SEZ) 221, 241-2, 246,248

trade liberalization 218

trade unions 223

Transnet National Ports Authority

(TNPA) 227

transport tariffs 227

unemployment 211, 216, 224

South Korea 9-10, 18, 206, 285

aid 104, 107, 113

aspiration 47

bank nationalization 107

business-government relationship 103-21

case-study evidence 71

catch-up 127

Chaebols 113-19

communications sector 228

comparative advantage 31

defence industry 113

democracy 8, 116, 117-18

a developmental state 104-7, 116-17

Economic Planning Board (EPB) 7, 107, 116-17

export-orientation 109-10

Five-Year Economic Development Plans (FYEDPs) 6, 54, 107, 109-10, 112, 116 growth 109-10, 117

Heavy and Chemical Industrialization (HCI) 112-16

Illicit Wealth Accumulation Charges 108, 110-11

industrialization 13

Korea Institute of Science and Technology

(KIST) 51

manufacturing 110

military coup 106-8

Ministry of Finance (MOF) 107, 117

Ministry of Science and Technology

(MOST) 51
Ministry of Trade and Industry (MOTI) 107, 111

private business 111-12

rural development 112

small and medium-sized enterprises

(SMEs) 119-20

Social Development Commission 11

state learning 54-5

state-business relationship 110-11

structural change 109

sunset industries 117

Soviet Union 104-5, 239

special economic zones (SEZs) 234-51

Africa 13, 15, 236-7, 240-7

described 235-6

distorted incentives 234, 248-9

due diligence analyses 249

failures 237, 246

feasibility studies $248-50$

flexible regime 249-50

inadequate knowledge 234, 245-9

investment promotion 244

one-stop shops 243-4

political economy implications 247

power structure 250

shared fiscal proceeds 251

South Africa 221, 241-2, 246, 248

tax revenue 251

transparent deliberation 248

see also export-processing zones (EPZs);

free-trade zones (FTZ)

Sri Lanka 244

state weakness 80

in Africa 85-91

definition 85

historical 88-90

and industrial transformation 81

lack of bureaucracy 92-3

measurement of 81

state-business relations (SBRs) 192, 194

case-study evidence 70-2

China 145-65

conditions for success 73

definition 65-6

econometric studies $68-75$

and economic performance $63-77$

effectiveness $67,75,256$

Ghana 5, 255-73

indicators $74-6$

international 73-4

in neoclassical theory 66

South Korea 103-21

theory of 65-7

see also coordination

state-owned enterprises (SOEs) 111-12, 168

Ethiopia 202

Ghana 259

Viet Nam 168, 170, 173, 183, 185 
states

authoritarian 108-9, 120

capacity 7-8, 80-96

capture 92, 94

Country Policy and Institutional Assessment (CPIA) rating 87-9

definition 82

developmental 9, 37, 82-3, 91-3, 104, 107-9, 111-12, 114-21, 127

learning 53-6

neopatrimonial 94-5

power 90-1

predatory $82-3,91-2$

role $45,64-5,82-5$

see also developmental state; government; state weakness

Stiglitz, J. E. 3, 5, 11, 17, 28-9, 31

structural change

policy framework 46-59

role of the state $64-5$

structural transformation 27-8, 109

structuralist economics 82

sub-Saharan Africa (SSA) see Africa

Sunkyong 115

sunset industries 117

supervisor training 65

Swaziland 219

Syrquin, M. 127

Taiwan 125, 127, 206, 285

Industrial Technology Research Institute (ITRI) 51-2

Ministry of Economic Affairs (MOEA) 51

Technology Advisory Committee (TAC) 51

Tanzania 149, 219, 283

Investors' Round Table 282

Presidential Investors' Advisory Council (PIAC) 278, 282-3, 285-92

Special Economic Zone (SEZ) 13, 242-4

$\operatorname{tax} 3,24,72,107,171,182,205,223$

administration 280-1

audits 108, 114

breaks 131, 134, 139, 147, 164-5, 206, 209 , $221,236,247$

corporate 268

evasion 110

expenditures 246

export 35,284

on financial transactions 271

income 138, 158

industrial parks 160

local government 153-4, 156

profit 201-2

reform 281

revenue $154,247,251$

te Velde, D. W. 4-5, 7, 12, 63, 66, 68-9, 74, 76,256 technology 215

capabilities 130

change 30

deepening 139

diffusion 31,41

upgrading 128-30, 135-41, 137,140

Thailand 72

Third World Network (TWN) 264

trade policy $31-4$

trade unions 223

Trade-Related Aspects of Intellectual Property Rights (TRIPS) 34

Tran Xuan Gia 179-80

transparency 17, 24, 67, 248, 255

Treichel, V. 94

Truong Chinh 175

trust 67

building 11-12, 19

mutual 184, 255, 272, 287

of the public 112

weakened 223

Tullock, G. 238

Turkey 215-16, 219

Uganda 198, 244

Cabinet Implementation Committee 285

Energy Equity Fund 284

National Backbone Infrastructure project 284

Presidential Investors' Advisory Councils (PIAC) 15, 278

Presidential Investors' Roundtable (PIRT) 283-4, 286-92

unemployment 211, 224

United Arab Emirates 235

United Nations Industrial Development Organization (UNIDO) 83

United States 33

Guam Doctrine 113

Solyndra 25

value chain, global 3, 5, 217-18

Van Reenen, J. 65

Veblen, T. 127

Velasco, A. 64

Viet Nam 4, 9-10, 44

aid 170,174

aspiration 48

case-study evidence $70-1$

Central Institute of Economic Management (CIEM) 178-80

Common Investment Law 169

Company Law 175, 178

Doi Moi 167-8, 175, 178-81, 184

domestic-private enterprises (DPEs) 168, 172-3, 176-7, 183 
Viet Nam (cont.)

foreign direct investment 169, 175, 177

foreign-invested enterprises (FIEs) 168-73, 183

industrial performance $167-86$, 171-3

land policy 242

Law on Encouraging Foreign Investment 175

Law on Enterprise 177-8, 180-3

Law on Private Enterprise 175, 178

licensing agencies $182-3$

low value-added trap 168

National Steering Committee on

Information and Communication

Technology (ICT) 7-8

policy failures $182-4$

political ideology 169-71, 184

Prime Minister's Research Commission

(PMRC) 6-7, 11, 178-81, 183, 185-6

private sector emergence $173-6$

productivity 173

small and medium-sized enterprises

(SMEs) 169-70

State Planning Committee 181

state-owned enterprises (SOEs) 168, 170, $173,183,185$

Unified Enterprise Law 169

Vietnamese Communist Party (VCP) $168-9,183$

Vo Van Kiet 179
Vu, K. M. 5-7, 11

Vu-Thanh, T.-A. 4, 6, 10-11

Wade, R. 83, 85, 127

Warwick, K. 82

Weber, M. 258

West Germany 47

Whitfield, L. 67, 71, 73

Wolfensohn, J. 275-6, 285, 292

Woodruff, C. 65

Woolcock, M. 90

worker skills 147, 151, 153, 158-9

World Bank 16-17, 67, 71, 75, 262-3, 268, 271-2, 275-92

Country Policy and Institutional Assessment (CPIA) ratings 86-9, 91

Private Investment Promotion Project (PIPP) 281

World Bank-IMF Investors Councils 13

World Trade Organization (WTO) 32, 169-71, 183,221

Worldwide Governance Indicators (WGI) 86

Yoon Po Son 106

Young, A. A. 127

Zaire $85,91-2$

Zambia $69,72-3,163$

Zenawi, M. 14

Zimbabwe 198, 219

zone planning 237 